The Quality of Our Nation's Waters

\title{
Effects of Urban Development on Stream Ecosystems in Nine Metropolitan Study Areas Across the United States
}

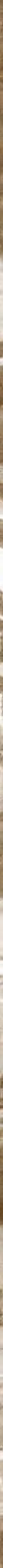


Cover. Fly fishing in the Chattahoochee River below Powers Ferry Road in Atlanta, Georgia, 2011.

Photographs in this report are by Alan M. Cressler, U.S. Geological Survey, unless otherwise indicated. 
The Quality of Our Nation's Waters

\section{Effects of Urban Development on Stream Ecosystems in Nine Metropolitan Study Areas Across the United States}

By James F. Coles, Gerard McMahon, Amanda H. Bell, Larry R. Brown, Faith A. Fitzpatrick, Barbara C. Scudder Eikenberry, Michael D. Woodside, Thomas F. Cuffney, and Wade L. Bryant, U.S. Geological Survey,

and

Karen Cappiella, Lisa Fraley-McNeal, and William P. Stack, Center for Watershed Protection

National Water-Quality Assessment Program

Circular 1373 


\section{U.S. Department of the Interior \\ KEN SALAZAR, Secretary \\ U.S. Geological Survey \\ Marcia K. McNutt, Director}

\section{U.S. Geological Survey, Reston, Virginia: 2012}

For more information on the USGS - the Federal source for science about the Earth, its natural and living resources, natural hazards, and the environment, visit http://Www.usgs.gov or call 1-888-ASK-USGS.

For an overview of USGS information products, including maps, imagery, and publications, visit $h t t p: / / w w w . u s g s . g o v / p u b p r o d$

To order this and other USGS information products, visit http://store.usgs.gov

Any use of trade, firm, or product names is for descriptive purposes only and does not imply endorsement by the U.S. Government.

Although this information product, for the most part, is in the public domain, it also may contain copyrighted materials as noted in the text. Permission to reproduce copyrighted items must be secured from the copyright owner.

Suggested citation:

Coles, J.F., McMahon, Gerard, Bell, A.H., Brown, L.R., Fitzpatrick, F.A., Scudder Eikenberry, B.C., Woodside, M.D., Cuffney, T.F., Bryant, W.L., Cappiella, Karen, Fraley-McNeal, Lisa, and Stack, W.P., 2012, Effects of urban development on stream ecosystems in nine metropolitan study areas across the United States: U.S. Geological Survey Circular 1373, $138 \mathrm{p}$.

Available online at http://pubs.usgs.gov/circ/1373/

\section{Library of Congress Cataloging-in-Publication Data}

Effects of urban development on stream ecosystems in nine metropolitan study areas across the United States : the quality of our nation's waters / by James F. Coles ... [et al.].

p. cm. - (Circular ; 1373)

Quality of our nation's waters

Includes bibliographical references and index.

ISBN 978-1-4113-3447-2

1. Stream ecology_United States - Case studies. 2. Urbanization—Environmental aspects—United States— Case studies. 3. Water quality_United States—Case studies. I. Coles, James F. II. Geological Survey (U.S.) III. Title: Quality of our nation's waters. IV. Series: U.S. Geological Survey circular ; 1373.

OH104.E335 2012

$577.6^{\prime} 4-\mathrm{dc} 23$ 


\section{Foreword}

The United States has made major investments in assessing, managing, regulating, and conserving natural resources such as water, minerals, soils, and timber. Sustaining the quality of the Nation's water resources and the health of our ecosystems depends on the availability of sound water-resources data and information to develop effective, science-based policies. Effective management of water resources also brings more certainty and efficiency to important economic sectors. Taken together, these actions lead to immediate and long-term economic, social, and environmental benefits that make a difference to the lives of millions of people (http://water.usgs.gov/nawqa/applications/).

Two decades ago, the Congress established the U.S. Geological Survey's National Water-Quality Assessment (NAWQA) Program to meet this need. Since then it has served as a primary source of nationally consistent information on the quality of the Nation's streams and groundwater; how water quality changes over time; and how natural features and human activities affect the quality of streams and groundwater. Objective and reliable data, water-quality models and related decision support tools, and systematic scientific studies characterize where, when, and why the Nation's water quality is degraded and what can be done to improve and protect it for human and ecosystem needs. This information is critical to our future because the Nation faces an increasingly complex and growing need for clean water to support population, economic growth, and healthy ecosystems. For example, two thirds of U.S. estuaries are impacted by nutrients and dead zones that no longer fully support healthy fish and other aquatic communities. Forty-two percent of the Nation's streams are in poor or degraded condition compared to reference conditions. Eighty percent of urban streams have at least one pesticide that exceeds criteria to protect aquatic life. Groundwater from about 20 percent of public and domestic wells - which serve more than 150 million people — contains at least one contaminant at a level of potential health concern.

This report is one of a series of publications, The Quality of Our Nation's Waters, which describes major findings of the NAWQA program on water-quality issues of regional and national concern. This report presents an assessment of the effects of urban development on the hydrology, habitat, chemistry, and aquatic communities of streams in nine metropolitan areas_-Portland, Oregon; Salt Lake City, Utah; Birmingham, Alabama; Atlanta, Georgia; Raleigh, North Carolina; Boston, Massachusetts; Denver, Colorado; Dallas, Texas; and Milwaukee, Wisconsin. These comprehensive investigations describe how the effects of urbanization vary regionally, and which urban-related stressors are most closely linked to degradation of aquatic biota.

Other reports in this series focus on occurrence and distribution of nutrients, pesticides, and volatile organic compounds in streams and groundwater, the effects of contaminants and streamflow alteration on condition of aquatic communities in streams, and on the quality of untreated water from private domestic and public supply wells. Each reports builds toward a more comprehensive understanding of the quality of regional and national water resources (http://water.usgs.gov/nawqa/nawqa_sumr.html). All NAWQA reports are available online at $h$ ttp://water.usgs.gov/nawqa/bib/.

The information in this series is intended primarily for those interested or involved in resource management and protection, conservation, regulation, and policymaking at regional and national levels. In addition, the information should be of interest to those at a local level who wish to know more about the general quality of streams and groundwater in areas near where they live and how that quality compares with other area across the Nation. We hope this publication will provide you with insights and information to meet your needs, and will foster increased citizen awareness and involvement in the protection and restoration of our Nation's waters. 


\section{Acknowledgments}

Special thanks are extended to the following individuals and organizations for their contributions:

NAWQA personnel in study areas across the Nation for their contributions of data and results.

NAWQA's many partners in the governmental and non-governmental sectors who have helped guide scientific efforts and ensure that NAWQA information meets the needs of local, State, Tribal, regional, and national stakeholders.

Technical Advisors:

- David L. Courtemanch, Maine Department of Environmental Protection

- Thomas J. Danielson, Maine Department of Environmental Protection

- Joseph A. MacDonald, American Planning Association

- Thomas R. Schueler, Chesapeake Stormwater Network

- Paul E. Sturm, Ridge to Reefs

- Keith D. Van Ness, Montgomery County (Maryland) Department of Environmental Protection

USGS reviewers:

- Cathy M. Tate

- Jonathan G. Kennen

- Nina Burkardt

- Douglas A. Harned

- J. Bruce Moring

- Lori A. Sprague

- Ian R. Waite

- Dennis A. Wentz

External reviewers:

- Ronald E. Bowen, Department of Public Works, Anne Arundel County Maryland

- Susan P. Davies, Maine Department of Environmental Protection

- Kate Schofield, USEPA, Office of Research and Development

Technical editor:

- Chester Zenone, Editorial Consultant 


\section{Contents}

Chapter 1 - Findings and Management Implications ……...........................................................

Multiple Stressors Influence How Stream Ecosystems Respond to Urban Development.......1

No Single Factor Related to Stream Hydrology, Habitat, or Chemistry

Was Universally Important in Explaining Responses of Biological

Communities to Urban Development

Hydrology—Streamflow Flashiness Increased With Urban Development

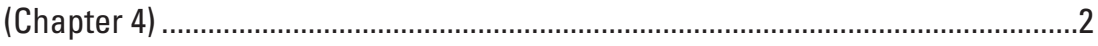

Habitat—Urban Development Can Alter Stream Channels (Chapter 4) ...........................2

Stream Chemistry-Concentrations of Contaminants in Water Increased

With Urban Development (Chapter 4) ...............................................................

Aquatic Biota-Loss of Sensitive Species Was the Most Consistent Biological

Response to Urban Development (Chapter 5) .....................................................

Invertebrate Communities Begin to Degrade at the Earliest Stages

of Urban Development (Chapter 5) ...................................................................

Management Implic ations ..................................................................................

Urban Development Affects Stream Ecosystems Differently Across the Country.....................5

Regional Differences in the Types of Land (Forested or Agricultural) Undergoing Urban Development Influenced the Response of Stream Chemistry and Aquatic Biota (Chapters 4 and 5) .........................................................................

Management Implic ations .............................................................................

New Innovative Tool Predicts the Effects of Hydrology, Habitat, and Chemistry on Stream Health.

\section{Chapter 2 - Background—Understanding Influences of Urban Development}

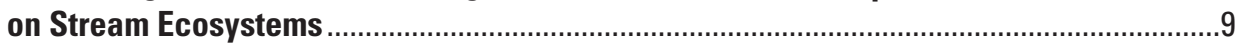

Why Do We Care About Stream Ecosystems? ..................................................................10

Sidebar: Ecosystem Services Provide a Way to Link the Condition of a Stream

Ecosystem to Societal Well-Being ...................................................................11

How Do Natural Stream Ecosystems Function? ...............................................................12

Sidebar: The Clean Water Act Provides a Regulatory Context for Restoring and Maintaining Water Quality .......................................................................12

Aquatic Biota Function Within a Foodweb ......................................................................13

Sidebar: Streams Change Continually as They Flow From Headwaters to the Mouth ......................................................................................................14

Stream Hydrology, Habitat, and Chemistry Define the Living Spaces Available to Aquatic Biota ............................................................................14

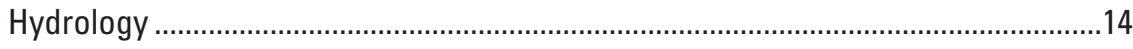

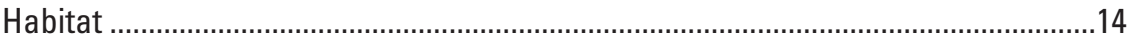

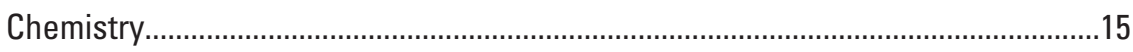

Sidebar: Stream Habitat Is Home for Aquatic Biota .................................................... 15

How Does Urban Development Alter a Stream Ecosystem?...............................................16

Diversity of Aquatic Biota Declines as Sensitive Species Are Lost.................................16

Sidebar: Aquatic Biota Serve as Sentinels for Watershed Changes...............................16

Streamflow Pattern Becomes More Flashy …………………….......................................18 
Chapter 2 - Background—Understanding Influences of Urban Development

on Stream Ecosystems - Continued

Sidebar: Impervious Cover Increases Streamflow Flashiness .......................................19

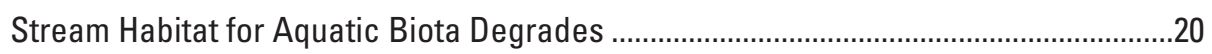

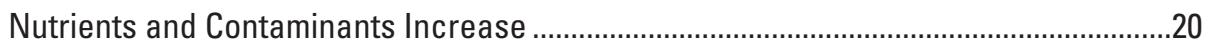

Framework for Understanding Urban Stream Ecosystems .................................................21

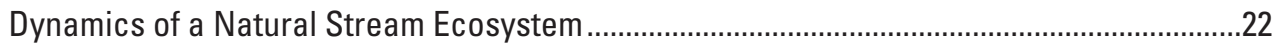

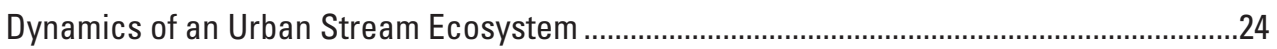

Chapter 3 - USGS Approach to Assessing the Effects of Urban Development

on Stream Ecosystems ...................................................................................................27

Accounting for the Natural Variability Among Watersheds in Different Regions ..................28

Sidebar: Stream Ecosystems Are Shaped by Processes Occurring at Multiple Spatial Scales.......................................................................................29

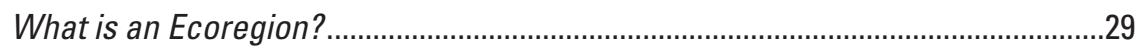

Substituting Space for Time: A Rural-to-Urban Gradient....................................................30

A Common Approach for Measuring Ecosystem Characteristics.............................................30

Urban-Development Patterns .....................................................................................30

Sidebar: How Well do the USGS Study Watersheds Represent the Gradient of Urban Development in Each Level III Ecoregion?..........................................31

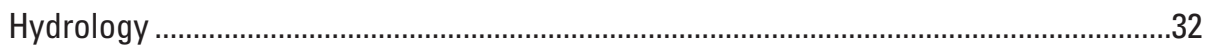

Sidebar: Land-Cover Data for USGS Urban-Development Study …………………........32

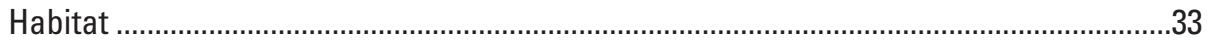

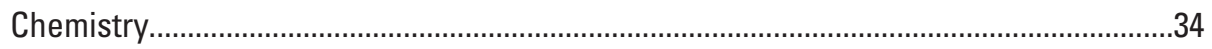

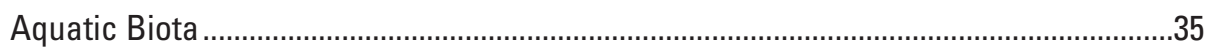

Chapter 4 - Responses of Stream Hydrology, Habitat, and Chemistry to Urban Development.....37

Responses of Hydrology and Habitat to Urban Development.................................................38

Streamflow Flashiness Increased With Urban Development .........................................38

Sidebar: A Tale of Two Streams - Contrasting Hydrologic Situations in Raleigh Study Area Watersheds ................................................................... 40

Habitat Responses to Urban Development Were Inconsistent ......................................41

Sidebar: Why Were Habitat Responses to Urban Development Inconsistent?..............42

Response of Stream Chemistry to Urban Development...........................................................4

Regional Differences in Types of Predevelopment Land (Forested or Agriculture) Influenced Stream Nutrient and Pesticide Responses

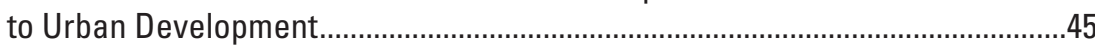

Chloride Increased With Urban Development Even in Areas Where Deicing Chemicals Are Infrequently Used.

Sidebar: Characterizing Water Quality Can Depend on Time of Year When Stream Chemistry Is Measured .................................................................4

Sidebar: Measuring the Potential Toxicity of Pesticide Combinations.............................48

Concentrations of Insecticides in Water and Their Toxicity Increased With Urban Development..

The Types of Organic Contaminants in Water Vary by Region and Depend on Current and Historical Use Patterns.

Sidebar: Characterizing Hydrophobic Contaminants With Semipermeable Membrane Devices. 
Chapter 4 - Responses of Stream Hydrology, Habitat, and Chemistry to Urban DevelopmentContinued

Case Study: Contamination and Toxicity of Stream Sediments Increase

With Urban Development.

By Lisa H. Nowell, Robert J. Gilliom, Nile E. Kemble, Christopher G. Ingersoll, Kathryn M. Kuivila, Michelle M. Hladik, Patrick W. Moran, and Daniel L. Calhoun

Chapter 5 - The Response of Biological Communities to Urban Development . .55

Broad-Scale, Regional Factors Exert a Strong Influence on the Composition of Biological Communities . .56

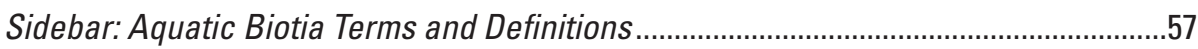

Algal, Invertebrate, and Fish Communities Respond Differently to Urban Development.......58

Prior Land-Use Activities Can Affect How Aquatic Biota Respond

to Urban Development .60

Sidebar: Species Richness of Invertebrates and Diatoms Can Respond Differently to Urban Development.

A Loss of Sensitive Invertebrate Species Was the Most Consistent Biological Response to Urban Development.

Invertebrate Communities Begin to Degrade at the Earliest Stages of Urban Development .64

Sidebar: Aquatic Biota Have No "Safe Zone" in Urban Development.

\section{Chapter 6 - Understanding Complexity in Stream Ecosystem Response} to Urban Development

Response of Aquatic Biota to Urban Development Is Influenced by Regional

Environmental Factors. .68

Sidebar: Understanding How Regional-Level Factors Affect Biological Response.......69

Multiple Stressors Influence How Aquatic Biota Respond to Urban Development................70

Sidebar: Modeling Reach-Scale Stressors. . .71

Sidebar: An Increase in Stream Temperatures Associated With Urban Development Can Lead to a Decline in Biological Communities

Building on Prior Knowledge of Ecosystem Processes Helps Link Multiple

Interacting Stressors to Biological Endpoints

Case Study: Predicting the Effects of Urban Development on Stream Health in the Northeast: Using a Bayesian Network to Link Ecosystem Characteristics to Biological Condition Gradient Endpoints.

By Roxolana Kashuba

Chapter 7 - Key Challenges in Managing Urban Stream Ecosystems .

Urban Streams Are Affected by Multiple Stressors

Management Implications Associated With Findings Related to Multiple Stressors

Using Impervious Cover as a Surrogate for Multiple Stressors .....................................85

Benefits of Protecting Stream Buffers in Kansas City, Missouri ......................................86

Restoring Important Stream Habitats in Milwaukee, Wisconsin ....................................86

The Response of Streams to Urban Development Varies Across Regions of the Country.

Management Implications

Comparing Aquatic Biological Conditions Across Regions. 
Chapter 7 - Key Challenges in Managing Urban Stream Ecosystems-Continued Indicators of the Effects of Urban Development Must Be Both Scientifically Based and Relevant to Important Social Values ......................................................................90

Disconnect Between Jurisdictional and Watershed Boundaries.........................................91

Fiscal Disparity Law Enhances Cross-Jurisdictional Land-Use Planning ......................91

Managing Stormwater: Adapting Management Approaches to Lessons Learned.................92

Virginia's Runoff-Reduction Method..........................................................................92

Educating the Public on Recognizing Good Stream-Management Practices........................94

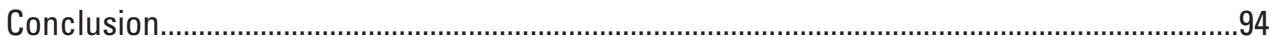

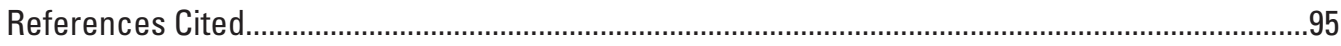

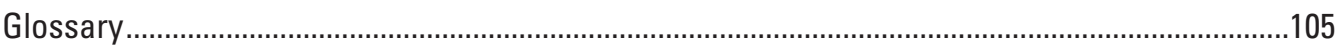

Appendix 1A - Study Watersheds in Nine Metropolitan Areas Used in the Effects

of Urban Development on Stream Ecosystems Study ..........................................112

Appendix 1B - Characteristics of Nine Metropolitan Study Areas................................................130 


\section{Acronyms and Abbreviations Used in This Report}

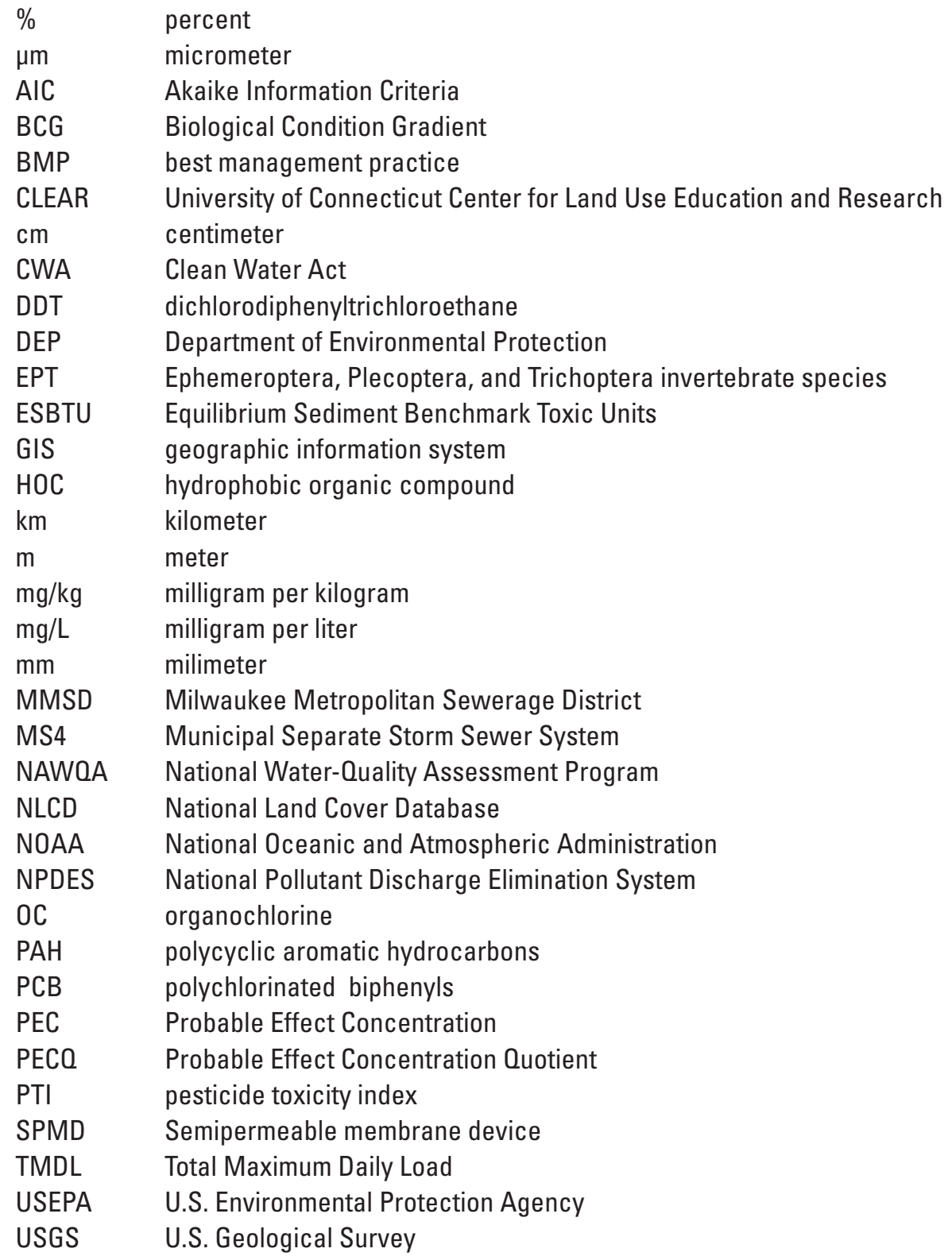





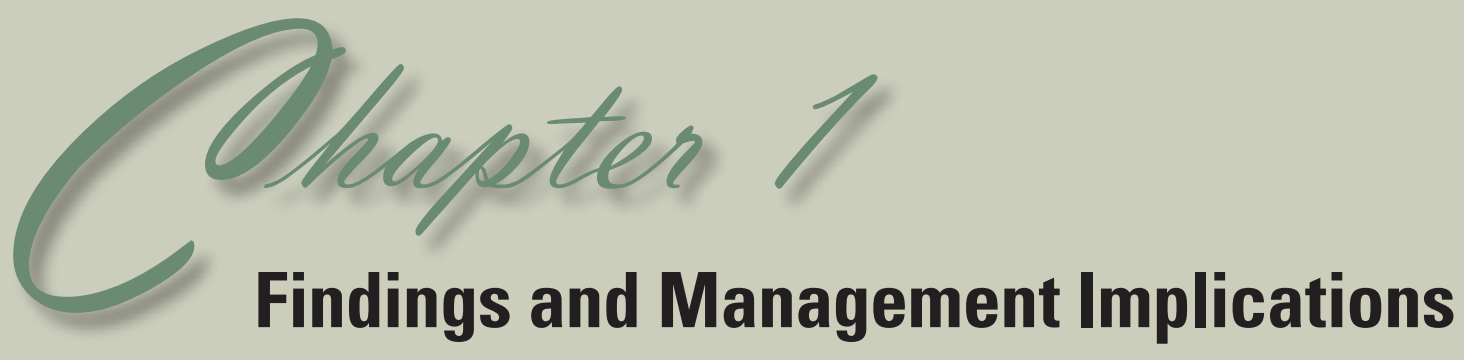

Urban development is an important agent of environmental change in the United States. The urban footprint on the American landscape has expanded during a century and a half of almost continuous development. Eighty percent of Americans now live in metropolitan areas, and the advantages and challenges of living in these developed areasconvenience, congestion, employment, pollution - are part of the day-to-day realities of most Americans. Nowhere are the environmental changes associated with urban development more evident than in urban streams. Contaminants, habitat destruction, and increasing streamflow flashiness resulting from urban development have been associated with the disruption of biological communities, particularly the loss of sensitive aquatic species. Every stream is connected downstream to larger water bodies, including rivers, reservoirs, and ultimately coastal waters. Inputs of chemical contaminants or sediments at any point along the stream can cause degradation downstream with adverse effects on biological communities and on economically valuable resources, such as fisheries and tourism.

In response to general concerns about the degradation of urban streams, the U.S. Geological Survey (USGS) conducted a national-scale, scientific investigation of the effects of urban development on stream ecosystems. Nine metropolitan study areas of the United States were selected-Portland, Oregon; Salt Lake City, Utah; Birmingham, Alabama; Atlanta, Georgia; Raleigh, North Carolina; Boston, Massachusetts; Denver, Colorado; Dallas, Texas; and Milwaukee, Wisconsin.
The studies were conducted in Salt Lake City, Birmingham, and Boston in 1999-2000; in Atlanta, Raleigh, and Denver in 2002-2003; and in Portland, Dallas, and Milwaukee in 2003-2004.

The comprehensive investigation of all nine studies focused on three broad questions of interest to decision makers:

1. What are the primary effects of urban development on stream ecosystems?

2. How do the effects of urban development on stream ecosystems vary regionally across the country?

3. Which urban-related stressors are most closely linked to biological community degradation, and how can multiple stressors be managed to protect stream health as a watershed becomes increasingly urbanized?

\section{Multiple Stressors Influence How Stream Ecosystems Respond to Urban Development}

The investigation provides a science-based approach for describing and explaining the effects of urban development on stream hydrology, habitat, chemistry, and ultimately, aquatic biota, which are separate components that function collectively in defining a stream ecosystem (fig. 1-1).
Figure 1-1. Predicting how an urban stream ecosystem will respond to management actions requires understanding the interactions among many environmental factors that affect processes operating at regional, watershed, and stream-reach scales. Processes can include such things as the hydrologic cycle at the regional scale, road construction at the watershed scale, and photosynthesis at the stream-reach scale.

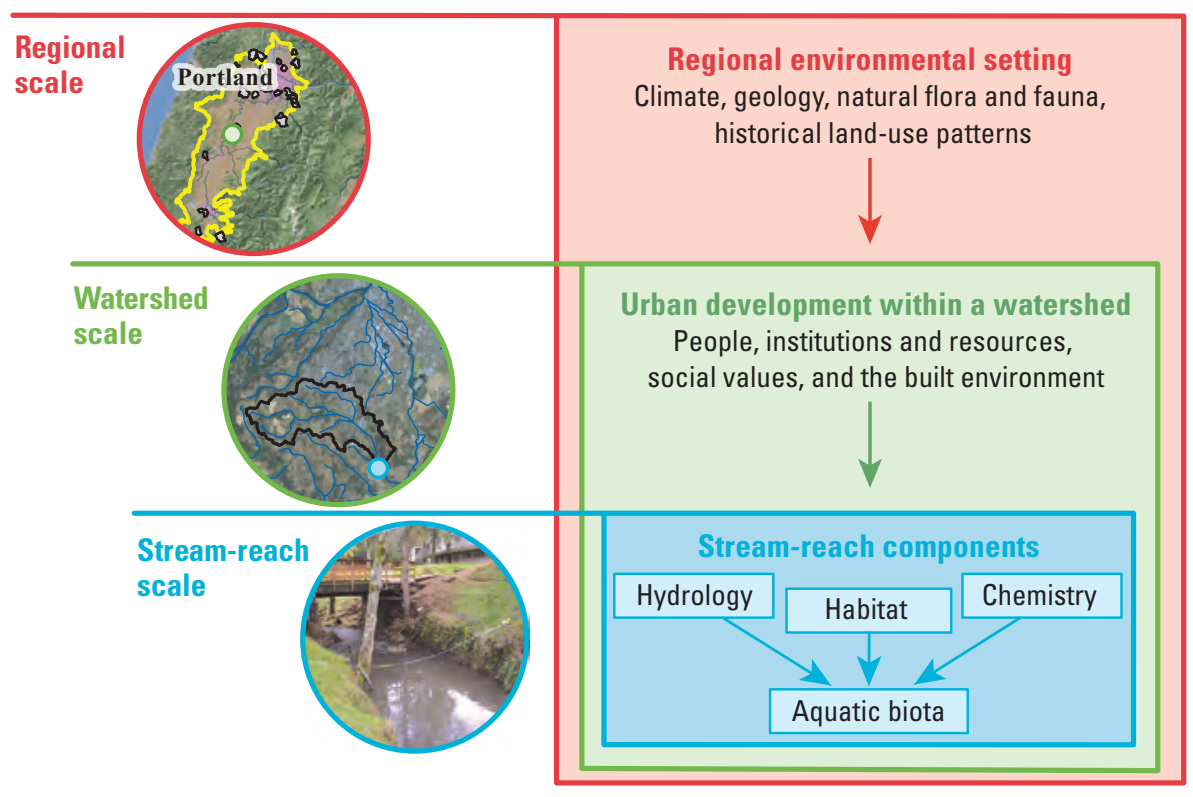




\section{No Single Factor Related to Stream Hydrology, Habitat, or Chemistry Was Universally Important in Explaining Responses of Biological Communities to Urban Development}

Analyses of how changes in stream hydrology, habitat, and chemistry relate to the species composition of biological communities indicate that no single environmental factor was universally important across all the study areas in explaining the effects of urban development on stream ecosystems. Even within a single study area, the three biological communities that were surveyed - algal, invertebrate, and fish—had different responses to urban development and changing environmental factors. The algal, invertebrate, and fish communities have different life cycles and requirements for food, shelter, and reproduction; consequently, their responses typically vary with stressors that arise from urban-related changes in physical and chemical factors. Different responses among the three communities, however, can provide important clues about the types of stressors that occur with urban development, which then can be linked to management actions that may be appropriate for improving stream conditions.

\section{Hydrology-Streamflow Flashiness Increased With Urban Development (Chapter 4)}

Urban development typically increases the amount of water entering a stream after a storm and decreases the time that it takes for the water to travel over altered land surfaces before entering the stream. Efforts to reduce flooding by draining water quickly from roads and parking lots can result in increased amounts of water reaching a stream within a short period of time, which can lead to stream flashiness and altered stream channels. Additionally, rapid runoff reduces the amount of water available to infiltrate the soil and recharge the aquifers, which often results in lower sustained streamflows, especially during summer. Increases in streamflows can cause erosion of streambeds and streambanks, thereby degrading spawning and feeding habitats for fish and reducing living space for invertebrates (fig. 1-2).

\section{Habitat-Urban Development Can Alter Stream Channels (Chapter 4)}

Stream habitats can be severely altered where urban development occurs along the streambanks, such as where a stream has been straightened by channelization or where manmade structures have replaced natural riparian vegetation. Habitat within a particular stream reach also can be altered as a result of development occurring much farther upstream in the watershed. The USGS investigation was designed specifically to measure the effects on streams from urban development throughout the watersheds; therefore, changes to habitat were attributed to development that was occurring upstream from the stream reach that was sampled.

The most consistently observed responses of habitat to urban development were related to changes in the stream channel, even when urban development was not occurring directly along the stream reach. Often, urban development was related to an increase in the stream-channel depth or an increase in the stream-channel cross-sectional area. Additionally, urban development in some regions was related to an increase in the percentage of sand and silt in the streambed sediment as levels of urban development increased in the watershed. These two changes in stream habitat are a result of erosional processes, but it is important to recognize that the potential for erosion frequently depends on natural environmental factors, such as the geology and soils of a region, that can influence the geomorphic characteristics of a stream and its watershed.

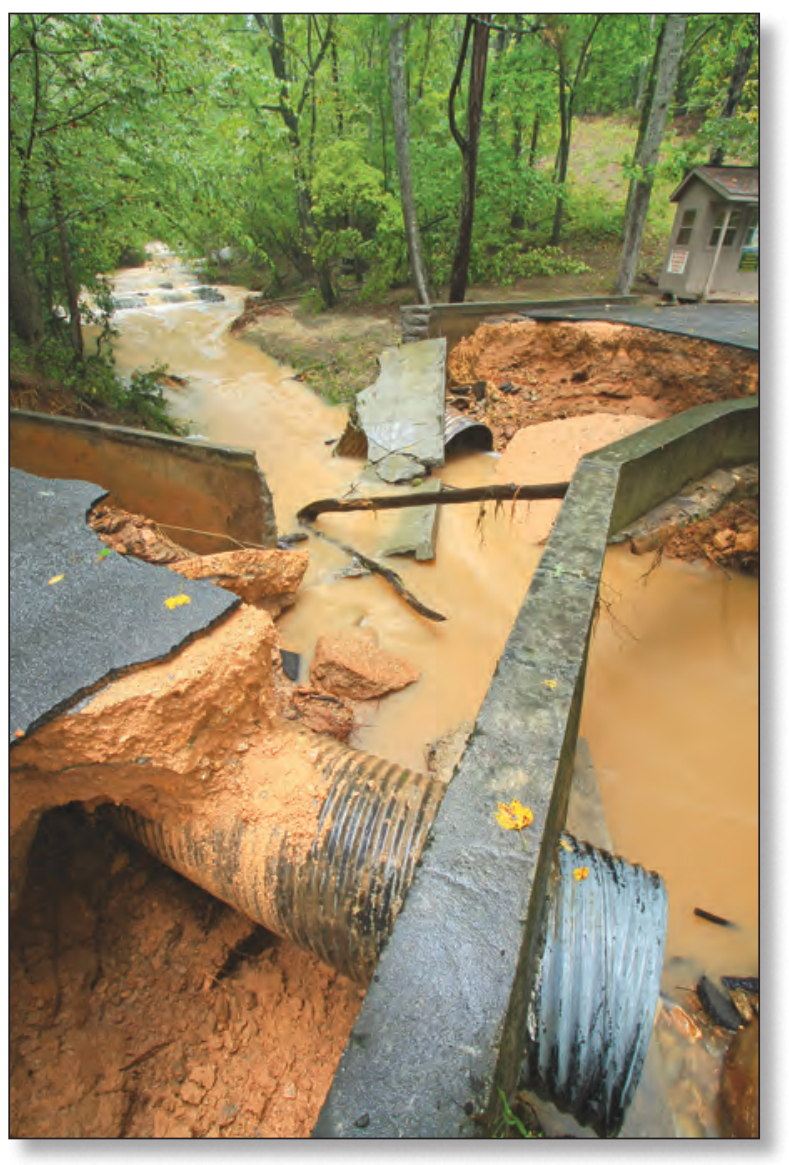

Figure 1-2. Frequent high flows increase the potential and severity of erosion, habitat degradation, and destruction of road crossings and infrastructure. This road crossing was washed out during a flood near Atlanta, Ga., in 2009. 


\section{Stream Chemistry-Concentrations of Contaminants in Water Increased With Urban Development (Chapter 4)}

Concentrations of contaminants, including nitrogen, chloride, insecticides, and polycyclic aromatic hydrocarbons (PAHs), increased with urban development, although few measurements exceeded any human or aquatic-life benchmarks. The total concentration of insecticides increased with urban development in seven of the nine study areas. The numbers of individual insecticides detected and the relation between total concentrations of these compounds and the amount of urban development varied across the study areas and appeared to coincide with regional pesticide-use patterns. For instance, higher concentrations of the insecticides chlorpyrifos and chlordane were detected in urban streams in the Atlanta, Dallas, and Raleigh study areas because of the historical use of these compounds for termite control. These results underscore the importance that regional differences need to be taken into account when comparing the influence of urban development on aquatic biota in different areas.

An increase in chloride concentrations relative to urban development was observed in all nine study areas (fig. 1-3). The link between urban development and increasing chloride concentrations occurred even in areas with warm climates where deicing chemicals are used infrequently, which suggests sources of chloride other than road salt.

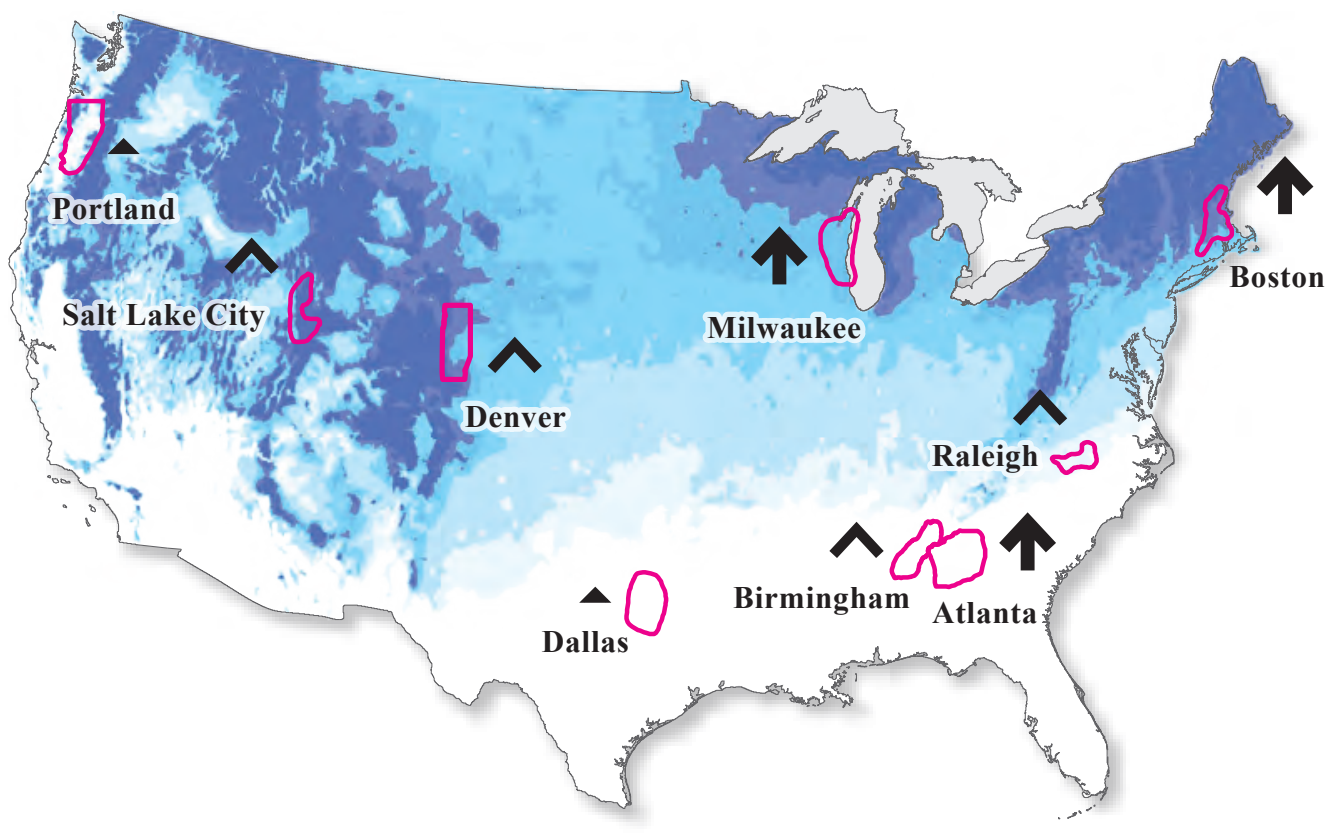

EXPLANATION

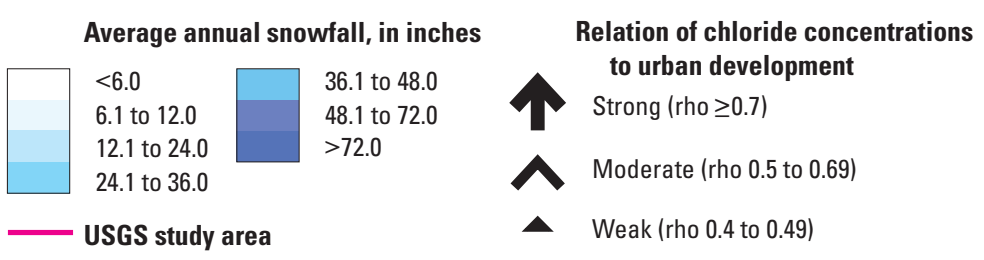

Figure 1-3. Chloride concentrations during low-flow conditions increased in response to urban development in all study areas, even in warmer climate areas with low amounts of snowfall where deicing chemicals are seldom used. The general pattern of increased chloride concentrations with urban development is noteworthy because such a change in water quality can adversely affect aquatic communities. 


\section{Aquatic Biota-Loss of Sensitive Species Was the Most Consistent Biological Response to Urban Development (Chapter 5)}

Urban development generally results in a shift in the species composition of the algal, invertebrate, and fish communities. However, the most consistent change in any of the biological communities was the loss of sensitive invertebrate species and a shift to species that are more tolerant to physical and chemical stressors. A loss in the numbers (richness) of sensitive species, which is related to a decrease in Ephemeroptera (mayflies), Plecoptera (stoneflies), and Trichoptera (caddisflies) invertebrate species (typically abbreviated as EPT), was a common response in all study areas where urban development occurred in forested watersheds. The number of EPT species is a biological condition metric that is used in many biomonitoring programs across the country because it is sensitive to environmental degradation. A reduction of more than 50 percent of EPT species was observed in some study areas as urban development increased in the watersheds (fig. 1-4).

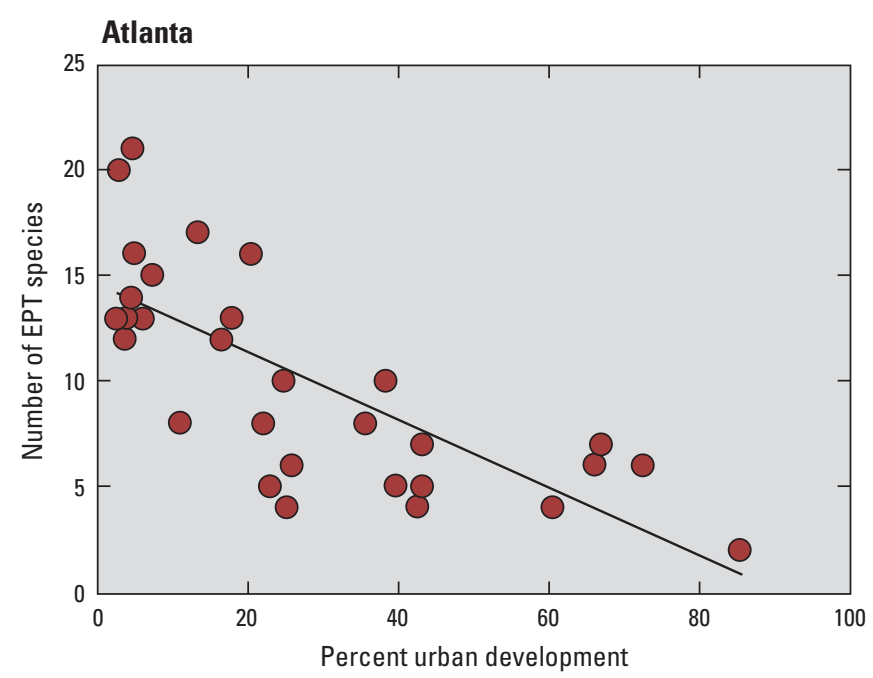

Figure 1-4. In the Atlanta study area, urban development resulted in the loss of Ephemeroptera, Plecoptera, and Trichoptera (EPT) species, many of which are sensitive to contaminants, changes in streamflow, and other stressors.

\section{Invertebrate Communities Begin to Degrade at the Earliest Stages of Urban Development (Chapter 5)}

Some invertebrate species are highly sensitive to physical and chemical changes associated with urban development (fig. 1-5). There was no evidence of a resistance threshold, which is a point along the response curve that indicates the invertebrate community begins to change after remaining

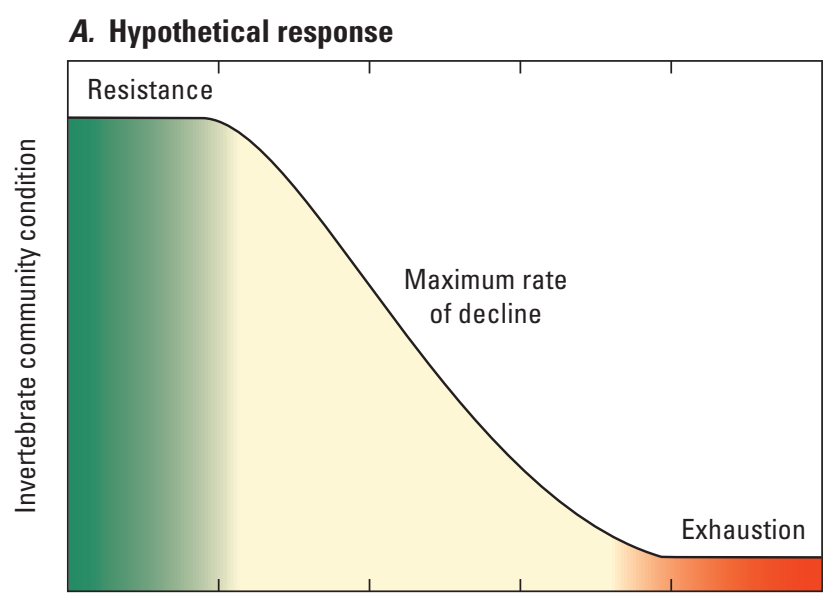

B. Observed response

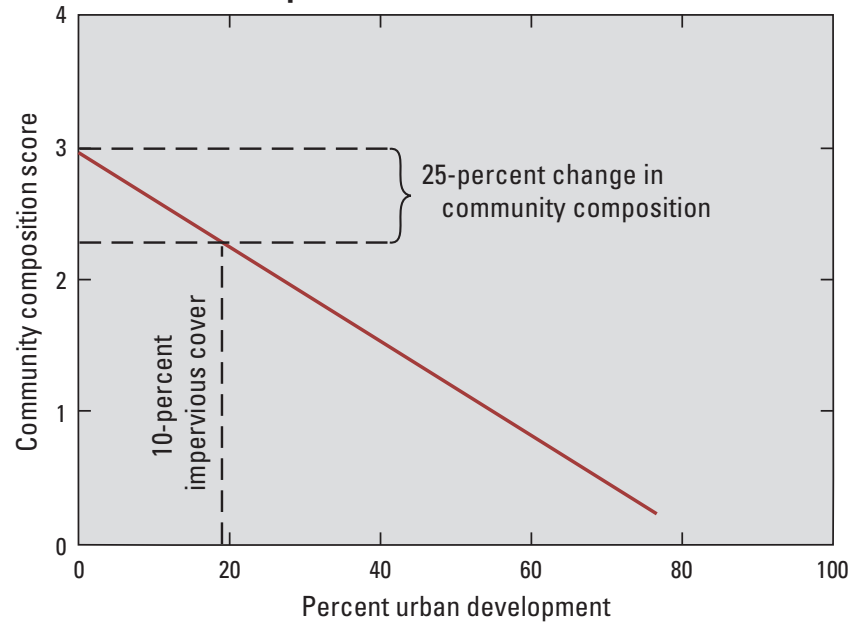

Figure 1-5. A frequent assumption is $(A)$ that biological communities are resistant to change at low levels of urban development. Then, as levels of urban development increase, a period of rapid degradation occurs in the community condition, ending in a period of exhaustion when no further change occurs. The observed response $(B)$ of invertebrate communities to urban development in the Boston study area differed from the hypothetical response. At 10-percent impervious cover (just under 20-percent urban development), the community composition changed by about 25 percent. 
stable during the early stages of urban development. Likewise, no indication of an exhaustion threshold was observed. An exhaustion threshold identifies a point along a response curve where the population of relatively sensitive species within a community is "exhausted" and only tolerant species remain. The lack of an exhaustion threshold indicates that stream-rehabilitation efforts could have a positive effect on the biological condition of a stream regardless of the level of urban development in the watershed.

\section{Management Implications}

- Stormwater-management strategies that result in disconnecting impervious cover from the stormdrainage systems may reduce streamflow flashiness, thereby reducing channel erosion and protecting stream habitat.

- Strategies that result in slowing the runoff of precipitation from developed areas to nearby streams can increase infiltration to groundwater, which can help sustain streamflows during the summer and fall and reduce the amounts of contaminants that are transported to streams in stormwater runoff.

- Because the response of fish, invertebrates, and algae to physical and chemical stressors varies, monitoring all three communities provides multiple lines of evidence when assessing the effects of disturbances to aquatic systems.

- Strategies that carefully manage development in undisturbed watersheds are important for minimizing detrimental effects on aquatic biological communities because the degradation of these communities begins at the onset of urban development.

- The lack of an exhaustion threshold in the biotic response indicates that stream-rehabilitation efforts are likely to improve the biological condition of many streams in urban areas.

- The continuous decline in the biological condition of a stream as the amount of urban development increases in a watershed indicates that biological diversity and food-web complexity may be reduced. These types of changes may make the stream and the ecosystem as a whole more vulnerable to other changes, such as the introduction of non-native species.

\section{Urban Development Affects Stream Ecosystems Differently Across the Country}

Stream ecosystems are defined by factors such as climate, geology, topography, land cover, and dominant land-use patterns that are fundamentally different across the country. These factors create a template for the streamreach components of hydrology, habitat, and chemistry that influences the species composition of aquatic biological communities. Consequently, even as a watershed undergoes urban development in a particular region, biological communities of the stream will still retain certain relatively distinct regional characteristics of species composition.

\section{Regional Differences in the Types of Land (Forested or Agricultural) Undergoing Urban Development Influenced the Response of Stream Chemistry and Aquatic Biota (Chapters 4 and 5)}

In-stream concentrations of total nitrogen increased with urban development in the Portland, Atlanta, Raleigh, and Boston study areas, which were regions where land cover prior to urban development was primarily forested. In the Denver, Dallas, and Milwaukee study areas, the predominant land cover prior to urban development was agriculture and grassland. Land-management practices associated with agriculture can contribute to elevated nitrogen concentrations in streams that are not related to urban development. Consequently, nitrogen concentrations were considerably higher in streams with low urban development in the Denver, Dallas, and Milwaukee areas than in comparable streams in study areas where urban development occurred in forested watersheds. As a result, a relation between urban development and nitrogen concentrations was not apparent in the Denver, Dallas, and Milwaukee study areas.

The response patterns for total herbicide concentrations were similar to the response patterns for nitrogen concentrations; increasing herbicide concentrations were observed only in study areas where forested land was being converted to urban uses (Portland, Salt Lake City, Birmingham, Atlanta, and Raleigh). In the Dallas and Milwaukee study areas, where agriculture was the pre-urban development land cover, herbicide concentrations were highest at sites with less than 20 percent urban development. 
In the Denver, Dallas, and Milwaukee study areas, the pre-urban land cover (grassland and agriculture) was an important factor in how the biological communities responded to urban development. In these three study areas, the decline in biological communities was consistently less than in the other study areas. The reason for this difference was not because biological communities in these regions were more resilient to stressors from urban development but because the biological communities already had lost sensitive species to stressors from preurban agricultural land-use activities. Thus, the biological communities had been degraded before the onset of urban development (fig. 1-6).

\section{Management Implications}

- The response of stream chemistry and biological communities to urban development varies strongly from region to region across the country because of the variation in natural factors, such as geology, climate, and soils. Because natural factors are essential in shaping stream ecosystems, it is critical that these regional differences be taken into account when developing management strategies to protect and improve urban streams.

- Assessing the health of a stream ecosystem is improved by the use of biological community endpoints that are sensitive to changes in urban development for a specific region.

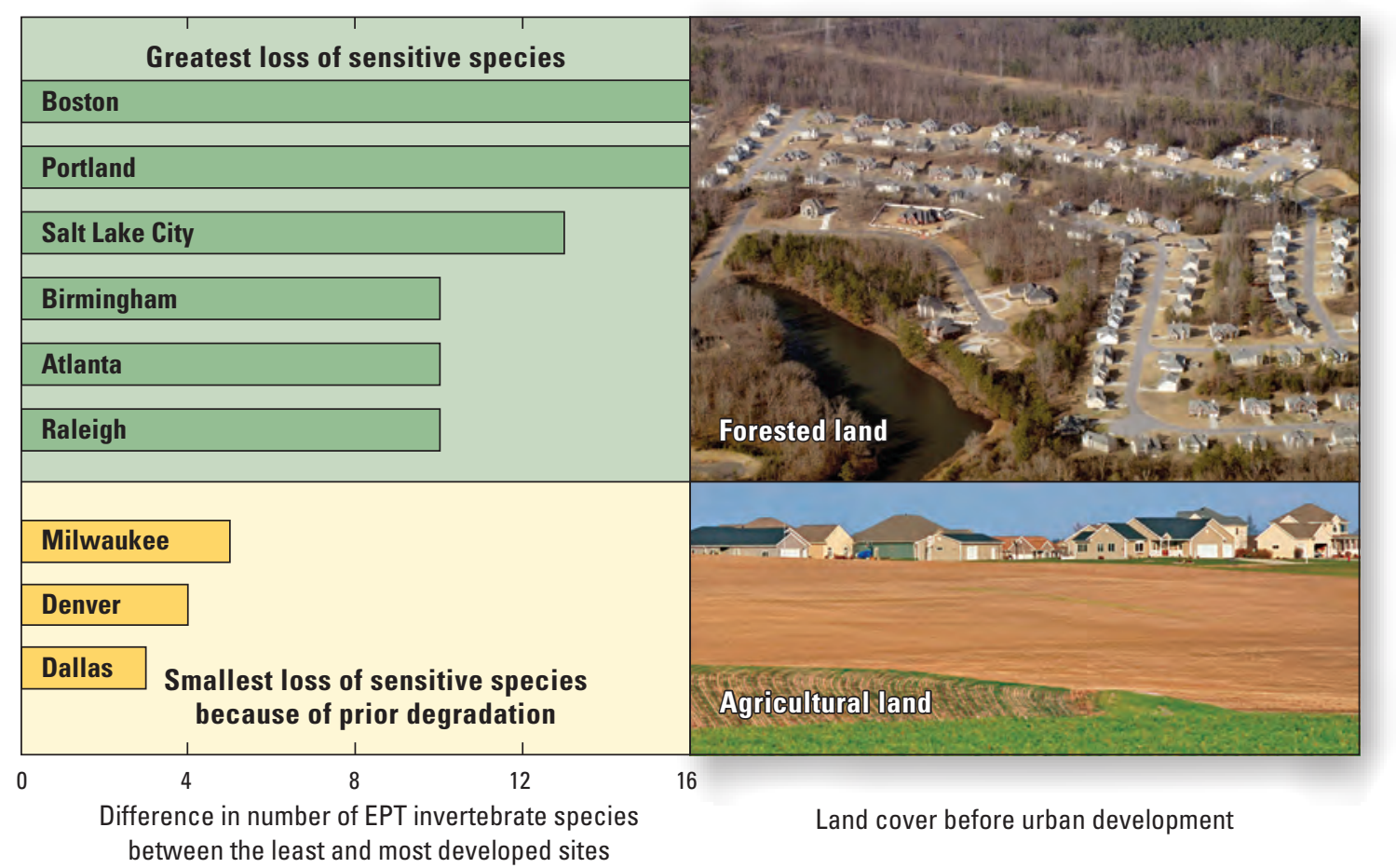

in each study area

Figure 1-6. The loss of Ephemeroptera, Plecoptera, and Trichoptera (EPT) invertebrate species was greatest when urban development occurred on forested land (green bars). Fewer species were lost in streams of agricultural watersheds (yellow bars) because the biological communities already had endured some degree of degradation associated with agricultural land-use activities, and relatively sensitive EPT species were already absent in streams in these areas. 


\section{New Innovative Tool Predicts the Effects of Hydrology, Habitat, and Chemistry on Stream Health}

In a pilot investigation using data from the Boston study area, an innovative regional model was developed for New England to predict how different combinations of urbanrelated stressors associated with stream hydrology, habitat, and chemistry affect stream health, as measured by changes in the invertebrate community. The tool can be used to evaluate how changes to one or multiple urban stressors can affect biological endpoints and the likelihood of attaining the desired stream-health goal (fig. 1-7). The model was structured to predict the probability of attaining six tiers of stream health, which makes it possible for different management scenarios to be evaluated for protecting stream health in urbanizing areas. For example, the model predicted that the likelihood of attaining a healthy stream would be only about 25 percent when the levels of urban development in a watershed exceeded 31 percent. Management actions to improve water quality and reduce stream flashiness are predicted to increase the likelihood of attaining a healthy stream to about 70 percent.
Figure 1-7. Stream health in urban areas is often affected by multiple stressors associated with stream hydrology, habitat, and chemistry. New multi-stressor models can provide insights on how management actions to improve one or more of these stressors may increase the likelihood of obtaining a desired biological condition. For instance, management actions to reduce stream flashiness and improve water quality in the Boston study area are predicted to increase the likelihood of attaining a healthy stream to about 70 percent.

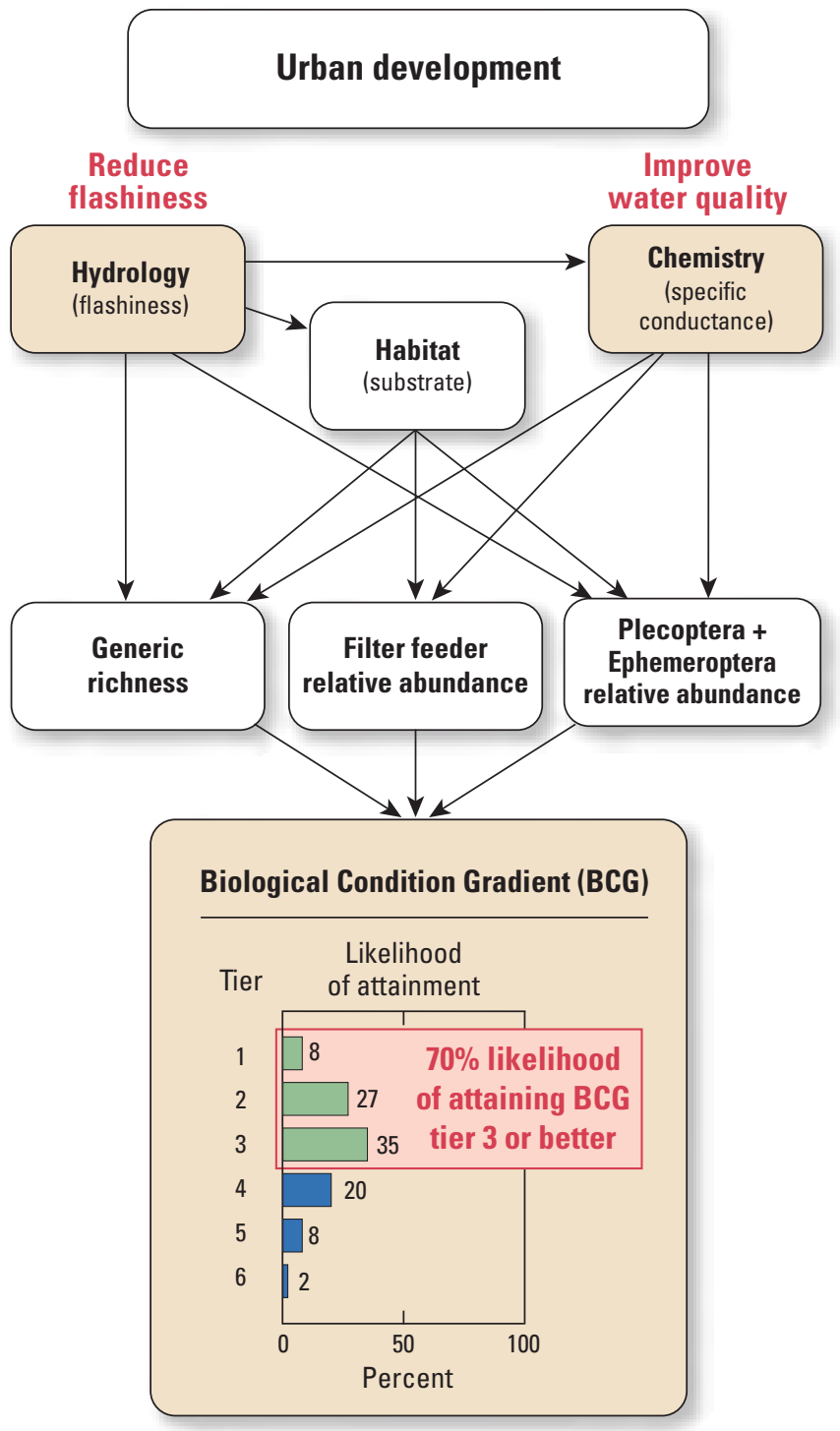





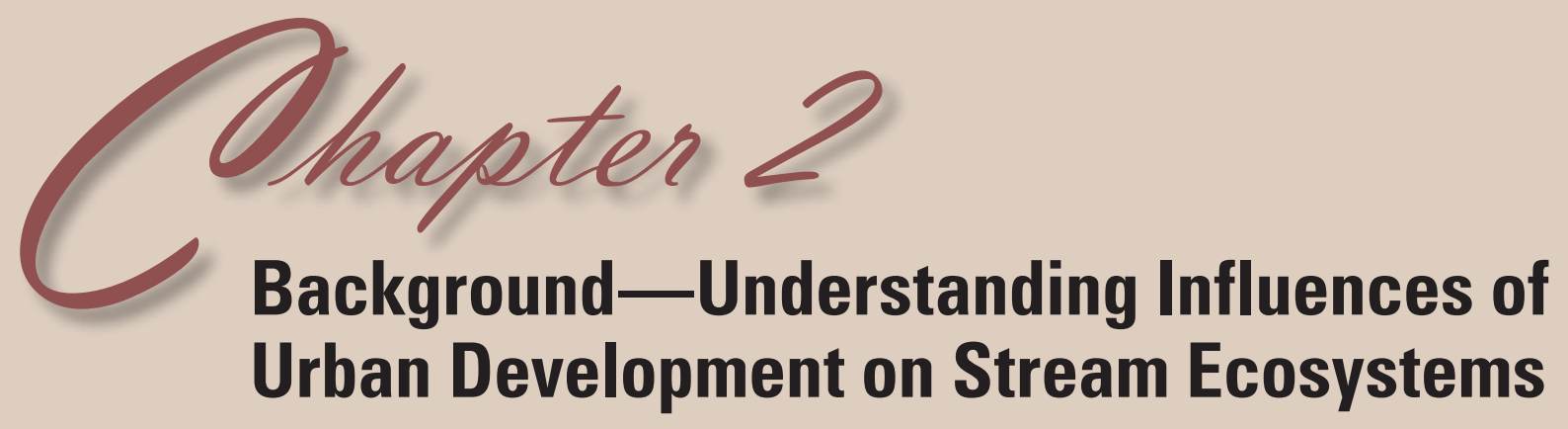

The advantages and challenges of living in metropolitan areas are a fundamental part of the day-to-day realities of most Americans and much of the world's population. The challenges will continue as global populations grow at an unprecedented rate. Cities are currently home to half of the world's 7 billion people (2012), and more than 95 percent of the net increase in population will occur in urban areas during the next 50 years (Ash and others, 2008; Grimm and others, 2008). The highest rates of population growth and land development across the United States occur at the edges

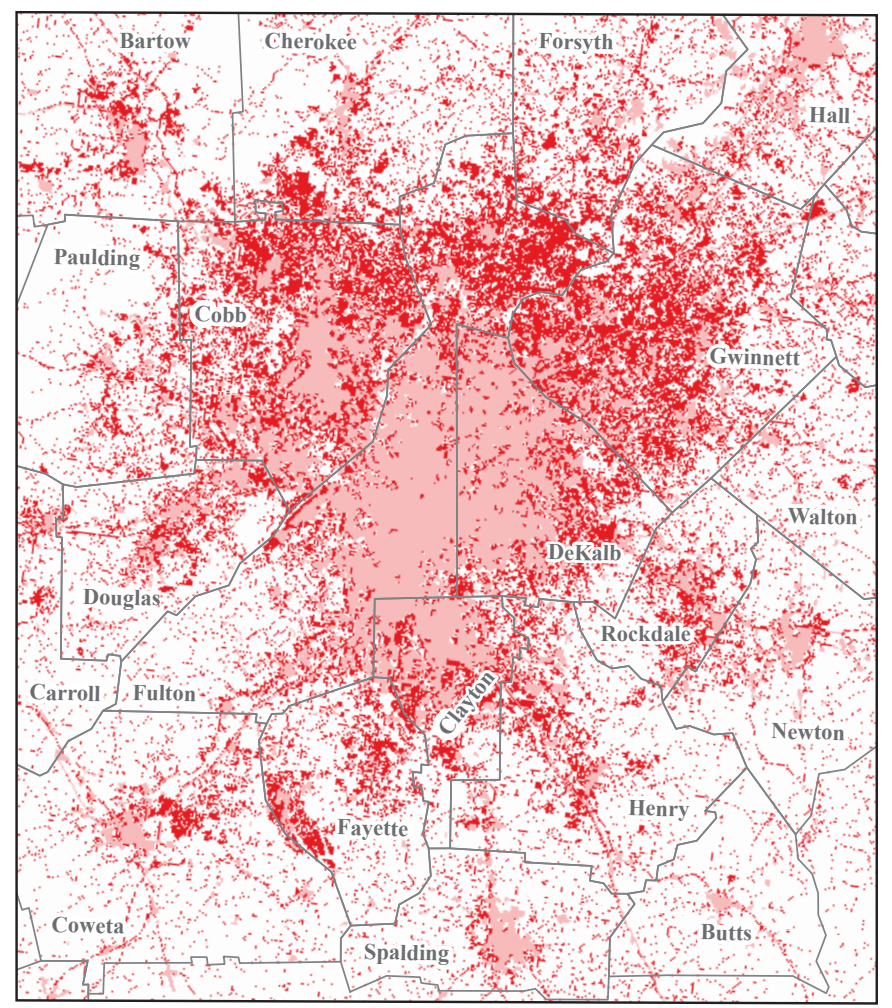

\section{EXPLANATION}

Developed land 1973-1974

Developed land 2001

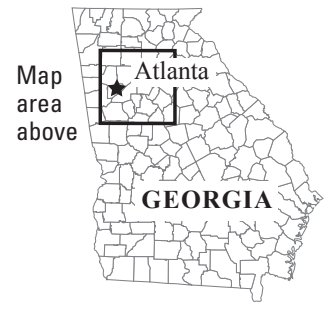

of existing metropolitan areas (Fulton and others, 2001; Markham and Steinzor, 2006). The U.S. population from 1982-1997 increased 17 percent, and urbanized land area increased 47 percent (Fulton and others, 2001; Sierra Club, 2003; American Farmland Trust, 2009). About 20 percent more land was developed by 2003 per person (for housing, schools, shopping, manufacturing, roads, and other land uses) than had been 20 years earlier, as suburbs spread out from dense city cores (Markham and Steinzor, 2006).

The pattern of urban development through time is visible in the expanding footprint of developed land in the Atlanta area between the early 1970s and 2001. This metropolitan area recorded phenomenal growth, as demonstrated by an average of 69,000 people moving into the area each year during the 1990s. With most of the population growth occurring outside the city limits, urban land area in the Atlanta metropolitan area increased by 50 percent during this period, and it was estimated that almost 50 acres of tree cover were lost to urban growth every day during the 1990s (Georgia Forestry Commission, 2001; modified from Bluestone and others, 2008).
This chapter introduces a framework for understanding the influences of urban development on stream ecosystems. Key features of urban development and stream ecosystems are described that will be useful for understanding the study design (chapter 3), the findings (chapters 4-6), and the management options (chapter 7). 
Metropolitan areas provide opportunities for employment, housing, medical services, education, and recreation to both residents and visitors (Bluestone and others, 2008). Compared to rural areas, however, metropolitan areas consume more resources, generate more waste, and create a greater need for waste treatment and disposal. Many of the resources required to support a metropolitan area, such as clean drinking water, are imported from elsewhere, which can often result in management practices that extend the effects of urban development outside the municipal borders (Rees and Wackernagel, 1994; Alberti and others, 2003; Grimm and others, 2008).

Effects of urban development are particularly evident in the physical, chemical, and biological characteristics of local streams. Urban development often results in natural vegetation and native topsoil being replaced with impervious cover (rooftops and pavement, such as roads, parking lots, and driveways) that blocks the infiltration of rain and snowmelt into the ground. Thus, the water-retention and evapotranspiration functions of the soil and natural vegetation are lost and replaced by the construction of artificial drainage systems that alter the natural movement of precipitation to streams. These modified systems often result in high volumes of stormwater flowing rapidly over the landscape to receiving streams. The speed and amount of water flowing to streams combined with pollutant sources, such as sediment, nutrients, fertilizers, and other contaminants, have been linked to changes in

1. Stream hydrology — The amount, movement, and distribution of water (U.S. Environmental Protection Agency, 1997; Poff and others, 2006; Poff and others, 2010; Steuer and others, 2010);

2. Stream habitat-The physical structure of the stream that is home for organisms (biota), such as invertebrates and fish (Roy and others, 2003; Chin, 2006; Fitzpatrick and Peppler, 2010);

3. Stream chemistry-The chemical characteristics of the stream that are associated with water quality (Mahler and others, 2005; Gilliom and others, 2006; Sprague and others, 2007); and

4. Aquatic biota-Degradation of the stream's biological communities: algae (Walker and Pan, 2006; Coles and others, 2009), insects and other invertebrates (Roy and others, 2003; Cuffney and others, 2010), and fish (Meador and others, 2005; Roy and others, 2007; Brown and others, 2009).

Degraded urban streams have fewer beneficial uses than healthy urban streams. More frequent or severe flooding and a decrease in recreational opportunities result from declining health of streams and the surrounding land areas. Loss of the beneficial uses of a stream may discourage certain development opportunities and require expensive stream rehabilitation efforts (fig. 2-1; U.S. Environmental Protection Agency, 1995).

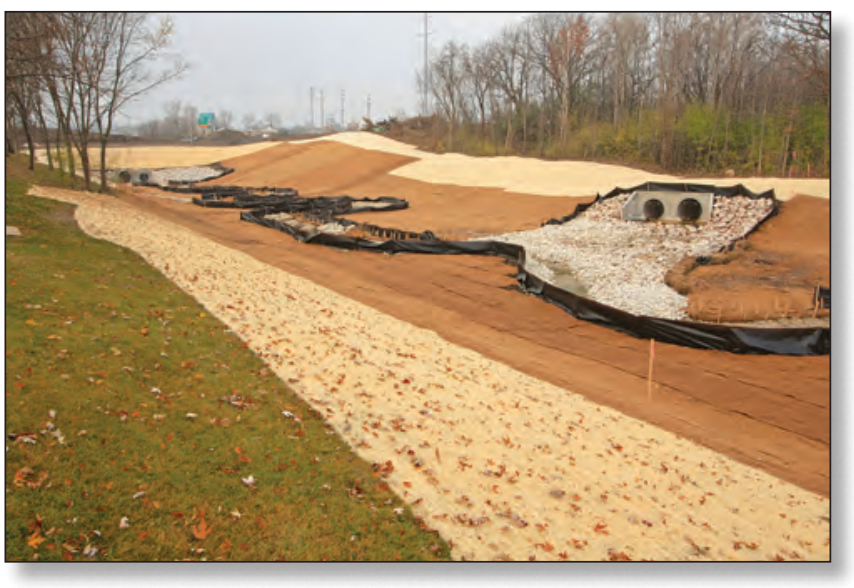

Figure 2-1. Rehabilitation of urban streams, such as this effort in Milwaukee, Wis., to reconnect the stream with the flood plain can be expensive and can require years of planning, construction, and monitoring.

\section{Why Do We Care About Stream Ecosystems?}

Healthy, natural streams provide many benefits to society (see sidebar, Ecosystem Services Provide a Way to Link the Condition of a Stream Ecosystem to Societal Well-Being). Among these benefits is the ability to capture and use nutrients such as nitrogen and phosphorus. Nutrients are transformed by biological, chemical, and physical processes occurring in the flood plain, near-stream or riparian areas, and within the stream. For example, nutrients that are dissolved in water can be retained within the flood plain and riparian areas where the nutrient-laden water is taken up by plants and microorganisms in the soil, such as fungi and bacteria (Pinay and others, 2002; Groffman and others, 2003; Pickett and others, 2008). Thus, nutrients that could foster nuisance algal blooms if introduced directly into the stream are assimilated instead into biological organisms that live within the flood plain and riparian areas.

Intact flood plain and riparian areas along urban streams that retain their natural vegetative cover and are well connected to the stream are important in flood reduction. Trees, shrubs, and other vegetation decrease the speed of water flowing over the land surface, thus allowing time for the water to infiltrate into the soil or be taken up by plants. Additionally, plant roots anchor the soil in the flood plain and the streambank. Well-vegetated riparian areas around a stream can provide communities with opportunities to incorporate green space around its waterways. The flood plains and riparian areas along many urban streams have been enhanced with paths for walking, jogging, and bicycling. Appreciation for the streams and nearby lands is strengthened by these interactions.

Biodiversity - the number of species and "evenness" in the number of individual organisms among the different species - plays a central role in the healthy functioning of streams. Biodiversity supports stream processes such as 


\section{Ecosystem Services Provide a Way to Link the Condition of a Stream Ecosystem to Societal Well-Being}

The ecosystem services concept provides a framework for linking the chemical, physical, and biological processes in a stream, and the outcomes of these processes to the well-being of the people who appreciate the stream ecosystem (Boyd and Banzhaf, 2007). Appreciating a healthy stream ecosystem begins with understanding the processes - for example, nutrient assimilation, the hydrologic cycle, and photosynthesis - and by recognizing that they influence measurable outcomes, such as a change in the diversity of a stream's biota. A healthy stream ecosystem in turn contributes to societal well-being by providing recreation, drinking water, and aesthetics (fig. 2-2). Two examples illustrate the concept of ecosystem services.

Cardinale (2011) discusses how a diverse algal community in streams contributes to the removal of nutrients that might otherwise degrade water quality. Complex stream habitats require many different algal species to fully occupy and use all the available habitats. Loss of algal diversity can result in vacant or under-used habitats and reduce the processing of nutrients (Cardinale, 2011; Cardinale and others, 2011; Hector, 2011). By serving as a buffer against the ecological impacts of nutrient pollution, biodiversity contributes directly to at least two outcomes beneficial to human communities: aesthetic (avoiding nuisance blooms of undesirable algae species) and practical (meeting Clean Water Act nutrient standards).

Ecosystem services also are produced by the forested watersheds that are part of New York City's water-supply system. By utilizing the natural filtration abilities of the forests and forest soils while restricting activities that can occur on the land, New York City's Department of Environmental Protection has been able to avoid substantial water-filtration

\author{
costs. Compliance with \\ U.S. Environmental \\ Protection Agency \\ (USEPA) source-water \\ protection regulations \\ would have cost the \\ city an estimated $\$ 4$ to \\ $\$ 6$ billion to develop \\ a filtration system \\ (Budrock, 1997).
} A Watershed Memorandum Agreement allows the city to work collaboratively with partners to use a variety of source-water protection techniques - many focused on preservation of forest lands - to preserve water quality and exempt the city from the USEPA's filtration requirement (see http://www.nycwatershed.org/ and http:// www.nyc.gov/html/dep/html/watershed_protection/index.shtml).

In each case, processes at work in the stream (algae occupying available habitat) or watershed (protecting forested land) create outcomes that are of value to society. An ecosystem services framework links these ecosystem processes and outcomes and then provides a mechanism for valuing these outcomes. Society may be able to value these outcomes in monetary terms, such as the cost savings of not having to develop a watershed-management plan or install a water-filtration system. Other outcomes, such as avoiding unsightly blooms of nuisance algae, may be difficult to value in monetary terms but still contribute to societal well-being.

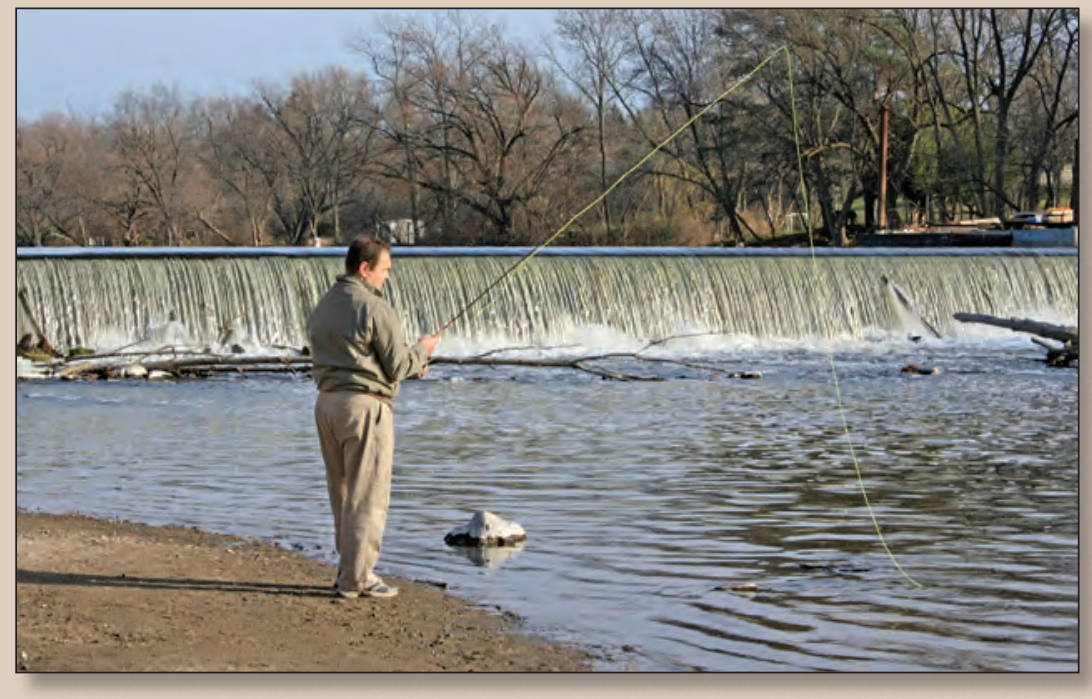

Figure 2-2. Recreational benefits, such as fishing or swimming, can become limited when stream ecosystems are degraded by alterations either to a stream or within its watershed. 
nutrient removal and dynamic interactions between flood plains and streams. Furthermore, a stream with a diverse collection of biota can better withstand natural and human disruptions and have a greater chance to recover from various disturbances (Karr and Dudley, 1981). Moreover, every stream is connected to downstream water bodies, including rivers, reservoirs, and ultimately, oceans. Inputs of chemical contaminants or sediments at any point along the stream can cause degradation downstream with adverse effects on biological communities and on economically valuable resources, such as fisheries and tourism. Healthy urban streams can be protected with regard to beneficial uses under the Clean Water Act (CWA), which establishes water-quality goals aimed at protecting and restoring the chemical, physical, and biological integrity of the Nation's waters (see sidebar, The Clean Water Act Provides a Regulatory Context for Restoring and Maintaining Water Quality).

\section{How Do Natural Stream Ecosystems Function?}

Natural stream ecosystems include habitats for plants and animals, the cycling of water through the system, the chemistry of the water, and the aquatic biota, as well as the watershed that is part of a larger region of the country. These characteristics are linked by processes, such as the transformation of energy that occurs in a stream ecosystem from the cycling of water and nutrients, and from human activities that alter the landscape. Although stream ecosystems can be resilient to shortterm disturbances (for example, a flood), the extent of the resilience from long-term disturbances (for example, urban development) in any stream is often unknown (Baron and others, 2002; Alberti and Marzluff, 2004; Millennium Ecosystem Assessment, 2005; Walsh and others, 2005b).

\section{The Clean Water Act Provides a Regulatory Context for Restoring and Maintaining Water Quality}

The key legislative authority for regulating urban water-quality issues is the Clean Water Act (CWA), especially the amendments in 1987 and 1999 that established programs for regulation of urban stormwater discharges. Under the National Pollutant Discharge Elimination System (NPDES) permitting program, industrial and municipal sources are required to limit stormwater discharges to waters of the United States. Many municipalities are required to issue permits to limit stormwater discharges. However, because permits have not been tied directly to meeting a specific water-quality standard or outcome, the achievement of waterquality improvements has been an elusive goal (National Research Council, 2008).

Major parts of the CWA that are currently being used to address urban stormwater issues and improve water quality include water-quality standards and the Total Maximum Daily Load (TMDL) Program. Implementation of these requirements begins with identifying beneficial uses for each water body in a state by its use classification, such as recreation, drinking water, and aquatic life; or economic uses associated with agriculture, industry, or municipalities. Some states and tribes designate tiers of beneficial uses above a baseline level of acceptable water quality; these multiple tiers are used to help prevent degradation of high-quality waters. The description of these uses can serve as a water-quality standard. Measurable water-quality criteria are used to assess whether these standards have been attained. Criteria can be quantitative or descriptive, and can be developed for physical, chemical, and biological measures. Maine, for example, uses multiple tiers of biological criteria to determine if water bodies are attaining water-quality standards (Maine Department of Environmental Protection, 2005).

The USEPA, states, and tribes are responsible for implementing the CWA. States monitor their waters to identify water bodies that are impaired and do not meet water-quality standards. A TMDL plan must be prepared when a water body is listed as impaired. A TMDL is used to estimate the amount of a pollutant (for example, nutrients, sediment, metals, bacteria) that a water body can receive from different sources and still meet waterquality standards. Guidelines can be developed for landscape characteristics (for example, the amount of impervious cover in a watershed) and for pollutants. Successful implementation of these guidelines typically requires establishing a range of management practices. TMDLs for impaired streams in urban areas are enforced through NPDES permit requirements and can be very costly to address and achieve. Failure to meet CWA goals, as they are reflected in federal and state regulations and standards, can result in the classification of waters as impaired and subject to expensive cleanup efforts. 


\section{Aquatic Biota Function Within a Foodweb}

The aquatic biota that are the focus of this investigation - algae, invertebrates, and fish - function as an ensemble. The stream foodweb illustrates how material and energy are transferred within the biological community (fig. 2-3). This transfer of material and energy also occurs along the length of a stream (see sidebar, Streams Change Continually as They Flow From Headwaters to the Mouth). In a healthy stream ecosystem, the needs of one organism are met by its environment and often by other biota. High biodiversity often allows for these needs to be met by more than one species, which can provide some level of resilience against natural and human-induced disturbances.

Algae are the primary producers in streams, using photosynthesis (sunlight, water, nutrients, and carbon dioxide) to produce food (plant matter, sugars, and oils) and oxygen that can then be used by other aquatic biota. Generally, diatoms are the most abundant group of algae in healthy streams (Lowe and LaLiberte, 1996). Algae that are attached to rocks, sediment, and woody debris are the principal algal types in small and moderate-sized streams.

Invertebrates and fish that feed directly on algae and plant matter are called primary consumers. Primary consumers scrape algae, bacteria, and fungi from submerged rocks and other surfaces, filter algae and detritus from flowing water, or shred plant matter that has come into the stream from the surrounding landscape. Invertebrates include animals such as snails, mussels or clams, worms, leeches, and the larvae of many insects.

Fish that feed on animals, such as invertebrates or other fish, are examples of secondary consumers. Because fish have life cycles that span years and are affected by many disturbances that occur over time, they reflect long-term changes in the aquatic foodweb. The larval stages of some insects, such as stoneflies and dragonflies, are considered secondary consumers because they eat other invertebrates and sometimes small fish. Humans are also secondary consumers.

Finally, decomposers are mostly fungi and bacteria that break down waste products and dead or decaying organisms into simpler compounds of carbon and nitrogen that are used by producers. The decomposition processes are a form of "respiration" and, thus, can reduce the concentration of dissolved oxygen in water when these processes are at especially high levels. Algae, fungi, and bacteria make up biofilms that coat surfaces of rocks, woody debris, and the bottom of streams. Biofilms are used by many aquatic organisms as a source of food.

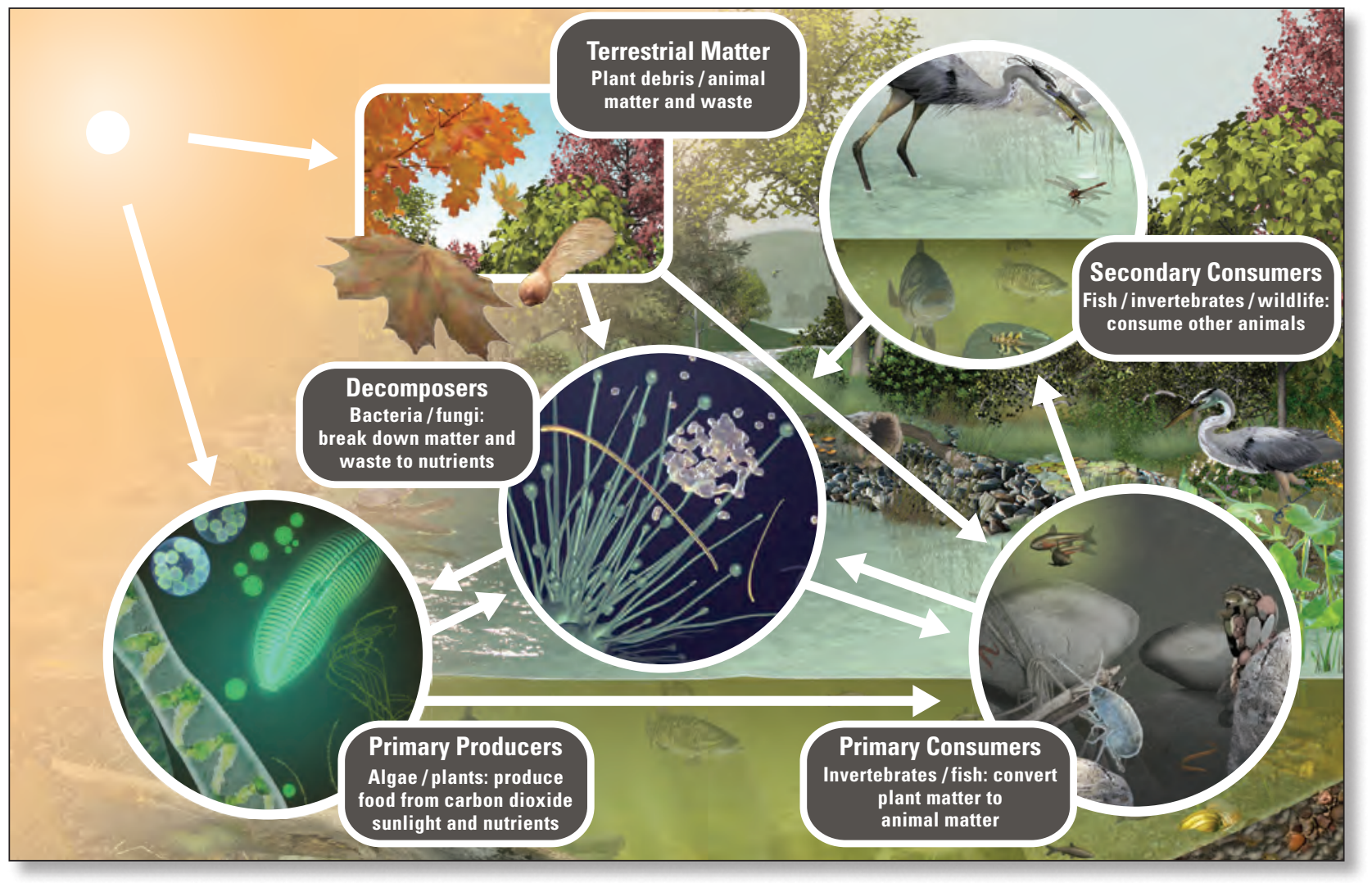

Figure 2-3. A simplified foodweb in a stream ecosystem, showing the interaction between energy coming from the sun and the biota, which include primary producers (diatoms and green algae), primary consumers (caddisflies, amphipods, and minnows), secondary consumers (herons, bass, dragonflies, and stoneflies), and decomposers (bacteria and fungi). (Drawing by Frank Ippolito, Production Post Studios, 110 North Fulton St., Bloomfield, N.J.) 


\section{Streams Change Continually as They Flow From Headwaters to the Mouth}

The aquatic biota, stream hydrology, habitat, and chemistry of a stream ecosystem change continually from the headwaters of a watershed downstream to a receiving body, such as a reservoir, estuary, or ocean (Vannote and others, 1980; Allan and Castillo, 2007; Meyer and others, 2007). Small streams can be shaded by vegetation for most of the growing season, and dead plant matter, or detritus, such as fallen leaves and wood, enters the streams from the surrounding landscape. The invertebrates in these small streams or headwaters shred plant matter into smaller particles; microorganisms, such as fungi and bacteria, further break down these particles; other invertebrates and fish harvest these smaller particles and microorganisms for food. The headwaters of a stream tend to have fewer species than larger, downstream reaches because of limited habitat and nutrients.

As headwater streams merge with other streams and become wider, more light reaches the water, and habitat for biota becomes more varied. Biodiversity generally increases with increasing stream size in natural systems. Increased light enhances photosynthesis so that algae can grow on submerged surfaces, such as cobble and woody debris. Invertebrates in these larger streams collect and gather their food from the streambed, scrape algae from submerged surfaces, or filter organic particles that are floating downstream. Fish communities become more diverse and begin to include species with wide-ranging feeding preferences that include algae, invertebrates, and other fish.

\section{Stream Hydrology, Habitat, and Chemistry Define the Living Spaces Available to Aquatic Biota}

The condition of the living spaces for biota in a stream, as determined by the hydrology, habitat, and chemistry, plays a critical role in determining the species and abundance of biota living there and the overall biodiversity of the stream ecosystem (see Dynamics of a Natural Stream Ecosystem on pages 22-23; drawing by Frank Ippolito, Production Post Studios, 110 North Fulton St., Bloomfield, N.J.).

\section{Hydrology}

The movement of water is the main process that connects the landscape to stream ecosystems. In a natural or undeveloped watershed, rainfall and snowmelt reaches a stream through multiple pathways, including overland runoff, infiltration into the soil, and subsurface flow (as groundwater) toward the stream (fig. 2-4).

Natural seasonal patterns of streamflow, together with seasonal changes in light and temperature, serve as life-cycle

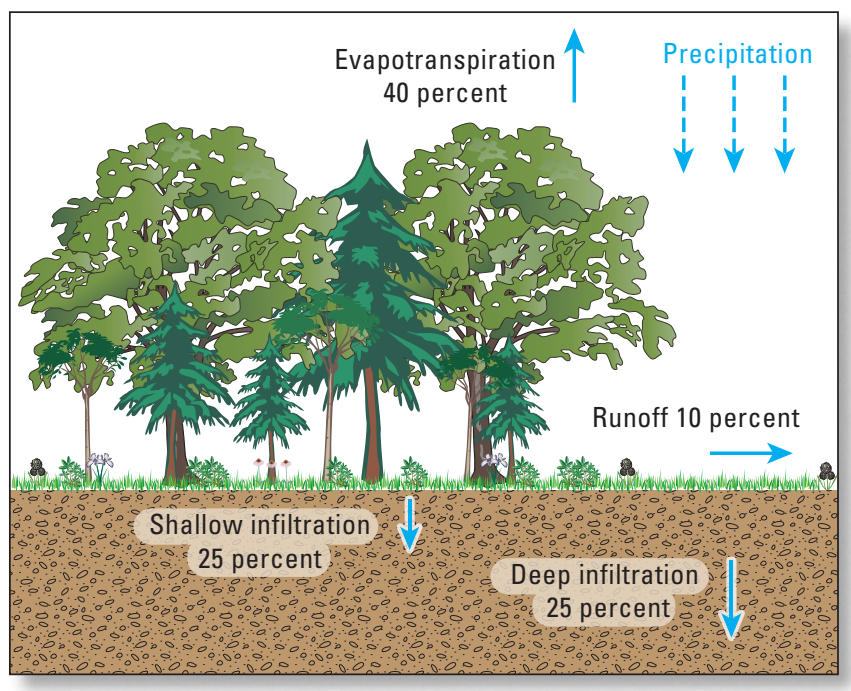

Figure 2-4. In a natural setting, about 40 percent of precipitation returns to the atmosphere through evapotranspiration from vegetation, 50 percent infiltrates into the groundwater system, and 10 percent runs off the land surface. (Modified from Livingston and McCarron, 1992.)

cues to aquatic biota. Some aquatic insect larvae and clams depend on particular streamflow velocities to transport food to them. Dispersal of offspring for some species is dependent on flow patterns and temperature. Reproduction, larval survival, and growth patterns of many invertebrates and fish are synchronized with seasonal temperatures, day length, and streamflow patterns (Bunn and Arthington, 2002; Lytle and Poff, 2004). Brief, local floods are normal in natural settings, while large floods that inundate the river flood plain are infrequent. Brief floods can increase the biodiversity of a stream while redistributing sediment and nutrients.

\section{Habitat}

The bottom and sides of a stream channel provide a substrate or base on which algae and invertebrates can attach, or into which invertebrates can burrow (see sidebar, Stream Habitat is Home for Aquatic Biota). Stream substrate ranges from small particles of sediment, such as clay and silt, to increasingly larger particles, such as sand, gravel, cobble, and boulders. Substrate also includes woody debris such as submerged tree limbs. Typically, the more varied the types and sizes of substrate, the greater the biodiversity, in part because diverse habitat provides refuge for aquatic biota during disturbances or extreme conditions, such as flash floods or droughts (Schlosser, 1987; Sedell and others, 1990).

The riparian area, the narrow corridor of land immediately adjacent to both sides of a stream, is where terrestrial and aquatic ecosystems meet. Vegetation in the riparian area contributes carbon and other nutrients to the stream from decay of fallen plant matter, and it reduces erosion by helping to stabilize soil in streambanks. Trees that fall into the stream create areas that have varying flow velocities and 
can result in undercut streambanks where fish seek refuge (Allan and others, 1997). A well-developed tree canopy shades a stream for much of the day and helps moderate water temperatures during summer (fig. 2-5). Natural riparian areas are oases of biodiversity, providing food, shelter, and resting spots for insects, amphibians, and other terrestrial biota that may depend on streams for part of their lives. These same areas serve as refuges for terrestrial biota displaced by urban development. This oasis effect is one reason riparian areas have aesthetic value to humans and make prime locations for parks and recreational activities.

\section{Chemistry}

Carbon and nutrients, such as nitrogen and phosphorus, are required for all stream life. They are taken up by algae and biofilms, which are then consumed by other biota to provide building blocks for the entire stream foodweb. Nutrient concentrations tend to be relatively low in streams draining undeveloped watersheds. In some instances, naturally occurring nutrient concentrations are low enough to limit the growth of algae and other plants.

Other chemical elements, such as chloride, iron, magnesium, oxygen, potassium, sodium, and sulfur, influence the nature of chemical reactions in streams. Water temperature

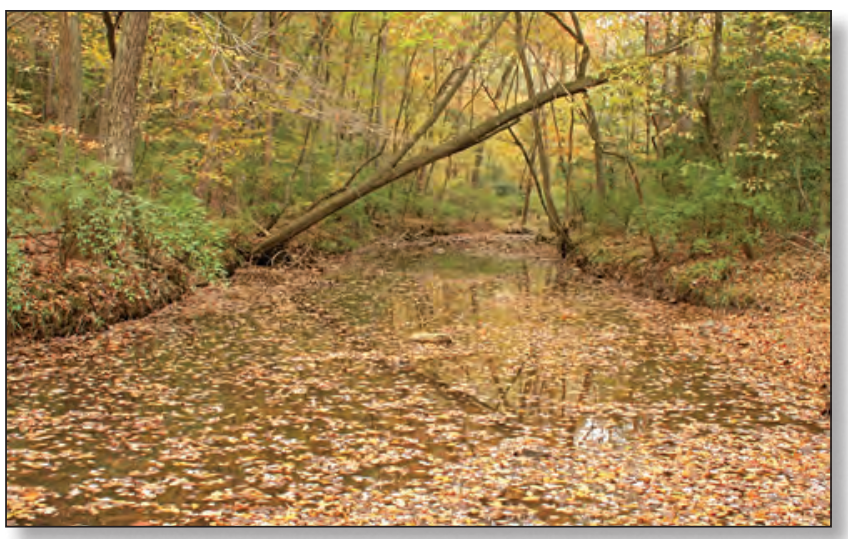

Figure 2-5. Trees and shrubs along the stream shade the water surface and help to moderate temperature changes during summer. Leaves falling into the stream are an important source of food and nutrients for aquatic biota.

and $\mathrm{pH}$ control the rate of many chemical reactions and the relative toxicity of some chemicals to aquatic biota. Oxygen dissolved in water is essential for all aquatic biota, and adequate amounts are necessary for optimal biodiversity. Concentrations of dissolved oxygen in a stream are greatly affected by streamflow characteristics, such as velocity and depth, as well as water temperature, sunlight, and plant respiration.

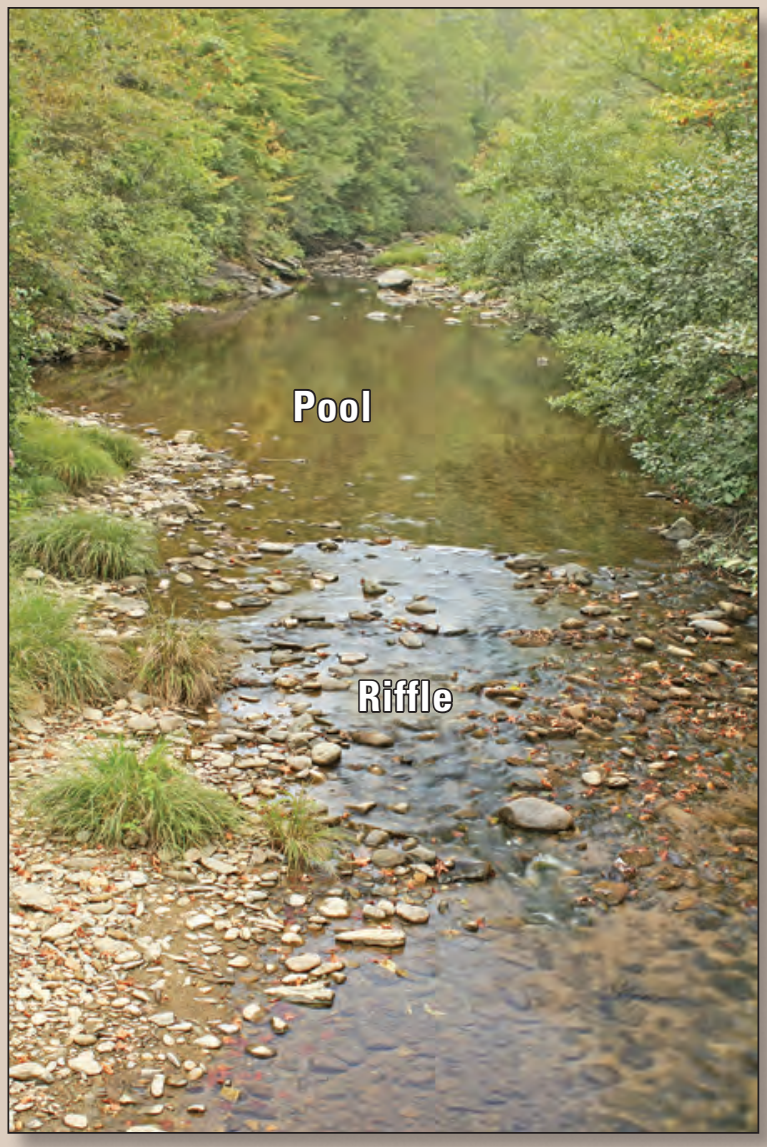

\section{Stream Habitat Is Home for Aquatic Biota}

Diverse habitat is essential for healthy stream ecosystems. Stream features, such as the channel, streambed sediment, and streambanks, affect shelter, food, and reproduction for all forms of aquatic biota. Measurements of habitat allow assessment of links among stream processes and biological communities.

Important aquatic habitats include riffles (shallow rocky areas with fast flows) and pools (deep areas with slow-moving water), bars (areas in the channel or sides of channels where gravel or sand builds up), undercut streambanks, backwaters (areas where the direction of streamflow is reversed), and side channels. The location of a stream is not permanent, and streams naturally meander across valley bottoms. As streams slowly migrate across the flood plain, variations in streamflow speed and direction, sediment deposits, woody debris and other flow-resistant materials, and vegetation create a diversity of habitats. When a channel unexpectedly widens or narrows, or if the streambed builds up or is cut downward, it is an indication that the stream is unstable and something has changed in the flow, sediment inputs, or in the vegetation surrounding the stream. Natural vegetation along stream corridors provides shelter, food, and energy sources for aquatic biota. An important aspect of stream habitat, flood-plain connectivity, is the degree to which a channel is hydrologically connected with its flood plain. Flood plains provide habitat for plants, insects, amphibians, reptiles, birds, and mammals, many of which have some connection with life in the stream. The physical connection between the flood plain and stream can be easily altered by changes in streamflow and sediment inputs. 


\section{How Does Urban Development Alter a Stream Ecosystem?}

Anyone walking along an urban stream can find evidence of the effects of urban development, from highly eroded streambanks to plastic grocery bags caught in tree branches to abandoned shopping carts and tires (see Dynamics of an Urban Stream Ecosystem on pages 24-25; drawing by Frank Ippolito, Production Post Studios, 110 North Fulton St., Bloomfield, N.J.). Urban stream ecosystems are complex and dynamic. Human activities associated with urban development, including the conversion of land from rural to urban uses, addition of impervious cover, chemical contamination, protective structures along streambanks, and use of storm drains and dams affect the biological, physical, and chemical components of streams. The collective outcome of these activities is referred to as the "urban stream syndrome" (Walsh and others, 2005b).

\section{Diversity of Aquatic Biota Declines as Sensitive Species Are Lost}

Urban development has a substantial effect on aquatic biota. The most notable effect is a decline in biodiversity as the number of sensitive species in a biological community is reduced by altered stream hydrology, habitat, and chemistry conditions (Paul and Meyer, 2001; Gurnell and others, 2007; Brown and others, 2009; Coles and others, 2009; Cuffney and others, 2010). The number of exotic or introduced species may increase, and the number of native species may decrease. Urban development can result in a loss of stream connectivity, which is the degree to which a stream is connected with upstream and downstream areas and other streams. Impoundments and water diversions are typical water-management features that result in a loss of stream connectivity. Maintaining stream connectivity is important because it allows seasonal migrations and recolonization of areas by native fish and other aquatic biota when an event, such as a drought or chemical spill, has occurred. By contrast, newly created stream connections between dissimilar watersheds can provide an entry for undesirable and non-native species (see sidebar, Aquatic Biota Serve as Sentinels for Watershed Changes; fig. 2-6).

\section{Aquatic Biota Serve as Sentinels for Watershed Changes}

Algae, invertebrates, and fish have distinct life cycles, respond differently to physical and chemical stresses, and provide complementary information about the response of stream ecosystems to urban development. Identification of these responses and their relation to stressors from urban development can indicate potential avenues for management actions.

Algae have short life cycles - from days to weeks - and usually respond quickly to local changes in light and stream chemistry. Algal communities are often the initial sentinels for changes in water quality, typically showing a response before the invertebrate or fish communities.

Invertebrates have complex life cycles that span periods of months to several years. The invertebrate community in a stream is sensitive to broad, continuous changes in stressors, such as an increase in chloride concentration and sediment load that can occur in an urbanizing watershed. The ability of invertebrate communities to integrate the effects of local and watershed-wide changes that occur over an extended period of time makes them ideal sentinels for monitoring the effects of urban development.

Fish typically have the most variable response to changes in the hydrology, habitat, and chemistry of a stream, but fish communities are no more resistant to the effects of urban development than other biological communities. Generally, fish live the longest of all aquatic biota, sometimes surviving for many years and moving great distances over their lifetime. Thus, the species composition of the fish community reflects many different influences, such as local changes in stream hydrology, habitat, and chemistry, and watershed changes in land cover and stream connectivity. 
Unaltered

Biological communities

Altered
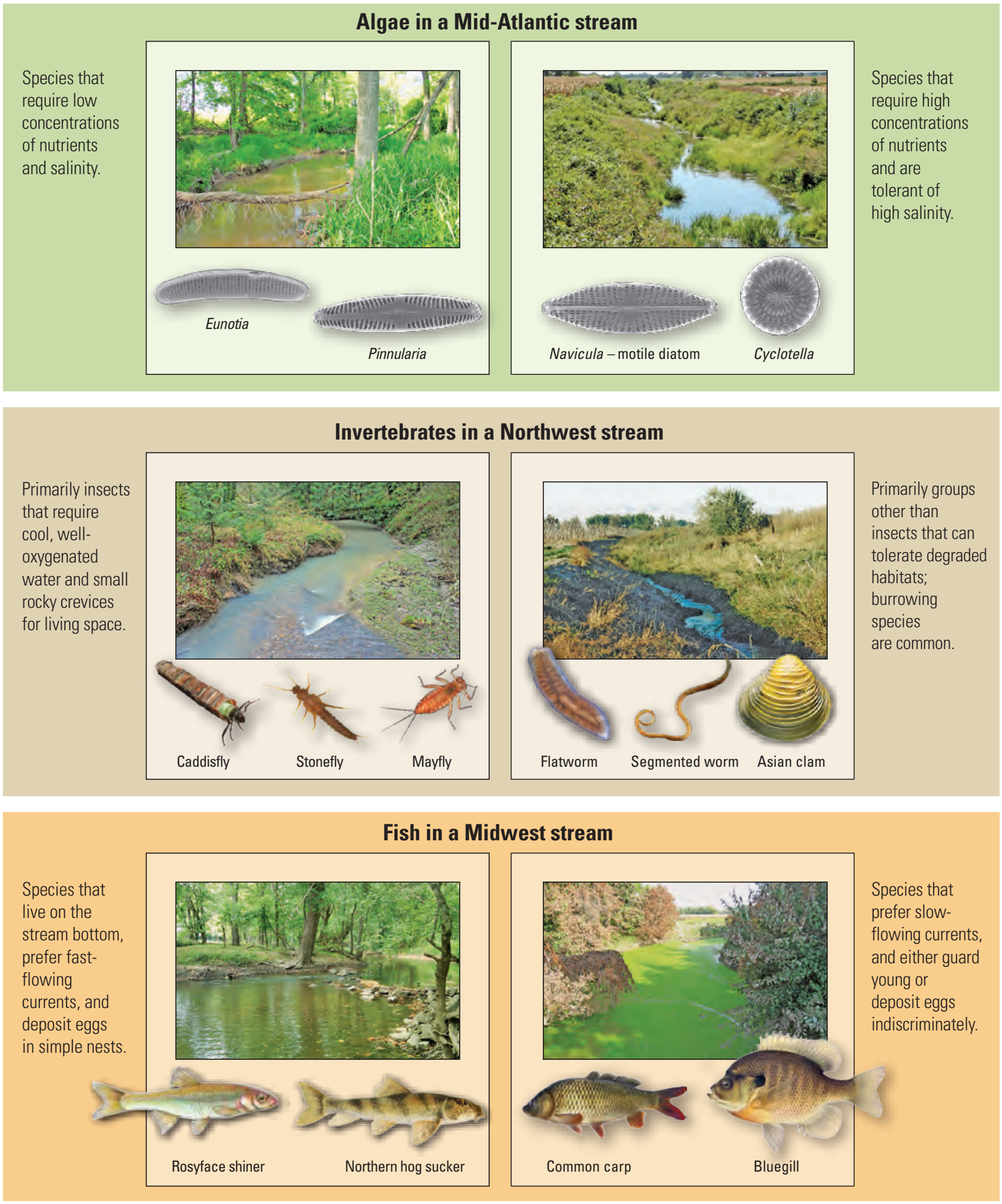

Figure 2-6. The algal, invertebrate, and fish species typically found in altered biological communities differ from those present in unaltered communities. The differences in these communities are often indicative of physical and chemical changes that can accompany urban development across different regions of the country. 


\section{Streamflow Pattern Becomes More Flashy}

Urban development in a watershed speeds up the movement of water from the time rainfall reaches the ground until the water reaches a stream (fig. 2-7). This acceleration results from the addition of impervious cover and the installation of artificial storm-drain systems that commonly accompany urban development. Stormwater moves quickly to urban streams, leading to a characteristic pattern of "flashy" streamflow - a rapid increase in flow during or following a storm and similarly a rapid decrease when storm runoff ceases (see sidebar, Impervious Cover Increases Streamflow Flashiness). Flashy streamflow patterns can be further exaggerated if stream channels are straightened or lined with concrete to remove stormwater quickly to prevent local flooding.

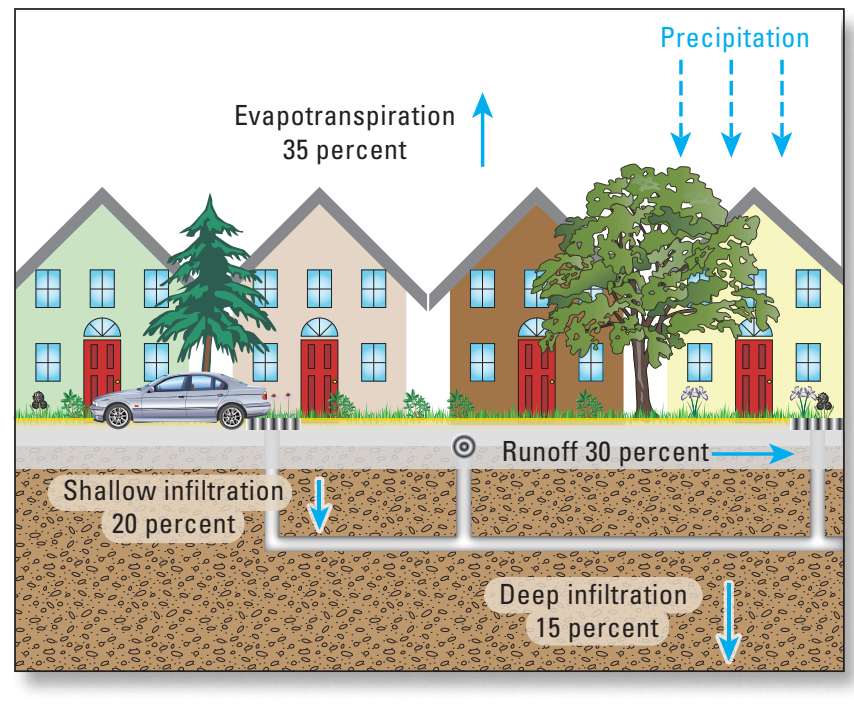

Figure 2-7. Impervious cover and storm drains deliver precipitation rapidly to urban streams, conveying pollutants and adversely affecting stream habitat, chemistry, and aquatic biota. About 35 percent of precipitation in an urban setting returns to the atmosphere through evapotranspiration from vegetation, 35 percent infiltrates into the groundwater system, and 30 percent runs off the land surface, compared to 40 percent evapotranspiration, 50 percent infiltration, and 10 percent runoff in a natural setting (see fig. 2-4). (Modified from Livingston and McCarron, 1992.) 


\section{Impervious Cover Increases Streamflow Flashiness}

Variations in streamflow, such as high flows and low flows, are natural and provide the diverse habitats needed to sustain a species-rich community of aquatic biota. Precipitation within the watershed in natural ecosystems reaches streams through a combination of overland flow, infiltration into the soil, and the subsequent underground flow toward the stream. Urban development alters these natural patterns of response to precipitation.

Streamflow flashiness refers to a characteristic pattern of streamflow in response to storm events: a rapid onset of high magnitude streamflow of relatively short duration, frequent occurrence of high streamflow conditions, and rapid decline in high streamflows. These characteristics of streamflow flashiness can be used to describe the degree of hydrologic alteration from natural conditions (Poff and others, 1997; McMahon and others, 2003; Steuer and others, 2010).

Magnitude of stormflow is defined as the difference between the peak flow during a storm event and the streamflow prior to the storm event. Impervious cover and storm drains in urban areas deliver larger amounts of runoff to streams than does natural ground cover. This often results in a large increase in peak-stream discharge that can increase the potential for erosion and channel enlargement.
Duration of a high-flow event is the length of time over which a high-flow event occurs. The duration of an individual event usually decreases with development because impervious cover and storm drains transport runoff over a shorter period of time than does natural ground cover. Overland runoff in natural areas is slowed and reduced by vegetation and infiltration into the ground; not all of the water reaches the stream at once. The indicator used in this investigation is the median duration of high-flow events.

Rate of decline in streamflow is a measure of how fast or slow streamflow returns to normal conditions following the peak stormflow. Because impervious cover and storm drains cause a larger percentage of precipitation to enter the stream rapidly as runoff, the rate of decline in streamflow (following storms) is faster in urban streams than in streams in undeveloped (natural) areas. Rain seeps into the ground and drains slowly into streams long after the rainfall event has passed in undeveloped areas; therefore, the rate of streamflow decline is slower.

The frequency of high-flow events or periods of flashiness can increase as a result of urban development. An increased frequency of high-flow conditions can cause erosion of streambanks and streambeds, thereby degrading spawning and feeding habitats for fish and reducing living space for invertebrates.

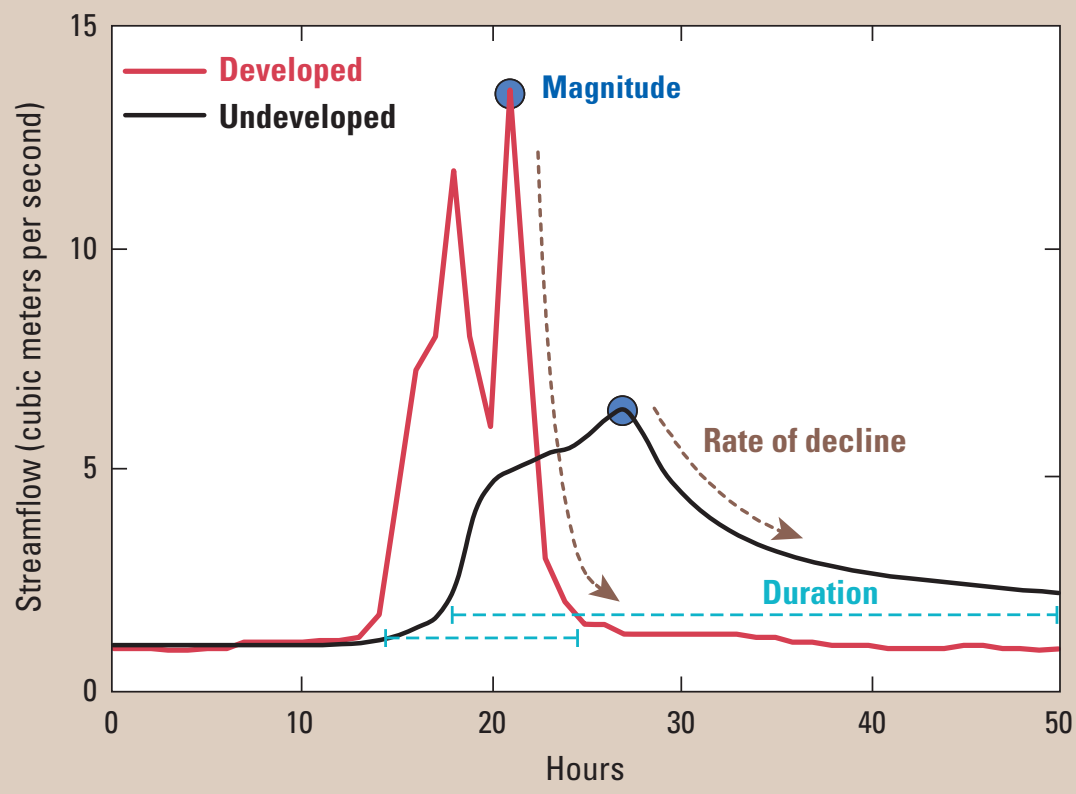




\section{Stream Habitat for Aquatic Biota Degrades}

Habitat changes that typically occur with urban development include changes in the size, shape, and alignment of stream channels; increases in fine-grained sediments on streambeds; the removal of woody debris; and alterations to riparian areas (Freeman and Bennett, 1969; Lemly, 1982; Waters, 1995; Walsh and others, 2005a; Roy and others, 2006). Rapid stormwater runoff from impervious cover causes an increase in the power of water flowing into the stream, resulting in channel incision or widening through a process of channel erosion (fig. 2-8). Erosion associated with road and building construction contributes large amounts of sediment to streams in some areas. Increased stream energy also can remove large woody debris from channels that would normally dissipate that energy, help sort bed sediment, stabilize the channels, and provide habitat for aquatic biota (Bunn and Arthington, 2002; Gregory and Bryant, 2003; Gurnell and others, 2007). Loss of riparian trees and shrubs by streambank erosion or urban development also removes sources of woody debris and allows more sunlight to reach the stream. Natural woody debris in unmodified stream channels provide habitat for aquatic organisms.

These changes in habitat reduce and degrade the living space for aquatic biota. Increased deposition of finegrained sediment in streams buries algae, invertebrates, and fish eggs; reduces habitat availability; and leads to declines in productivity and biodiversity (Waters, 1995). Sediment provides a bonding surface for chemicals, such as nutrients and metals, and for manmade compounds, such as pesticides. Sediment suspended in stream water can transport these chemicals and compounds within the stream ecosystem (Nowell and others, 1999; Bryant and Goodbred, 2008). Higher turbidity associated with increased suspended sediment decreases the amount of light penetrating to the stream bottom.

Algae and plants need light for photosynthesis, and invertebrates and fish need light for feeding and for triggering natural breeding cycles. Increases in sunlight reaching a stream after removal of riparian vegetation together with increased nutrients commonly present in urban streams, (described in the following section) can lead to increases in the rate of photosynthesis by algae and aquatic plants and a consequent increase in potential nuisance algal blooms. Increased rates of photosynthesis and higher water temperatures that can result from urban development also produce large fluctuations in dissolved oxygen concentrations in streams, which can be harmful to invertebrates and fish (Kaushal and others, 2010).

\section{Nutrients and Contaminants Increase}

Urban development and subsequent land-use practices lead to increases in the inputs of some otherwise beneficial chemicals to levels that greatly exceed those naturally present in streams, which can result in immediate and longterm effects on aquatic biota. Elevated levels of nutrients and other contaminants are released into urban streams from treated sewage, industrial wastewater discharges, and burning of fossil fuels, as well as from surface runoff that conveys fertilizers and organic matter from leaves, grass clippings, and animal waste (Klein, 1979; Graffy and others, 1996; Sprague and others, 2007). Algal abundance in streams is dependent on nutrient inputs, and excessive nutrient inputs can cause nuisance algal blooms.

The use of salt to prevent or melt ice on pavement in cooler climates also can add excess amounts of sodium and chloride to streams, killing salt-sensitive biota and contributing to higher year-round values of specific conductance in streams (Corsi and others, 2010).

Chemicals other than nutrients can find their way into urban streams through stormwater runoff, point-source discharges, spills, or even through atmospheric inputs such as precipitation. Inputs of contaminants toxic to aquatic biota, such as polycyclic aromatic hydrocarbons (PAHs), herbicides, and pesticides, typically increase with urban development (Nowell and others, 1999; Van Metre and others, 2000; Mahler and others, 2005; Munn and others, 2006; Leiker and others, 2009). Certain chemical contaminants, such as lead

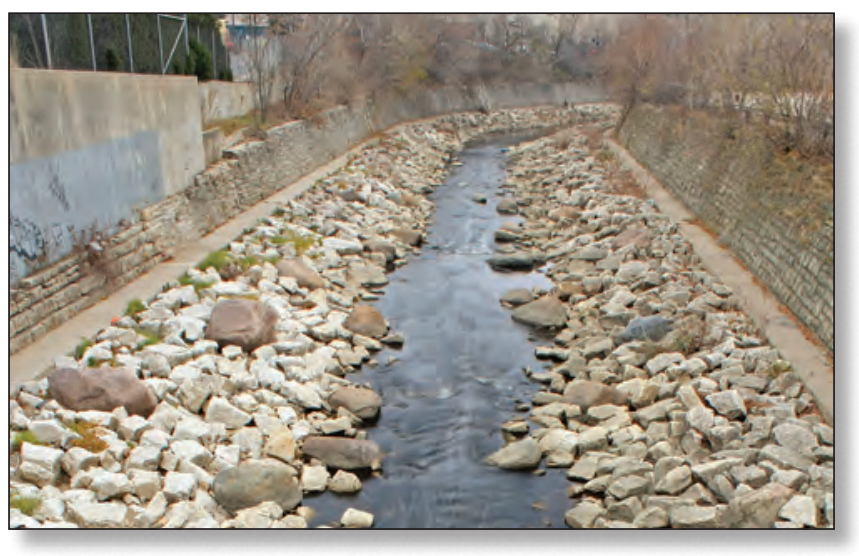

Figure 2-8. Changes to the hydrology and habitats of streams arising from human activities can adversely affect the living spaces for aquatic biota and, subsequently, the diversity of biological communities. 
and zinc (Callender and Rice, 2000), may be taken up by algae and plants and can accumulate and increase in concentration in invertebrates or fish that eat the algae or plants. Higher concentrations of these contaminants can occur in fish that prey on these invertebrates and fish. Consequently, these contaminants accumulate in other wildlife and humans that eat the contaminated fish.

Chemicals that do not kill aquatic biota outright might reduce their populations through long-term sublethal or chronic effects on hormones, reproduction, and lifespan. Studies in recent years have concluded that fish and other biota have developed both male and female sex organs as a result of exposure to waterborne chemicals, such as pharmaceuticals (Blazer and others, 2007; Vajda and others, 2008). These chemicals are not removed completely during conventional wastewater treatment and can accumulate in aquatic biota (Chambers and Leiker, 2006; Hinck and others, 2009).

\section{Framework for Understanding Urban Stream Ecosystems}

A simplified framework can be used to examine the connections that exist between urban development and streams (fig. 2-9). Urban development is shaped by the interactions of people, institutions and resources, and social values. The "built environment" results from individual and group decisions that are influenced by an area's institutions, its economic resources, and the social values of those who live and work in the area. These values play an important role in shaping the development of the built environment through zoning, water-quality regulations, and stormwater and other management practices. Consequently, the built environment is the component of urban development that has the most direct effect on the stream ecosystem as measured at the stream reach.

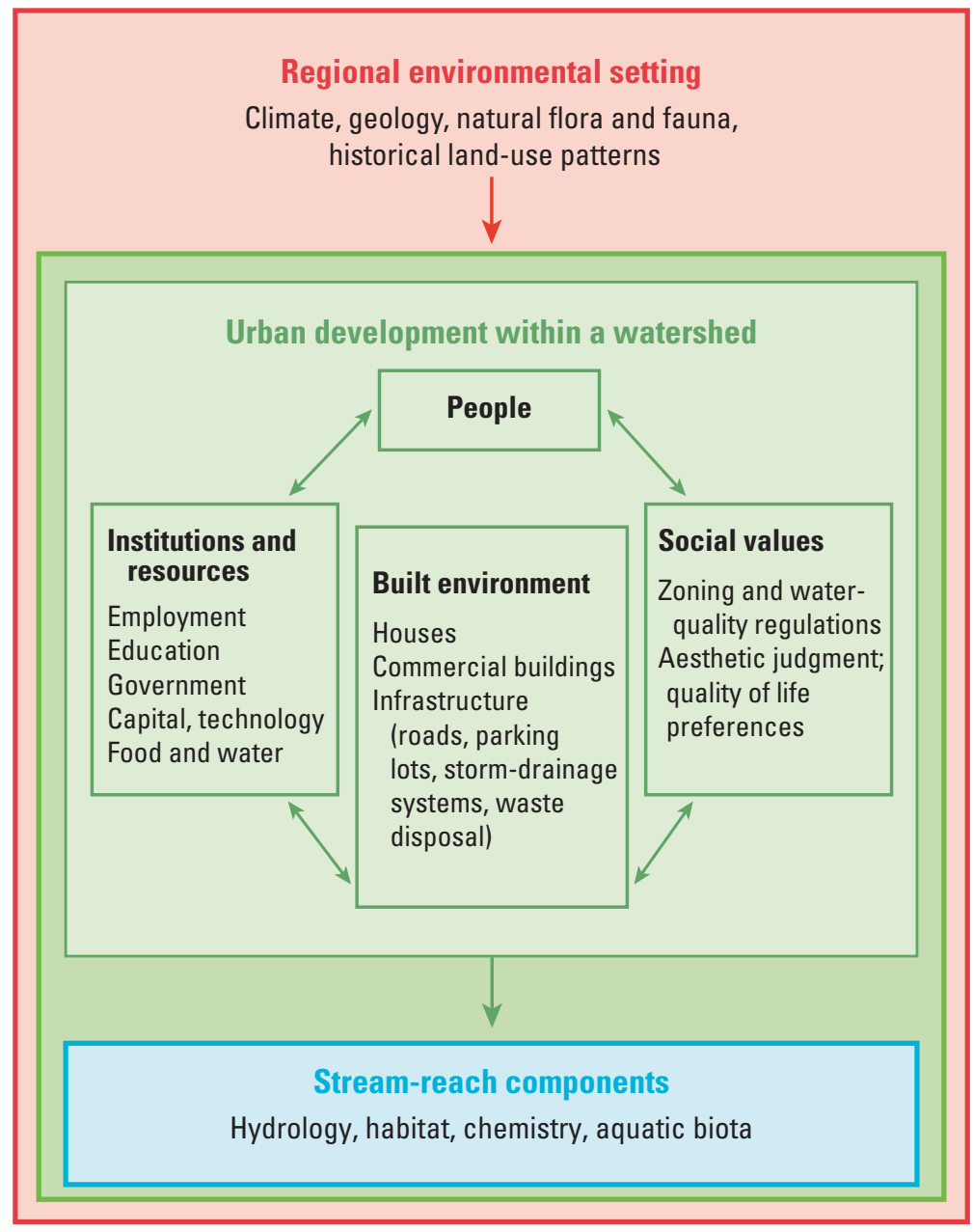

Figure 2-9. Urban development is shaped by the regional setting and interactions of people, institutions, resources, the built environment, and social values. A prudent management strategy should consider all of these elements and their interactions. Arrows indicate flows of energy, materials, and (or) information. (Modified from Machlis and others, 1997; Pickett and Grove, 2009.) 

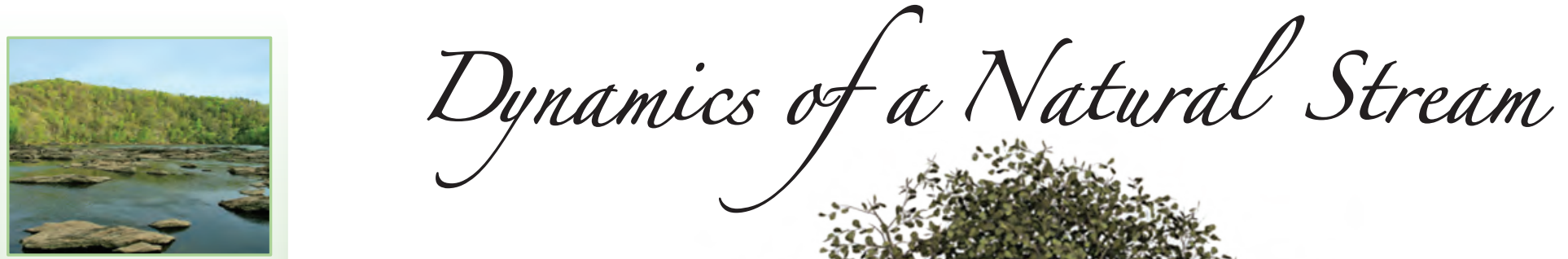

Hydrology: Water connects the human and natural components of a stream ecosystem. In a natural or undeveloped stream setting, rainfall reaches a stream gradually by flowing over the vegetated land surface into the stream and by infiltrating the soil and flowing underground (as groundwater) toward the stream. Natural seasonal patterns of streamflow, together with seasonal changes in light and temperature, serve as life-cycle cues to aquatic organisms (biota).

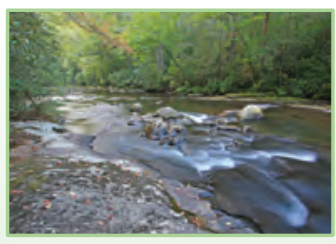

\section{Water Chemistry:}

Carbon and nutrients, such as nitrogen and phosphorus, are required for all stream life. Nutrients are incorporated into algae, which are then consumed by other biota, introducing the nutrients into the aquatic foodweb. Oxygen dissolved in water is essential for all aquatic biota and is necessary for maximum diversity of a stream ecosystem.

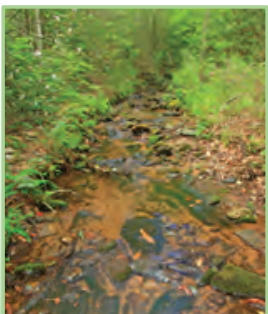

Drawing by Frank Ippolito, Production Post Studios, 110 North Fulton St. Bloomfield, N.J.

Habitat: Stream habitat is the physical living space of aquatic biota and includes the water in the stream and the physical structure (channel area, sediment, and vegetation). A stream with a more diverse habitat generally will have a more diverse biological community.
Mayfly
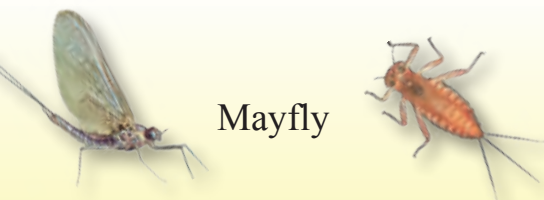


\section{Ecosystem}

In a natural, healthy stream, the condition of the physical

living space - defined by hydrology, habitat, and

chemistry-supports diverse biological communities.

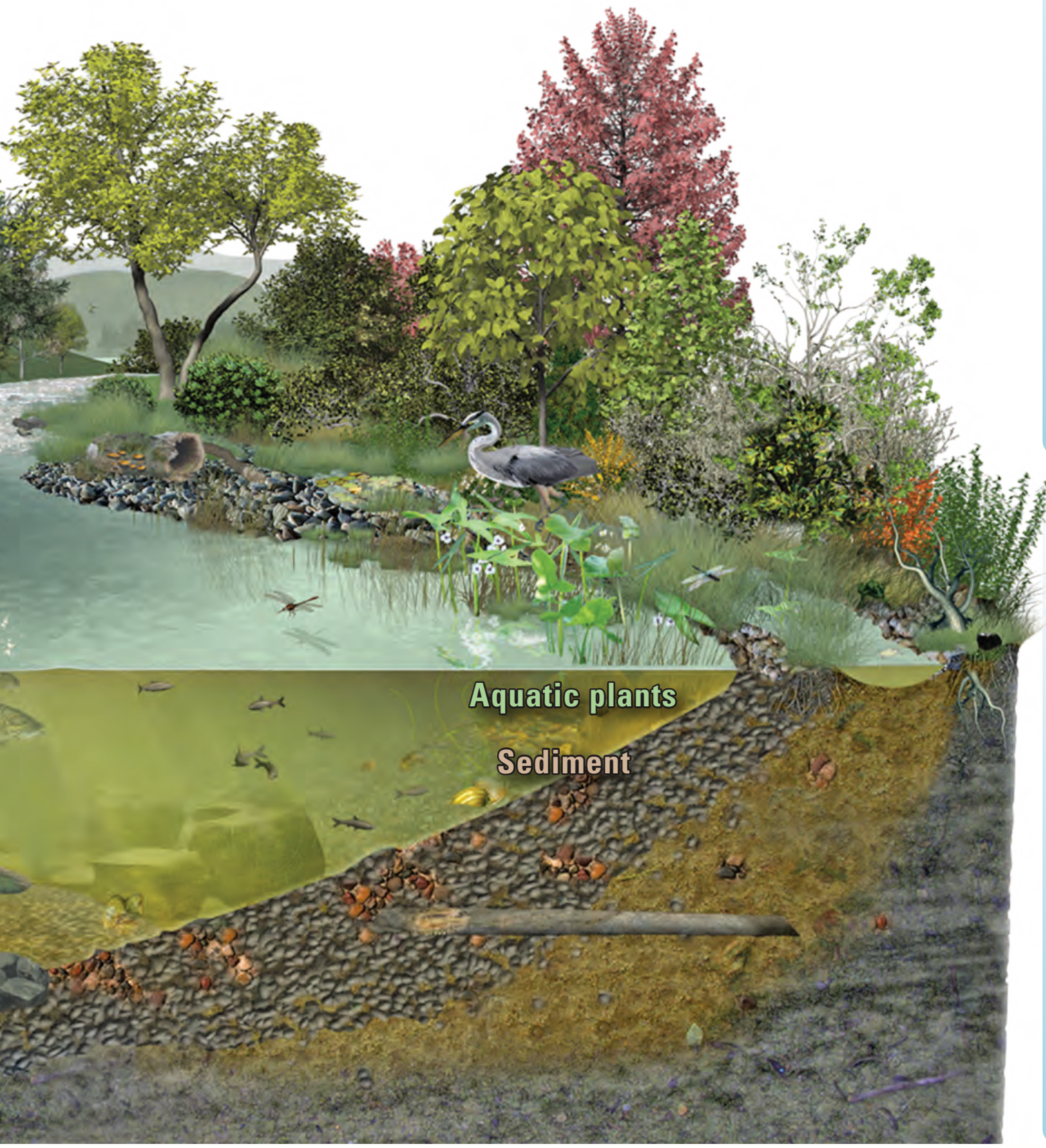

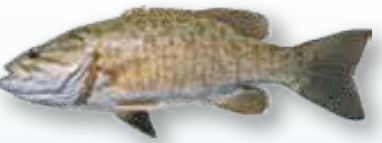

Smallmouth bass

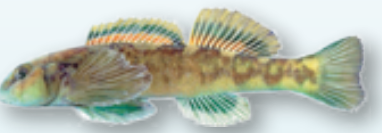

Greenside darter

Fish: The life cycles of fish can span years and are affected by streamflow, habitat, water chemistry, and other biota in the local area as well as conditions throughout the watershed. Fish can be relatively mobile along the stream as they search for food. Smallmouth bass may hide under logs or undercut banks, along stream edges or in pools, emerging to feed on crayfish and small fish. Greenside darters live in riffle habitats of streams, where they feed on aquatic insects, such as mayflies and other invertebrates.

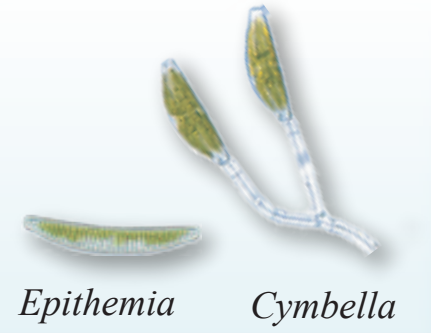

Algae: The life cycles of algae are short, lasting only days to weeks, and they respond relatively rapidly to changes in sunlight, water chemistry, and streamflow. Diatoms, the most common algae found in natural streams of small to moderate size, attach to underwater surfaces, such as rocks and aquatic plants. The diatom Cymbella is found in riffles, while the diatom Epithemia is found in both pools and riffles. Algae, such as these diatoms, are the foundation of aquatic foodwebs.

Invertebrates: The life cycles of invertebrates, such as the aquatic insects shown here, generally are complex and occur over time spans of weeks to years. Most aquatic insects spend nearly all their life in the water as eggs and larvae, and then leave the water and develop wings as adults. Many mayflies crawl on the surfaces of rocks and feed by gathering fine particles of organic matter or scraping off algae. Some species of stoneflies are predators on other insects, while others feed by shredding leaf material that has been colonized by

Dragonfly larvae bacteria and fungi. Dragonfly larvae live in areas of slower streamflow, where it preys on other invertebrates and even some small fish. 


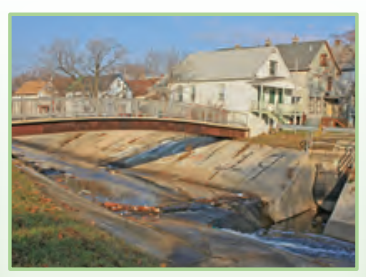

Hydrology: Urban

development alters the hydrology, or movement of water through a watershed. The addition of impervious surfaces (for example, roads, parking lots, and buildings) reduces the infiltration of precipitation into groundwater, and the construction of artificial drainage systems (for example, storm-drainage networks) moves stormwater runoff from developed sites very quickly. The rapid runoff and high streamflows increase the power or energy of the water flowing in the stream, which can deepen or widen stream channels and cause streambank erosion.

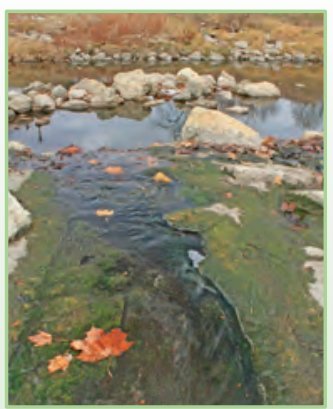

Water Chemistry: Urban development may increase the inputs of otherwise beneficial chemicals to levels that greatly exceed those found naturally in streams, leading to both immediate and long-term effects on aquatic biota. For example, excess amounts of nutrients, such as phosphorus and nitrogen, can lead to an abundance of algae, resulting in extreme highs and lows in dissolved oxygen concentrations.

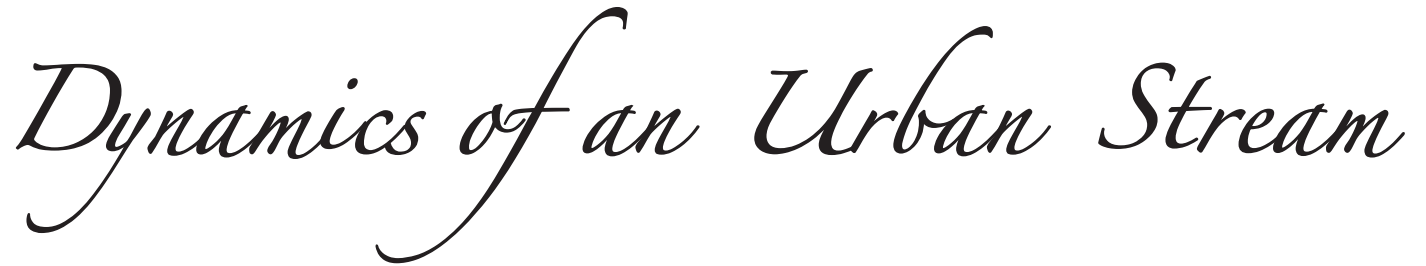

In a highly degraded urban stream, the poor condition of the physical living space-streambank and tree root damage from altered hydrology, low diversity of habitat, and inputs of chemical contaminants - contributes to biological communities with low diversity and high tolerance to disturbance.

\%





\section{Chapter 3 \\ USGS Approach to Assessing the Effects of Urban Development on Stream Ecosystems}

The USGS assessment during 1999-2004 is the first national-scale assessment of the effects of urban development on stream ecosystems that has been completed in the United States. The assessment used a nationally consistent study design in nine metropolitan study areas of the United States-Portland, Oregon; Salt Lake City, Utah; Birmingham, Alabama; Atlanta, Georgia; Raleigh, North Carolina;
Boston, Massachusetts; Denver, Colorado; Dallas, Texas; and Milwaukee, Wisconsin. The nine study area settings represent a contrast in regional factors that affect stream ecosystems. Examples of these regional factors include the type of land cover (forest or agricultural land) being converted to urban development and the climate, ranging from the arid west to the humid east.

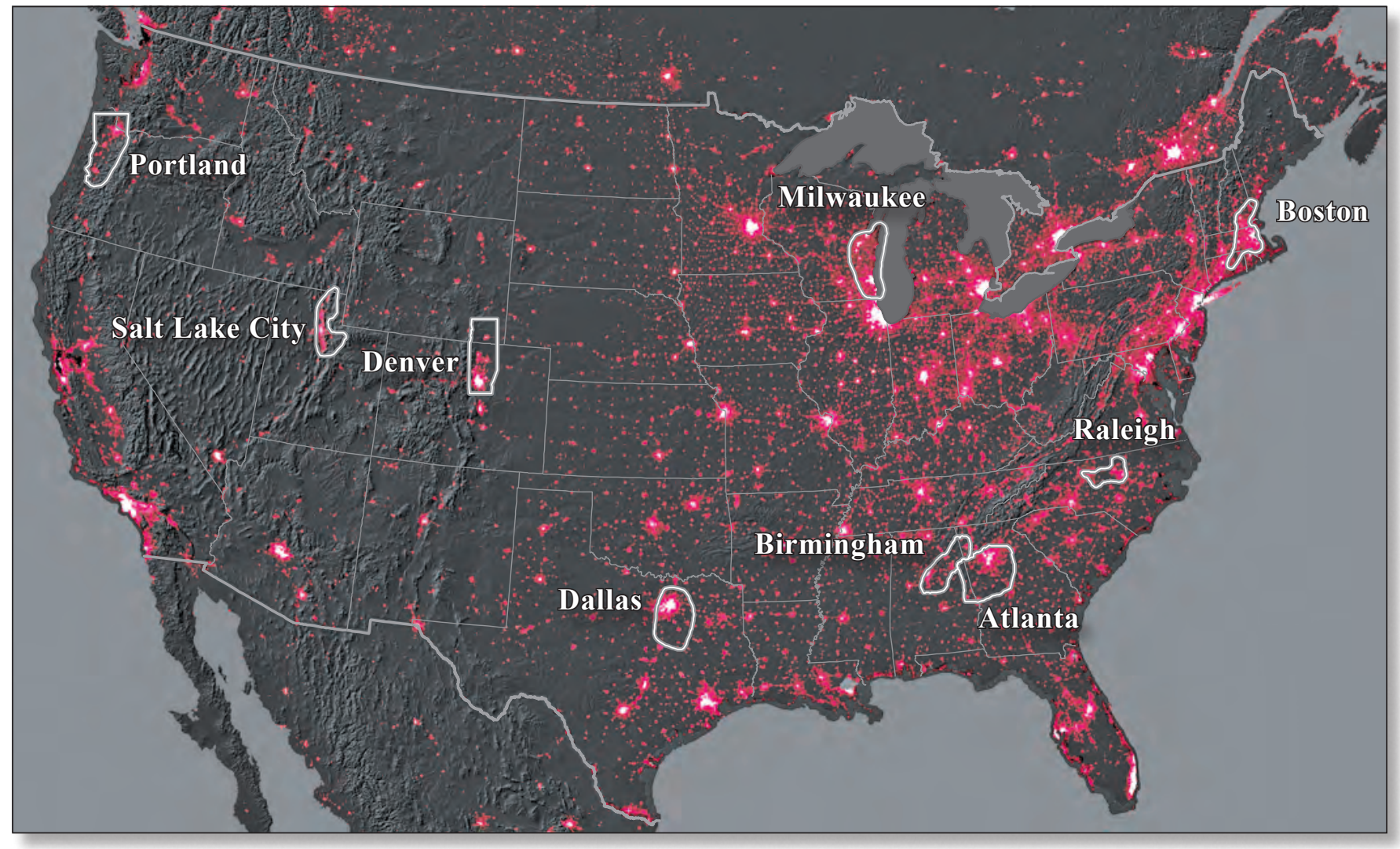

This image of the night lights in the United States was created with data from the Defense Meteorological Satellite Program. The interstate highway system appears as a lattice connecting city centers.
This chapter describes the approach used by the USGS for assessing the effects of urban development on stream ecosystems. Project objectives were accomplished by using three key attributes of the study design:

1. Minimize the variability of natural factors that affect stream ecosystems across the country;

2. Study watersheds that collectively represent a rural to urban gradient; and

3. Use common protocols for sample collection and processing in all study areas. 
The primary objectives of the investigation were to determine (1) the physical, chemical, and biological responses of streams to urban development; and (2) the manner in which these responses vary across the country. The assessment used a nationally consistent study design in nine metropolitan study areas of the United States-Portland, Oregon (Waite and others, 2008); Salt Lake City, Utah (Giddings and others, 2006); Birmingham, Alabama; Atlanta, Georgia (Gregory and Calhoun, 2007); Raleigh, North Carolina (Giddings and others, 2007); Boston, Massachusetts (Coles and others, 2004); Denver, Colorado (Sprague and others, 2006a,b); Dallas, Texas (Moring, 2009); and Milwaukee, Wisconsin (Richards and others, 2010; app. $1 \mathrm{~A}$ ).

The project objectives were addressed by investigating urban stream ecosystems defined by interacting human and natural systems (fig. 3-1). These interactions are affected by processes operating at three primary spatial scales: stream reach, watershed, and region (see sidebar, Stream Ecosystems Are Shaped by Processes Occurring at Multiple Spatial Scales). Natural and human processes operating at the regional scale influence processes operating at the watershed scale. Watershed processes, such as urban development, influence the physical, chemical, and biological characteristics of a stream reach. The approach used to assess these interrelated systems was to constrain variability in natural factors within each study area, examine watersheds representing a rural to urban gradient, and use common methods for reach-scale sample collection and processing.

\section{Accounting for the Natural Variability Among Watersheds in Different Regions}

Because the physical, chemical, and biological characteristics of a stream respond to changes in both urban conditions and natural characteristics, isolating and understanding the influences of urban development required constraining the variability of natural factors (such as soils, climate, elevation, and slope) among the watersheds selected for each of the nine study areas (see appendix 1B for more information on the regional factors). U.S. Environmental Protection Agency (USEPA) Level III Ecoregions delineate regions representing a relatively homogeneous combination of climatic, topographic, geologic, and general land-cover characteristics (Omernik, 1987; see What is an Ecoregion? in sidebar, Stream Ecosystems Are Shaped by Processes Occurring at Multiple Spatial Scales). Thus, the variability in natural factors was constrained, in part, by restricting the watersheds selected in each study area to a single Level III Ecoregion. Because Level III Ecoregions are large, smaller Level IV Regions were used to further constrain the selection of watersheds in several study areas.
Figure 3-1. An integrated approach to understanding the effects of urban development on stream ecosystems must account for the interrelations among human and natural systems at the regional, watershed, and streamreach scales rather than treating any pair of systems as isolated entities.

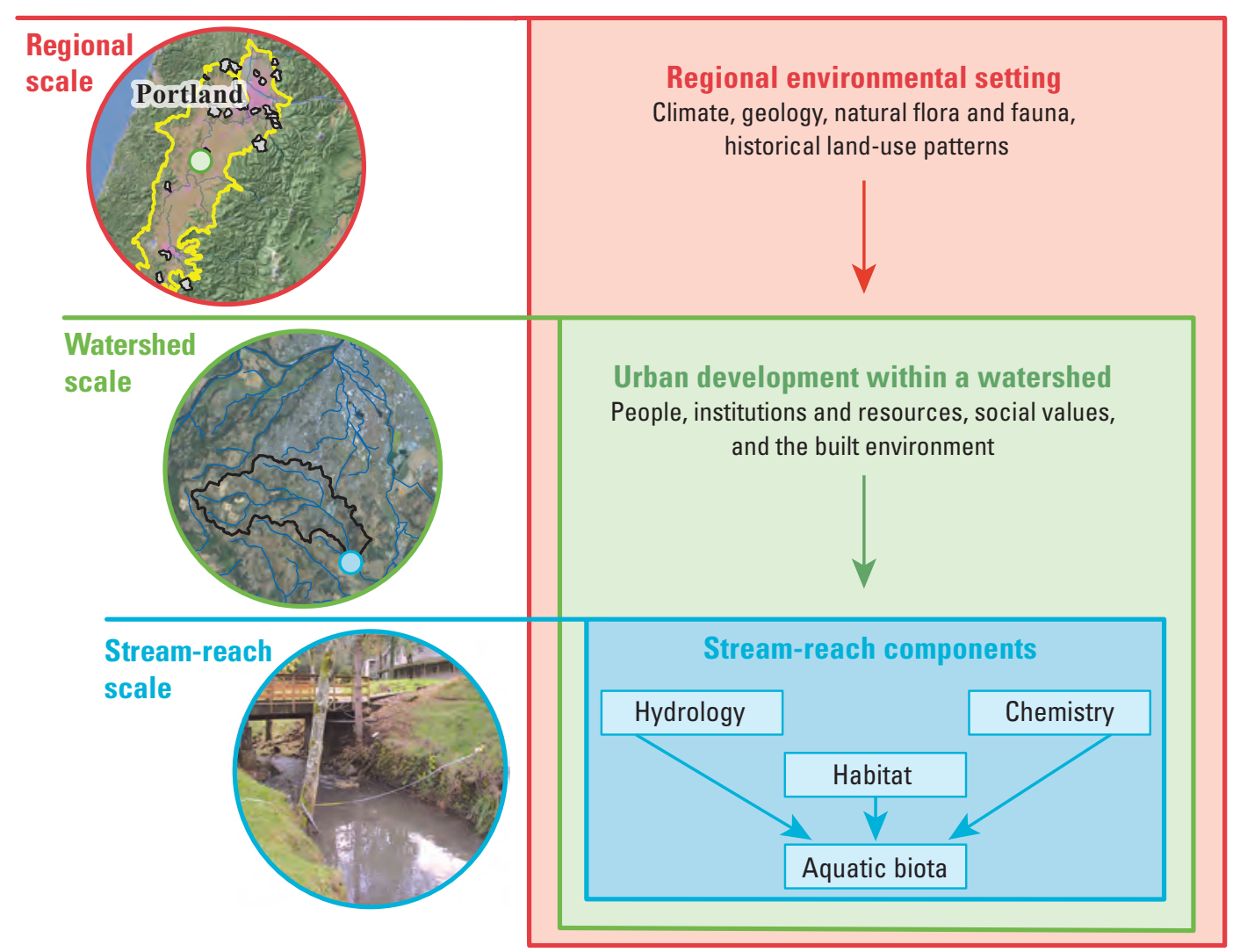




\section{Stream Ecosystems Are Shaped by Processes Occurring at Multiple Spatial Scales}

The physical, chemical, and biological characteristics of a stream are shaped by processes that occur within a stream reach, the watershed upstream of the reach, and the region where a watershed is located. A stream reach refers to a short stretch, or length, of a stream that is viewed when someone is fishing, taking a short walk, or collecting a water sample. The stream reach is the most likely point of contact with a stream ecosystem for most people because it is the place they see and interact with a stream. Therefore, characteristics of stream hydrology, habitat, chemistry, and aquatic biota are observed typically at the stream-reach scale.

A watershed is the area upstream that collects and conveys water to the stream reach. Conditions at a stream reach are defined, in large part, by processes that occur throughout a watershed, including urban development or agricultural production, and natural factors such as rainfall and soil permeability. Therefore, interactions among these processes help determine the characteristics of hydrology, habitat, chemistry, and aquatic biota in downstream reaches.

A region is typically a large area of land with many watersheds that have similar natural characteristics associated with the general climate, geology, soils, and vegetation. This natural similarity among watersheds sets up a framework for defining physical, chemical, and biological features that are distinct to a region; therefore, processes altered by urban development in a watershed will reflect changes to the biological communities in the stream reach that are characteristic to the region. For this investigation, USEPA Level III Ecoregions (Omernik, 1987) were used to designate the regions; in each study area, all watersheds were located in a single Level III Ecoregion (fig. 3-2).

\section{What is an Ecoregion?}

Ecoregions are defined as areas of relative homogeneity in the type, quality, and quantity of environmental resources, and within which there exists spatial similarity in characteristics of the quality, health, and integrity of ecosystems (Omernik, 2004). Because they delineate large areas within which similar ecosystems exist throughout a region, ecoregions provide a spatial framework for ecosystem assessment, resource inventory, monitoring, and ultimately management. Thus, ecoregions are extremely useful for structuring and implementing ecosystem-management strategies across agencies and organizations that are responsible for different types of resources within the same geographical areas. They have proven to be an effective aid for inventorying and assessing national and regional environmental resources, for setting regional resourcemanagement goals, and for developing biological criteria and water-quality standards.
Figure 3-2. Level III Ecoregions provide a framework for delineating regions by ecosystems that have similar environmental characteristics. The watersheds in the nine study areas were constrained to a single Level III Ecoregion to account for natural variability across the country.

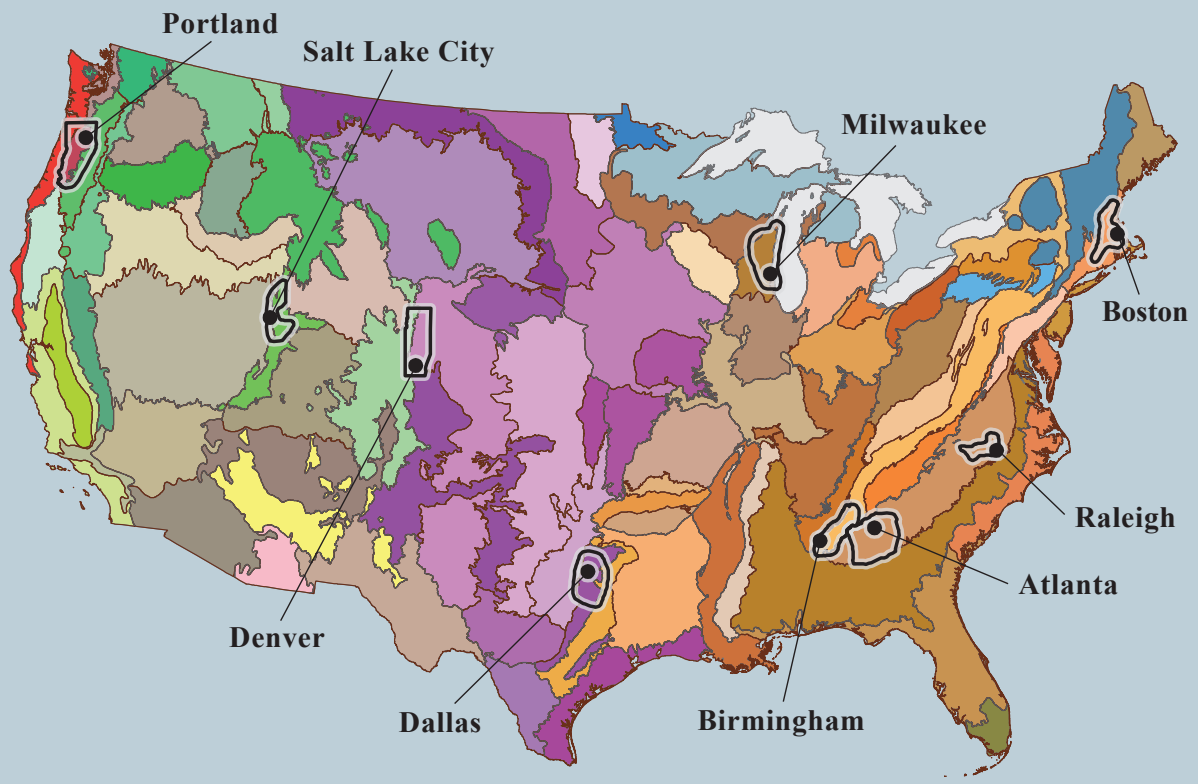




\section{Substituting Space for Time: A Rural- to-Urban Gradient}

The process of urban development can occur over many years. Rather than study how the physical, chemical, and biological characteristics of an individual stream changes as the watershed becomes urbanized over time, this investigation employed a gradient approach that substituted space for time. In other words, it would have been impractical to measure changes to a stream ecosystem as a natural watershed becomes urbanized over perhaps decades. Instead, a set of approximately 30 watersheds in each of the nine study areas was selected to represent the range of urban-development conditions in the Level III Ecoregion within which the study area was located (see sidebar, How Well do the USGS Study Watersheds Represent the Gradient of Urban Development in Each Level III Ecoregion?). However, it should be noted that with this gradient approach, it is not possible to control for differences in urban-development characteristics that might arise because development occurred in different time periods.

In each of the nine study areas, the streams within the approximately 30 watersheds were sampled during the same period. The dominant land cover in watersheds at the rural or less developed end of the gradient was typically either forested or agricultural and was assumed to represent the type of land cover within each study area being converted to urban uses. The physical, chemical, and biological characteristics of streams in each of these watersheds were then assumed to represent the stream condition for a given level of urban development in the watershed. Thus, differences in stream conditions in increasingly developed watersheds within a study area were assessed to indicate how streams respond to urban development. The Salt Lake City, Birmingham, and Boston studies were completed in 1999-2000; studies in Atlanta, Raleigh, and Denver were completed in 2002-2003; and studies in Portland, Dallas, and Milwaukee were completed in 2003-2004. Maps and other information about the watersheds in each study area are in appendix 1A. Sprague and others (2007) provide details on the watershed selection process as well as steps taken to constrain natural variability and to define a rural-to-urban gradient.

\section{A Common Approach for Measuring Ecosystem Characteristics}

Urban-development patterns within each study watershed and the physical, chemical, and biological characteristics of the stream within the watershed were measured or estimated using a standard set of methods. Giddings and others (2009) contains all data and additional information about the study design.

\section{Urban-Development Patterns}

The pattern of urban development in any watershed reflects the culmination of choices made by individuals, businesses, lending institutions, and governments about where, when, and how development occurs, such as housing, stores, businesses, and roads. In this investigation, several measures of land cover and land use were used to characterize urban development in the watersheds (Falcone and others, 2007).

Land cover refers to physical materials, such as vegetation and human-constructed roads and buildings that cover the land surface. Urban development in these nine study areas occurred primarily through the conversion of either agricultural or forested land. The type of land cover that is being converted to urban uses (predevelopment land cover) is potentially important, as the terrestrial characteristics and activities associated with these two landcover types can influence the relation that urban development has on the stream ecosystem. Watersheds in which the predominant land cover prior to urban development is agricultural land might already have some degree of waterquality impairment. Natural and human environmental legacies, such as differing natural biological communities and historical land cover, can alter the starting point for assessing the effects of urban development on streams. The effects of urban development can be present but are difficult to tease out because of these legacies. Two related measures of urban land cover were used in this investigation: (1) the percentage of urban development in a watershed and (2) the percentage of impervious land cover in a watershed (fig. 3-3).
Figure 3-3. The relation between the percentage of developed land and impervious cover in watersheds was very strong across the United States, as seen in this plot for all watersheds used in the investigation.

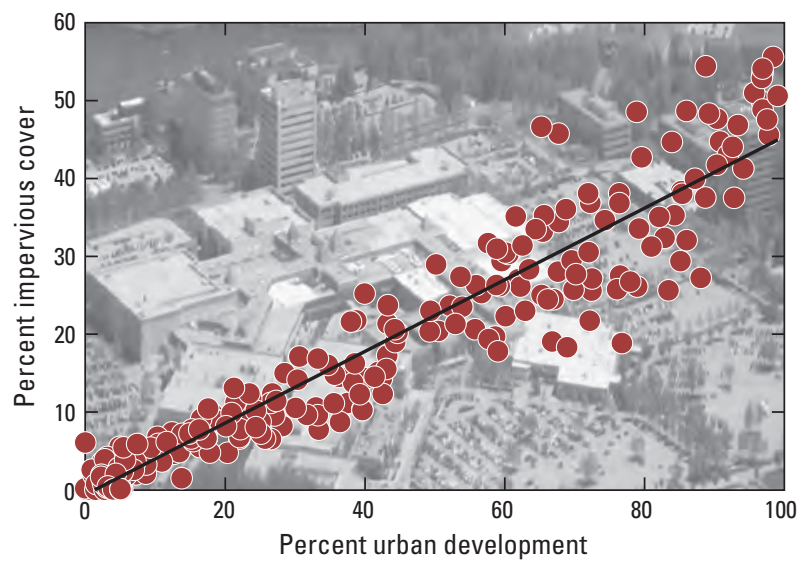




\section{How Well do the USGS Study Watersheds Represent the Gradient of Urban Development in Each Level III Ecoregion?}

The amount and spatial distribution of land that is classified as urban varies across the Level III Ecoregions in which the USGS studies occurred (Terziotti and others, 2012). When examining all possible watersheds of a given size in an ecoregion, some ecoregions, such as the Central Basin and Range (Salt Lake City study), have a relatively small proportion of watersheds with a medium to high percentage of developed land. Other ecoregions, such as the Northeast Coastal Zone (Boston study), have a larger proportion of watersheds with a medium to high percentage of developed land.

For each ecoregion plot in figure 3-4, the blue line indicates the cumulative percentage of all watersheds of a given size that have undergone urban development at the level indicated on the x-axis. In several of the ecoregions, the curvature of the line changes from a relatively steep upward angle to a more gradual curve, indicating a diminishing number of watersheds that have large areas of developed land. For example, in the Northeastern Coastal Zone, approximately 60 percent of the watersheds in the ecoregion (y-axis) have less than 20 percent of developed land (x-axis). A distinctly different blue line shape occurs in the Central Basin and Range as a result of more than 95 percent of the watersheds having less than 20 percent developed land.
Each red diamond along each blue line in figure 3-4 indicates the actual amount of developed land in a watershed that was investigated in a particular USGS study area. Consequently, the extent to which the watersheds represent the urban gradient in an ecoregion can be seen by how evenly the symbols are spaced relative to the percentage of developed land (x-axis), irrespective of the shape of the blue line. Generally, across all metropolitan areas studied, the group of study watersheds represents the range of developed-land conditions that occur across the ecoregion as a whole, especially at the low and the high end of the gradient. An obvious exception is a major gap that occurs in the Dallas study area for watersheds that contain between approximately 40 and 75 percent developed land. Watersheds within this range of urban development that were suitable for the study were not available. Relatively few watersheds with 40 to 75 percent developed land exist in that ecoregion (that is, the blue line is relatively flat in that range of developed land cover). Finally, in all USGS study areas, the percentage of watersheds at the upper end of the developed land-cover gradient was larger than the percentage of watersheds with this amount of developed land in the ecoregion as a whole. While these highly developed watersheds were relatively rare in all ecoregions, the USGS study teams were able to identify enough highly developed watersheds to represent the gradient of developed land for the study.
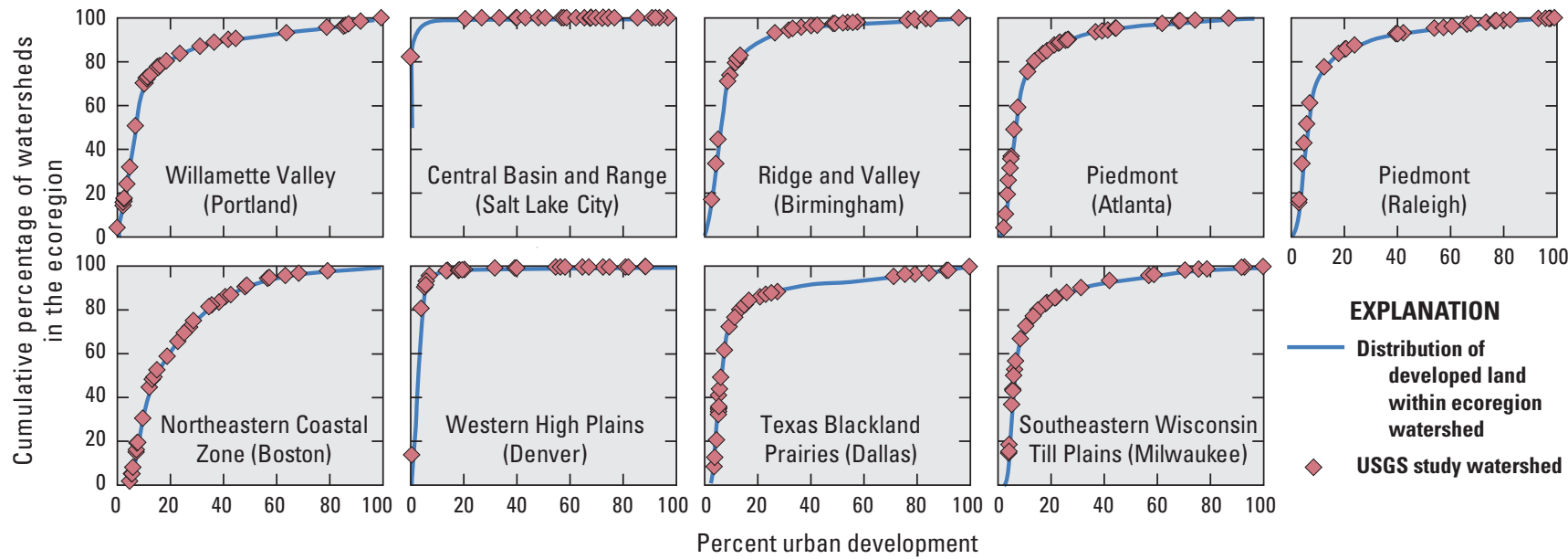

EXPLANATION

Distribution of developed land within ecoregion watershed

$\diamond \quad$ USGS study watershed

Figure 3-4. There is an even distribution of sites in six of the USGS studies relative to the range of urban development in Level III Ecoregions. In contrast, more than 80 percent of the watersheds in the Central Basin and Range (Salt Lake City) and Western High Plains (Denver) have less than 5 percent urban development. The symbols (red diamond) represent the study watersheds, and their distribution along the curve indicates how well they represent the various stages of urban development along the gradient. 
The study design assumes that, within each study area, the predevelopment land cover is equivalent to the dominant land cover occurring in watersheds at the low end of the urban gradient, typically either forested land (including shrubland) or agricultural land (including rangeland). Forest is the dominant land cover at the low end of the gradient in Portland, Salt Lake City, Birmingham, Atlanta, Raleigh, and Boston, whereas in the three other study areas (Denver, Dallas, and Milwaukee), the predevelopment land cover reflects some form of agricultural activity (see sidebar, Land-Cover Data for USGS Urban-Development Study).

\section{Hydrology}

Hydrology can be described in terms of streamflow characteristics, many of which influence stream ecosystems. These characteristics include seasonal flow patterns, the frequency, predictability, and duration of extreme flows, and the rate of change of daily, seasonal, and annual flows (fig. 3-6; Poff and others, 1997; Poff and others, 2010). Hydrologic data are not usually collected in stream ecology studies because the cost can be prohibitive. This investigation deployed relatively inexpensive data recorders that measured

\section{Land-Cover Data for USGS Urban-Development Study}

Land-cover data compiled for the USGS investigation, including impervious-cover data, represent conditions in 2001. These data are from the 2001 National Land Cover Database 2001 (NLCD; Homer and others, 2004; Falcone and others, 2007; Homer and others, 2007). Land cover in each study watershed was classified as belonging to one of several categories, including urban land, forested land, shrubland, agricultural land, and wetlands (fig. 3-5). Landcover data and GIS-derived watershed boundaries were used to estimate the proportion of watershed area associated with these land-cover types, as well as the amount of land cover in riparian areas adjoining streams.

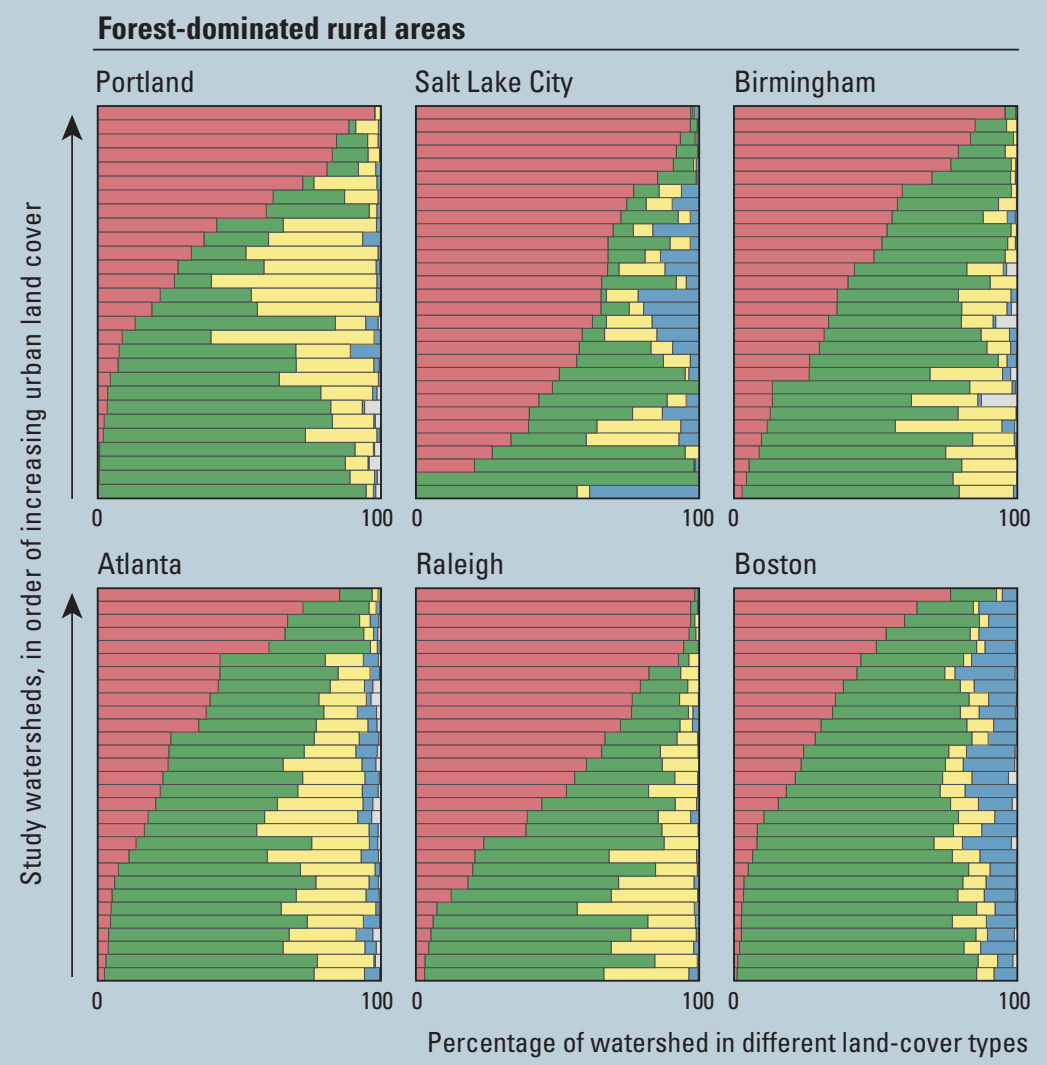

\section{Agriculture-dominated rural areas}
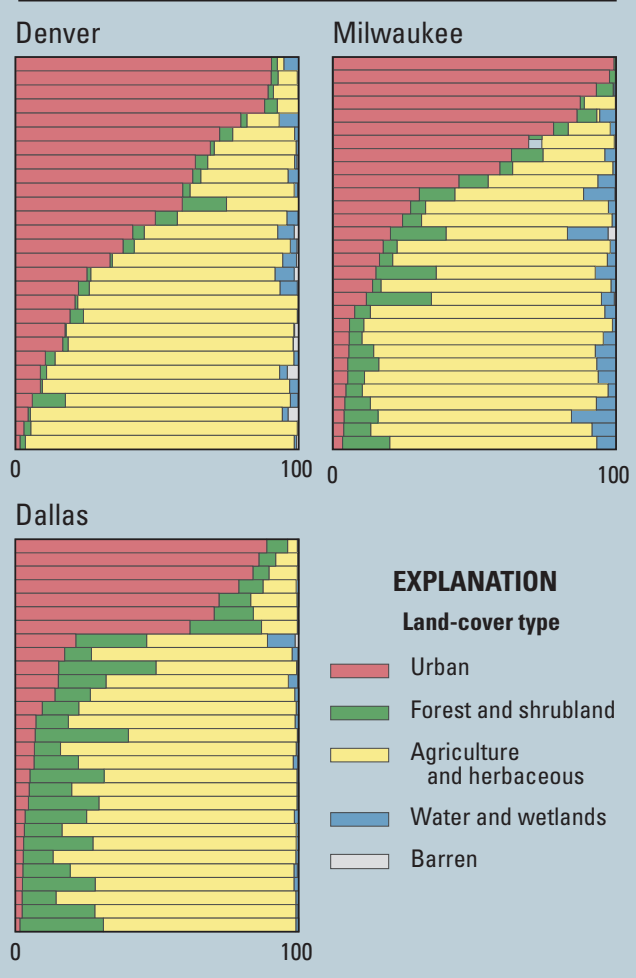

Figure 3-5. The predevelopment land cover is primarily forests in the Portland, Salt Lake City, Birmingham, Atlanta, Raleigh, and Boston study areas; the predevelopment land cover is primarily agricultural in the Denver, Dallas, and Milwaukee study areas. 
stream-water levels, or stage, every hour for 1 year that included the period when other physical, chemical and biological data were collected (fig. 3-7; Giddings and others, 2009). These data were used to summarize several characteristics of stream flashiness, including the magnitude, duration, and frequency of periods of high flow, and the rate of change in extreme high-flow conditions.

\section{Habitat}

Reach-scale habitat characteristics, such as channel shape and size, substrate size and distribution, water velocity, shade cover, aquatic and riparian vegetation, and bank and riparian stability, were measured once during late-summer low-flow periods in all investigation watersheds using standard USGS methods for wadeable streams (Fitzpatrick and others, 1998). Channel size and shape were measured relative to the level in the stream channel where rising streamflow begins to enter the flood plain (bankfull streamflow). Bankfull streamflows exert the greatest influence on the size and shape of the stream channel over a long period of time, and indicators of bankfull flow along the channel are used to estimate the magnitude of these flows (Wolman and Miller, 1960; Leopold and others, 1964). These physical characteristics are important because they define the places and conditions where biota live.

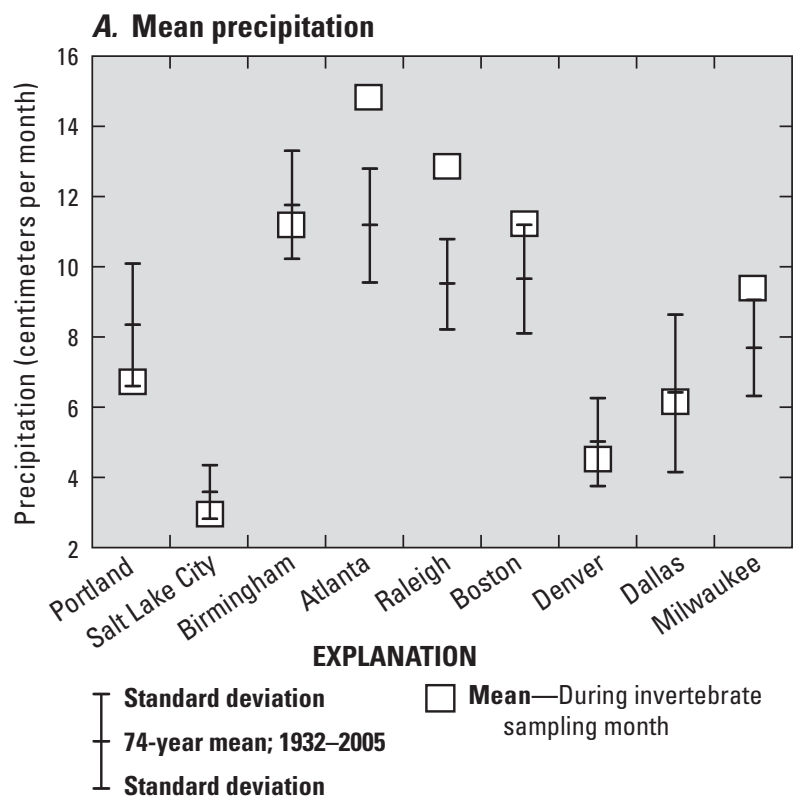

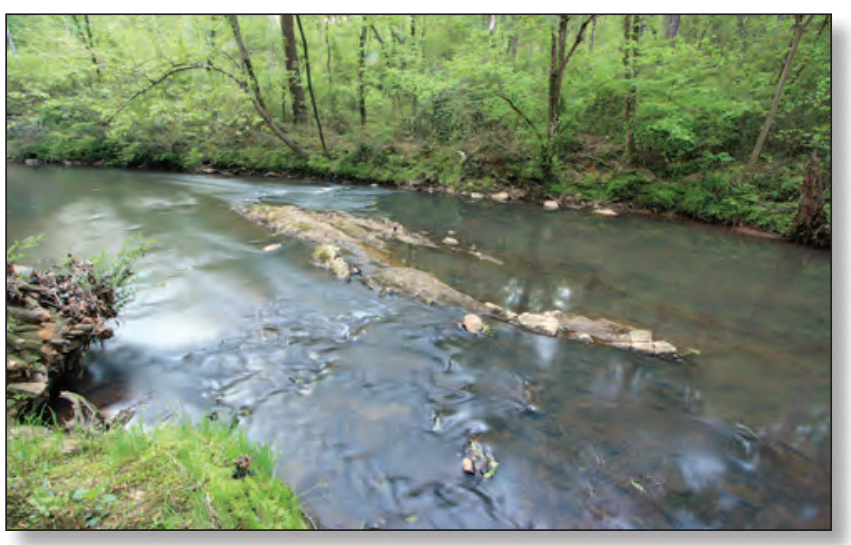

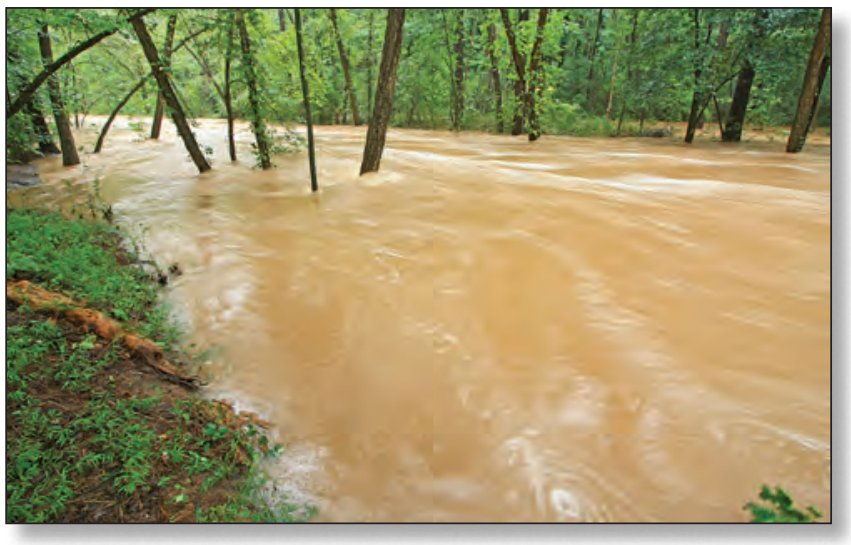

Figure 3-6. South Fork Peachtree Creek, Ga., during normal base flow (top) and during a high-flow event (bottom). Streamflow data provide information about high-flow frequency, duration, and magnitude characteristics in all nine study areas.

\section{B. Hydrologic data-collection periods}

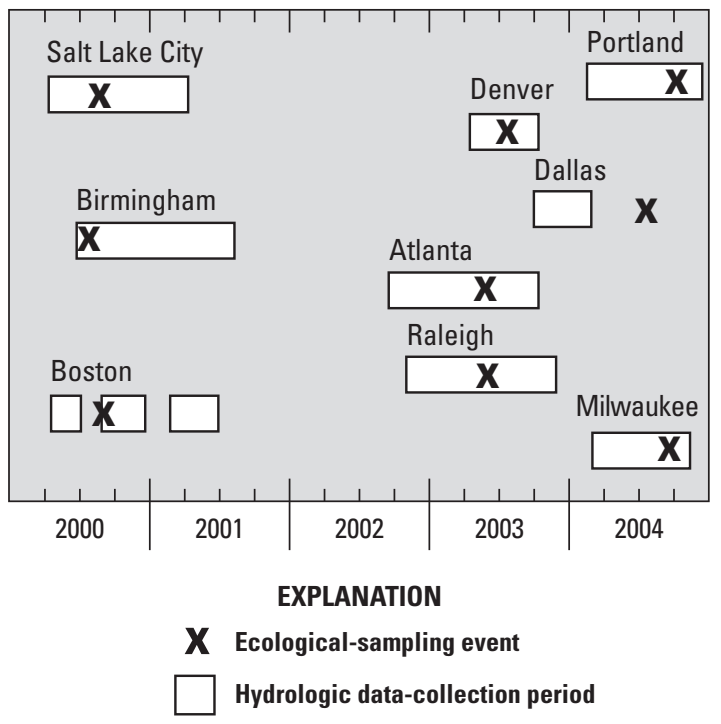

Figure 3-7. (A) The mean precipitation (square symbol) during the actual month invertebrate samples were collected in each study area in relation to the mean and typical range of precipitation (vertical line) for that month based on 74 years of data; and (B) hydrologic data-collection periods and dates of ecological-sampling events $(\mathbf{X})$ in each study area. 


\section{Chemistry}

Understanding the variations of stream chemistry can provide insights into the types of biological communities found in streams as watersheds are urbanized. Each type of aquatic organism has an optimal range of physical and chemical requirements; conditions outside these ranges can stress organisms and reduce their numbers. Stream chemistry in urban areas can vary considerably over time due to rapid changes in hydrologic conditions and the use of chemicals in the watershed. Water samples were collected during base-flow conditions at sampling locations in each study area, which was assumed would increase the likelihood of detecting stream-chemistry changes associated with urban development (fig. 3-8). The base-flow period was defined regionally as a period when, on average, few or no precipitation events occurred. Sampling during a base-flow period does not capture peak concentrations of many constituents; however, due to resource constraints, storm-event samples were not collected as part of this investigation.

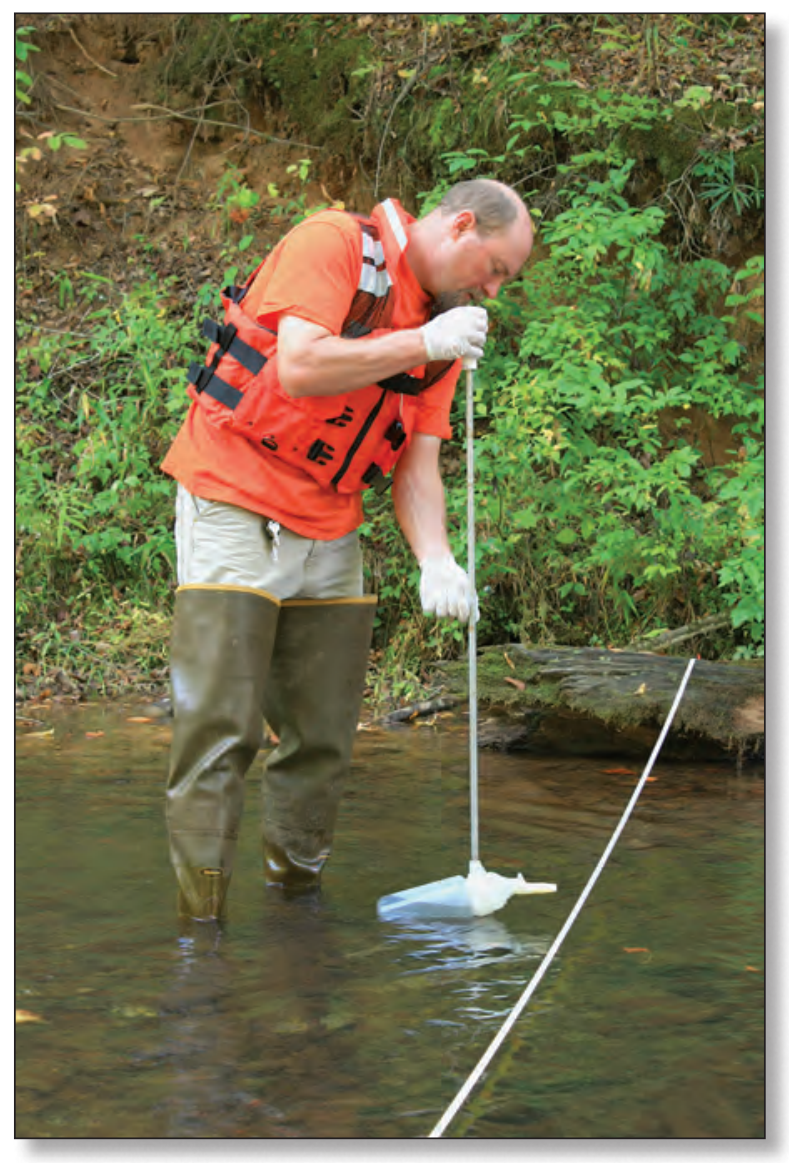

Figure 3-8. Water-quality samples were collected during base-flow conditions at sampling locations in each study area. These samples were analyzed for nutrients, dissolved pesticides and pesticide degradates, suspended sediment, sulfate, and chloride.
Water samples were analyzed for nutrients, dissolved pesticides and pesticide degradates (compounds resulting from the breakdown of the pesticide in the environment), suspended sediment, sulfate, and chloride. Field measurements made at the time of sample collection included water temperature, dissolved oxygen, $\mathrm{pH}$, specific conductance, and discharge. Additionally, water samples were collected bimonthly at 10 stream sites in the Portland, Atlanta, Raleigh, Denver, Dallas, and Milwaukee study areas during the year in which biological sampling occurred. Sprague and others (2007) contains details of all stream-chemistry sampling methods.

A pesticide toxicity index (PTI), which represents the potential acute toxicity of pesticide mixtures in a water sample, was calculated by combining the relative toxicity values of individual pesticide concentrations in each sample. The relative toxicity values for each individual pesticide were determined from laboratory bioassays that assessed the toxicity of those pesticides to various aquatic invertebrate and fish species (Munn and Gilliom, 2001). Separate PTI values were computed for cladocerans (an aquatic invertebrate) and fish. The PTI has several important characteristics; it assumes that toxicity is additive without regard to mode of action, considers acute toxicity only, and does not necessarily consider local species. Additionally, the PTI does not indicate whether water in a sample is toxic, but rather is used to compare the relative potential toxicity in different streams.

Not all chemicals that might be present in a stream can be effectively determined from water samples collected periodically because (1) sampling periods might not match times when chemicals are being transported in the stream, such as during storms, and (2) compounds that are commonly present in low concentrations, including hydrophobic compounds like polycyclic aromatic hydrocarbons (PAHs), polychlorinated biphenyls (PCBs), and dichlorodiphenyltrichloroethane (DDT), are difficult to measure. Semipermeable membrane devices (SPMDs) were used to collect samples for analysis of hydrophobic contaminants (Huckins and others, 1996). SPMDs are passive samplers that concentrate trace levels of hydrophobic contaminants in proportion to their concentration in the water column; they are designed to mimic the accumulation of manmade organic chemicals in stream organisms such as fish. The SPMDs were deployed for approximately 6 weeks during the period just prior to sampling invertebrates, algae, and fish in each stream. The SPMDs were first piloted in 2000 at a few sites in Birmingham and then were deployed in the six study areas that started after 2002. The SPMDs were not used in the Salt Lake City or Boston studies. In addition to making standard chemical analysis for hydrophobic contaminants, the potential toxicity of compounds collected by the SPMDs was evaluated using a standard bioassay (Bryant and others, 2007). Bed sediment was not sampled for analysis of contaminants in this investigation, although a follow-up study did analyze contaminants in six of these study areas (Moran and others, 2012). 


\section{Aquatic Biota}

Nationally consistent methods were used to collect samples from streams in each study area from three different communities of aquatic biota: algae, invertebrates, and fish. Samples for each community were collected once from each stream reach. Fish were collected throughout the entire stream reach (fig. 3-9), identified in the field, counted, weighed, measured, and released, except for those needing further identification. Invertebrate and algal samples were collected from five locations within each reach and combined into one composite sample for each community.

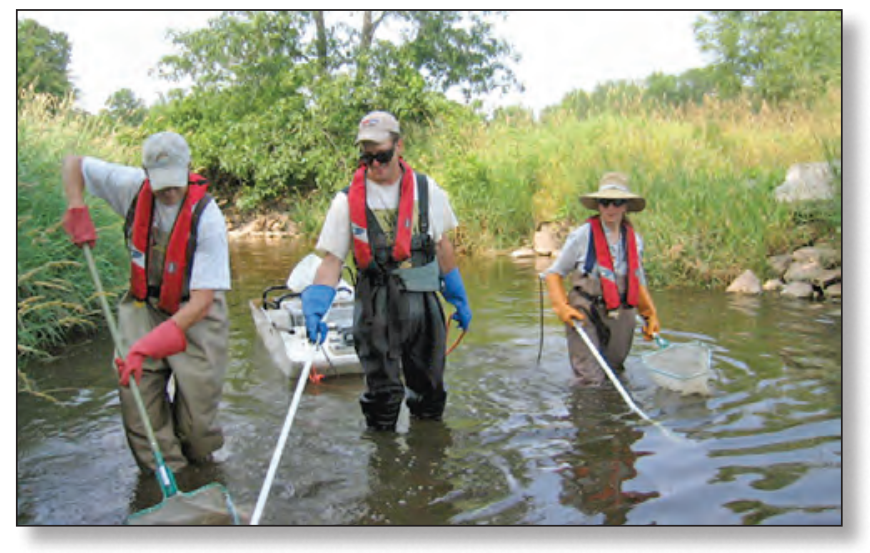

Figure 3-9. Fish community surveys were conducted at each of the streams to assess the effects of urban development. (Photograph by Amanda Bell, USGS.)
The biological community response to urban development was determined by using two types of response measures: community composition scores and biological condition metrics. A set of community composition scores was calculated for each biological community to represent the relative difference among streams in the types of species and density of organisms within the sampling reach. These were calculated using a technique called multivariate ordination, which measures the differences and similarities in the species composition of a community across all sites in a study area. The difference between any two community composition scores indicates the extent to which the biological community is different between the two sites; this difference then can be related to how the two sites differ in the degree of urban development. Therefore, community composition scores are very effective indicators of how strongly a biological community changes with urban development.

Biological condition metrics generally focus on particular species within a community. These metrics are often regarded as biological indicators because they are based on certain species in a community that respond to specific environmental stressors. For example, if a decline occurred in certain species that were sensitive to a particular type of contaminant, the indication might be that a specific urban-related stressor was degrading the biological community. These stressors then could be the focus of management actions to address the adverse effects of urban development. 



\section{Ohapter 4 Responses of Stream Hydrology, Habitat, and Chemistry to Urban Development}

Urban development in a watershed may bring about the following changes to a stream: (1) alter the hydrology, or movement of water through a watershed, (2) increase the inputs of otherwise beneficial chemicals to levels that greatly exceed those found naturally in streams, leading to both immediate and long-term effects on aquatic biota, and (3) alter habitats in and near streams that provide living spaces for biota.

1984

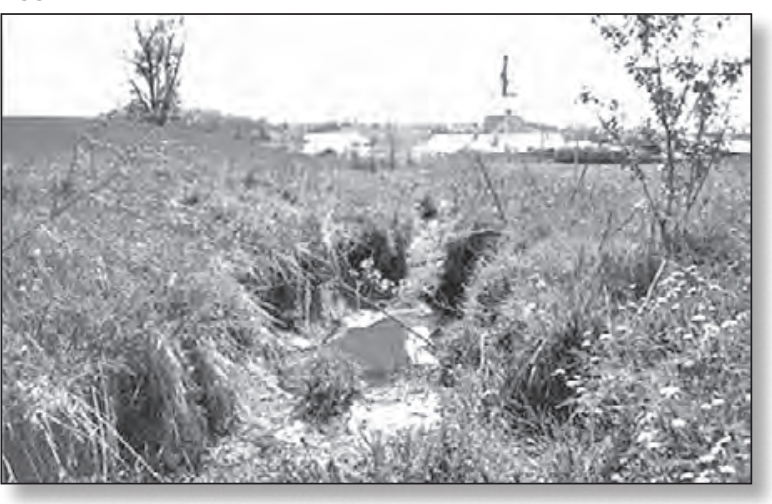

\section{1}

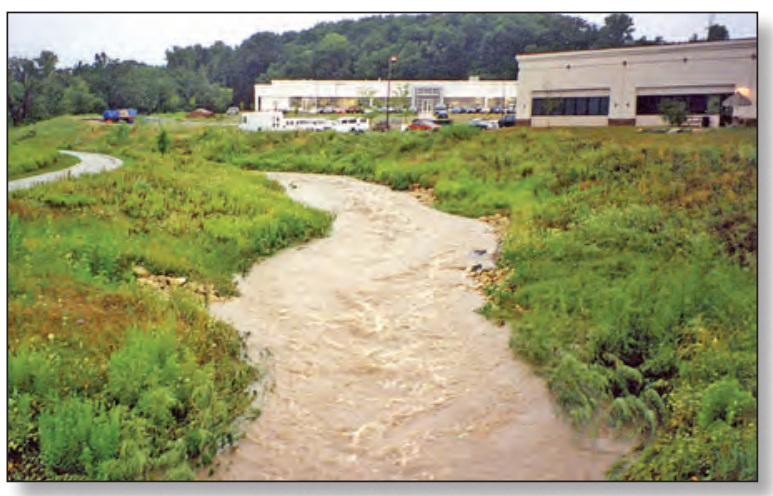

This time sequence of stream photographs illustrates some common hydrologic and habitat changes that can result from increased urban development. Prior to urban development, there might be a small drainage ditch like the one shown in the 1984 photograph. A new, larger channel was constructed as urban development continued into the 1990s to handle anticipated increases in runoff from additional impervious cover. Frequent high flows caused extensive streambed and bank erosion, even in the larger channel. By 2010, the channel had widened and downcut enough to start the formation of a new flood plain within the confines of the old channel. (Photographs by Herbert Garn, Barbara Scudder Eikenberry, and Alan M. Cressler, USGS.)
1997

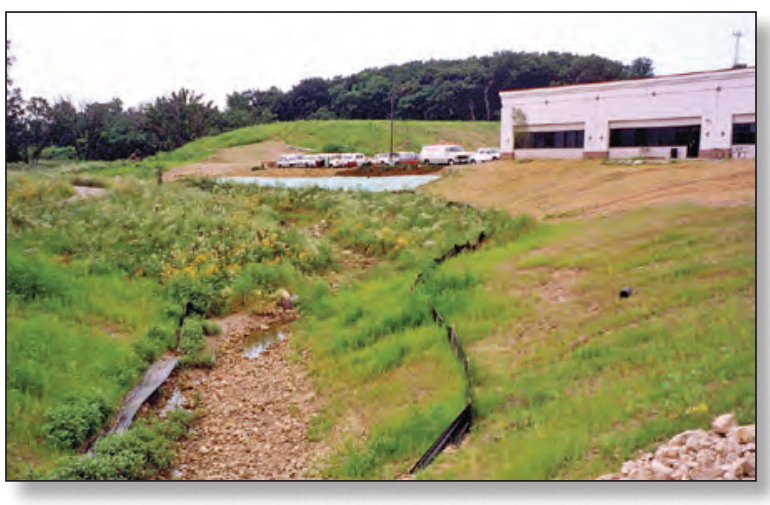

2010

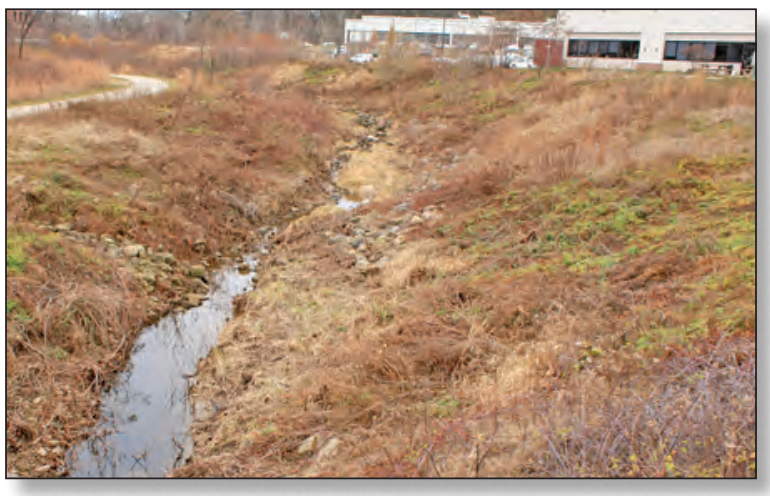

This chapter provides a summary of the effects of urban development on the hydrology, habitat, and chemistry of stream ecosystems. Urban development results in increased

1. Streamflow flashiness,

2. Nutrients and chloride concentrations, and

3. Contaminants that are toxic to aquatic biota.

Regional differences in types of land cover (forested or agricultural) undergoing urban development have influenced stream nutrient and pesticide concentrations. 


\section{Responses of Hydrology and Habitat to Urban Development}

Hydrologic responses to urban development were more consistent among the USGS study areas than were habitat responses (table 4-1). The four hydrologic and three habitat characteristics selected for inclusion in table 4-1 are drawn from a much larger group of physical factors measured during the USGS urban-development investigation and represent the major physical changes associated with urban development that may have detrimental effects on biological communities (Paul and Meyer, 2001; Walsh and others, 2005b).

\section{Streamflow Flashiness Increased With Urban Development}

Hydrologic responses to urban development for one or more of the four measures of streamflow flashiness were moderate to strong in all but the Salt Lake City study area. Streamflow flashiness is the rapid response of streamflow to storm events, characterized by frequent, large increases in flow (frequency and magnitude of high flow), rapid changes in flow conditions (maximum streamflow recession), and short duration of high flows (duration of high flow) (table 4-1; see sidebar, A Tale of Two Streams - Contrasting Hydrologic Situations in Raleigh Study Area Watersheds, and chapter 2 for more detailed explanation). Rapidly changing flow conditions degrade habitat and biological communities by eroding and scouring streambeds and banks.

An increase in the frequency of high flows was the most common and strongest hydrologic response to urban development (table 4-1), a finding consistent with that in other studies (Konrad and Booth, 2005; Walsh and others, 2005a; Kennen and others, 2010; Steuer and others, 2010). Graphs of the frequency of high flows in the Atlanta and Milwaukee study areas illustrate differences in the hydrologic responses to urban development in two different regions (fig. 4-1). Even though predevelopment watersheds in the Atlanta area are forested and in the Milwaukee area are agricultural, the frequency of high flows at the low end of the urban gradient is about three times higher in Atlanta than in Milwaukee. High flows are more frequent under natural conditions in Atlanta than in Milwaukee because Atlanta receives more precipitation and the precipitation is more evenly distributed throughout the year (fig. 3-7A).

Table 4-1. Hydrologic measures of streamflow flashiness and habitat responses to increasing urban development in nine metropolitan study areas (data are summarized in Giddings and others, 2009, and available at http://pubs.usgs.gov/ds/423//).

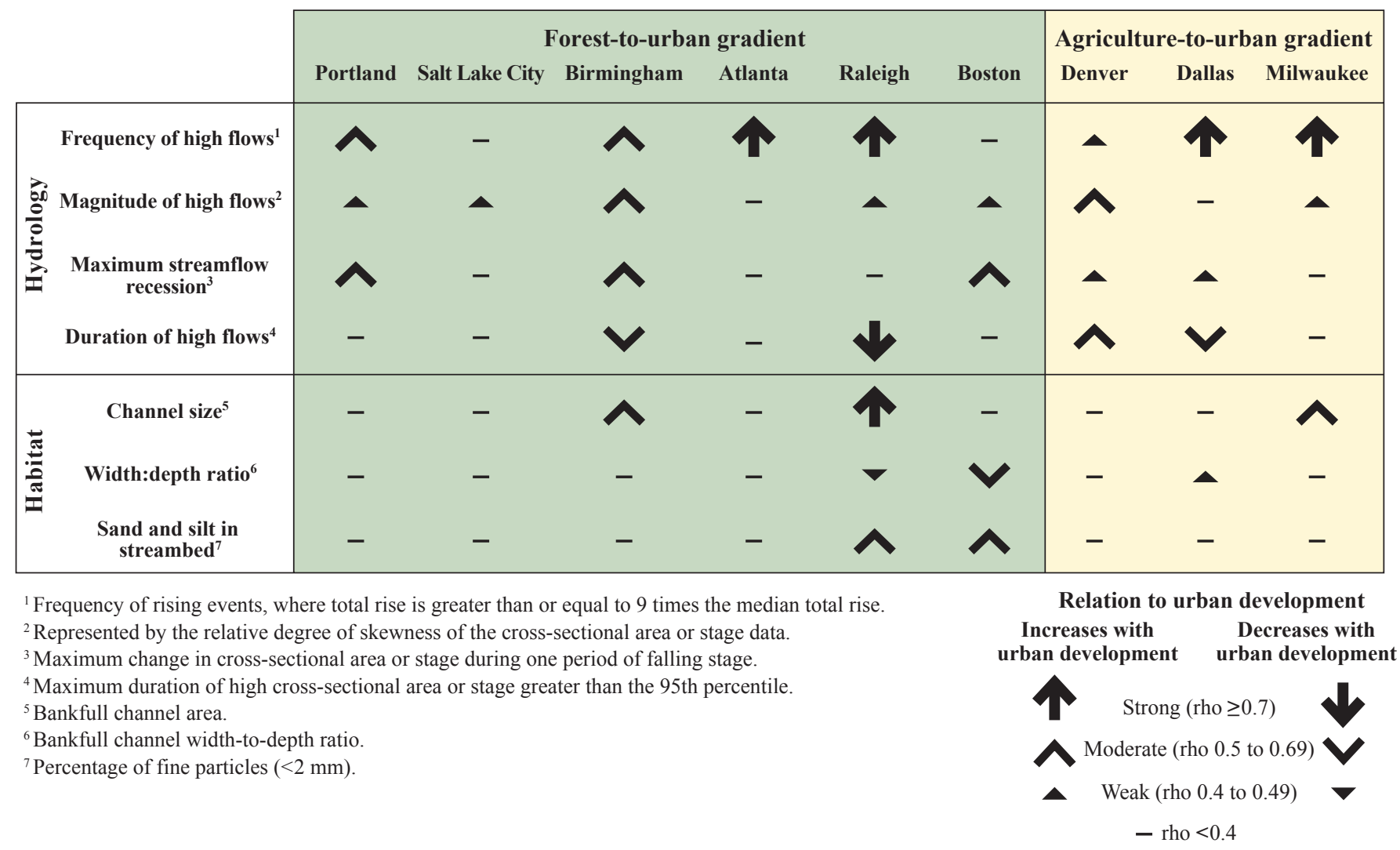


Streams at 80 percent urban development in the Milwaukee study area have about the same frequency of high flows as undeveloped forested streams in the Atlanta study area. This comparison highlights how management strategies for urban streams might differ depending on the regional environmental setting, especially in regions with naturally flashy streams.

The Salt Lake City and Boston study areas did not show increases in the frequency of high flows with increases in urban development (table 4-1). The weak hydrologic responses in Salt Lake City are a consequence of widespread diversions (fig. 4-2), interbasin transfers, and irrigation withdrawals; many of these practices were in place before urban development. Streamflow responses to storms in Boston could have been moderated by the large number of dams that slow the movement of water through the stream system. On average, more than 75 percent of the area of the watersheds in the Boston study was upstream from dams, which is almost five times more than in the other study areas.

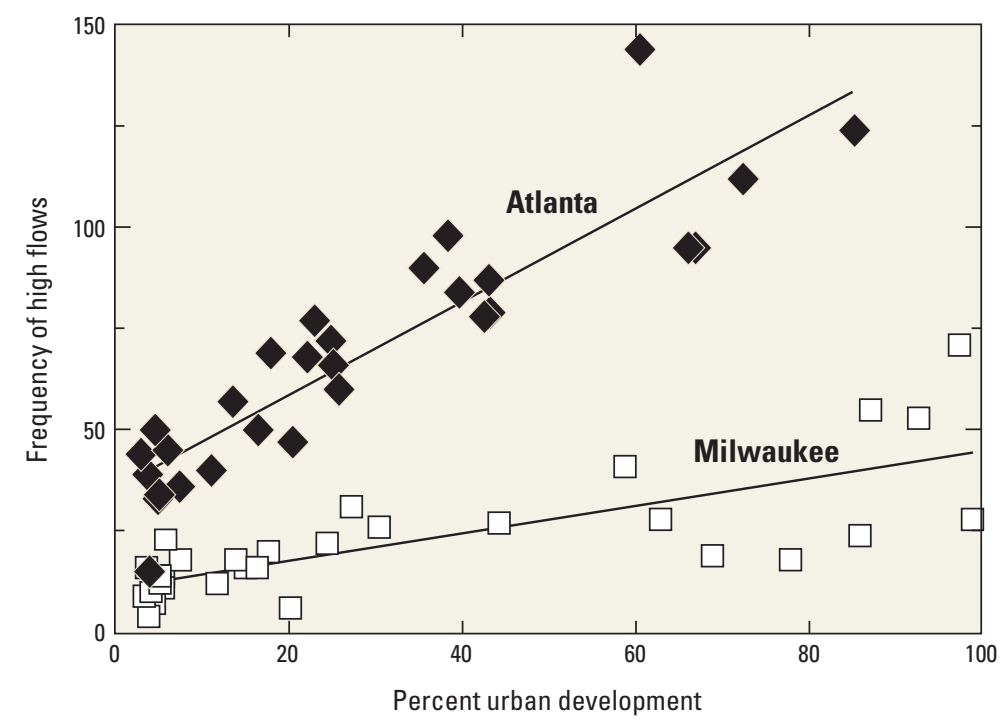

Figure 4-1. The frequency of high flows increased with urban development, although the rate of change differed among study areas, as seen by the different slopes of the lines in this example for Atlanta, Ga., and Milwaukee, Wis.

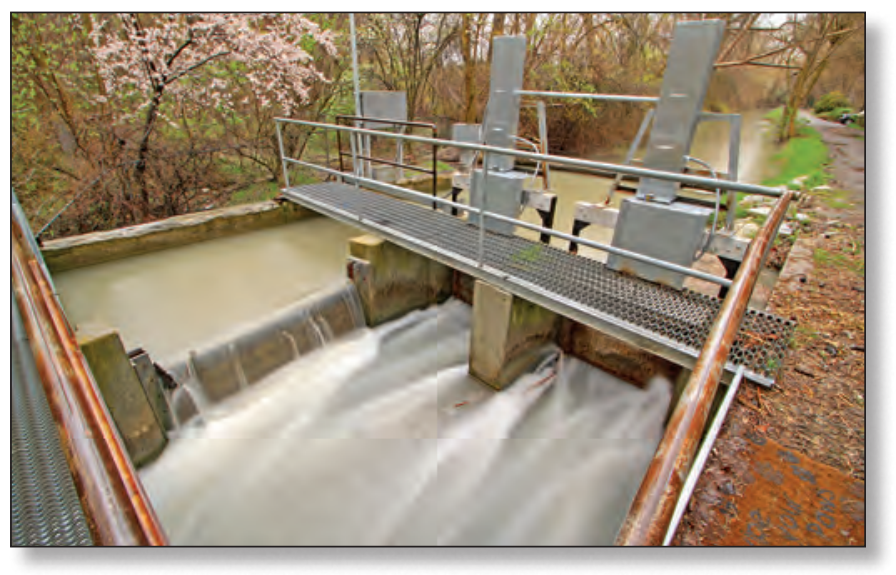

Figure 4-2. Water-diversion structures and interbasin transfers are common in semiarid areas such as Salt Lake City, Utah, where snowmelt and stormwater are stored and diverted. 


\section{A Tale of Two Streams-Contrasting Hydrologic Situations in Raleigh Study Area Watersheds}

A comparison of two watersheds in the Raleigh study area- undeveloped, forested Brooks Creek and highly developed Pigeon House Branch-illustrates how streamflow and habitat can change with urban development (table 4-2). Streamflow-flashiness characteristics are remarkably different in the two watersheds. Runoff from rain storms in the Brooks Creek watershed causes small, infrequent high flows, while similar storms in the Pigeon House Branch watershed result in large, frequent high flows that have a high potential for eroding streambeds and banks (fig. 4-3).

The streamflow differences between Brooks Creek and Pigeon House Branch also are reflected in habitat differences. The narrow, deep channel in Pigeon House Branch likely resulted from a combination of larger streamflows and bankstabilization projects that directed the stream energy toward the streambed. Large concrete blocks litter the near-bank zones of Pigeon House Branch, suggesting previous bankstabilization efforts.

"There are four interrelated but separable effects of land-use changes on the hydrology of an area: changes in peak flow characteristics, changes in total runoff, changes in quality of water, and changes in the hydrologic amenities. The hydrologic amenities are what might be called the appearance or impression which the river, its channel and its valleys, leaves with the observer. Of all the land-use changes affecting the hydrology of an area, urbanization is by far the most forceful." (Leopold, 1968)

Table 4-2. The flow of undeveloped Brooks Creek is much less flashy than that of Pigeon House Branch, with less frequent high flows and much longer duration of high flows.

[ $\mathrm{km}^{2}$, square kilometers; $\mathrm{m}^{2}$, square meters]

\begin{tabular}{lcc}
\hline \multicolumn{1}{c}{ Stream characteristics } & $\begin{array}{c}\text { Brooks Creek } \\
\text { (undeveloped) }\end{array}$ & $\begin{array}{c}\text { Pigeon House } \\
\text { Branch } \\
\text { (developed) }\end{array}$ \\
\hline Watershed area $\left(\mathrm{km}^{2}\right)$ & 23 & 11 \\
\hline Developed land (percent) & 3.1 & 98.4 \\
\hline Frequency of high flows ${ }^{1}\left(\mathrm{~m}^{2}\right)$ & 28 & 103 \\
\hline $\begin{array}{l}\text { Magnitude of high flow }{ }^{1}\left(\mathrm{~m}^{2}\right) \\
\text { Duration of maximum high } \\
\text { flow }{ }^{1}\left(\mathrm{~m}^{2}\right)\end{array}$ & 4.9 & 12.4 \\
\hline
\end{tabular}

${ }^{1}$ Streamflow was measured as cross-sectional area of the wetted stream channel. A high flow occurred when streamflow exceeded a pre-determined value of wetted cross-sectional area.
A. Brooks Creek

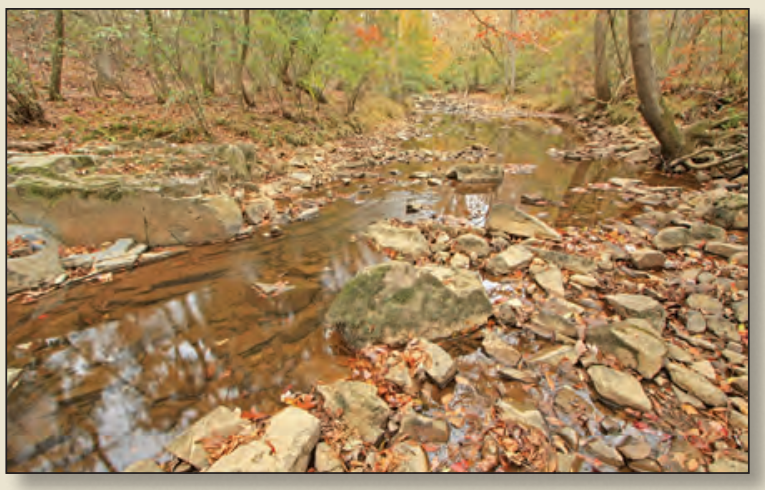

\section{B. Pigeon House Branch}
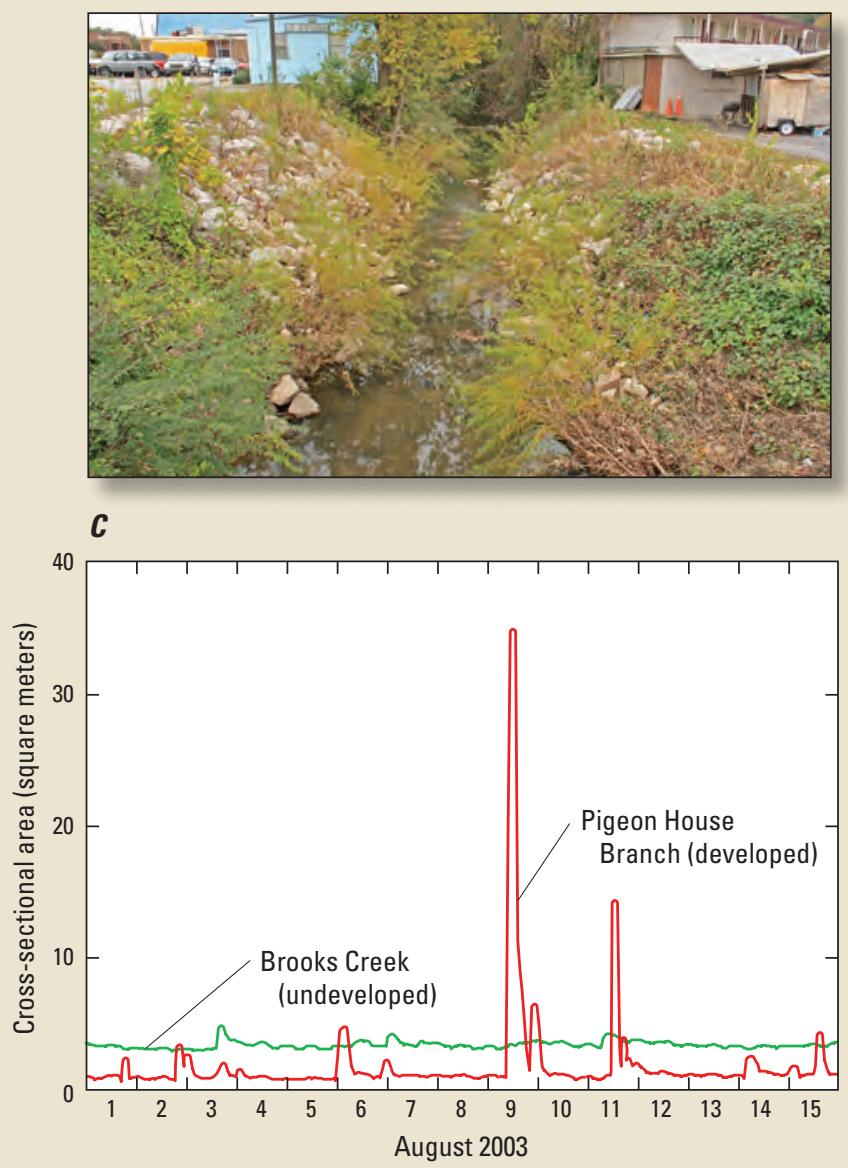

Figure 4-3. Storms in the Brooks Creek watershed $(A)$ cause small, infrequent increases in streamflow; similar storms in Pigeon House Branch $(B)$ cause large, frequent increases in streamflow $(C)$, as represented by the crosssectional area of the channel that is inundated by the water. Engineered channels are common in developed areas to prevent flooding and loss of infrastructure. These channels are designed to transport runoff and sediment efficiently and usually have banks and beds that are stabilized with large rocks and concrete. 


\section{Habitat Responses to Urban Development Were Inconsistent}

The habitat characteristics of a stream reach reflect a continually changing balance between the physical forces that drive changes in habitat, such as stream slope, streamflow, and sediment inputs, or loads, and the physical characteristics of the streambed and banks that resist these driving forces (fig. 4-4; Sear and Newson, 2003; Somerville and Pruitt, 2004; Chin, 2006). Increases in the driving forces need to exceed the strength of the resisting forces to initiate a habitat change. Urban development that leads to an increase in these driving forces, such as increased stream flashiness and sediment (see chapter 2), might not result in clear-cut evidence that habitat is changing if the resisting forces are particularly strong or if habitat changes are occurring over a long period of time.

Habitat responses to urban development in the nine areas studied were less evident than hydrologic responses. Changes in channel size (channel area) and shape (width-to-depth ratio) and the size composition of sediment, which can range from

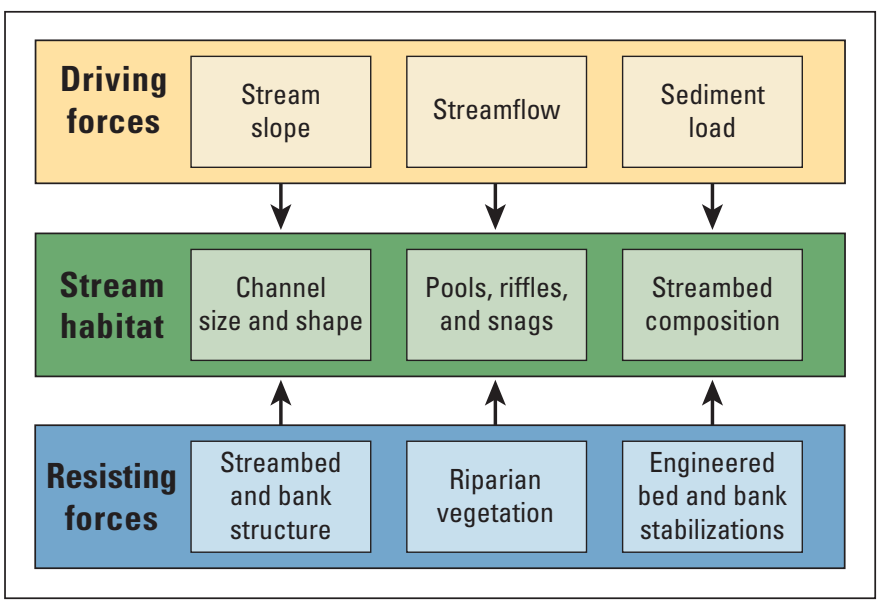

Figure 4-4. Habitat features are determined by the physical balance of driving and resisting forces. If the driving forces related to increased streamflow exceed the resisting forces of the size of streambed or bank sediment, channels will erode through downcutting or widening. silt to boulders, were the most common habitat responses; however, these changes were observed in only five of the nine areas (table 4-1). The Raleigh study area had the most definitive changes in habitat, including an increase in channel size, channel deepening (decreased width-to-depth ratio), and an increase in fine-grained sediment (table 4-1; fig. 4-5; Fitzpatrick and Peppler, 2010). In other study areas, the fewer habitat responses were due in part to efforts during the study-site selection to avoid streams with evidence of human modification (see sidebar, Why Were Habitat Responses to Urban Development Inconsistent?). Despite the inconsistent response, stream-habitat characteristics are important for understanding the effects of urban development on stream ecosystems because they define the places and conditions where biota live.

A key finding was that channel modifications, such as riprap channels, channel straightening, and weirs, were common even in streams with little urban development. Stream channels were modified in about half of the study watersheds in Dallas, Portland, and Atlanta and in more than 85 percent of the study watersheds in the remaining six study areas.

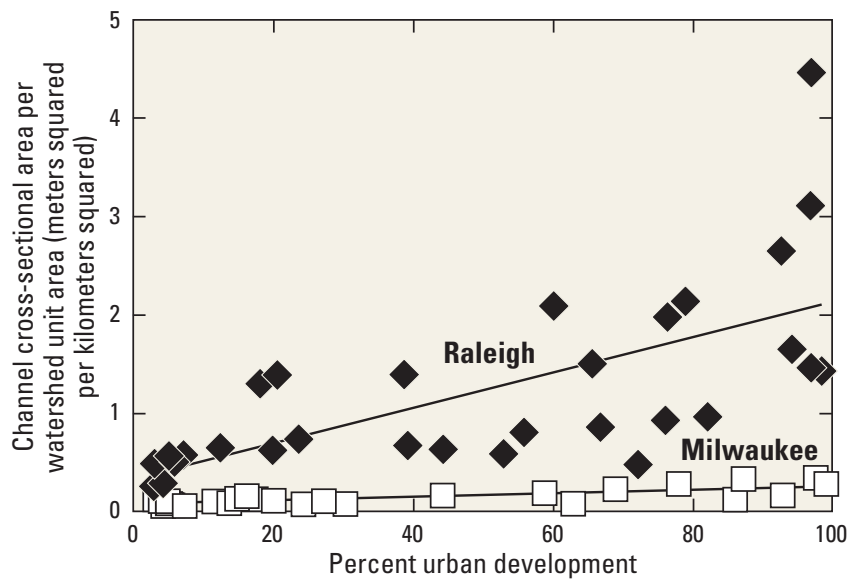

Figure 4-5. Channel cross-sectional area increased with urban development in the Raleigh and Milwaukee study areas. Channel areas are dependent on drainage area and were normalized by watershed area before comparisons. The slope of the line for the Raleigh study area is steeper because the resisting forces were greater in the Milwaukee study area.

"We often talk about stream incision as a result of increased runoff response in urban watersheds, and there are lots of places where we can see steep eroding banks and exposed utility pipes. But the evidence suggests that incision of the bed is not the only way that streams adjust to urban development. In some places-for example, Luna Leopold's famous study site in Watts Branch, Maryland - we actually have evidence for accumulation of sediment that raised the bed of the stream (at least temporarily) as well as the flood plain in response to upstream erosion delivering sediment to that part of the valley. This happened during the same period when the channel was enlarging to convey more frequent high flows. There are many other places where localized deposition of coarse sediment diverts flow against the opposite bank and induces channel instability and widening." (Professor Andrew J. Miller, University of Maryland-Baltimore County, written commun., 2009.) 


\section{Why Were Habitat Responses to Urban Development Inconsistent?}

The relation between urban development and changes in habitat can be masked if the resisting forces are stronger than the driving forces (fig. 4-4). An increase in the area of impervious cover alters the amount and timing of stormwater runoff that reaches a stream after a storm and typically increases potential for erosion (fig. 4-6). The previous sidebar, A Tale of Two Streams - Contrasting Hydrologic Situations in Raleigh Study Area Watersheds, explains how a storm in the Pigeon House Branch watershed can result in large, rapid increases in streamflow, which can increase the driving forces leading to habitat changes. An increase in runoff can alter the shape of a stream channel to a degree that will depend, in part, on the type of channel material; stream channels with mostly fine-grained sediment will typically become relatively narrow and deep compared to stream channels with mostly coarse-grained sediment (Einstein, 1950; Schumm and Khan, 1972). Channel stabilization measures, however, can reduce the erosive effects of flashy streamflow by armoring the streambank (fig. 4-7).

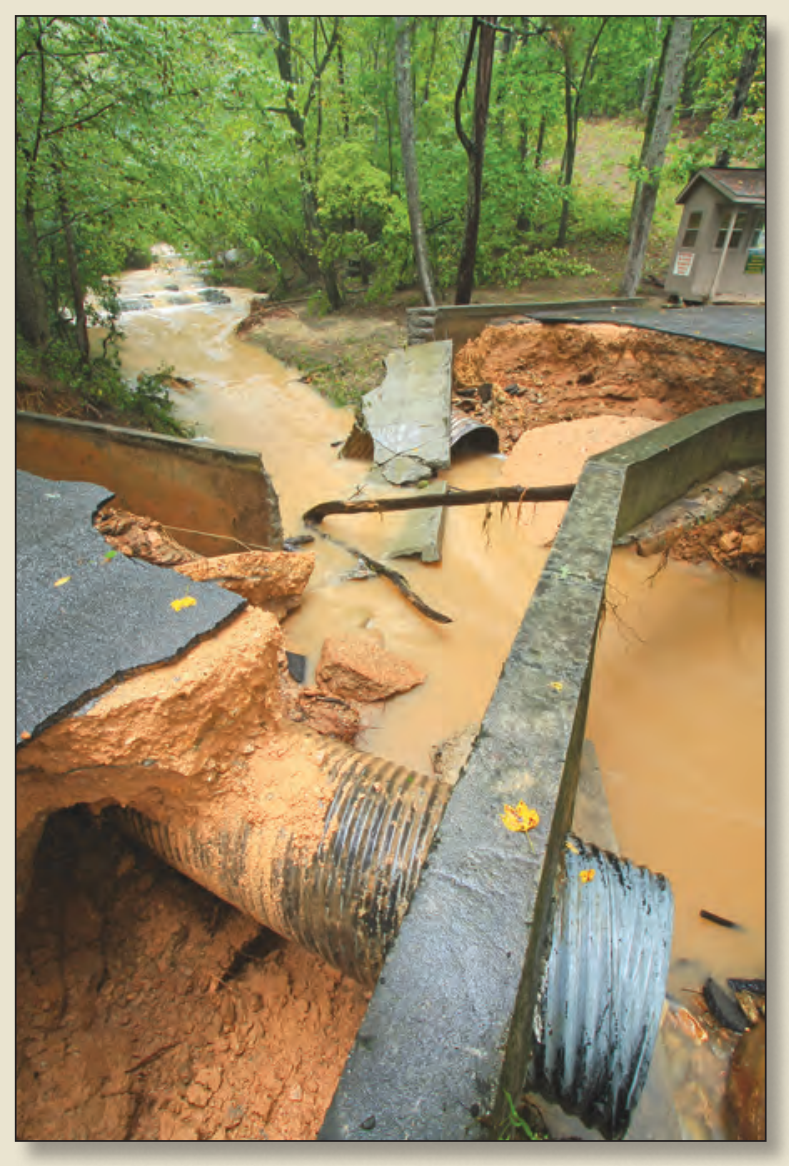

Figure 4-6. Frequent high flows increase the potential and severity of erosion, habitat degradation, and destruction of road crossings and infrastructure. This road crossing was washed out during a flood near Atlanta, Ga., in 2009.

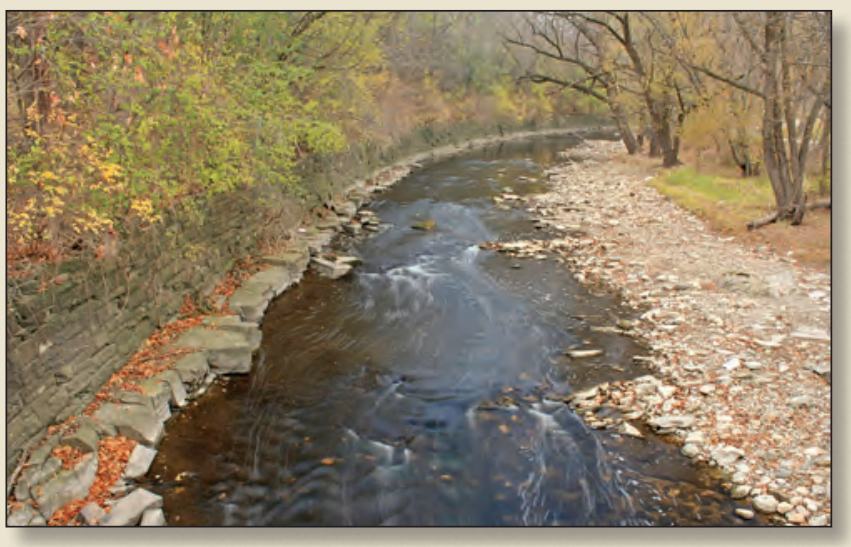

Figure 4-7. Engineered channels are common in developed areas to prevent flooding and loss of infrastructure. These channels, designed to transport runoff efficiently, usually have banks and beds that are stabilized with large rocks and concrete.

Stream-habitat features at any one point in time also are influenced by processes other than development and by factors that influence the introduction and processing of sediment. The steeper the slope of a channel, the greater the potential for the water to erode the channel and its banks and to damage or destroy infrastructure, such as water and sewer lines, bridges, and roads. The slope of a channel can vary extensively along the length of a stream, and habitat characteristics depend on the slope of the reach. For example, a stream carrying the same amount of suspended sediment throughout its length might have a cobble and boulder bed in steep reaches and a silt and sand bed in more gently sloping reaches. Human activities that occur prior to urban development, such as logging, farming, drainage improvements, and the construction of millponds, have different long-term effects on sediment loads. Changes in drainage networks in urban settings (ditching and channelization) can increase the movement of fine sediment into streams, whereas millponds can trap sediment (Gellis and others, 2009; Lee and Ziegler, 2010).

The effects of urban development on habitat features in the USGS studies might be obscured by three factors. First, a criterion for site selection was that there be no evidence of recent human modifications in the selected stream reach and that streams have relatively well-defined banks with at least 50 percent mature vegetative cover. This criterion was intended to minimize local-scale habitat differences that might confound interpretation of broader-scale impacts of urban development (Short and others, 2005). Second, while unmodified channels were preferred in this study, artificial channels and stabilized banks were common and could not be avoided. Third, the habitat response to urban development may have been obscured by the long period of time needed for channel morphology and streambed characteristics to adjust to changes in sediment loads. 
The percentage of streams with some type of channel modification differed among the nine study areas, with Portland, Atlanta, and Dallas having the fewest modified stream reaches (between 50 and 60 percent); however, more than 85 percent of the measured stream reaches in the remaining six study areas had some type of channel modification. More than 50 percent of the streams studied had grade controls (features that resist streambed erosion, such as culverts, weirs, and low-head dams) in or near the measured reach. Almost 30 percent of the reaches had some type of bank stabilization. Bank-stabilization measures had been implemented on more than 75 percent of the measured reaches in the Salt Lake City study area, where stream channels are relatively steep and hydrologic modifications had occurred decades prior to urban development.

Habitat response to urban development might have been obscured by the long period of time needed for channel morphology and sediment characteristics to adjust to changes in sediment loads (Schumm and Lichty, 1965; Wolman, 1967; Leopold and others, 2005). Major adjustments in suspendedsediment loads occur during urban development as sediment sources and the sediment amount, size, transport, and storage change over time (fig. 4-8). Early stages of urban development, such as land clearing associated with construction activities, can cause large amounts of fine-grained sediment (silt, clays, and sand) to be deposited in streams with gentle slopes. The amount of sediment entering a stream from new construction sites can be many times greater than sediment from agricultural areas (Owens and others, 2000; Lee and Ziegler, 2010); however, the proportion of sediment contributed by soil erosion in older urban settings with few areas of bare soil can be much less than in streams draining agricultural or newly developed areas (Wolman, 1967; Leopold and others, 2005).

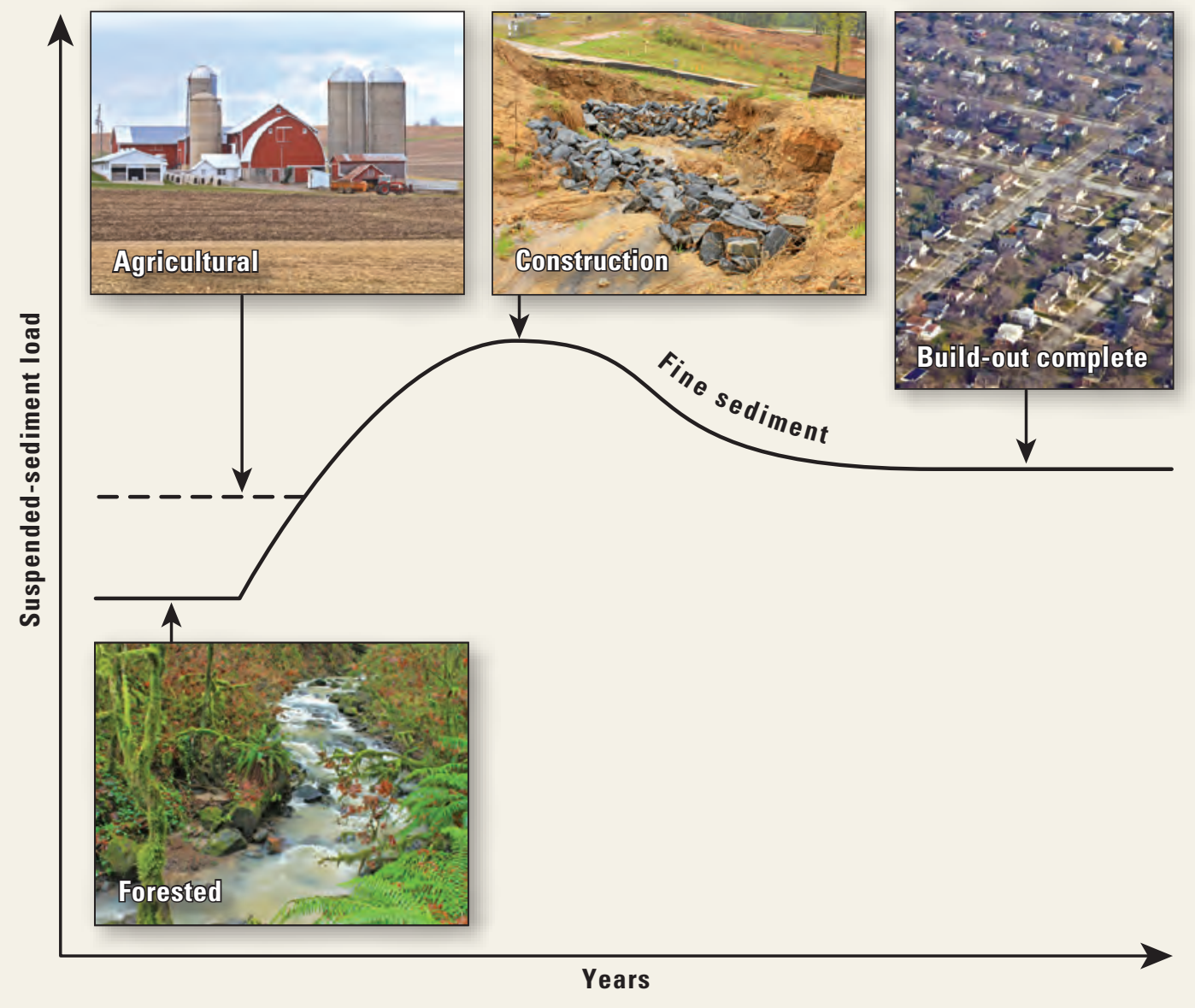

Figure 4-8. The sources of sediment can change over time, shifting from soil erosion at construction sites to bank and channel erosion after land surfaces are covered with pavement and buildings. The high suspended-sediment load that occurs early in the watershed development process is a result of sediment coming from construction-site erosion, which can be many times greater than sediment coming from agricultural areas or established urban areas (Wolman, 1967; Leopold and others, 2005). Channel adjustments from changes in suspended-sediment loads can last for decades (Schumm and Lichty, 1965; Owens and others, 2000). 


\section{Response of Stream Chemistry to Urban Development}

The influence of urban development on stream chemistry was evident in three ways (table 4-3). First, chloride, pesticides (particularly insecticides), and hydrophobic contaminants generally increased (either in concentration, number of compounds detected, or both) with urban development in most study areas. This response to urban development is consistent with results reported in Gilliom and others (2006) that indicated (1) total insecticide concentrations generally were highest in urban streams, and (2) detections of measurable concentrations occurred even during low-flow, summer months.
Second, the relative toxicity of chemical contaminants in streams increased with urban development. The toxicity response reported for this investigation was based on analyses of samples collected at a single time of the year and provides a conservative estimate of the toxicity of contaminants present in these streams.

Third, regional differences in types of land being developed (whether forested or agricultural) influenced stream-chemistry responses. Generally, concentrations of nitrogen and herbicides increased in five of the six study areas where urban development occurred on forested land, while responses of these chemicals were weak overall when development occurred on agricultural land.

Table 4-3. Stream-chemistry responses to urban development (data are available in Bryant and others, 2007; Giddings and others, 2009).

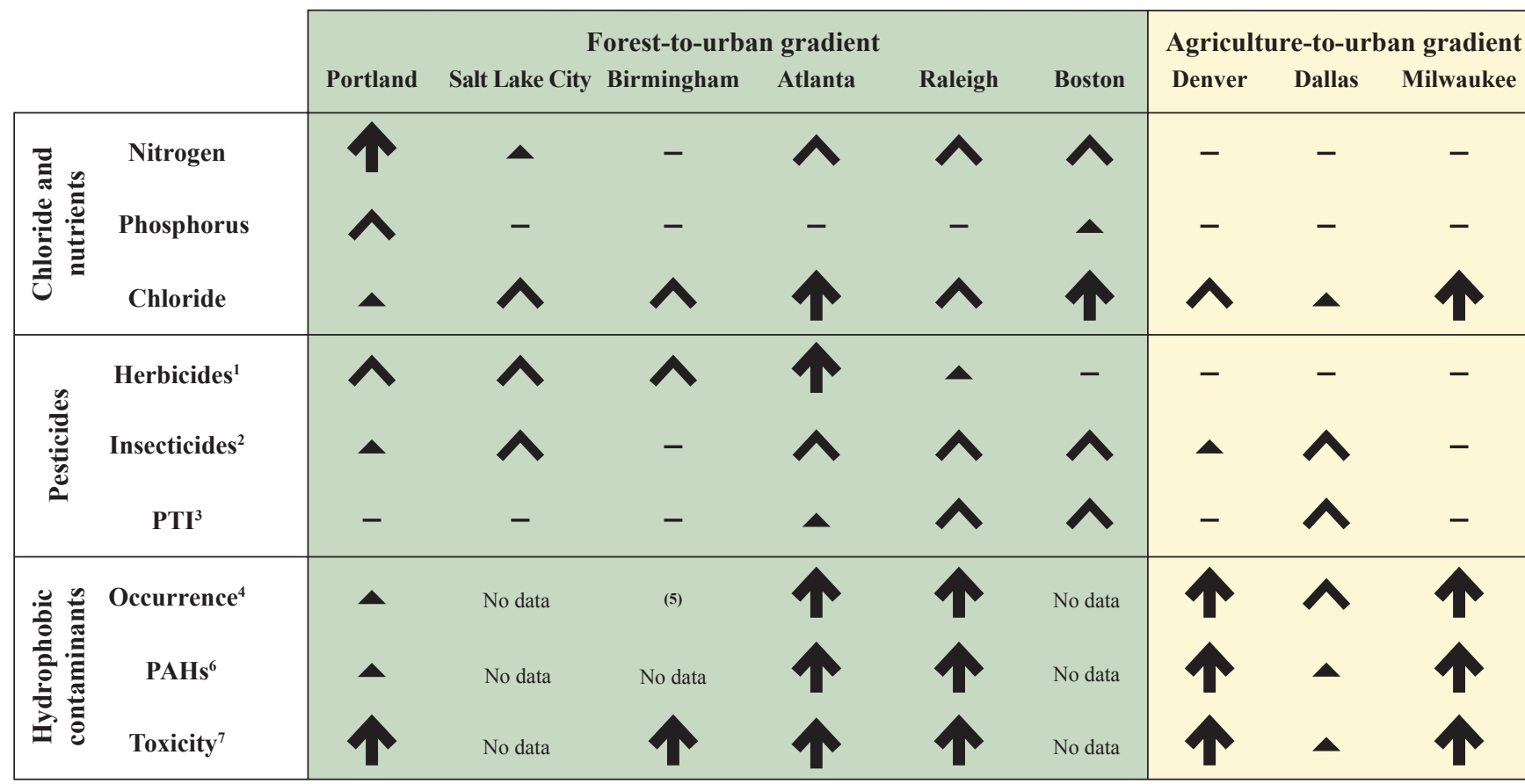

Total herbicide concentration.

${ }^{2}$ Total insecticide concentration.

${ }^{3}$ Pesticide Toxicity Index (PTI).

${ }^{4}$ Number of different hydrophobic contaminants detected with semipermeable membrane devices (SPMDs).

${ }^{5}$ Birmingham samples were evaluated only for overall toxicity, not individual contaminants.

"Concentration of polycyclic aromatic hydrocarbons (PAHs).

${ }^{\urcorner}$Toxicity of overall mixture of hydrophobic contaminants based on the P450 bioassay.
Relation to urban development Increases with urban development

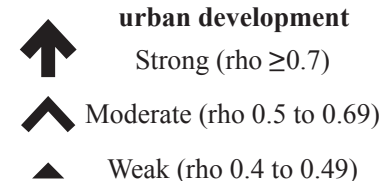

- rho $<0.4$ 
Regional Differences in Types of Predevelopment Land (Forested or Agriculture) Influenced Stream Nutrient and Pesticide Responses to Urban Development

Concentrations of nitrogen increased as urban development occurred on forested land. The increase was moderate to strong in the Portland, Atlanta, Raleigh, and Boston study areas (table 4-3). Increases in stream nitrogen concentrations were not apparent in study areas where agriculture, including grassland (Denver, Dallas, and Milwaukee), was the predominant type of land being converted to urban uses. Nitrogen concentrations in these study areas were considerably higher in watersheds with minimal urban development in comparison to study areas where urban development occurred on forested land. For example, the median nitrate concentration in watersheds with less than 20 percent urban development in Milwaukee (0.79 milligram per liter, $\mathrm{mg} / \mathrm{L}$ ) were more than 8 times higher than the median nitrogen concentration in forested watersheds in Portland $(0.09 \mathrm{mg} / \mathrm{L})$. Agricultural activities in the Milwaukee study areas, therefore, may have contributed to elevated nitrogen concentrations.

Concentrations of phosphorus generally indicated little association with the level of urban development, except in the Portland and Boston study areas where phosphorus concentrations indicated moderate and weak positive correlations, respectively, with urban development (table 4-3). In the study areas where agriculture was the predevelopment land use, phosphorus concentrations were relatively high in some streams with low levels of urban development. For example, in the Milwaukee study area, total phosphorus concentrations were highest in several streams with low levels of urban development (less than 30 percent), and phosphorus concentrations overall decreased with urban development, although not substantially (fig. 4-9).

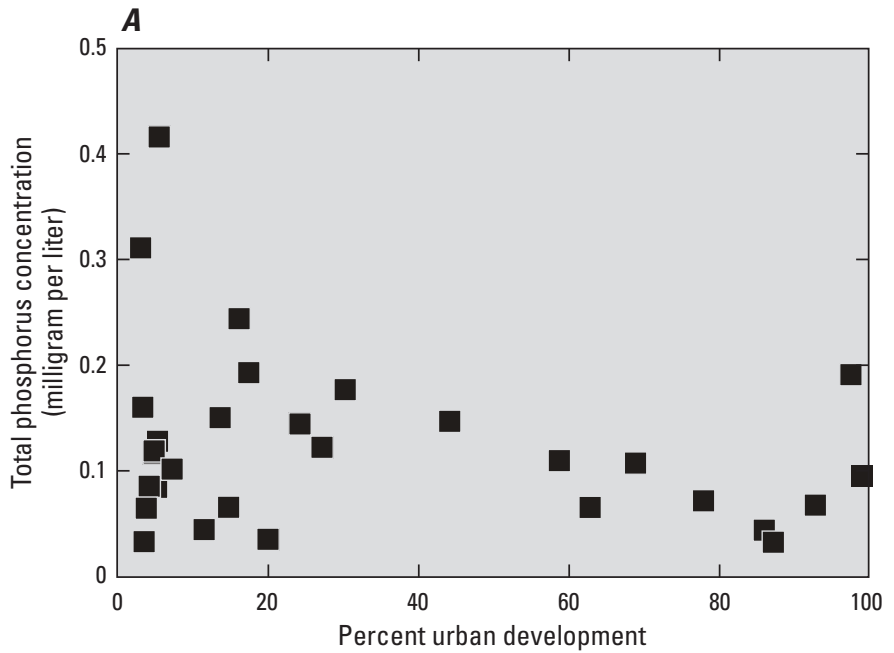

Figure 4-9. The highest phosphorus concentrations among all streams in the Milwaukee study area occurred where levels of urban development were $(A)$ less than 30 percent and $(B)$ associated with predominantly agricultural land use.

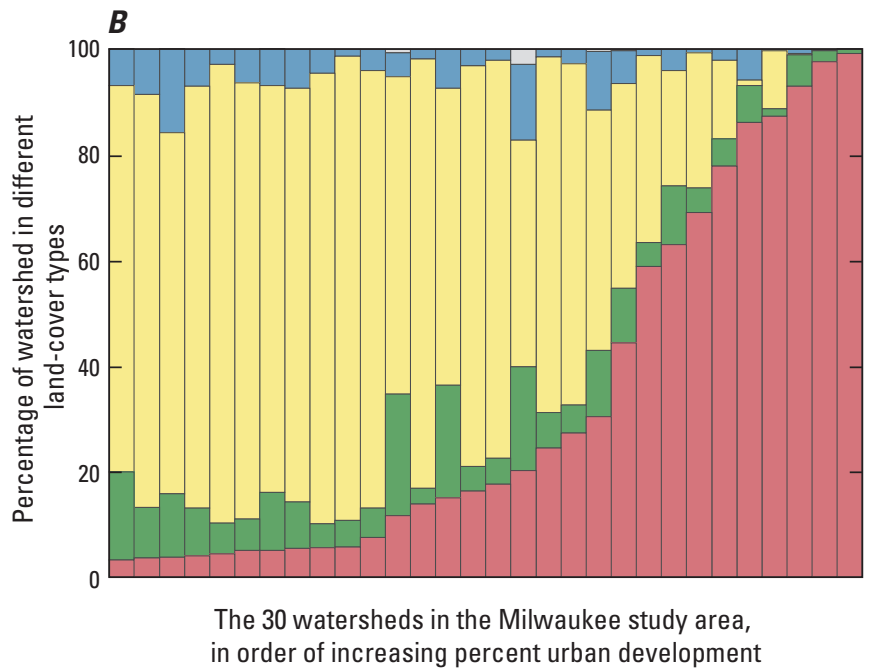

in order of increasing percent urban development

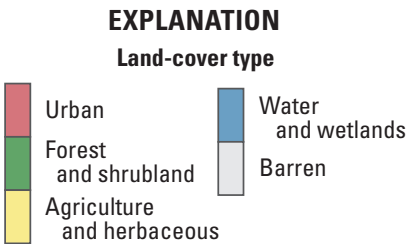




\section{Chloride Increased With Urban Development Even in Areas Where Deicing Chemicals Are Infrequently Used}

Chloride was the only chemical measured that increased in concentration in stream water with urban development in all nine study areas (table 4-3). This was true regardless of whether road-salt use was expected to be high in study areas with cold climates (Salt Lake City, Boston, Denver, and Milwaukee; fig. 4-10) or low in study areas with warm climates (Portland, Birmingham, Atlanta, Raleigh, and Dallas). Increases in chloride concentrations can result from leaking sewage lines and septic tanks, fertilizer use, and the use of water softeners, bleach, and swimming pool chemicals; chloride can be transported to streams through groundwater and wastewater-treatment plant discharges. This relation, based on analyses of water samples collected during low-flow conditions, indicates that elevated chloride concentrations associated with urban development can persist across seasons (see sidebar, Characterizing Water Quality Can Depend on Time of Year When Stream Chemistry Is Measured). This is consistent with findings in studies in the northeastern United States, which indicate that a gradual accumulation of chloride in groundwater from a variety of sources can lead to elevated concentrations during summer low-flow periods (Kaushal and others, 2005; Mullaney and others, 2009).

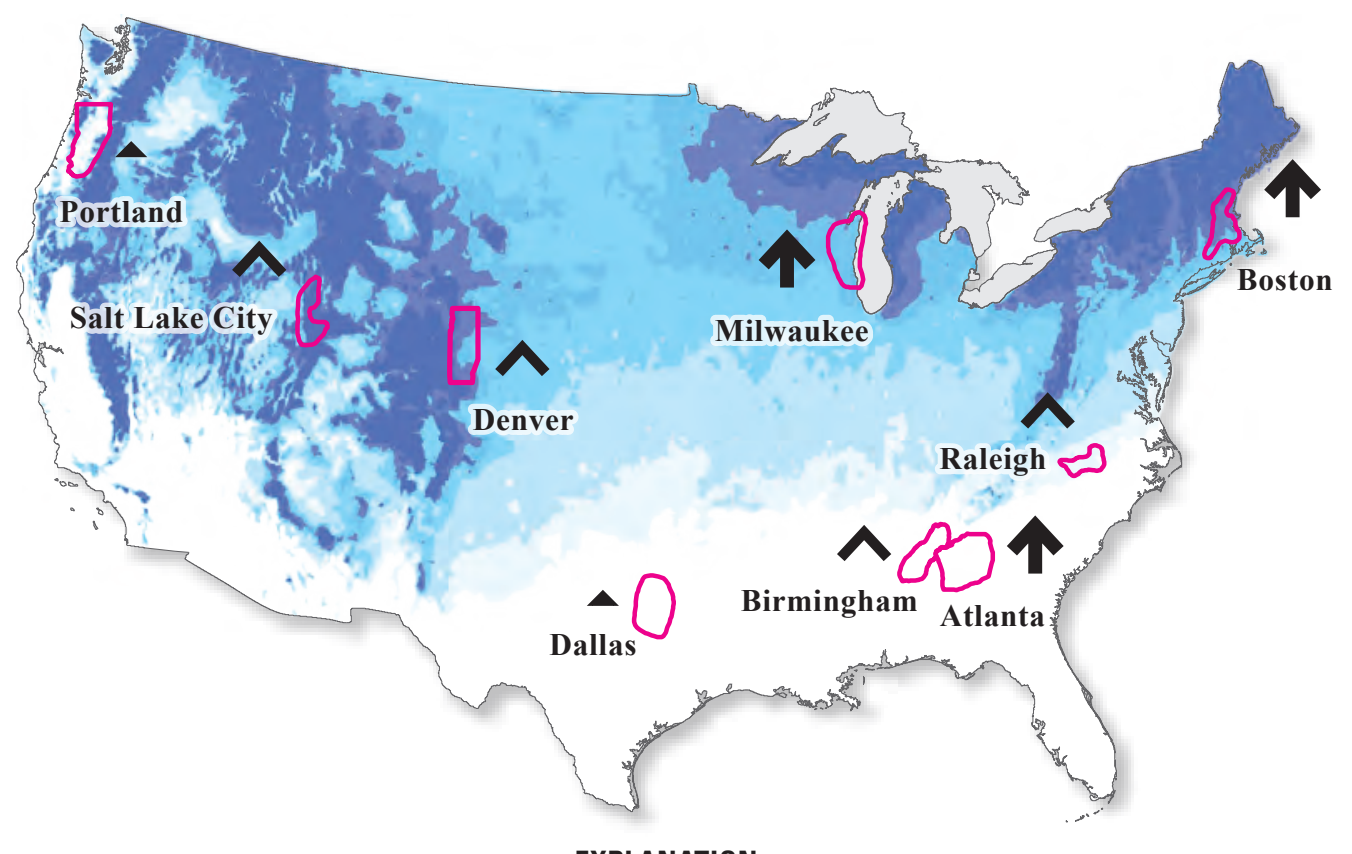

EXPLANATION

$\begin{gathered}\text { Average annual snowfall, in inches } \\
\text { (data from NOAA, 1999c) }\end{gathered}$
\begin{tabular}{|l|l|l|}
\hline$<6.0$ & 36.1 to 48.0 & $\begin{array}{c}\text { Relation of chloride concentrations } \\
\text { to urban development }\end{array}$ \\
6.1 to 12.0 & 48.1 to 72.0 & Strong (rho $\geq 0.7$ ) \\
12.1 to 24.0 & $>72.0$ & Moderate (rho 0.5 to 0.69 ) \\
24.1 to 36.0 & & Weak (rho 0.4 to 0.49 )
\end{tabular}
USGS study area

Figure 4-10. Chloride concentrations during low-flow conditions increased in response to urban development in all study areas, even in warmer climate areas with low amounts of snowfall where deicing chemicals are used infrequently. The general pattern of increased chloride concentrations with urban development is noteworthy considering the potential for these concentrations to affect the health of aquatic organisms. (Modified from Corsi and others, 2010.) 


\section{Characterizing Water Quality Can Depend on Time of Year When Stream Chemistry Is Measured}

The relations between urban development and stream chemistry reported in table $4-3$ are based on water samples collected during the low-flow period, defined as a period in which few precipitation events occur. It generally was acknowledged in designing the USGS investigation, however, that water-quality conditions in a region might show greater variation throughout the year, which would not be characterized by samples collected only during the low-flow period. For example, in the temperate regions where snow cover dominates the winter landscape, springtime snowmelt and rain can flush contaminants from the watershed, resulting in higher flows and higher contaminant concentrations.

In addition to describing stream chemistry for the low-flow period, supplemental characterizations were made during the year for nitrogen, phosphorus, chloride, and the pesticide toxicity index (PTI) based on water samples collected bimonthly at approximately 10 sites in 7 study areas: Portland, Atlanta, Raleigh, Boston, Denver, Dallas, and Milwaukee (Beaulieu and others, 2012). For each constituent, the bimonthly data were used to calculate a median value (to represent yearly "integrated" conditions) and the standard deviation (to represent the amount of seasonal variability). The relation between a constituent and urban development was calculated in two ways: by levels of the constituent based on (1) low-flow values and (2) median values. Results from these two relations were compared to determine how closely the low-flow sample characterized the integrated (for example, median) waterchemistry conditions. In addition, for each constituent, the relation between the standard deviation of its values and urban development was used to determine if the amount of seasonal variation increased with urban development.
The strength of the relation between a constituent and urban development was generally comparable when using either the low-flow or median value (table 4-4). For nitrogen and phosphorus, the relations based on low-flow values were slightly stronger in a few cases, but for chloride and the PTI, the relations were somewhat stronger overall using the median values. This latter difference may be a result of seasonal applications of road salts and pesticides within a watershed; therefore, chloride and PTI values would not be as well characterized in water samples collected under low-flow conditions.

The amount of seasonal variation in the levels of a constituent also generally increased with urban development (table 4-4). Notable exceptions were for nitrogen in the Dallas study area and phosphorus in the Milwaukee study area, both with a negative response, possibly because variation in these nutrients decreased as land use in these regions changed from agriculture to urban. Consistent with the result that chloride and PTI are best characterized by median values, the amount of seasonal variation in these constituents increased steadily as levels of urban development increased. This result is especially relevant regarding chloride in urban areas because, unlike nutrients and pesticides, the use of chemicals that contain chloride generally is not associated with agricultural practices (especially direct applications of salt). The chloride median value was related to urban development in all study areas (table 4-4), but was strongest (rho, 0.9 or greater) in high-snowfall areas of Denver, Milwaukee, and Boston (fig. 4-10). Furthermore, seasonal variance in chloride was most strongly related to urban development in these three areas (rho, 0.75 or greater), which suggests that winter applications of deicing chemicals may contribute to particularly high chloride concentrations at certain times of the year.

Table 4-4. The relation of chemical constituents (nitrogen, phosphorus, chloride, and pesticide toxicity index levels) to urban development, based on the single low-flow value and the median value from samples collected bimonthly over 1 year. Seasonal variation indicates how strongly urban development was related to the amount of variation in the levels of the constituent during the year. As watersheds were developed, seasonal variation generally increased, indicating that greater shifts in water quality can occur throughout the year in areas of high urban development.

[Relation to urban development: Strong (rho $\geq 0.7)$; Moderate $(0.5$ to 0.69$)$; Weak $(0.4$ to 0.49$)$; $-(<0.4)$ ]

\begin{tabular}{|c|c|c|c|c|c|c|c|c|}
\hline \multicolumn{2}{|c|}{ Constituent } & Portland & Atlanta & Raleigh & Boston & Denver & Dallas & Milwaukee \\
\hline \multirow{3}{*}{ Nitrogen } & Low-flow value & $\underline{0.61}$ & 0.70 & $\underline{0.69}$ & 1.00 & - & -0.43 & - \\
\hline & Median value & $\underline{0.62}$ & $\underline{0.67}$ & - & 0.94 & - & - & - \\
\hline & Seasonal variation & - & - & - & 0.83 & 0.43 & -0.42 & 一 \\
\hline \multirow{3}{*}{ Phosphorus } & Low-flow value & 0.75 & - & - & 0.94 & 0.47 & - & -0.50 \\
\hline & Median value & $\underline{0.66}$ & - & - & 0.71 & $\underline{0.52}$ & - & -0.70 \\
\hline & Seasonal variation & 0.78 & - & -0.62 & - & 0.73 & - & -0.62 \\
\hline \multirow{3}{*}{ Chloride } & Low-flow value & 0.44 & $\underline{0.57}$ & - & 0.83 & 0.72 & $\underline{0.60}$ & $\underline{0.68}$ \\
\hline & Median value & 0.75 & 0.82 & 0.43 & 1.00 & 0.90 & 0.45 & 0.99 \\
\hline & Seasonal variation & $\underline{0.50}$ & - & - & 0.77 & 0.75 & - & 0.96 \\
\hline \multirow{3}{*}{ Pesticide toxicity index (PTI) } & Low-flow value & $\underline{0.68}$ & 0.43 & 0.43 & No data & - & $\underline{0.50}$ & - \\
\hline & Median value & $\underline{0.67}$ & 0.88 & - & No data & 0.73 & $\underline{0.63}$ & -0.66 \\
\hline & Seasonal variation & 0.65 & 0.97 & 0.40 & No data & 0.77 & 0.42 & - \\
\hline
\end{tabular}




\section{Measuring the Potential Toxicity of Pesticide Combinations}

A pesticide toxicity index (PTI; Munn and Gilliom, 2001; Munn and others, 2006) was used as a measure of the potential toxicity of multiple pesticides co-occurring in stream water. The index is based on the concentrations of all pesticides measured in the water sample, each weighted by its individual toxicity threshold, as estimated from laboratory toxicity studies. Although the index does not indicate whether water in a sample is toxic, it can be used to rank or compare the relative potential toxicity of different streams and to empirically evaluate an association between potential toxicity and urban development. An index can be specific to a type of organism. The pesticide toxicity index values used in this chapter are specific to cladocerans, an aquatic invertebrate that often is used for testing the toxicity of contaminants in water.

\section{Concentrations of Insecticides in Water and Their Toxicity Increased With Urban Development}

Numerous pesticides are registered for use in urban settings and are applied to combat home and garden pests, maintain rights-of-way, and protect structures. The large number of pesticides registered for urban uses is reflected in the mixture of pesticides detected in stream samples in each study area. A national survey conducted by Gilliom and others (2006) determined that urban streams almost always contained complex mixtures of pesticides and pesticidedegradation products; 80 percent of urban streams (those in watersheds having greater than 25 percent urban land cover) had pesticide concentrations that exceeded one or more benchmarks for the protection of aquatic life.

Figure 4-11. Insecticides (blue bars) accounted for a greater proportion of relative toxicity in streams than herbicides (orange bars) but were detected less frequently and at lower concentrations. Example shown is for Honey Creek, a highly urbanized stream in the Milwaukee study area.
The total concentration of insecticides in stream water increased with urban development in all study areas except Birmingham and Milwaukee (table 4-3). The number of detections and the relation between concentrations of individual insecticides and urban development varied across the study areas and appeared to follow patterns of pesticide use (Bryant and others, 2007). For example, the concentration of the insecticide chlorpyrifos was strongly related to urban development in Atlanta, Raleigh, and Dallas, and the concentration of chlordane was strongly related to urban development in Raleigh. All three study areas are in areas of high termite activity (Beal and others, 1994), and the detection of chlorpyrifos and chlordane in stream water corresponds to the historical use of these compounds for termite control (Nowell and others, 1999; Gilliom and others, 2006). These compounds continue to be detected even though there have been no approved uses of chlordane since 1988 .

The relative potential toxicity of pesticides in stream water for cladocerans increased with urban development in the Atlanta, Raleigh, Boston, and Dallas study areas (table 4-3; see sidebar, Measuring the Potential Toxicity of Pesticide Combinations). Insecticides accounted for a greater proportion of the potential toxicity in streams than herbicides, but insecticides were detected less frequently and at lower concentrations. For example, in Honey Creek, a highly urbanized stream in the Milwaukee study area, the pesticide detected at the highest concentration was the herbicide atrazine (Richards and others, 2010; fig. 4-11). However, the insecticides diazinon and chlorpyrifos accounted for most of the toxicity.

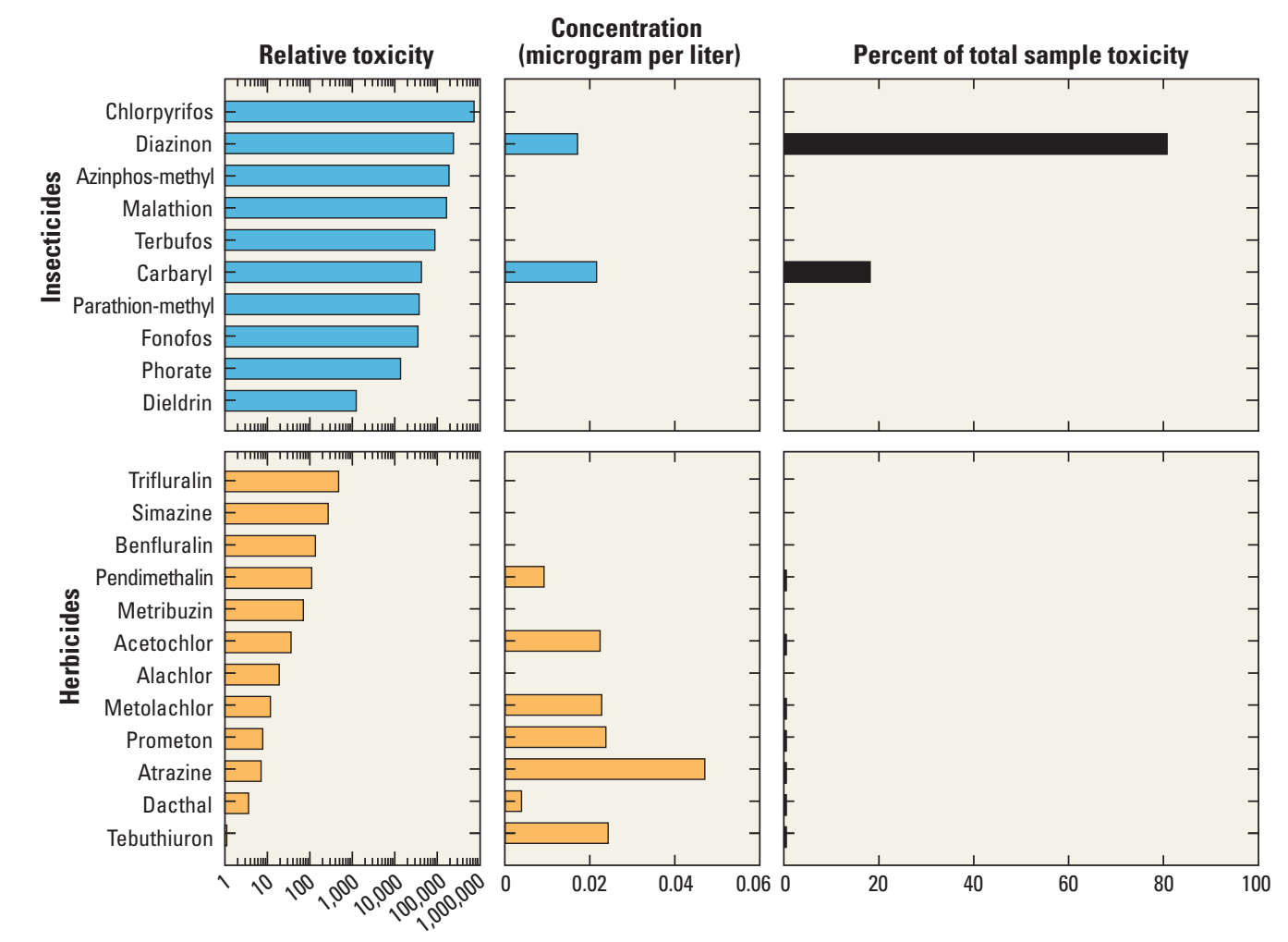




\section{The Types of Organic Contaminants in Water Vary by Region and Depend on Current and Historical Use Patterns}

The number of hydrophobic contaminants in water increased with urban development in Portland, Atlanta, Raleigh, Denver, Dallas, and Milwaukee study areas (Salt Lake City and Boston were not included in this assessment, and only gross toxicity was measured in Birmingham), but the mixture of compounds varied (see sidebar, Characterizing Hydrophobic Contaminants With Semipermeable Membrane Devices). The relation to urban development was especially strong in Raleigh, Atlanta, Denver, and Milwaukee (table 4-3). The number of individual contaminants ranged from 3 in Dallas and Portland to 21 in Raleigh. The types of contaminants detected include pesticides, compounds associated with fragrances or personalcare products, flame retardants, polycyclic aromatic hydrocarbons (PAHs), and plasticizers. These varying responses to urban development reflect different sources and transport processes; thus, different management approaches may be required to improve stream quality in different metropolitan areas. Additional information describing specific contaminants associated with urban development is provided in the case study: Contamination and Toxicity of Stream Sediments Increase With Urban Development.

The potential toxicity of hydrophobic contaminants increased with urban development in all seven study areas where toxicity was assessed (Bryant and Goodbred, 2008; table 4-3). A bioassay was used to evaluate the degree of toxicity in the overall mixture of contaminants in the sample, but the bioassay does not indicate which compounds were responsible for the toxicity. The actual effects of these compounds on organisms of interest, such as fish, often are not directly observed. Exposure to toxic compounds need not be lethal, but the health of organisms can still be affected to the extent that the species composition of the biological community is altered.
The most frequently detected hydrophobic contaminants were PAHs. Contamination of urban streams and lakes by PAHs is widespread in the United States (Chalmers and others, 2007; Van Metre and Mahler, 2010). PAHs in the environment are largely a result of the incomplete combustion of petroleum, oil, coal, and wood (Takada and others, 1991). Emissions, such as from industrial processes, power plants, home heating, and vehicles, and runoff from parking lots with coal-tar-based pavement sealants are considered to be the principal sources to the environment (Van Metre and Mahler, 2010, and references therein). PAHs are of environmental concern because they are toxic to aquatic life and because many are probable or suspected human carcinogens (U.S. Environmental Protection Agency, 1993). Scoggins and others (2007) reported a loss of sensitive species and overall decline in species richness in urban streams receiving runoff from parking lots sealed with coal-tar-based sealants. Coal-tar-based pavement sealants were only recently identified as an important source of PAHs in urban environments (Mahler and others, 2005), and on average, they were the largest source of PAHs to 40 urban lakes (Van Metre and Mahler, 2010).

Concentrations of several frequently detected PAHs (phenanthrene, fluoranthene, and pyrene) were correlated with urban development in the Atlanta, Raleigh, Denver, and Milwaukee study areas (table 4-3); however, very few streams in the Portland or Dallas study areas had detectable levels of PAHs. Lack of detections indicates few sources of the compounds, dilution, or lack of delivery pathways to streams in the latter two study areas (Bryant and Goodbred, 2008). Higher concentrations of PAHs in pavement dust and urban lakes east of the Continental Divide have been linked to use patterns of coal-tar-based sealants, which are much less commonly used in the west (Van Metre and others, 2009). This spatial pattern appears to be supported by the results of this study, with the exception of the Dallas study area.

\section{Characterizing Hydrophobic Contaminants With Semipermeable Membrane Devices}

Semipermeable membrane devices (SPMDs) were used to collect the bioavailable fraction of waterborne hydrophobic contaminants that are present at low levels (Gourlay and others, 2005; Huckins and others, 1996, 2006). These devices offer an advantage over the collection and analysis of discrete water samples because SPMDs mimic the bioaccumulation of these compounds across the gill membranes of fish. These devices were deployed for a 6-week period in streams in the Portland, Atlanta, Raleigh, Denver, Dallas, and Milwaukee study areas. The relative toxicity of contaminants detected in the SPMD was determined by using the P450 bioassay, which indicates the overall toxicity for the mixture of contaminants rather than identifying which compounds were responsible for the toxicity. Results from the P450 bioassay are reported in toxic equivalents (Bryant and Goodbred, 2008). 


\title{
Contamination and Toxicity of Stream Sediments Increase With Urban Development
}

\author{
Lisa H. Nowell, Robert J. Gilliom, Nile E. Kemble, Christopher G. Ingersoll, Kathryn M. Kuivila, \\ Michelle M. Hladik, Patrick W. Moran, and Daniel L. Calhoun
}

Contaminant concentrations in stream sediments, predicted sediment toxicity, and observed toxicity to amphipods - a common group of benthic invertebrates found in streams - all generally increased with degree of watershed urban development in seven major metropolitan areas distributed across the Nation. The pyrethroid insecticide bifenthrin and, to a lesser extent, polycyclic aromatic hydrocarbons (PAHs) are estimated to be the primary contributors to sediment toxicity in the streams studied. Urban pyrethroid uses have increased since about 2000, as this class of insecticides has replaced organophosphates in applications such as home and garden use, landscaping, and termite control (Spurlock and Lee, 2008). PAH concentrations also may be increasing in urban areas, as evidenced by increasing long-term trends in sediment cores from urbanized lake basins across the United States (Van Metre and Mahler, 2005). Findings for bifenthrin illustrate how the use of a single new product in an urban environment can significantly change the toxicity of stream sediments, whereas findings for PAHs confirm the continued importance of this long-recognized class of urban contaminants.

\section{Study Design}

The contamination and toxicity of sediments were assessed for streams in six of the nine metropolitan study areas, plus an additional study area, Seattle, Washington (Moran and others, 2012). In each study area, 12 to 21 stream sites were selected to represent a gradient of urban development among the watersheds. During low-flow conditions in the late spring to late summer of 2007, one sediment sample was collected at each site by compositing surficial bed sediments from multiple depositional areas within a stream reach. Samples were analyzed for five classes of sediment contaminants: pyrethroid insecticides, a class of contaminants reported at toxic concentrations in some urban stream sediments, and four that have long been associated with urban development: metals, PAHs, polychlorinated biphenyls (PCBs), and organochlorine pesticides (Weston and others, 2005; Holmes and others, 2008).
Sediment toxicity was assessed in laboratory tests using the amphipod Hyalella azteca (exposed for 28 days) and the midge Chironomus dilutus (exposed for 10 days) and was evaluated based on comparisons to reference conditions within each study area (Kemble and others, in press; Moran and others, 2012). These are widely used test organisms that have been demonstrated in standardized toxicity tests to be predictive of effects of contaminated sediments on resident benthic communities in streams across North America. The endpoints measured were lethality, weight, and biomass.

Sediment-quality guidelines were used to predict whether or not samples are likely to be toxic based on contaminant concentrations exceeding a guideline. Sediment-quality guidelines for individual contaminants or specific groups of contaminants include Probable Effect Concentrations (PEC) from MacDonald and others (2000), similar PECs for pyrethroids estimated from toxicity data in the literature (Moran and others, 2012), and the summed Equilibrium Sediment Benchmark Toxic Units (ESBTU) for PAH mixtures (U.S. Environmental Protection Agency, 2003).

The predicted toxicity of sediment due to the combined toxicity of multiple contaminants was assessed using each sample's mean Probable Effect Concentration Quotient (PECQ). The mean PECQ for a sample weights the concentration of each contaminant in the sample by its relative toxicity by dividing the concentration of each contaminant by its PEC and then averaging these weighted concentrations for all contaminants in the sample. The mean PECQ for a sample predicts greater influence by contaminants that are more toxic, as well as by contaminants that are present at higher concentrations.

Multiple studies have shown that sediment-quality guidelines, including those based on individual PECs and mean PECQs, can accurately predict sediment toxicity in both laboratory toxicity tests and in situ invertebrate communities (Ingersoll and others, 2001, 2005). A higher likelihood of toxicity is predicted for samples that exceed individual PECs, have ESBTU values of $>1$ for PAH mixtures, or have mean PECQ values of $>0.1$ for complex contaminant mixtures (Ingersoll and others, 2001, 2009; U.S. Environmental Protection Agency, 2003). 


\section{Contaminant Occurrence and Concentrations Increased With Urban Development}

Organic contaminants were detected at almost every site (98 percent), and mixtures of multiple organic contaminants were frequent, with 10 or more contaminants detected at 78 percent of sites. PAHs were detected most often ( 98 percent of sites) and at the highest concentrations. PCBs and the organochlorine pesticides DDT, chlordane, and dieldrin each were detected at 41 to 47 percent of sites, and one or more pyrethroids were detected at 45 percent of sites (Nowell and others, in press). Of the pyrethroids, bifenthrin was detected most frequently - at 41 percent of sites and in all seven study areas (fig. 4-12), whereas cyhalothrin, permethrin, resmethrin, and cypermethrin were detected at 1 to 11 percent of sites (Kuivila and others, 2012).

Concentrations of bifenthrin, PAHs, PCBs, DDT, dieldrin, chlordane, cadmium, copper, lead, and zinc in sediments were correlated with urban development in stream watersheds.
The degree of urban development, together with the organic carbon concentration in the samples (many of these contaminants tend to accumulate in organic-rich particles and coatings), explained 30 to 70 percent of the variability in contaminant concentrations among all sites. There were significant differences, however, in contaminant concentrations among the seven study areas, even after accounting for differences in urban development and sediment organic carbon (Nowell and others, in press). PAH concentrations were significantly lower in Seattle and Salt Lake City than in other study areas. Pyrethroids were detected most frequently (77 percent of sites) and at the highest concentrations in the Dallas study area. These and other differences probably result from variations in contaminant sources among different metropolitan areas, combined with variations among the areas in climate, soils, and other factors that affect contaminant transport to streams. Overall, pyrethroid detections occurred only in watersheds containing more than 34 percent urban land or more than 28 percent agricultural land (Kuivila and others, 2012).

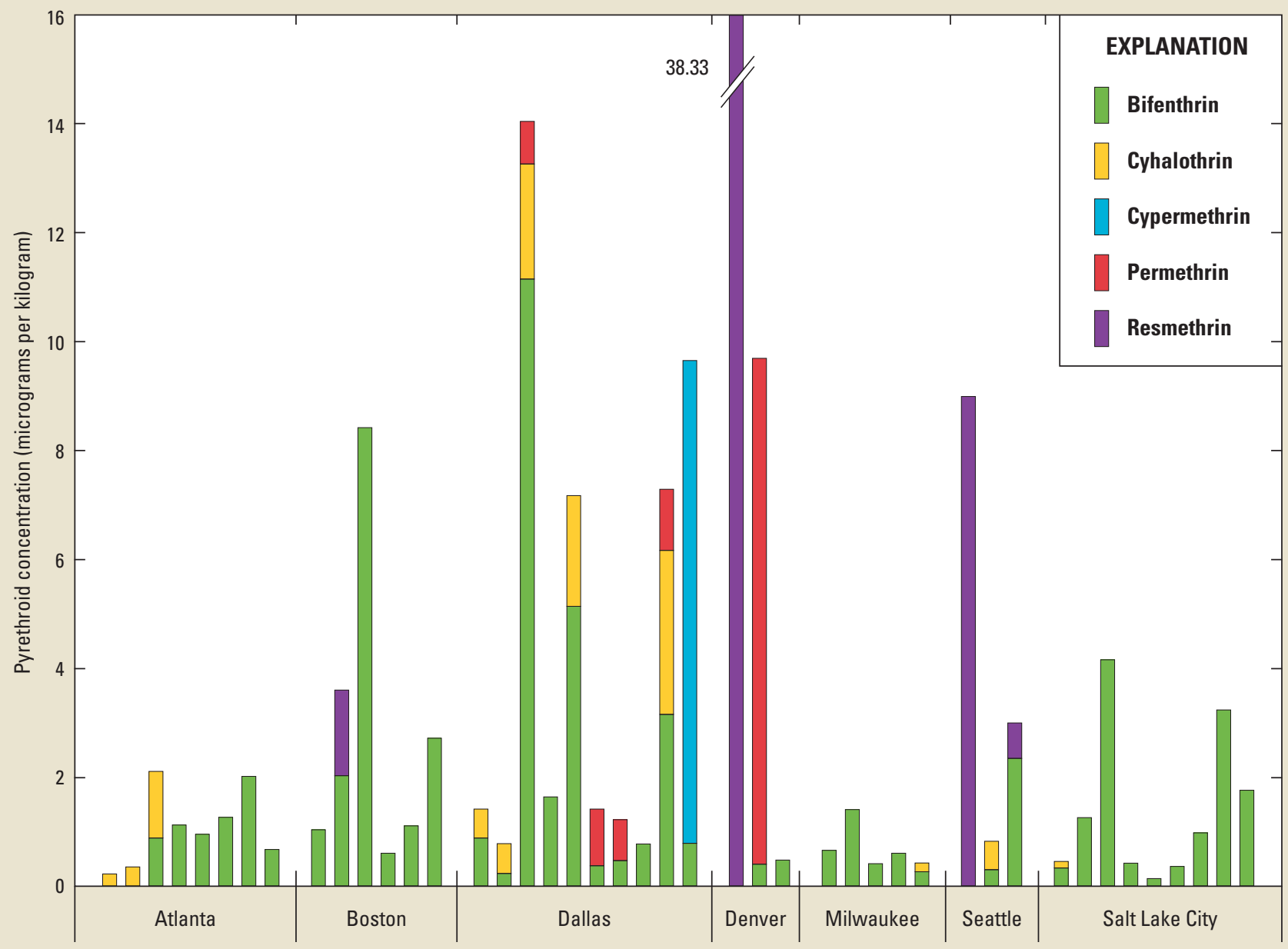

Figure 4-12. Bifenthrin was the most frequently occurring pyrethroid in all study areas, as shown by results for these 44 sites that had detections of one or more pyrethroids in sediment. Urban pyrethroid use has increased since about 2000, as this class of insecticides has replaced organophosphates in applications such as home and garden use, landscaping, and termite control. 


\section{Sediment Toxicity Increased With Urban Development}

Predicted toxicity due to the combination of all five contaminant classes, as indicated by the mean PECQ for each sample, and observed sediment toxicity to amphipods in laboratory tests, both generally increased with degree of urban development (Nowell and others, in press). Nine undeveloped sites ( $<5$ percent urban land in the watershed) had predicted toxicities below toxicity thresholds, and only one had sediment that was toxic to amphipods - this site had bifenthrin, which probably originated from agricultural land ( 65 percent of the watershed). In contrast, 32 of 55 highly urbanized sites ( $>50$ percent urban development in the watershed) exceeded one or more sediment toxicity thresholds, and 21 of the 55 sites had sediment that was toxic to amphipods in laboratory tests.

When all five contaminant classes were included in the toxicity predictions using the mean PECQ, samples from 83 percent of sites were correctly predicted to be toxic, or nontoxic, to amphipods (fig. 4-13; Kemble and others, in press). The reasonable agreement between predicted and observed toxicity supports the application of mean PECQs

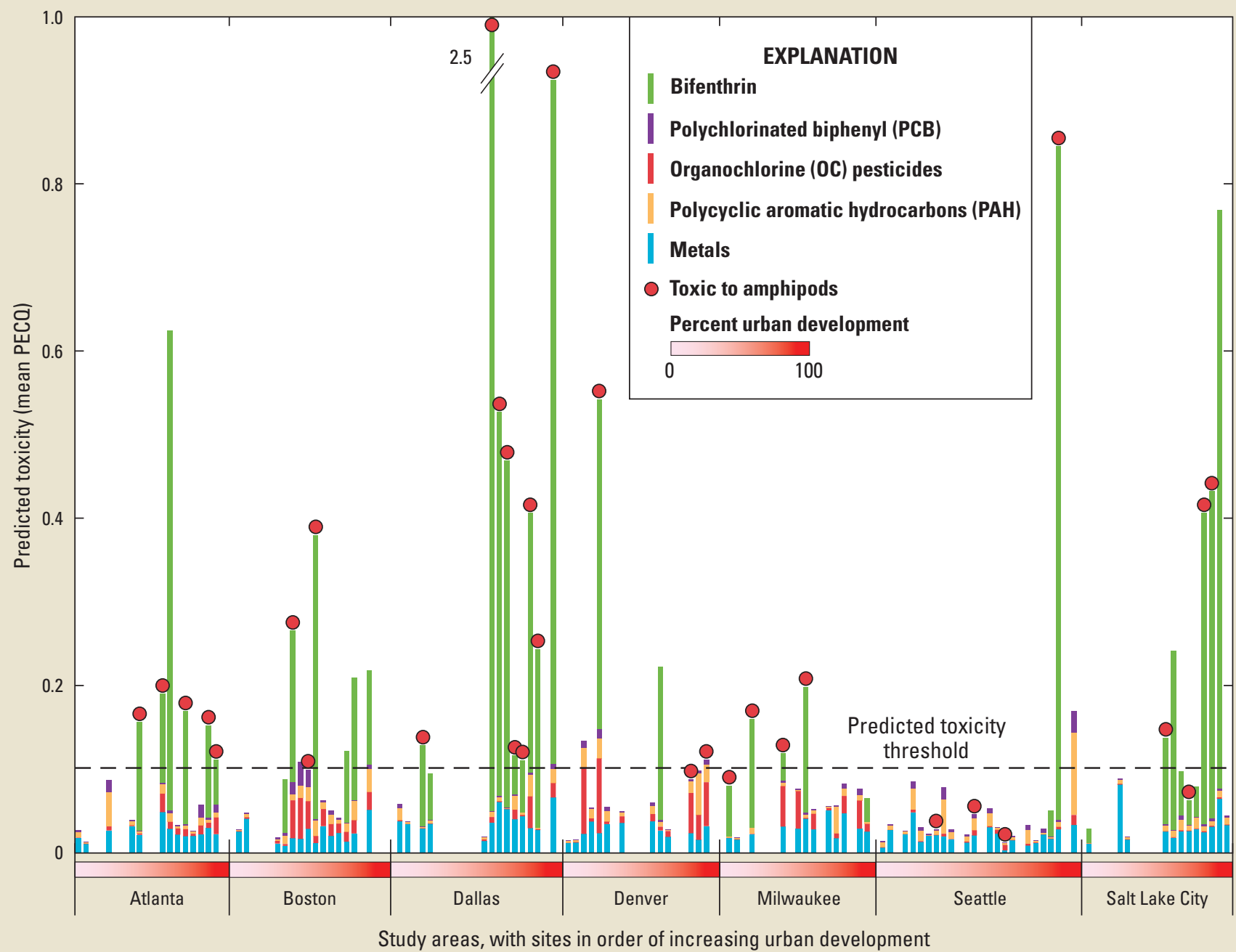

Figure 4-13. The predicted toxicity due to all measured contaminants, as well as their relative contributions, varied across the seven urban study areas, but the highest predicted toxicity was generally found at sites with over 40 percent urban development. The pyrethroid insecticide bifenthrin generally contributed the largest percentage of predicted toxicity, based on the mean probable effect concentration quotient (mean PECQ) for five contaminant classes. The mean PECQ values shown are based on five contaminant classes, with bifenthrin representing the pyrethroids. Samples were predicted to be toxic if their mean PECQ values exceeded the toxicity threshold (shown as the dashed black line). This predicted indicator of toxicity closely matched observed amphipod toxicity (indicated by red dots). Sediment samples from 83 percent of sites were correctly predicted by the mean PECQ (in relation to the predicted toxicity threshold of 0.1 ) to be toxic, or nontoxic, to amphipods. 
and related sediment-quality guidelines to explain likely causes of toxicity in this study. Of 32 sites with observed toxicity, 27 were predicted to be toxic because they exceeded one or more guidelines, including 25 predicted to be toxic based on the samples with a mean PECQ exceeding the 0.1 toxicity threshold. Bifenthrin was the dominant contributor to predicted toxicity at 23 sites, including 11 where the individual PEC for bifenthrin also was exceeded. Eight of the 25 sites predicted to be toxic based on the mean PECQs also exceeded the ESBTU guideline for PAHs. In addition, two sites with observed toxicity were predicted to be toxic because PAHs exceeded the ESBTU guideline, even though the sample PECQ was below the predicted toxicity threshold.

The particular importance of bifenthrin is supported by both amphipod and midge results from toxicity tests. Amphipod survival decreased significantly as the bifenthrin concentration increased (fig. 4-14; Kemble and others, in press; Kuivila and others, 2012). In contrast to amphipods, the limited toxicity observed with midges was poorly predicted by the sediment toxicity thresholds for the contaminants measured, including pyrethroids. This is consistent with pyrethroids being a primary cause of amphipod toxicity because midges are less sensitive to pyrethroids than are amphipods (Amweg and others, 2006; Maul and others, 2008). Compared to other studies, both the incidence of amphipod toxicity and bifenthrin concentrations were lower than reported for sediments from urban streams and storm drains in California, Texas, and Illinois (Weston and others, 2005; Holmes and others, 2008; Hintzen and others, 2009; Ding and others, 2010) but higher than in urban streams (without storm sewers) in Tennessee (Amweg and others, 2006).

Overall, albeit with substantial variation among metropolitan areas and limited to the contaminants measured in this study, bifenthrin and to a lesser extent PAHs are estimated to be the primary contributors to increased sediment toxicity in the streams as urban development in the watersheds increased. Although the other contaminants measured may have contributed to toxicity, their concentrations were usually below sediment toxicity thresholds. For five sites, the contaminants detected could not account for the observed toxicity to amphipods, suggesting that other contaminants not measured in this study may also have contributed to sediment toxicity.
Figure 4-14. Survival of the amphipod Hyalella azteca decreased significantly as the bifenthrin concentration increased (Spearman rank correlation at a 0.05 significance level). Amphipod survival was adjusted for reference conditions, and bifenthrin concentrations are divided by the bifenthrin PEC, so that values greater than 1.0 indicate predicted toxicity. Red symbols represent samples found to be significantly toxic relative to reference conditions within a study area, based on analysis of all measured endpoints. Blue symbols indicate samples that were not toxic. Toxicity observed in some sediments with low bifenthrin concentrations $(<1.0$ bifenthrin PECQ) indicates other contaminants may have contributed to the toxicity.

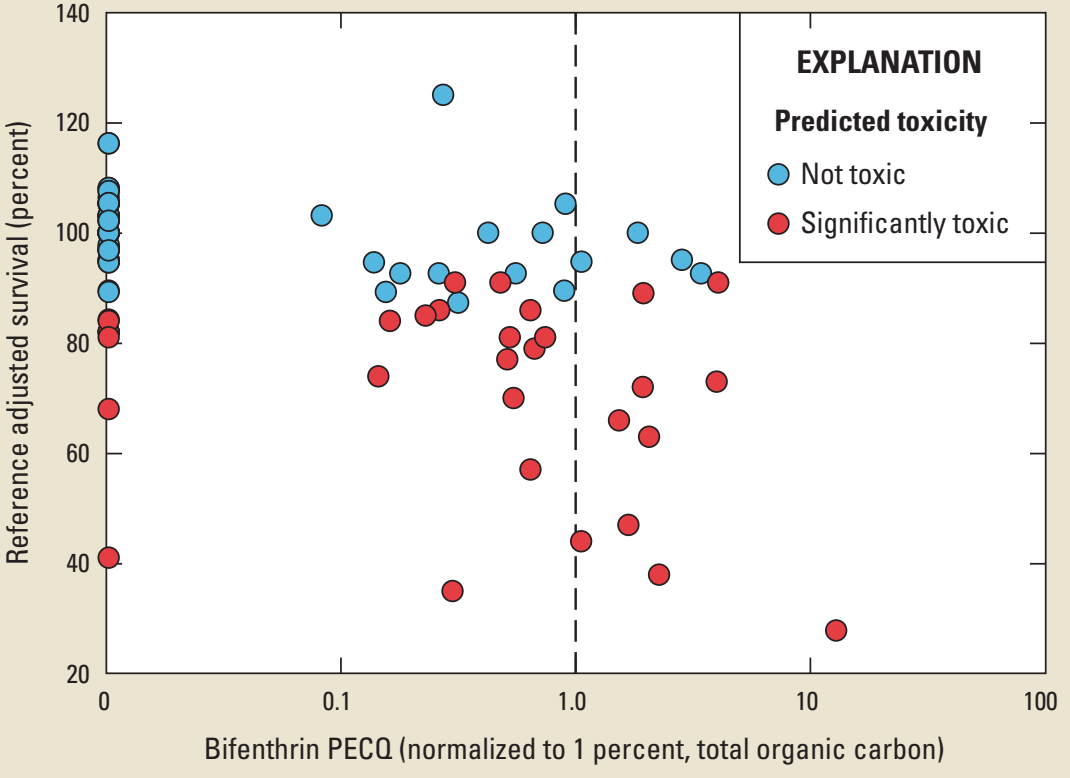





\section{Ohapter 5 \\ The Response of Biological Communities to Urban Development}

“... The most direct and effective measure of the integrity of a water body is the status of its living systems. These systems are the product of millennia of adapting to climatic, geological, chemical, and biological factors. Their very existence integrates everything that has happened where they live, as well as what has happened upstream and upland. [The integrity of running waters] depends on processes spanning many temporal and spatial scales." (Karr and Chu, 1999)
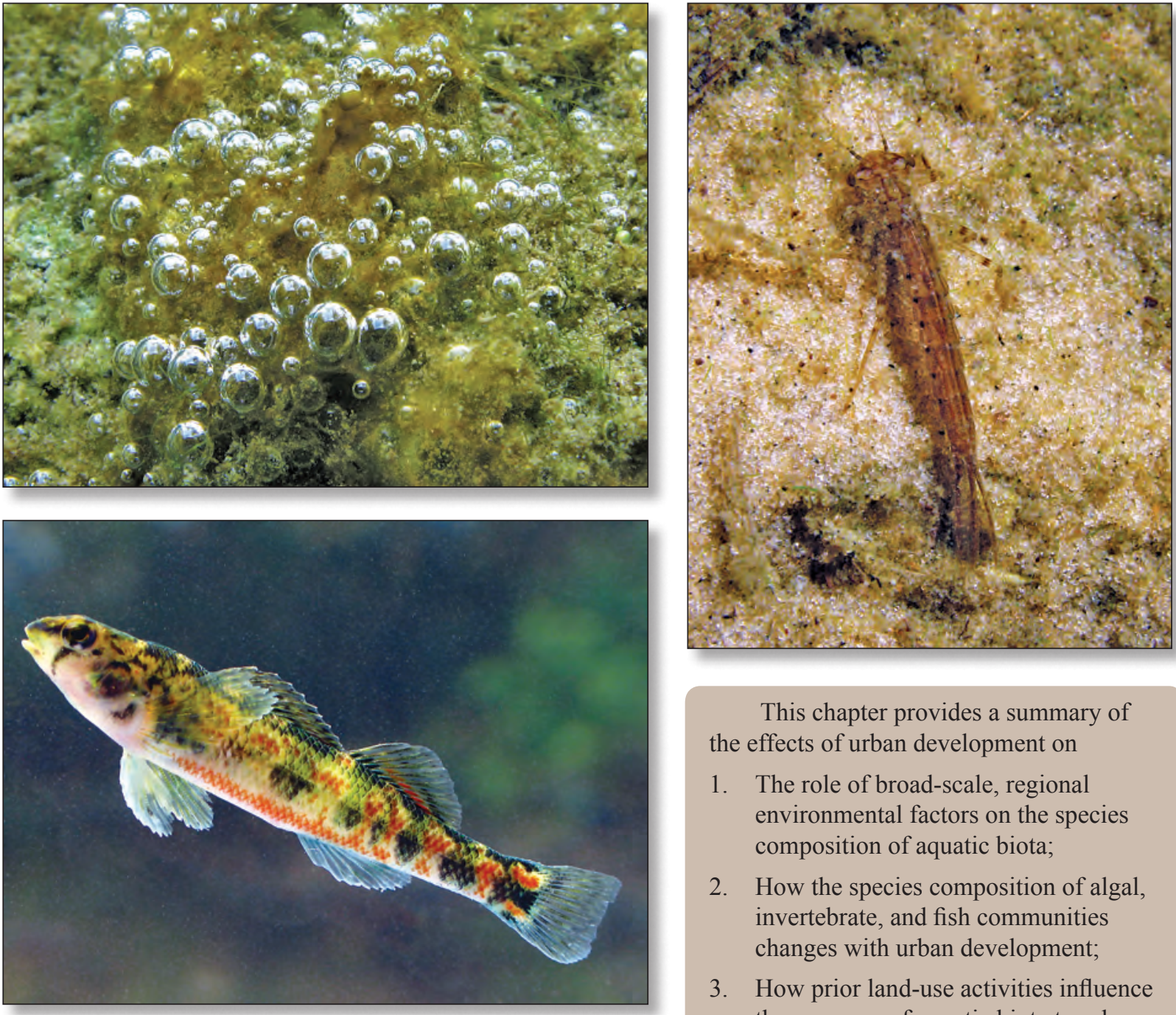

This chapter provides a summary of the effects of urban development on

1. The role of broad-scale, regional environmental factors on the species composition of aquatic biota;

2. How the species composition of algal, invertebrate, and fish communities changes with urban development;

3. How prior land-use activities influence the response of aquatic biota to urban development; and

Three biological communities were assessed in this investigation: algal, invertebrate, and fish.

4. The level of urban development that results in a measurable change to biological communities. 
Algal, invertebrate, and fish communities function as an ensemble within a stream, and a well-functioning stream ecosystem has diverse, sustainable biological communities (see sidebar, Aquatic Biota Terms and Definitions). Urban development alters stream ecosystem processes, disrupts stream ecosystem functions, and causes changes in the composition of biological communities. For example, urban development can alter hydrologic patterns and lead to an increase in streamflow flashiness or prolonged low-flow conditions. The altered streamflow can influence stream habitat and stream chemistry. These cumulative physical changes can "stress" the biological community and lead to changes in the species composition. A shift in species composition can alter ecosystem processes and function, such as the feeding structure among organisms in the foodweb.

\section{Broad-Scale, Regional Factors Exert a Strong Influence on the Composition of Biological Communities}

Regional environmental factors, such as climate, geology, topography, and land cover, strongly influence the species composition of the biological communities in streams. Regardless of the level of urban development in a watershed, the biological communities that were sampled throughout streams in a study area maintained certain characteristics of species composition that were associated with the region. For example, the invertebrate data collected from stream sites in all nine study areas were analyzed together to show how sites would group in patterns based on the relative degree of resemblance (differences and similarities) in their invertebrate communities. The most noticeable result was that the sites did not group by levels of urban development but rather grouped by their respective geographic region (fig. 5-1). Furthermore, as shown by the close groupings in figure 5-1, the sites in the Raleigh and Atlanta study areas are similar with respect to their biological communities because they are both in the Piedmont ecoregion. Conversely, the invertebrate communities in Dallas and Milwaukee are vastly different, as shown by the distance between the sites in these two groups (fig. 5-1); this result is expected because these study areas are in different ecoregions that reflect differences in regional environmental factors such as temperature, geology, and land cover.

Regional environmental factors were also the primary influence on algal and fish species composition, especially when dominant species or groups within those communities were evaluated. Overall, the finding that biological communities were distinct across the nine study areas coincidentally illustrates the importance of the approach used in the USGS investigation to constrain natural variability among sites by selecting watersheds for each study area from within a single Level III Ecoregion (Omernik, 1987, explained in chapter 3). The strength of these regional geographic influences on the species that make up biological communities demonstrates why biotic responses to urban development tend to differ across the country. Because the species composition of a biological community differs from region to region, metrics used to measure a biotic response should take into account regionally endemic species (species prevalent in a particular region) that are sensitive to environmental disturbances typical for the region. Preserving the integrity of aquatic biological communities characteristic of a region, therefore, depends on understanding how urban development affects the regionally defined environmental factors and processes at the watershed scale.

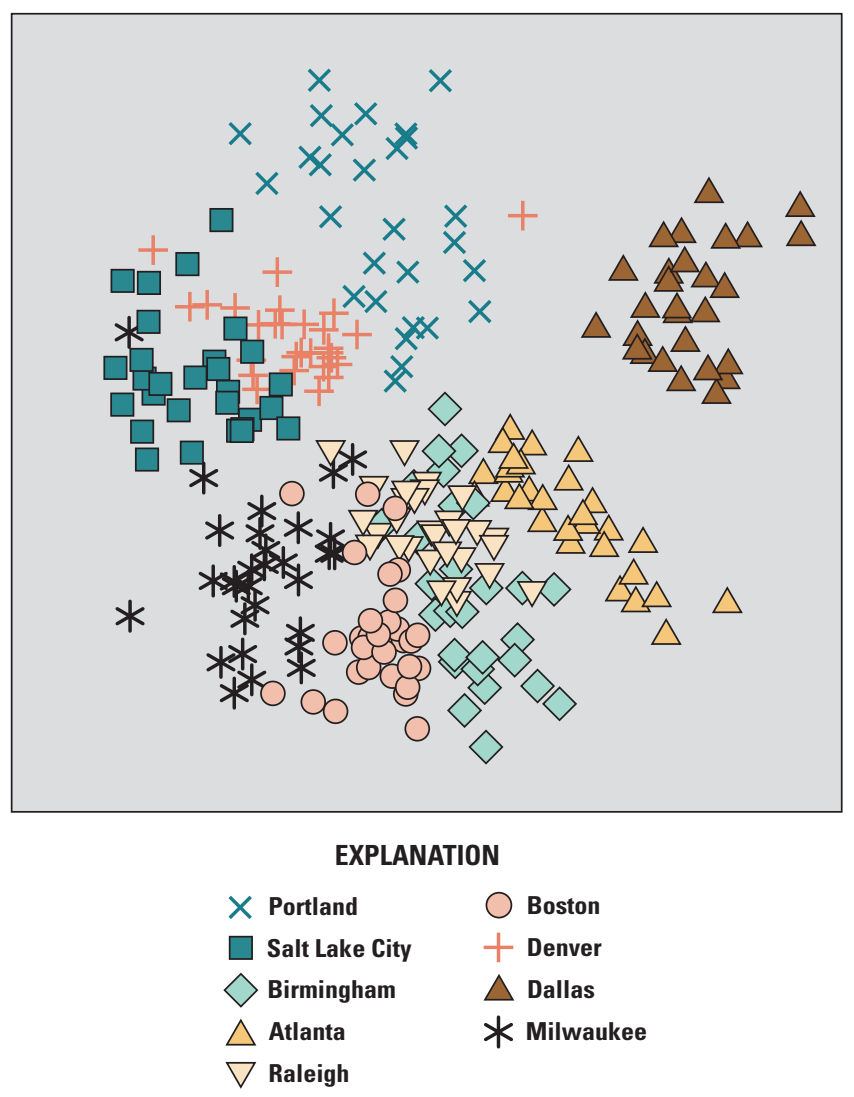

Figure 5-1. The regional pattern of variability in aquatic biota (invertebrates, in this example) is indicative of the dominant influence of broad-scale, regional factors, such as climate, geology, topography, and land cover, in shaping the composition of biological communities. The dimensions of the figure are relative (no scale), where the distance between any two symbols indicates the relative degree of resemblance in the invertebrate communities between the two sites. For example, the upper right quadrant is dominated by the Dallas study area, indicating that the invertebrate communities at these sites more closely resemble each other than do communities at sites in other study areas. 


\section{Aquatic Biota Terms and Definitions}

Several common biological terms are used in this report to describe, in more general terms, different levels of classification and groupings of organisms. Biota refers to the ensemble of all aquatic organisms present at a stream location. The term species refers to different groups of related individuals within a community, even when biological data were reported at taxonomic levels other than species. For example, some invertebrates could be identified only to genus because certain diagnostic features for species-level identification were indistinct. Even though the term taxa is more accurate when referring collectively to organisms at different taxonomic levels, the term species is used in this report because it is generally more familiar. The term community is used herein to refer to a general group of organisms, either algae, invertebrates, or fish, that interact within the physical area defined by the stream reach. Other reports have used the term "biological community" to include the ensemble of biotic groups (algae, invertebrates, and fish) at a particular location. Richness of a community, as defined in this report, refers to the number of different species in a stream reach. Richness is important when discussing the biodiversity of a community, which depends on the number of different species in a community as well as the relative number of individual organisms in each species. A diverse community, therefore, has a high species richness and the number of individuals of each species is relatively even.

Community composition scores and biological condition metrics, two complementary types of response measures, were used to determine how a particular biological community has been altered by urban development. A set of community composition scores was calculated for each biological community to represent overall changes in the types of species and the number of organisms in the community. These scores were calculated by using a technique called multivariate ordination, which looks at the differences and similarities in the species composition of a community across all sites in a study area. The difference between any two community composition scores indicates the relative degree of resemblance between the biological communities at the two sites, which then can be related to the difference in urban development between the two sites. The primary advantage of using community composition scores is that they are highly effective at showing how strongly an entire biological community changes with urban development.

Biological condition metrics generally focus on particular species that are likely to be affected by urban development. These metrics are regarded as "indicators" because they are based on certain species in a community that respond to specific environmental stressors, such as degraded water quality, loss of habitat, or changes in streamflow patterns. Brook trout are an example of a sensitive species that are particularly sensitive to environmental stressors. Common carp are an example of a tolerant species that often tolerate high levels of environmental stressors.

The community composition scores and biological condition metrics are calculated from information about multiple species, and they can indicate the overall response of a biological community to urban-related stressors. Although the response of a biological community can be continuous over the urban-development gradient, it is also important to account for the response of individual species of interest. Understanding the response curve of individual species is important because it can indicate the range of values along a stressor gradient within which the conditions for the survival of that species are optimal (fig. 5-2). A metric that will indicate the level of urban development at which a species declines in abundance can be monitored if the protection of the species is of concern in a watershed.

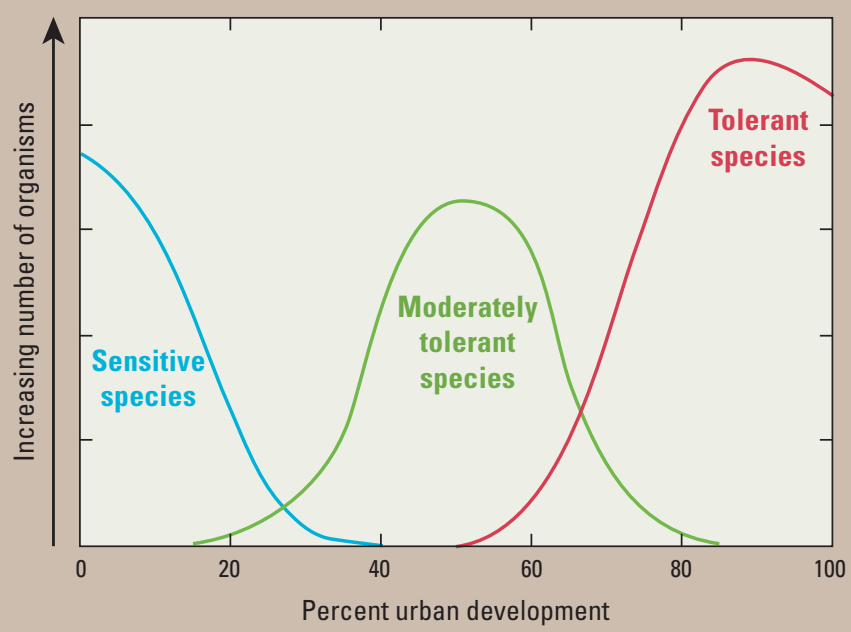

Figure 5-2. In this idealized example, the curves represent the ranges along an urban gradient where three species occur. The highest point along each curve represents the species optimum, or the most favored conditions for the species, which supports the greatest number of organisms. Sensitive species are most abundant in undisturbed areas and decline rapidly with the onset of development. Moderately tolerant species are most abundant at intermediate levels of development. Tolerant species can still occur in very high numbers at higher levels of urban development, even after unfavorable conditions have eliminated or reduced the sensitive and moderately tolerant species. 


\section{Algal, Invertebrate, and Fish Communities Respond Differently to Urban Development}

Urban development affected one or more biological communities either moderately or strongly in eight of the nine study areas, based on the response of the community composition scores (explained in the sidebar, Aquatic Biota Terms and Definitions) to urban development (table 5-1; Brown and others, 2009; Coles and others, 2009; Cuffney and others, 2010). The response of the biota was generally stronger in areas where urban development occurred on forested rather than agricultural lands; the reason for this difference is described below. Algal and fish communities showed a moderate to strong change in composition in four of the nine study areas, although Portland and Boston were the only areas where a moderate or strong relation was seen for all community types. Invertebrate communities appeared to be most sensitive to the effects of urban development by showing moderate or strong changes in community composition in eight of the nine study areas (Denver being the exception).

Generally, the change in the community composition scores with increasing level of urban development was associated with a loss of species that are sensitive to stressors such as contaminants, in-stream habitat destruction, or increased streamflow flashiness. The continuing change in community composition over higher levels of urban development suggests that the loss of aquatic species could result in a diminished ecological function of the stream by reducing the complexity of its foodweb and the level of resilience against natural and human-induced disturbances.

Whereas community composition scores describe overall changes in the community composition, biological condition metrics were used to assess changes in certain species in response to multiple stressors related to urban development (table 5-2). Pollution-sensitive diatoms typically were prevalent at rural sites and decreased with urban development. For example, the Milwaukee study area showed a 50-percent decline in the abundance of pollution-sensitive diatoms between the least and most developed watersheds, whereas the abundance of diatoms that are tolerant of high salinity increased with urban development. Overall, these biological condition metrics reflect degradation in the algal community as a consequence of changes in water quality that can occur with urban development.

The response of invertebrate communities to urban development was more consistent than for algae and fish, as shown in tables 5-1 and 5-2. The response of invertebrate communities in regions where land cover was primarily forested prior to development was typically strong, characterized by a general decline in numbers of sensitive species. These results are important when setting management goals in a particular region, especially in relation to predevelopment land cover.

The response of fish to urban development was more than that of algae or invertebrates because fish populations and distributions can be affected by a broader range of geographical factors, even within a single region. Changes in fish communities were associated with two biological condition metrics that reflect fish habitat preferences (table 5-2). The number of fish species that prefer gravel

Table 5-1. Relations between community composition scores and urban development for biological communities. The strength of a relation indicates the extent that species composition of the community was altered by urban development. Aquatic invertebrate communities appeared to be most sensitive to the effects of urban development by showing moderate or strong changes in community composition in eight of the nine study areas (Denver being the exception). Algal and fish communities showed a moderate-to-strong change in composition in four of the nine study areas.

\begin{tabular}{|c|cccccc|c|}
\hline $\begin{array}{c}\text { Biological } \\
\text { community }\end{array}$ & Portland & Salt Lake City & Borest-to-urban gradient & & Agriculture-to-urban gradient \\
Birmingam & Atlanta & Raleigh & Boston & Denver \\
Dallas & Milwaukee
\end{tabular}

Relation to urban development Decreases with urban development Strong (rho $\geq 0.7$ )

Moderate (rho 0.5 to 0.69 ) Weak (rho 0.4 to 0.49 ) 
substrate tended to decline with urban development; the loss of gravel habitat can result from sediment deposition or the loss of gravel riffles. Conversely, a weak but opposite response was seen in the Salt Lake City study area where gravel substrate appeared to become more prevalent with urban development because of geomorphologic differences between the low-intensity urban areas (along steep-gradient mountain streams) and high-intensity urban areas (along broad, low-gradient streams).

Urban development in some areas led to an increase in fish species, such as bass and sunfish that tend to spawn in low-velocity, pool habitats and use complex nests to provide a higher level of parental care after spawning. This response might seem counterintuitive because it is associating a complex development trait with urban development; however, these types of species have adapted to pool habitats in part by fanning the nests with their fins to keep the nest free of fine sediment and to maintain adequate oxygen levels. The weak decline in complex nesting species in the Birmingham study area likely represents a general decline in overall community composition with urban development because fish preferring gravel substrate also decline.

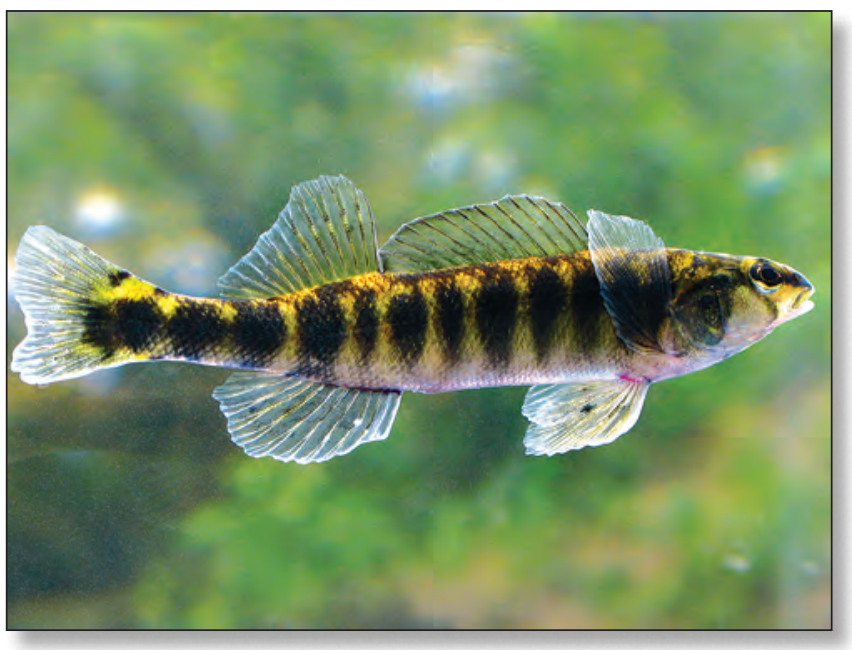

The blackbanded darter (Percina nigrofasciata) is an example of a species that prefers gravel substrates.

Table 5-2. Changes to the invertebrate communities in streams as a consequence of urban development were more consistent than changes to algal and fish communities. The response of invertebrate communities in regions where land cover was primarily forested prior to development was typically strong, characterized by a general decline in numbers of sensitive species and, in most cases, with the occurrence of other species that are more tolerant to stressors. In contrast, there was generally no response in the biological communities in streams in the Denver, Dallas, and Milwaukee study areas where urban development occurred on agricultural land.

\begin{tabular}{|c|c|c|c|c|c|c|c|c|c|c|}
\hline & \multirow{2}{*}{ Biological condition metrics } & \multicolumn{6}{|c|}{ Forest-to-urban gradient } & \multicolumn{3}{|c|}{ Agriculture-to-urban gradient } \\
\hline & & Portland & Salt Lake City & Birmingham & Atlanta & Raleigh & Boston & Denver & Dallas & Milwaukee \\
\hline \multirow{2}{*}{ 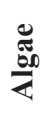 } & Pollution-sensitive diatoms ${ }^{1}$ & - & & - & - & - & & - & - & \\
\hline & Salinity-tolerant diatoms ${ }^{2}$ & - & $\Delta$ & $\Delta$ & - & & & - & - & \\
\hline \multirow{2}{*}{ 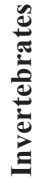 } & $\begin{array}{l}\text { Ephemeroptera, Plecoptera, } \\
\text { and Trichoptera richness }\end{array}$ & & & & & & & - & - & - \\
\hline & Community tolerance index ${ }^{4}$ & & & & & & & - & - & - \\
\hline \multirow{2}{*}{$\frac{5}{\frac{2}{2}}$} & Gravel substrate $^{5}$ & - & $\Delta$ & & 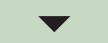 & - & & - & - & - \\
\hline & Complex nester 6 & & $\Delta$ & $\nabla$ & & - & & 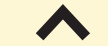 & - & - \\
\hline
\end{tabular}

${ }^{1}$ Percentage of diatoms in the algal community that do not survive in polluted systems.

${ }^{2}$ Percentage of diatoms in the algal community that are tolerant of high-salinity conditions.

${ }^{3}$ Total number of mayfly, stonefly, and caddisfly species, many of which are sensitive to stressors.

${ }^{4}$ Relative tolerance of community to stressors, based on average of tolerance values for all species.

${ }^{5}$ Percentage of fish in the community that prefer clean, gravel substrate free of sand and silt.

${ }^{6}$ Percentage of fish in the community that provide some level of parental care after spawning.

Relation to urban development

Increases with urban development
Decreases with urban development
1.

A Moderate (rho 0.5 to 0.69 )

- Weak (rho 0.4 to 0.49 ) 
These community-specific findings underscore the advantage of evaluating more than one biological community when assessing the effects of disturbances to aquatic systems. Because the life cycles of algae, fish, and invertebrates differ, their respective communities generally respond differently to stressors arising from changes in physical and chemical ecosystem processes. Therefore, the three communities typically do not show a unified response to disturbances from urban development (see sidebar, Species Richness of Invertebrates and Diatoms Can Respond Differently to Urban Development). Differing responses can provide important clues about the types of stressors that are present in the ecosystem and can indicate potential avenues for management actions.

\section{Prior Land-Use Activities Can Affect How Aquatic Biota Respond to Urban Development}

The response of aquatic biological communities to urban development in the Denver, Dallas, and Milwaukee study areas was not as strong as in the other study areas (tables 5-1, 5-2). In these three study areas, agricultural land was converted to urban uses, whereas in the other six study areas, urban development generally occurred on land that was either forested or shrubland. Thus, even at the low levels of urban development, the biological communities in the Denver, Dallas, and Milwaukee study areas were already degraded by agricultural land uses, resulting in a weak response to urban development. Comparing the responses of algal, invertebrate, and fish communities in Boston and Denver illustrates the difference in response patterns (fig. 5-3). The response of biological communities to urban development in the Denver study areas also appeared to be confounded by extensive hydrologic modifications associated with reservoirs, diversions and canals, and interbasin transfers of water.

The predevelopment influence of agricultural activities on biological communities is perhaps most evident in the general lack of response of biological condition metrics that indicate the loss of sensitive species, such as a decline in EPT richness (table 5-2). This biological condition metric represents the sum of insect species in the orders Ephemeroptera (mayflies), Plecoptera (stoneflies), and Trichoptera (caddisflies), referred to as EPT, many of which
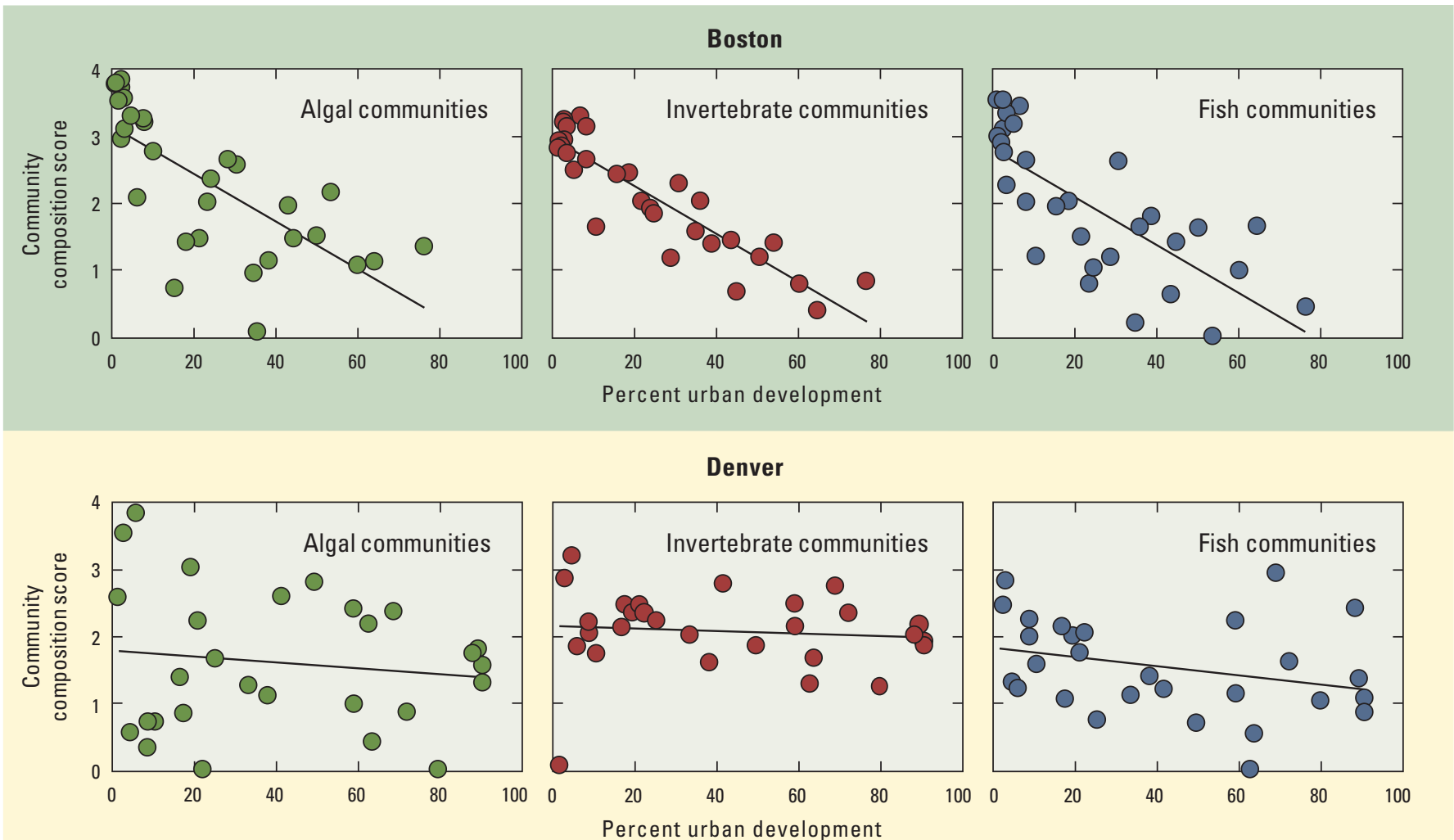

Figure 5-3. The importance of predevelopment land cover is evident in the differences in the response of algal, invertebrate, and fish communities to urban development in two regions of the country. Strong negative responses to urban development were observed in the Boston study area, whereas the responses in the Denver study area were relatively weak. 


\section{Species Richness of Invertebrates and Diatoms Can Respond Differently to Urban Development}

A decrease in species richness following urban development generally indicates that one or more stressors have reduced the capacity of the stream to support sensitive species. An example of this type of response is shown in figure 5-4 A. Invertebrate species richness declined over all stages of urban development in the Raleigh study area. Exceptions can occur where low invertebrate richness is associated with undisturbed streams, such as in areas naturally low in nutrients that tend to have a less complex foodweb with few species (Mabe, 2007). The onset of urban development under these conditions can lead to the assimilation of nutrients entering the stream into the foodweb, thereby increasing invertebrate species richness over the short term.

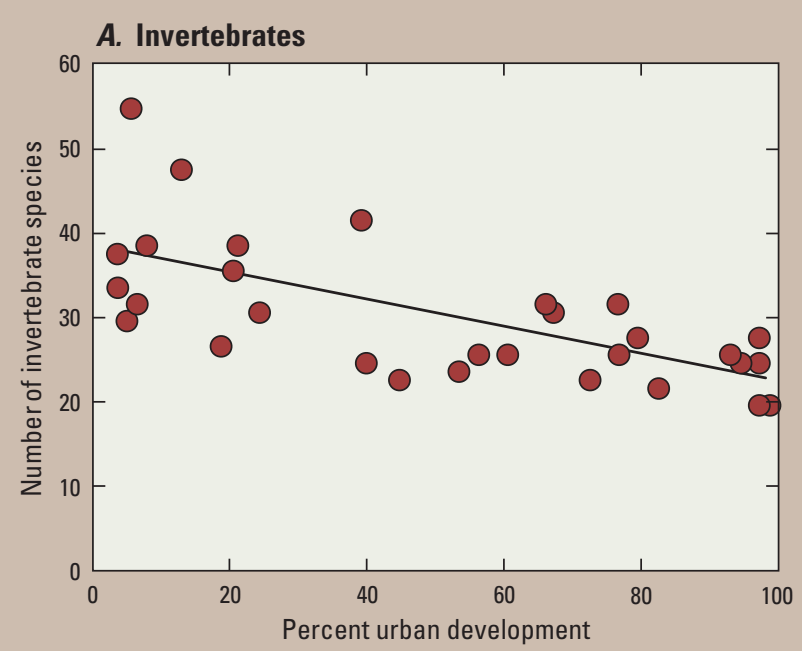

In contrast to the invertebrate response to urban development, diatom richness can increase at the low to medium levels of urban development, often in association with increased nutrient concentrations. Diatom richness increased with urban development in the Portland, Salt Lake City, Raleigh, and Boston study areas (Coles and others, 2009). In the Raleigh study area, the number of diatom species increased at low to medium levels of urban development, but decreased at higher levels (fig. 5-4B). This decrease was not associated with a decrease in nutrient concentrations, however. Other factors associated with a decline in water quality, such as increased contaminants or sediment, likely contributed to the decrease in the number of diatom species.

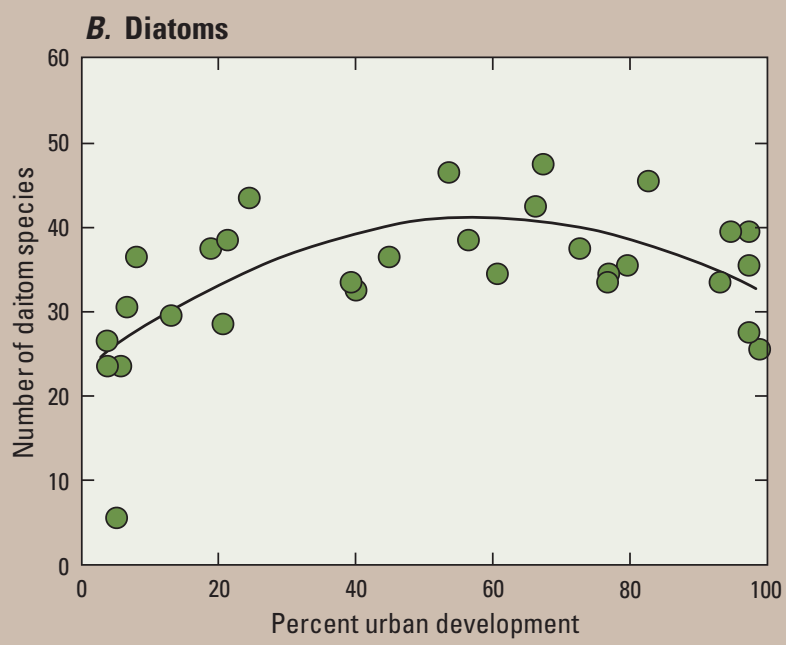

Figure 5-4. Species richness for $(A)$ invertebrates and $(B)$ diatoms in the Raleigh study area responded differently to urban development. The invertebrate species richness steadily declined with urban development, whereas the diatom richness increased over the initial stages of urban development but then leveled off and declined as urban development increased. 
are sensitive to environmental degradation. Species composition of the invertebrate communities in the Dallas, Denver, and Milwaukee study areas showed little variability across the urban gradient. The invertebrate communities in these study areas generally lacked the more sensitive EPT species compared to study areas in which urban development occurred in forested watersheds (fig. 5-5). Most of the changes in invertebrate communities in the forested regions resulted from a loss of the more sensitive insect species, which corresponded to a stronger response in the community composition scores and the biological condition metrics.

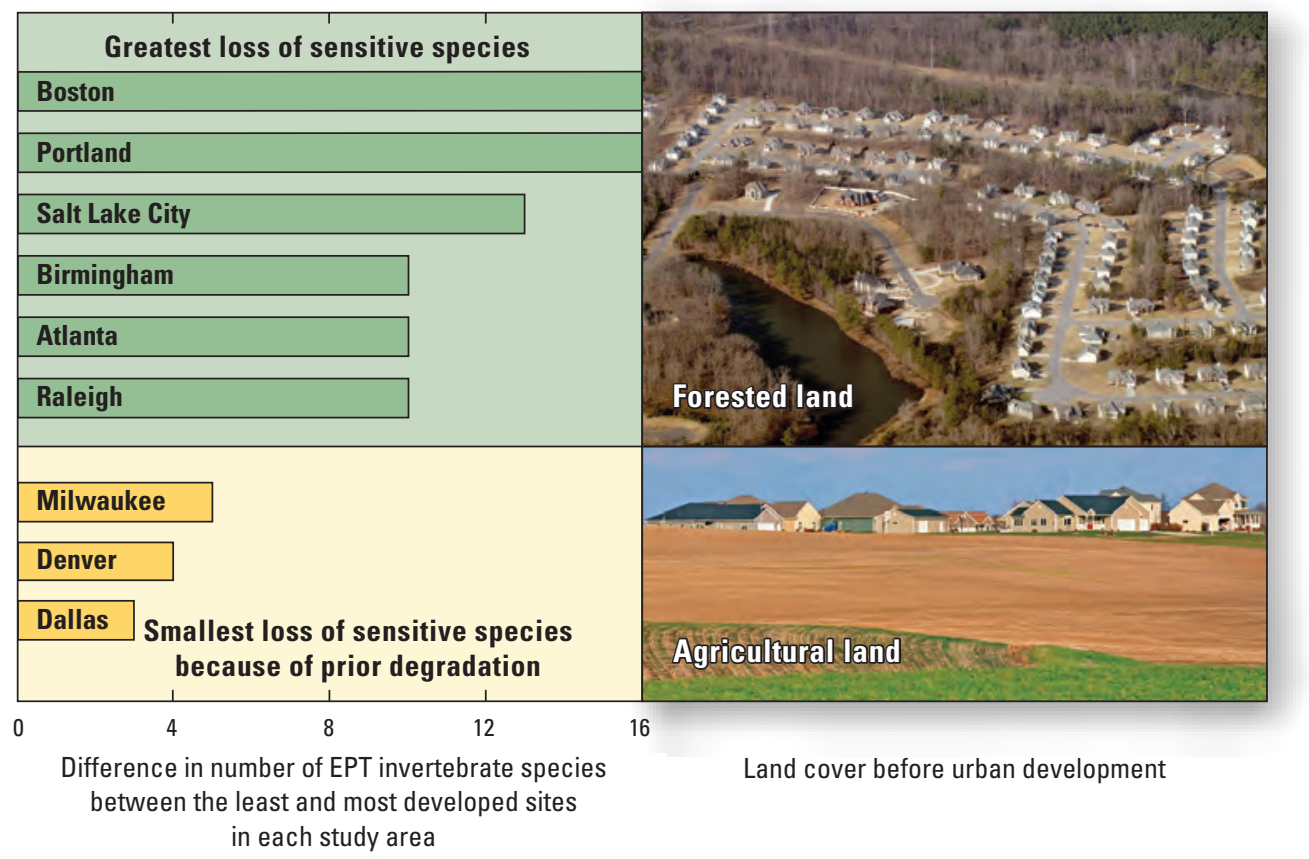

Figure 5-5. The loss of Ephemeroptera, Plecoptera, and Trichoptera (EPT) species was greater when urban development occurred on forested land than on agricultural land. Prior to urban development, streams in forested watersheds had more EPT species-many of which were sensitive to disturbances - than streams in agricultural watersheds. Therefore, streams in forested watersheds had more EPT species to lose as urban development began to occur.

Species of Ephemeroptera ( $A$, mayflies), Plecoptera ( $B$, stoneflies), and Trichoptera $(C$, caddisflies) are cumulatively referred to as EPT, and declining EPT values can indicate a loss of species that are sensitive to environmental degradation. (Photographs from the Society of Freshwater Science, formerly North American Benthological Society (NABS), http://www.benthos.org)

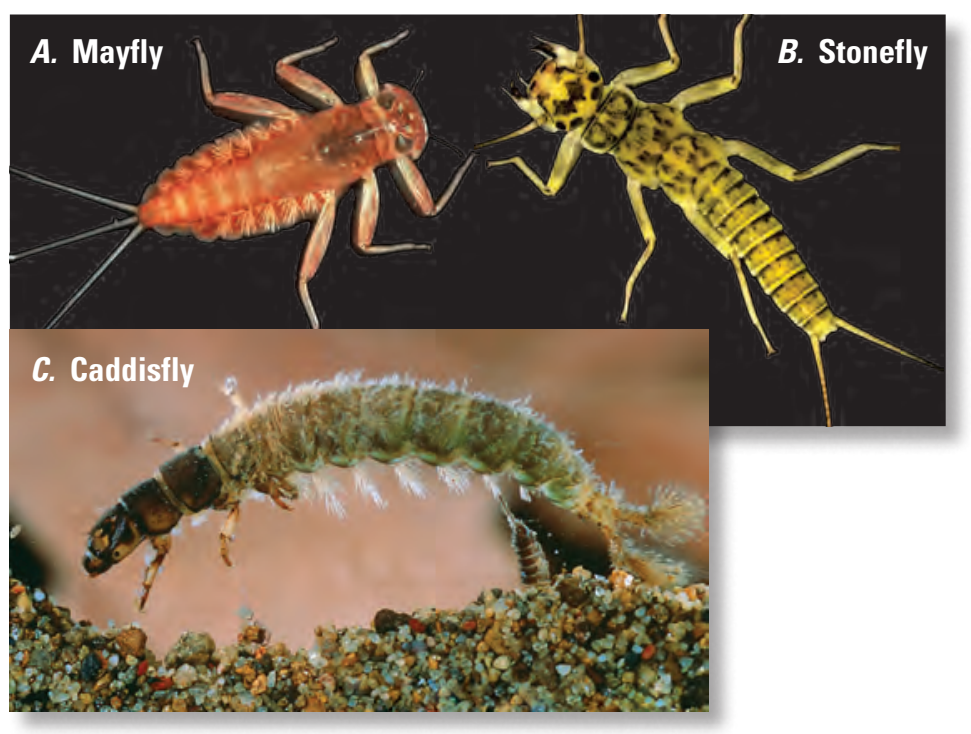




\section{A Loss of Sensitive Invertebrate Species Was the Most Consistent Biological Response to Urban Development}

The most definitive change in any of the biological communities associated with urban development was a loss of sensitive invertebrate species and a shift to species that are more pollution tolerant (table 5-2). EPT richness decreased in all study areas where urban development occurred in forested watersheds. Because many EPT species are sensitive to environmental degradation, it is not surprising that when urban development reached 50 percent in the six forested study areas, the number of EPT species decreased to about half the number present prior to urban development.

The rate at which EPT species were lost was different across the country, even in study areas within the same general region. For example, the rate of species loss was greater in the Atlanta study area compared to the Raleigh study area (fig. 5-6). These rates reflect differences in EPT species endemic to the regions and their sensitivities to stressors (prior land use and changes in stream chemistry, hydrology, or habitat) affected by urban development.

Another biological condition metric that indicated sensitive species were lost with urban development is the community tolerance index, which represents an average of the pollution-tolerance values for all species in the invertebrate community. This index, which ranges from 0 (most sensitive) to 10 (most tolerant), increased strongly with urban development in all previously forested study areas (table 5-2). The index values in Boston increased more than 50 percent (from about 4 to about 6.5) along the urban gradient (fig. 5-7). This increase indicates a change in species composition of the invertebrate community, where sensitive species were lost and the percentage of pollution-tolerant invertebrate species (typically non-insect invertebrates, such as isopods and leeches) increased.
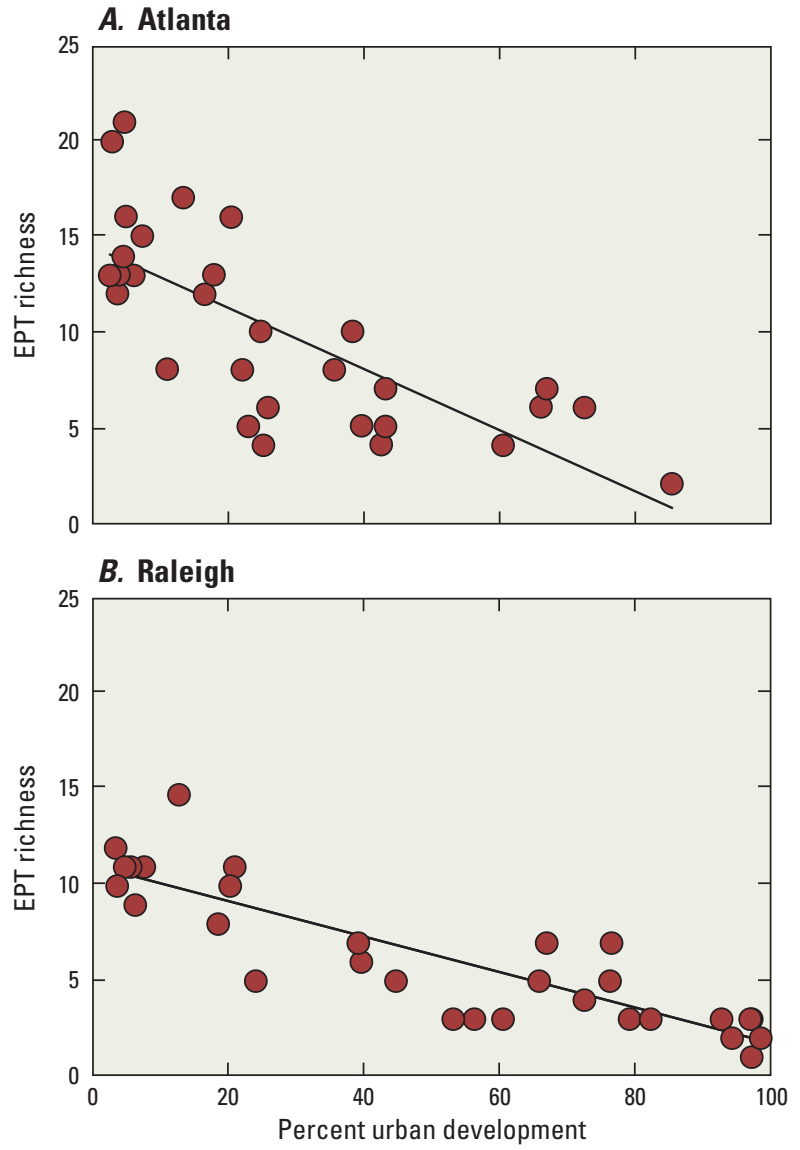

Figure 5-6. Urban development resulted in the loss of Ephemeroptera, Plecoptera, and Trichoptera (EPT) species, many of which are sensitive to contaminants, changes in streamflow, and other stressors. These examples from the Atlanta and Raleigh study areas show EPT richness decreasing with urban development, but the rate of loss, seen by the slope of the line, was greater in Atlanta.
Figure 5-7. The upward trend in the community tolerance index in the Boston study area indicates that sensitive species were lost and the percentage of pollutiontolerant invertebrate species increased as levels of urban development increased.
Invertebrate communities

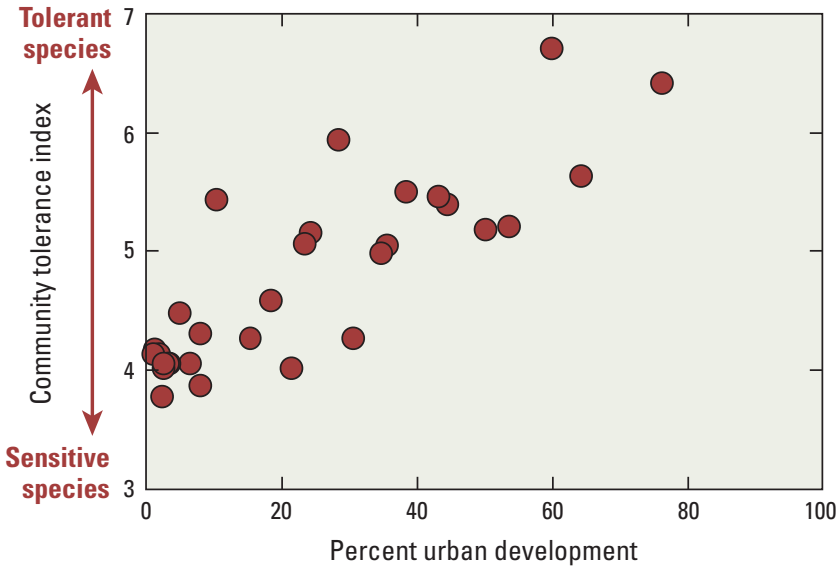




\section{Invertebrate Communities Begin to Degrade at the Earliest Stages of Urban Development}

The degradation of invertebrate communities began at the earliest levels of urban development in the six study areas in which urban development occurred in forested watersheds (table 5-1; see sidebar, Aquatic Biota Have No "Safe Zone" in Urban Development). The shape or form of the invertebrate response also can provide insight into how the stream ecosystem changes with urban development. It has been assumed that aquatic biota are resistant to degradation at low levels of urban development and that the community would begin to degrade after a resistance threshold is reached at some higher level of urban development (fig. 5-8A). However, the invertebrate community in most areas of the country declined as soon as the percentage of developed land in a watershed increased from background levels, with no indication of resistance to degradation (fig. 5-8B).

Two possible conclusions can be drawn from this decline in the invertebrate community. First, certain species within the communities are highly sensitive to the physical and chemical conditions of the stream. Even at low levels of urban development, small changes in these conditions can result in a loss of sensitive species thereby degrading the invertebrate community. Second, some prior degradation of the biological communities could have occurred from predevelopment disturbances at the low end of the urban gradient (for example, legacy effects caused by historical land use, such as agricultural activity during the 19th and early 20th centuries).

The lack of resistance in biological responses is an important finding for resource managers and indicates that no assumptions can be made with regard to a "safe zone" of urban development. The continuous biological response over the entire urban gradient also has strong implications for management. An exhaustion threshold would imply that the ecosystem function was depleted to the point that biological communities were no longer capable of responding to physical and chemical changes in the stream. The absence of an exhaustion threshold suggests stream rehabilitation efforts could improve the biological condition of a stream, regardless of the point along the urban-development gradient at which rehabilitation is implemented. USGS urban studies did not examine streams in some of the most intense urban settings such as those that are lined with concrete. The likelihood of an exhaustion threshold in the biotic response exists in areas of very intense development.
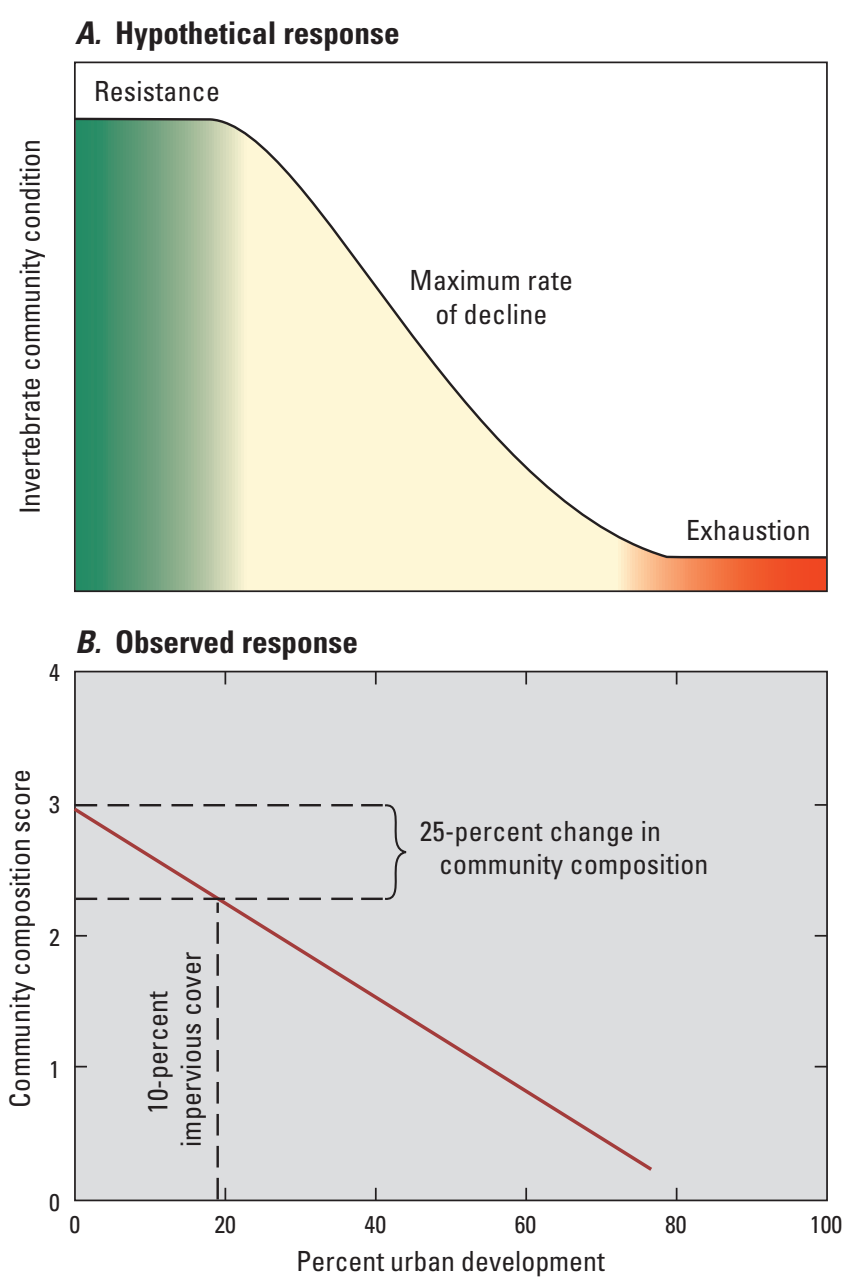

Figure 5-8. A frequent assumption is $(A)$ that biological communities are resistant to change at low levels of urban development. Then, as levels of urban development increase, a period of rapid degradation of the community condition occurs and then ends in a period of exhaustion, when no further change occurs to the community composition. The observed response $(B)$ of invertebrate communities to urban development in the Boston study area differed from the hypothetical response. At 10-percent impervious cover (just under 20-percent urban development), the community composition changed by about 25 percent. 


\section{Aquatic Biota Have No “Safe Zone" in Urban Development}

A frequent assumption regarding the effects of impervious cover on biological communities is that these communities would not be affected as long as the areas of impervious cover remained below about 10 percent of the watershed (Schueler, 1994). Because of the immediate decline in invertebrate condition at low levels of urban development and the strong relation between impervious cover and urban development (see chapter 3, fig. 3-3), it is unlikely that a safe zone of impervious cover can be defined.

The 10-percent impervious cover guideline has been reformulated, in part because of the results of this investigation. The most important change is that the relation of impervious cover to stream quality now is expressed as a cone rather than as a straight line (Schueler and others, 2009; fig. 5-9). The cone shown in figure 5-9 indicates that stream-quality responses at impervious cover of less than 10 percent can vary broadly from excellent to poor, and that sharply defined thresholds are probably rare. The cone-shaped response is intended to avoid the perception that watersheds in which impervious cover is less than 10 percent of the total watershed area always will be associated with good or excellent stream quality.

"Stream protection and management are top priorities of state and local officials. These USGS findings remind us of the unintended consequences that urban development can have on our aquatic resources. The information has been very useful in helping us revise scientific models related to imperviousness, which are used by watershed managers across the Nation to predict and manage future impacts of imperviousness on urban streams." (Tom Schueler, Chesapeake Stormwater Network, written commun., 2011.)

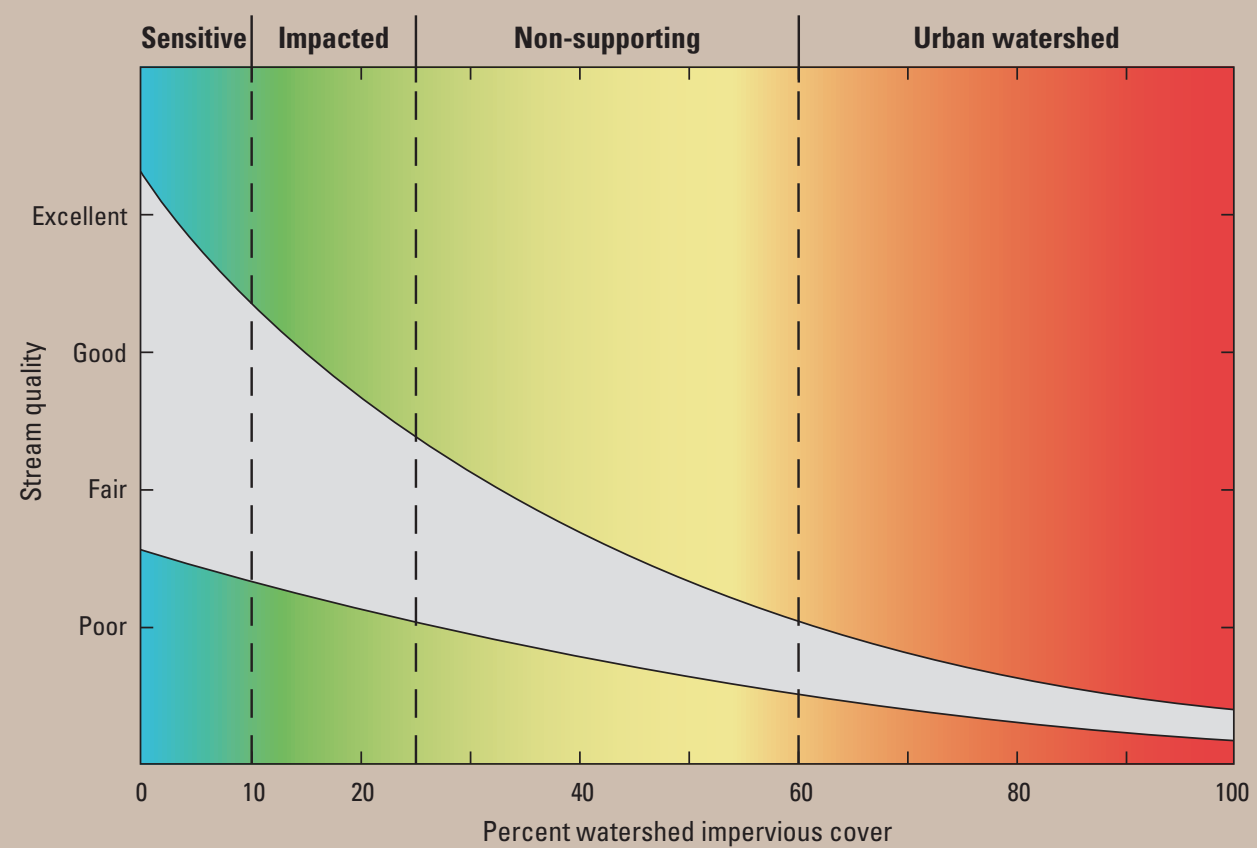

Figure 5-9. A reformulated impervious cover model indicates that adverse effects on stream condition can occur below 10-percent impervious cover and that the degree of effect can vary widely. This variability is due to such factors as predevelopment land cover. (Modified from Schueler and others, 2009.) 



\section{Chaptes o \\ Understanding Complexity in Stream Ecosystem Response to Urban Development}

The previous chapters have described how the physical, chemical, and biological factors associated with stream ecosystems are affected differently by urban development, and the extent to which these factors respond depends on the region where urban development is occurring. Consequently, interactions of multiple physical and chemical stressors can make it challenging to determine which ones are principally responsible for changes to the aquatic biological communities in an urbanizing watershed.

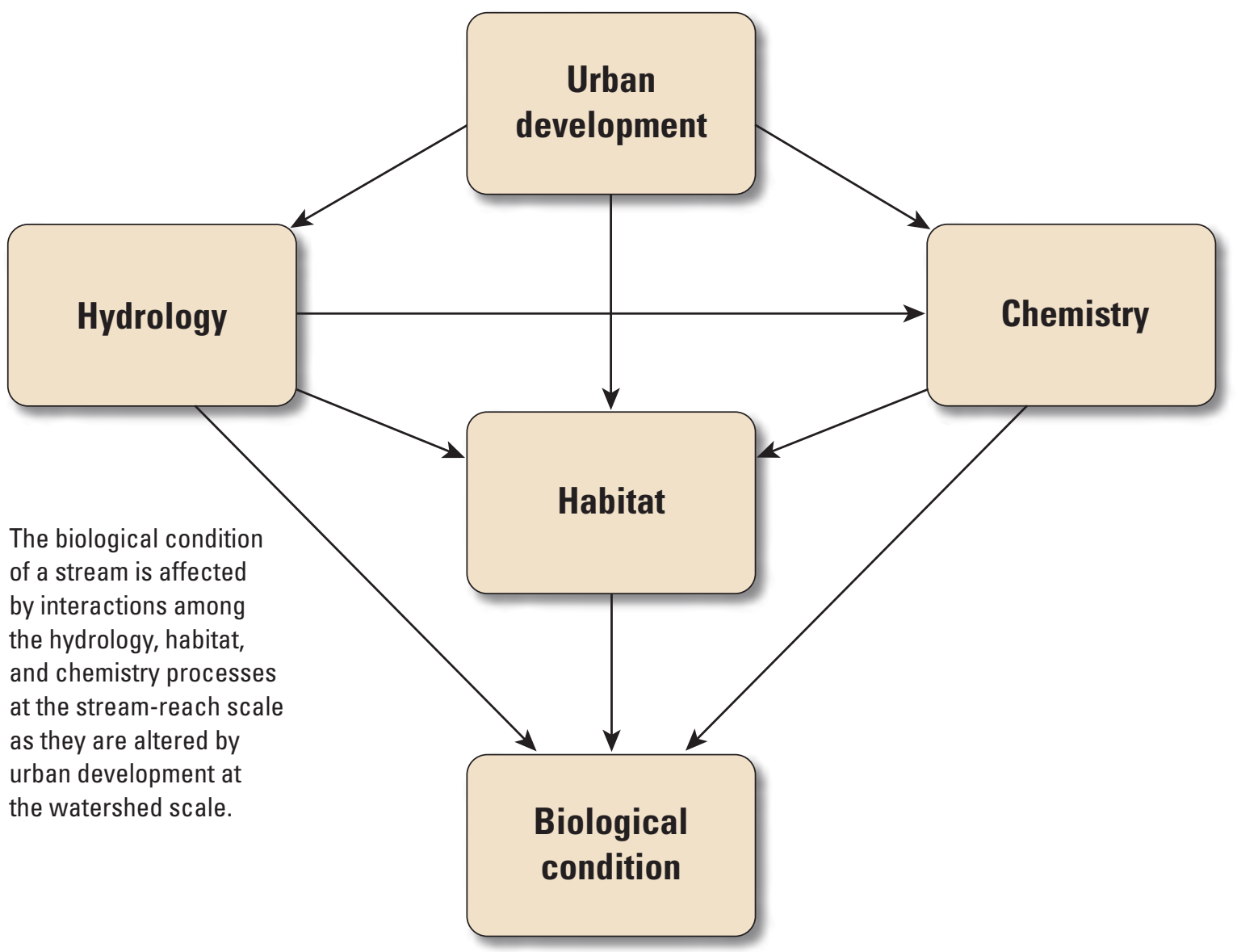

This chapter integrates results from earlier chapters, indicates how regional factors and multiple stressors affect the response of aquatic biota to urban development, and demonstrates an analytical tool that can be used to evaluate the effects of alternative management approaches designed to protect stream health. 
Understanding the effects of urban development on stream ecosystems requires consideration of the interrelations among multiple environmental components rather than treating each one as an isolated entity (Baily, 1996). This required a more complex approach than that employed in earlier chapters, where stream hydrology, habitat, chemistry, and aquatic biota were related only to urban development as a single stressor. Previous discussions recognized possible interactions across multiple components and the importance of spatial scale at which each component operated. Although this approach is convenient for discussions of responses of the individual components in urbanizing systems, the components are not independent and can interact in ways that make it difficult to predict effects of urban development on the stream ecosystem as a whole (fig. 6-1).

The USGS findings indicate that stream reachlevel components are affected by regional and watershed characteristics, including historical and current land-use patterns (Cuffney and others, 2011). Although urban development in a watershed affects the physical and chemical factors within a stream reach, how these changes occur and how they ultimately affect aquatic biota depend on regional environmental characteristics such as climate, soils, and historical land-use patterns.

Stream degradation in response to urban development can rarely be attributed to a single factor, and the relative importance of some stressors can vary along the urban gradient. For example, a fish community can be affected by both hydrology and contaminants. Changes in hydrology may be most important in the early stages of urban development, whereas contaminants might become more important stressors in areas with more extensive urban development.

Environmental conditions in specific stream reaches are determined by an interconnected set of regional, watershed, and reach-level factors. The reach-level factors are functionally linked so that a change in any one factor may bring about corresponding changes to the others.

\section{Response of Aquatic Biota to Urban Development Is Influenced by Regional Environmental Factors}

Previous chapters described how agricultural activities prior to urban development in a watershed can degrade the biological condition of streams so that the effects of development are less obvious than when development occurs in forested areas. However, understanding the reasons why predevelopment land cover can influence biological responses is crucial when developing effective methods for measuring and mitigating the effects of urban development.

When landscape features are altered on a regional scale, biological communities can begin losing sensitive species that require specific environmental conditions that exist in the natural landscape. Chapter 5 explains that the loss of sensitive EPT species was greater when urban development occurred
Figure 6-1. Urban stream ecosystems include processes operating at regional, watershed, and stream-reach scales. Understanding how a stream ecosystem responds to management actions designed to mitigate the effects of urban development requires an understanding of how processes are linked across spatial scales and how processes can interact within a given level (indicated by dashed lines for streamreach processes).

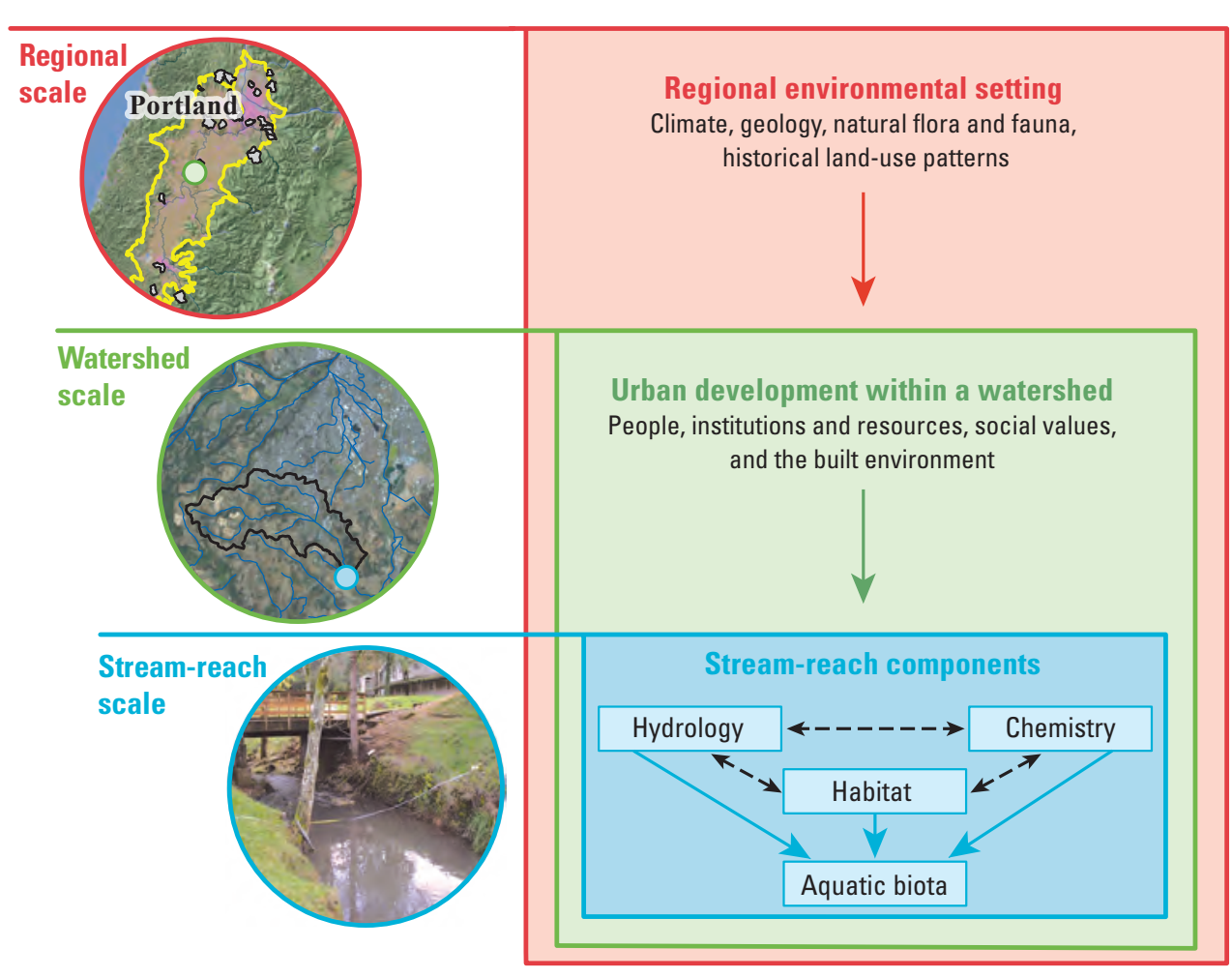


in forested landscapes than when development occurred on agricultural land (table 5-2; fig. 5-5). Similarly, an increase in community tolerance index scores with the onset of urban development in the six forested study areas is consistent with the loss of sensitive invertebrates in these areas, while the lack of response in the Denver, Dallas, and Milwaukee study areas is consistent with the idea that agricultural land cover reduced the number of sensitive invertebrate species and favored tolerant species before urban development began.

As previously described, the response of the invertebrate community to urban development depends in part on regional environmental factors, such as climate, and the extent that the landscape was altered prior to urban development (see sidebar, Understanding How Regional-Level Factors Affect Biological Response; Kashuba and others, 2010; Cuffney and others, 2011). Because differences in regional environmental factors define stream ecosystem conditions,

Figure 6-2. The response of biota to urban development can differ from region to region, with differences in responses associated with regional environmental factors such as historical land use and climate. The value of the community tolerance index prior to urban development was sensitive to both predevelopment land uses and the average annual air temperature for the region. As air temperature increases, the proportion of tolerant species increases regardless of land use. However, compared to forested areas, streams in agricultural areas tend to have fewer sensitive species and, thus, biological communities with a higher percentage of tolerant species (indicated by the yellow line positioned higher than the green line). the regional factors also influence the relative number of sensitive species that occur in streams even before the onset of urban development. For example, prior to urban development, the initial value of the community tolerance index was higher (indicating fewer sensitive species) in regions where the average annual air temperature was warmer and where the land cover was agriculture (fig. 6-2). Prior to the onset of urban development in either forested or agricultural regions, stream invertebrate communities in cooler regions commonly display a lower average tolerance to various stressors than communities in warmer regions. Furthermore, consistent with interpretations in previous chapters, predevelopment agricultural land uses eliminated some sensitive species before the onset of urban development. Comprehensively, these results indicate that streams in warmer regions where agriculture is the predevelopment land cover can be expected to have invertebrate communities with the fewest sensitive species.

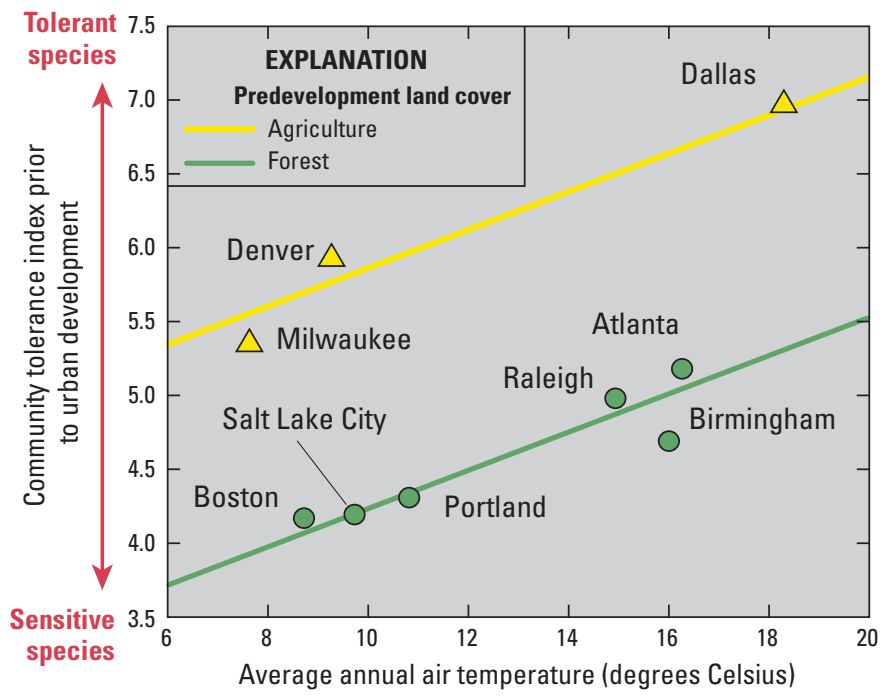

\section{Understanding How Regional-Level Factors Affect Biological Response}

A multilevel hierarchical model was used to explore how invertebrate and algal communities responded to urban development across the nine study areas, while simultaneously accounting for the effects of important regional-level factors, including climate, geology, and predevelopment agricultural land cover (Kashuba and others, 2010; Cuffney and others, 2011). The model was used to compare the response of biota to urban development among study areas by evaluating regression parameters that characterize the relation between biological condition metrics and urban development. The regression parameters included the regression slope, which is the rate of change in the biological condition metric in response to urban development, and the regression intercept, which is the projected value of the metric before any urban development has occurred (predevelopment). Separate hierarchical tiers of the same model were then developed for the relations of the slope and intercept with regional factors. Differences in the slope and intercept between regions were explained by regional factors within a second tier of the same model. These analyses evaluated invertebrate metrics, including the community composition score, EPT richness, and community tolerance index; algal metrics, including pollution-sensitive diatoms and salinity-tolerant diatoms; and regional-level factors, including mean annual precipitation, mean annual air temperature, percentage of clay soils, and antecedent agriculture (as percentage and categorized as low or high). The results indicated that regional-level factors were essential in explaining the response to urban development in all cases. 
Multiple Stressors Influence How Aquatic Biota Respond to Urban Development

An overview of the physical, chemical, and biological data shows that, with the exception of some contaminants, few environmental stressors respond to urban development in a common way across all study areas. Additionally, the community composition scores for algae, invertebrates, or fish were not strongly related with a common set of stressors in all study areas. This qualitative conclusion is consistent with results from more detailed analyses of algal, invertebrate, and fish data collected in these studies and with many other studies that have been described in the literature (Brown and others, 2009; Coles and others, 2009; Cuffney and others 2010).

No single factor was universally important in explaining responses to urban development across all the study areas or biological communities, based on the associations of the three biological communities with 11 reach-scale factors (fig. 6-3; see sidebar, Modeling Reach-Scale Stressors). Water temperature, however, appeared to be a factor that

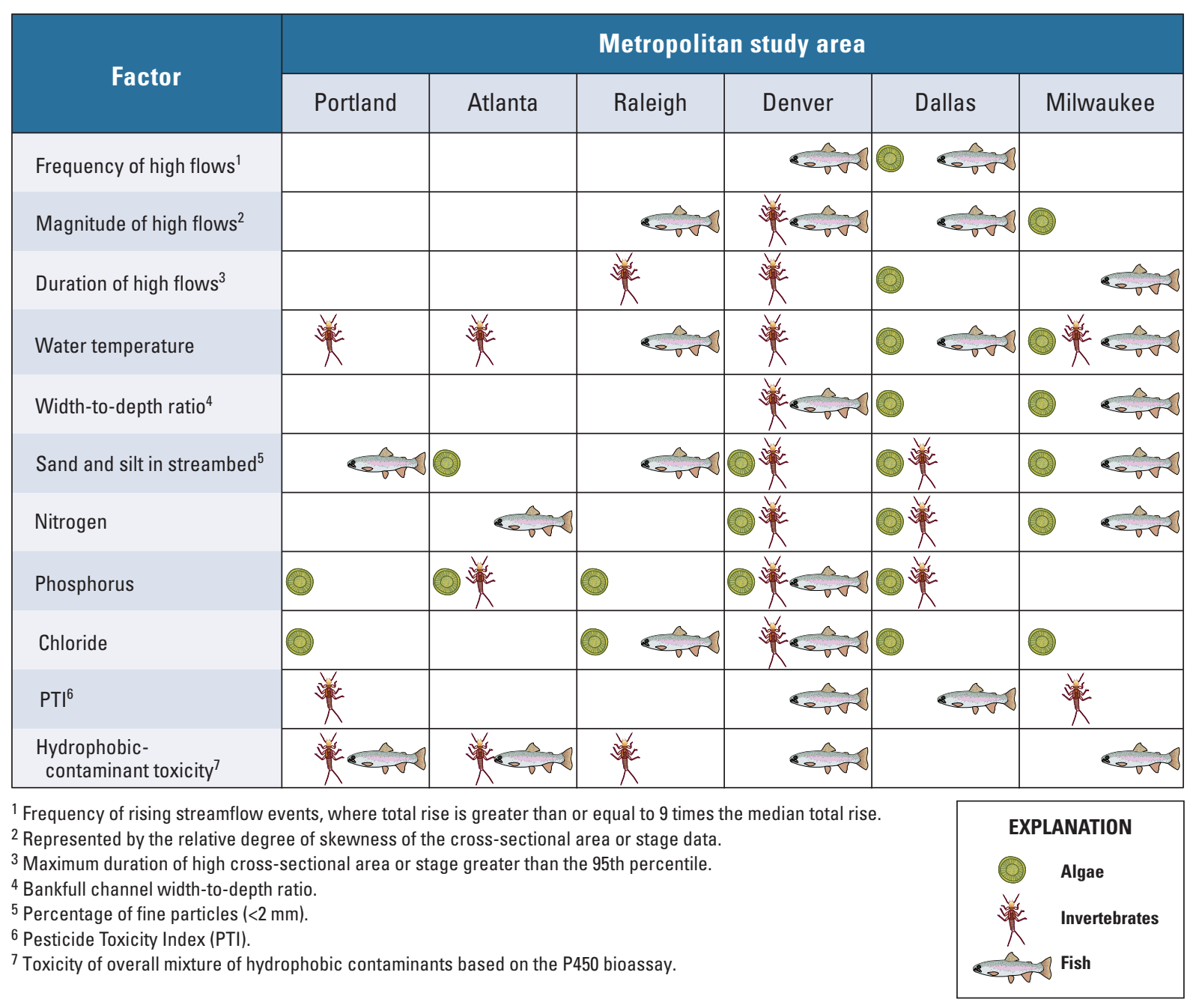

Figure 6-3. The three biological communities generally responded to different factors within a region, but no single factor fully explained the responses to urban development across all the study areas or biological communities. For example, depending on the study area, the algal response was related to concentrations of phosphorus or nitrogen or both factors, whereas the fish response was related to an increase in either water temperature or hydrophobiccontaminant toxicity or both factors. In all study areas, water temperature and the percentage of sand and silt in the streambed were important to at least one of the biological communities. 
was important to at least one biological community in every study area (see sidebar, An Increase in Stream Temperatures Associated With Urban Development Can Lead to a Decline in Biological Communities). The three biological communities generally responded to different factors within a region, supporting the idea that groups of biota respond to changes in the environment in different ways. Single-factor and two-factor models were derived to investigate various combinations of reach-scale factors that were most strongly associated with changes in the biological communities. Two-factor models of the relation between reach-scale factors and biota were generally stronger than single-factor models. Occasionally, more than one two-factor model was plausible for the same biological community in a study area, which can indicate interaction between factors. Confidence in the models is relatively low in study areas where many physical and chemical factors are associated with changes in a particular community because no strong relations could be identified with a concise set of factors. This result suggests that additional study is needed to identify the most important factors affecting that particular biological community. Confidence in the models of biotic response is higher in study areas where only a few factors are associated with a particular community, and consequently, most alternative models can be rejected. Therefore, when fewer alternative models are indicated, greater confidence can be placed in the factors included in those models as the factors most strongly related to changes in community composition.

Although these results highlight the need to consider multiple stressors in assessing stream ecosystems, only two-factor models were able to be evaluated because of limited sample size within each study area. Furthermore, models did not examine interactions between stressors because of these limitations. Establishing cause and effect between stressors and a particular biological response remains a challenging problem, as does establishing the relative importance of stressors. Observational studies would need to account for uncontrolled variability on multiple levels, and experimental studies at regional levels are logistically impractical. New analytical techniques, however, offer some prospects for gaining a better understanding of the complexity in how stream ecosystems respond to urban development.

\section{Modeling Reach-Scale Stressors}

Bryant and Carlisle (2012) analyzed comparable data sets for physical, chemical, and biological factors from six of the nine study areas to identify specific reach-scale factors that might cause changes to the aquatic biota. The Salt Lake City, Birmingham, and Boston study areas were excluded from this analysis because they lacked data from semipermeable membrane devices (SPMDs). Factors for the stream chemistry, hydrology, and habitat components were represented by 11 reach-scale factors that were selected as potential stressors. The authors used multiple regressions in combination with a statistical approach described in Burnham and Anderson (2002) for identifying plausible models, to explore which reach-scale factors were most strongly related to changes in the algal, invertebrate, and fish communities as measured by the community composition scores.

Using the general approach of Burnham and Anderson (2002), multiple alternative models were developed to determine which factors were most likely associated with a change in community composition scores. Through the use of this method, plausible single- or two-factor models were derived to investigate various combinations of reach-scale factors that were most strongly associated with changes in the biological communities. Alternative models were evaluated using a statistic called the Akaike information criterion (AICc) for small sample size. The model with the lowest AICc is considered the simplest model that best explained the changes in community composition scores. Models within two AICc points of the strongest model also were considered plausible. The advantage of this approach is that not only were potential stressors identified by the strongest model, but other combinations of stressors that might also be affecting the biological community were identified in alternative models. The most desirable outcome is that only a single best model is identified, which would indicate that confidence placed in this model is much greater than in any alternative model using the common set of factors. When several alternative models are equally likely, the relative importance of each factor is less certain, and additional studies would be needed to determine the factors most strongly related to changes in the community composition. 


\section{An Increase in Stream Temperatures Associated With Urban Development Can Lead to a Decline in Biological Communities}

Urban development can lead to higher stream temperatures in various ways, such as from loss of riparian vegetation canopy and a consequent increase in the amount of sunlight reaching the stream. Impervious cover in a watershed functions effectively as solar collectors as well as collectors of precipitation. Water flowing over these heated surfaces can become warmed, which can lead to an increase in the temperature of runoff that reaches the stream. An increase in stream temperature, in turn, can affect the biological communities of a stream (fig. 6-3).

A change in water temperature can affect aquatic biota in several ways. The rates of metabolism for algae, invertebrates, and fish are regulated by the temperature of their environment because they do not have internal mechanisms like birds and mammals to maintain a preferred internal temperature. Consequently, changes in water temperature throughout the year serve as important cues to aquatic biota for particular life cycles of various species, such as spawning in fish and mayfly hatches. Additionally, water temperature can have a more immediate effect on aquatic biota because the amount of dissolved oxygen in the water is inversely proportional to temperature - oxygen levels decrease as water temperature increases - resulting in stress to sensitive invertebrate and fish species.

Results from Kashuba and others (2010) and Cuffney and others (2011) indicate that the relation between temperature and biological condition is demonstrated by invertebrate communities in cool regions typically having a higher percentage of sensitive species than communities in warmer regions. Although these authors used air temperature to represent different regional climates in their investigations, the climate of a region drives seasonal water temperatures of streams, which can influence the species composition of a biological community. Relatively cool regions where urban development occurs in forested watersheds might be expected

Figure 6-4. Stream temperature, based here on the average annual water temperature, appeared to increase steadily as the percentage of urban development increased in the watersheds in the

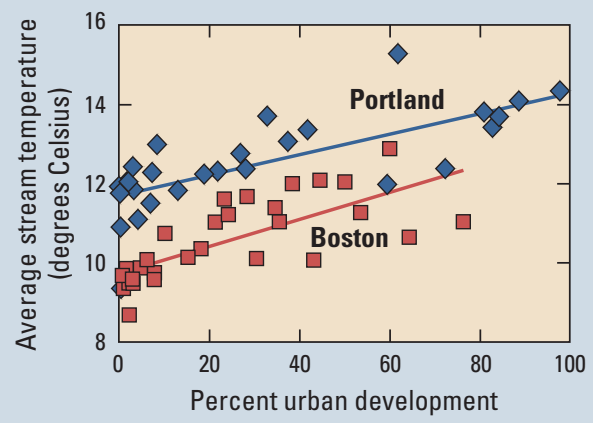

Portland and Boston study areas. The correlation coefficient (rho value) between average stream temperature and percentage developed land is 0.772 for Portland and 0.815 for Boston, indicating a strong relation in both regions. to have biological communities that are most sensitive to changes in water temperature, based on the relations shown in figure 6-2. The Portland, Salt Lake City, and Boston study areas meet these conditions (fig. 6-2, lower left part of graph). However, the relations among urban development, water temperature, and biological communities in the Salt Lake City study could not be characterized in simple terms because the design of that study had a geographic component that complicated the relation between urban development and stream temperature. Study watersheds were nested in 13 larger basins; the less developed watersheds typically had small streams, and the more developed watersheds had larger streams (Giddings and others, 2006).

A strong relation between urban development and water temperature of streams was an important factor in the species composition of biological communities in the Portland and Boston study areas (Coles and others, 2004; Waite and others, 2008). The relation between urban development and stream temperature was strong in both study areas (rho $>0.7$ ), based on correlations indicating that the average annual temperature of a stream increases steadily as a watershed is developed (fig. 6-4). The relation between stream temperature and changes in the invertebrate community was also strong in both study areas. The number of invertebrate species that are highly sensitive to stressors (sensitive species richness) decreased as the average stream temperature increased (fig. 6-5). The values of this metric are inversely related to the community tolerance index; that is, a decline in sensitive species richness is reflected in a higher value for the community tolerance index because the average tolerance value for the invertebrate community increases when the sensitive species are lost. Urban development can, therefore, be related to an increase in stream temperatures and a loss of sensitive invertebrate species, especially in naturally cooler regions of the United States.

Figure 6-5. The number of sensitive species was nearly 30 in the cooler streams in the Portland and Boston study areas, but these species were continually lost as streams became warmer and were

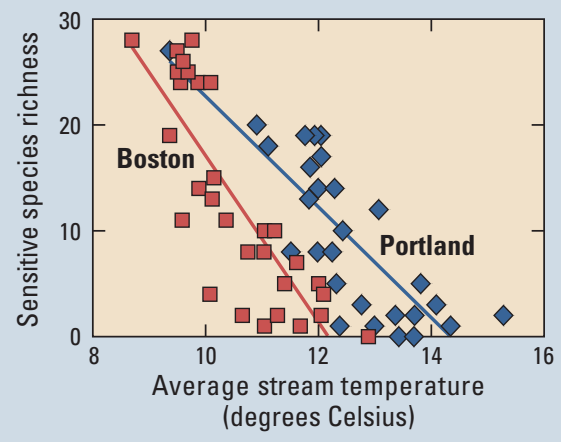
mostly absent in streams with the highest temperatures in the respective regions. The correlation coefficient (rho value) for the relations is 0.831 for Portland and 0.843 for Boston, indicating a strong relation in both regions. 


\section{Building on Prior Knowledge of Ecosystem Processes Helps Link Multiple Interacting Stressors to Biological Endpoints}

Based on an understanding that urban development creates multiple stressors that vary across regional environmental settings, resource managers are likely to ask, "Where should we focus efforts to reduce stream degradation resulting from urban development in our area?" Recognizing that urban development will likely generate various stressors that interact in complex ways should not discourage the design of management plans for reducing the effects of urban development. Instead, the findings from the USGS investigation provide a basis for identifying stressors that most likely lead to stream degradation in a particular region. In addition to the results of the USGS studies, information from other sources is valuable for gaining a more complete understanding of the factors affecting stream ecosystems and how they interact under various conditions. Integrating outside information to complement the USGS data creates a more comprehensive assessment of urban processes in a region and improves the ability of managers to reduce the adverse effects of the most important urban-related stressors.

An approach to gain a broader understanding of the factors affecting stream ecosystems in a region is to integrate the "prior knowledge" of scientists and managers that have worked in the region. For example, biological monitoring programs that were established by states and regions in response to the Clean Water Act (CWA, described in chapter 2) resulted in increased knowledge of stream ecosystems. A crucial step in developing an effective biomonitoring program for a particular region is to select biological indicators that respond to ecosystem processes characteristic of the region.

More than three decades of biomonitoring experience have enabled ecologists to develop a clearer understanding of the characteristics of a healthy biological community for a given set of natural conditions in a region. They also have clearer expectations about how a biological community will change when ecological processes are altered. Consistent with the finding of the USGS investigation that invertebrate communities most often had strong or moderate relations with urban development, many biomonitoring programs rely on invertebrate community metrics as indicators of stream health. Furthermore, land-use planners for a particular region understand how urban development alters the landscape in the area, while the ecologists recognize how these alterations can affect ecological processes and stream health. It is this type of information, developed over decades of experience, that is especially useful in understanding the links among multiple disturbances of urban development, the ecological processes involved, and the effects on the biological condition of the stream. Incorporating such experience directly into models that predict how urban development affects stream health provides better tools for mitigating disturbances and protecting the ecological services deemed important for the region.

Kashuba and others (2012) integrated USGS data with prior knowledge of experts and data collected by biomonitoring programs in a Bayesian network model to illustrate how urban development ultimately affects stream health. Stream health was measured for this effort by using biological endpoints that were scaled along the Biological Condition Gradient and developed by the USEPA in conjunction with the State of Maine and biologists from the Northeastern United States (Davies and Jackson, 2006). Following the conceptual model illustrated in figure 6-1 as a guideline, a network of interconnected processes was created using a Bayesian network model to: (1) help quantify how ecological processes altered by urban development could affect stream health as measured by the Biological Condition Gradient, and (2) identify where best management practices (BMPs) should be focused to reduce the effects of urban development on aquatic communities.

A Bayesian network model has several useful characteristics, including the ability to simultaneously account for multiple interacting stressors, relate their effects using a scale of stream health that is relevant to the region (as with the Biological Condition Gradient framework), and provide a method to test management options for protecting stream health by modifying levels of different stressors to simulate the effects of BMPs. Because the model is based on probabilistic relations (the likelihood that certain outcomes might occur), the model can illustrate the uncertainties in relating urban development to stream health. Additionally, a Bayesian network can be easily updated with new data and additional expert knowledge as they become available, which continually increases confidence in the model and management decisions based on model outputs. Additional information describing Bayesian networks is provided in the case study that follows: Predicting the Effects of Urban Development on Stream Health in the Northeast: Using a Bayesian Network to Link Ecosystem Characteristics to Biological Condition Gradient Endpoints. 


\title{
Predicting the Effects of Urban Development on Stream Health in the Northeast: Using a Bayesian Network to Link Ecosystem Characteristics to Biological Condition Gradient Endpoints
}

\author{
Roxolana Kashuba
}

A Bayesian network was constructed to explore relations among key ecosystem components that link the degree of urban development to the condition of aquatic biota. A Bayesian network uses a probabilistic graphical model to describe the interrelations among multiple factors simultaneously so that the effect of changing one factor can be measured on all remaining factors. The effort focused on the Northeastern Coastal Zone ecoregion in the Northeastern United States to make use of USGS data from the Boston study area and also data collected by the states and USEPA. The analysis provides an example of how the Bayesian network could be used to inform management decisions.

The Biological Condition Gradient (BCG) concept (Davies and Jackson, 2006) was used as the measurement endpoint in the Bayesian network because it provides a framework for standardizing the definition of how stream health changes in response to an environmental stress, such as urban development. The Bayesian network was constructed to incorporate stream hydrology, habitat, and chemistry components that affect aquatic biota so that the effectiveness of best management practices (BMPs) that target these drivers of ecological change could be evaluated.

\section{Measuring Biological Endpoints With the Biological Condition Gradient}

Defining biological condition endpoints that can be used for comparison across the country is a major challenge when assessing the biological conditions for streams in different parts of the country (Herlihy and others, 2008).

The results of the nine studies showed that urban development results in the loss of sensitive invertebrate species and that there was an overall shift to species that were more tolerant of pollution, which ultimately could reduce ecosystem function. While these findings generally hold true across the country, regionally specific biological condition metrics are typically used when making ecological assessments of streams because assemblages of sensitive species vary by region. This variability makes it challenging to compare stream health among regions. The BCG addresses this challenge by providing a common frame of reference for communicating the concept of "stream health" that can be used for different regions of the United States.

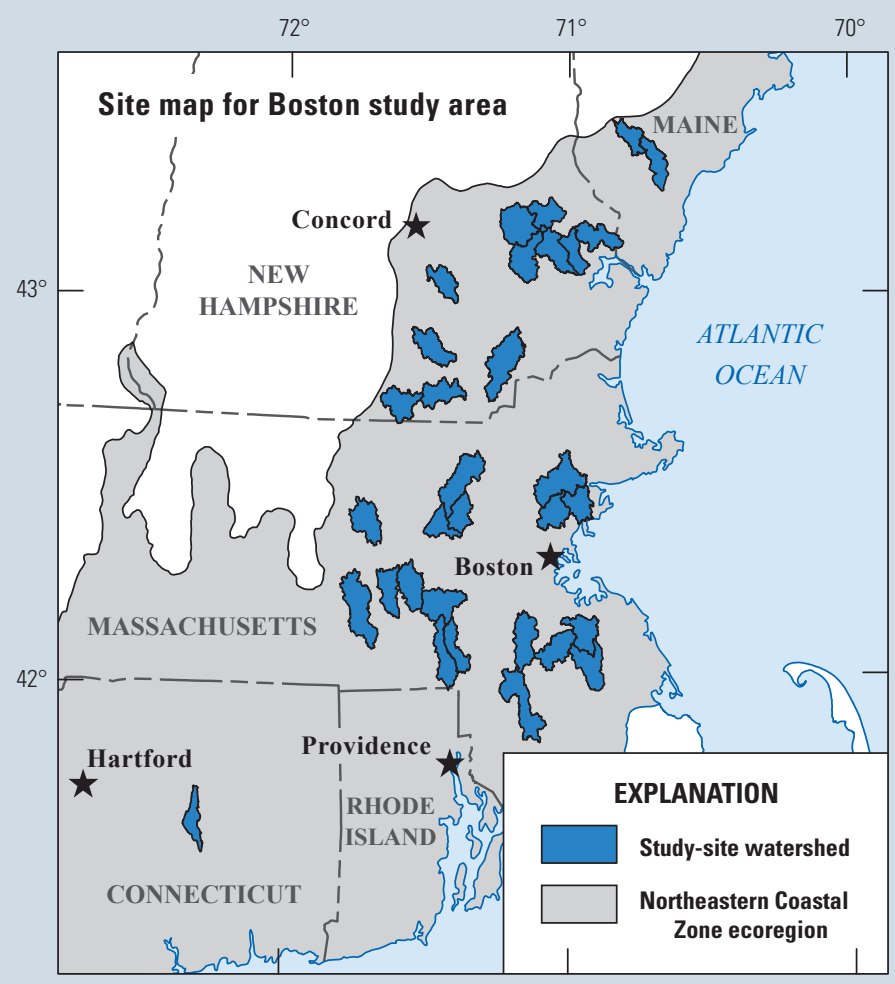

The BCG is a standardized ranking system that uses biological community data collected from streams to describe stream health. The BCG level for any stream is reported as one of six "tiers" that represent biological condition endpoints, ranging from natural (tier 1 ) to highly disturbed (tier 6) (fig. 6-6). The assignment of a particular BCG tier is based on an evaluation of 10 ecological attributes that describe aquatic biological data in terms of overall structure and function of the biological community (table 6-1). The specific metric for each attribute is usually refined and calibrated to biological data that are appropriate for a region. Accordingly, use of the BCG in a specific region requires ecologists to (1) identify biological metrics that are associated with the characteristics defining each of the 10 ecological attributes (table 6-1), and (2) identify values for these metrics that will indicate a response along a stream-disturbance gradient that is likely to result from alterations to ecosystem processes important in the region. This flexibility of the BCG, therefore, allows assignments and interpretations of stream health to be made in a similar manner among different regions but without imposing the limitations of using specific methods of data collection and analysis (Davies and Jackson, 2006). 
Tiers of biological condition

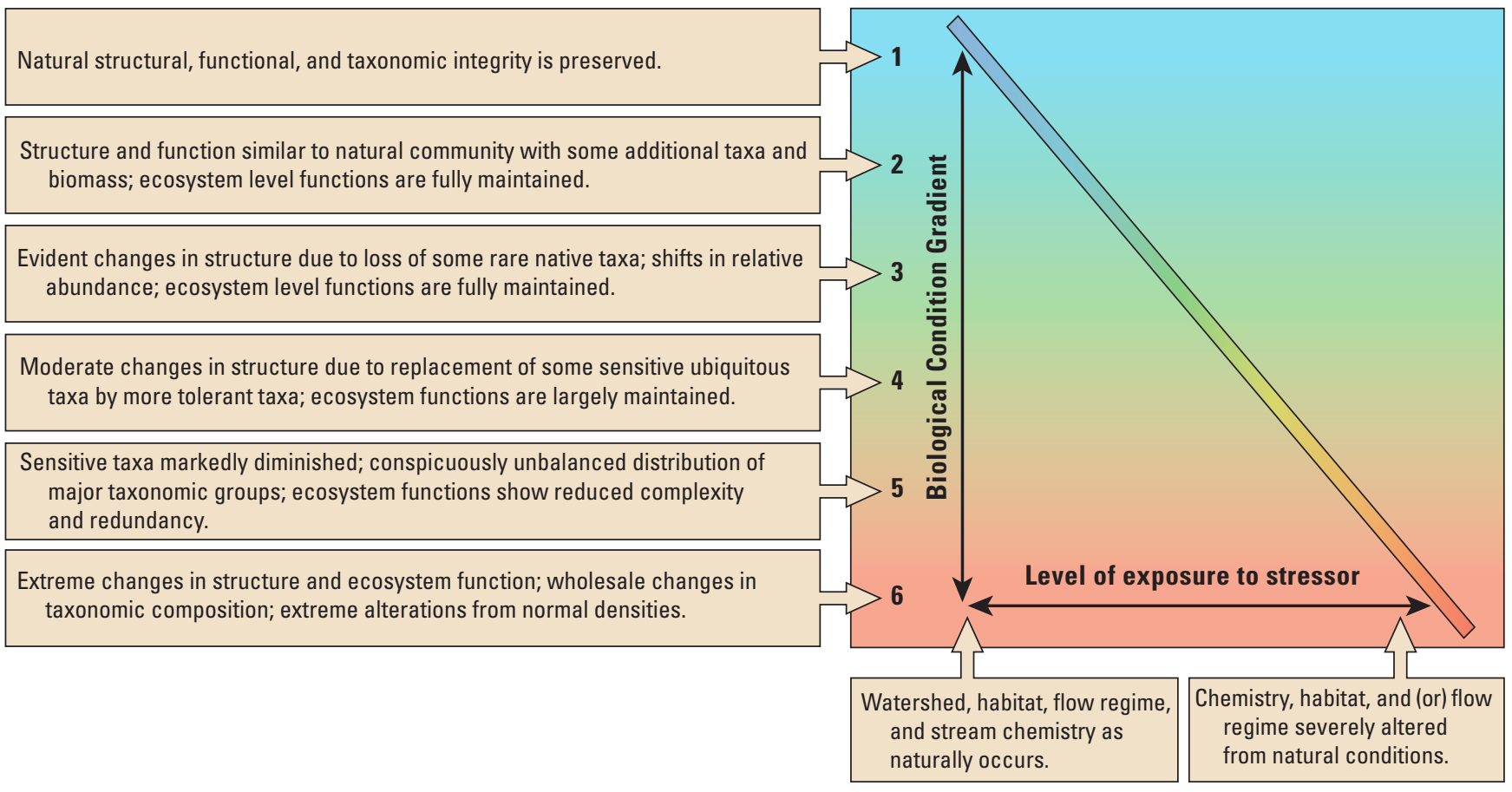

Figure 6-6. The Biological Condition Gradient (BCG) is a descriptive framework that can be used to measure and communicate characteristics of stream health. The transition from tiers 1 through 6 (y-axis) indicates a declining biological condition and stream health as the stressor levels increase ( $x$-axis). The description associated with each tier reflects the biological condition of a stream based on an assessment of its biological community. (Modified from Davies and Jackson, 2006.)

Table 6-1. Attributes that are used to assess the biological community of a stream to determine where it ranks along the Biological Condition Gradient (BCG). The metrics used to evaluate these attributes are specific to a region and its streams.

\begin{tabular}{|c|l|}
\hline Attribute & \multicolumn{1}{|c|}{ Characteristics } \\
\hline I & Historically documented, sensitive, long-lived, or regionally endemic taxa \\
\hline II & Highly sensitive, specialist taxa \\
\hline III & Sensitive, ubiquitous taxa \\
\hline IV & Taxa of intermediate tolerance \\
\hline V & Tolerant taxa \\
\hline VI & Non-native or introduced taxa \\
\hline VII & Organism condition \\
\hline VIII & Ecosystem function \\
\hline IX & Spatial and temporal extent of detrimental effects \\
\hline X & Ecosystem connectance across physical components in space and time \\
\hline
\end{tabular}




\section{Characterizing Ecosystem Processes in the Northeastern United States Using a Bayesian Network}

Conventional bivariate analyses of stream ecosystem data often have focused on relations between single pairs of environmental factors, without incorporating the influence of other factors or taking into consideration prior knowledge of the stream ecosystem. Multiple factors that are associated with the reach-scale processes of stream hydrology, habitat, and chemistry can become important as stressors that affect the aquatic biological community, either through direct pathways (solid arrows) or through interactions among the processes (dashed arrows) (fig. 6-1). A Bayesian network modeling approach examines the relations among the processes by dissecting this complex system into smaller sets of directly related factors.

The two main components of a Bayesian network are nodes, representing important concepts (processes and their factors), and arrows, representing relations between those concepts in the form of conditional probabilities (for example, the probability of any particular outcome depends on the occurrence of prior events). The structure of a model is depicted by nodes and arrows that are combined into a graphical representation with the use of a directed acyclic graph. For example, Urban development can indirectly affect Biological condition by first disrupting Physical condition and Chemical condition (fig. 6-7). The relations among these four major concepts are depicted with a directed acyclic graph through a set of nodes connected by ordered arrows where no pathway following the arrows goes through the same node twice; that is, there are no cycles (feedback loops) in the model. A directed acyclic graph describing this system, therefore, will only use four nodes and four arrows.

A node from which an arrow points is called a "parent" node, and a node toward which an arrow points is called a "child" node. Urban development is the parent of both Physical condition and Chemical condition in the example (fig. 6-7). This notation means that Physical condition and Chemical condition are both conditional on a watershed's Urban development level. Child nodes relative to one concept can also be parent nodes of another concept. For example, in addition to being children of Urban development, the nodes representing Physical condition and Chemical condition are also parents of Biological condition.

This modeling structure allows decomposition of a complicated overall system into sets of direct relations between every parent node and its children, so that child nodes can then be modeled as parents of subsequent child nodes to eventually link the entire system into one probabilistic network. Representing a network of associations as a series of these conditional relations reduces the difficulty of parameterizing such a model and greatly increases the amount of information available from output of the model. While requiring specification of relations only between directly linked factors, a Bayesian network describes the interrelations among all factors simultaneously so that the effect of changing one factor can be measured on all remaining factors.

This qualitative model structure is turned into a quantified Bayesian network by creating conditional probability tables using expert knowledge, existing data, or both. A conditional probability tables indicates a probability distribution for values likely to occur at each child node for every possible combination of parent node values. In a simplified example where Urban development is the parent node of the Physical condition child node, a conditional probability table is created that has two rows to indicate the Physical condition when the level of Urban development is either low or high (fig. 6-8A). Given the level of Urban development, a row indicates the probability of observing either good or poor Physical condition where the probabilities add up to 100 percent because each row describes a complete distribution across all possible child node values. The first row of this hypothetical conditional probability table, relating Urban development and Physical condition, indicates that if Urban development is low, there

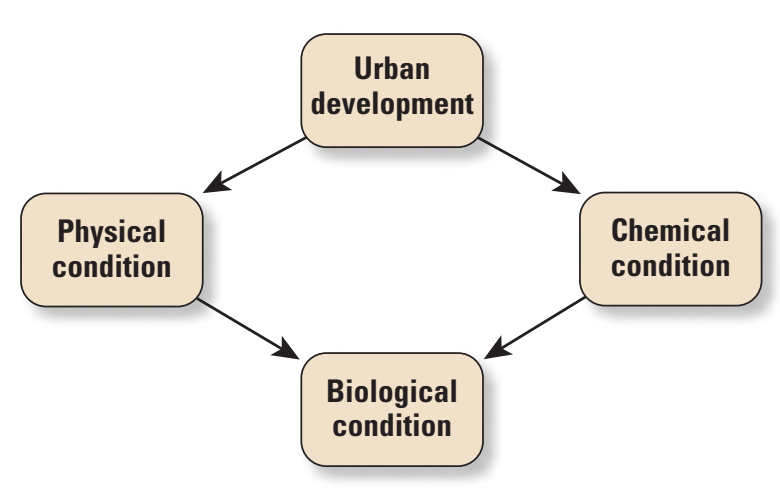

Figure 6-7. A simple Bayesian network with four nodes and four arrows. 
is a 90-percent chance that Physical condition is good and a 10-percent chance that Physical condition is poor. In more convenient terms, if 100 streams were selected from watersheds in low urban land cover, 90 streams are likely to have good physical characteristics, but 10 could have poor characteristics.

A primary advantage of using the Bayesian network over traditional methods of analysis is the ability to simultaneously model interacting system components. The simplified example indicates that Biological condition is affected by both Physical and Chemical conditions, so the associated conditional probability tables shows four probability distributions for Biological condition that account for all possible combinations of Physical and Chemical conditions (fig. 6-8B). The first row of the conditional probability table for Biological condition indicates a 95-percent chance that Biological condition is good if Physical condition is good and Chemical condition is good. The probability of observing good Biological condition then decreases if either Physical or Chemical condition is poor, down to 1 percent if both Physical and Chemical conditions are poor.

\section{A. Physical and Chemical conditions as CHILD nodes of Urban development:}

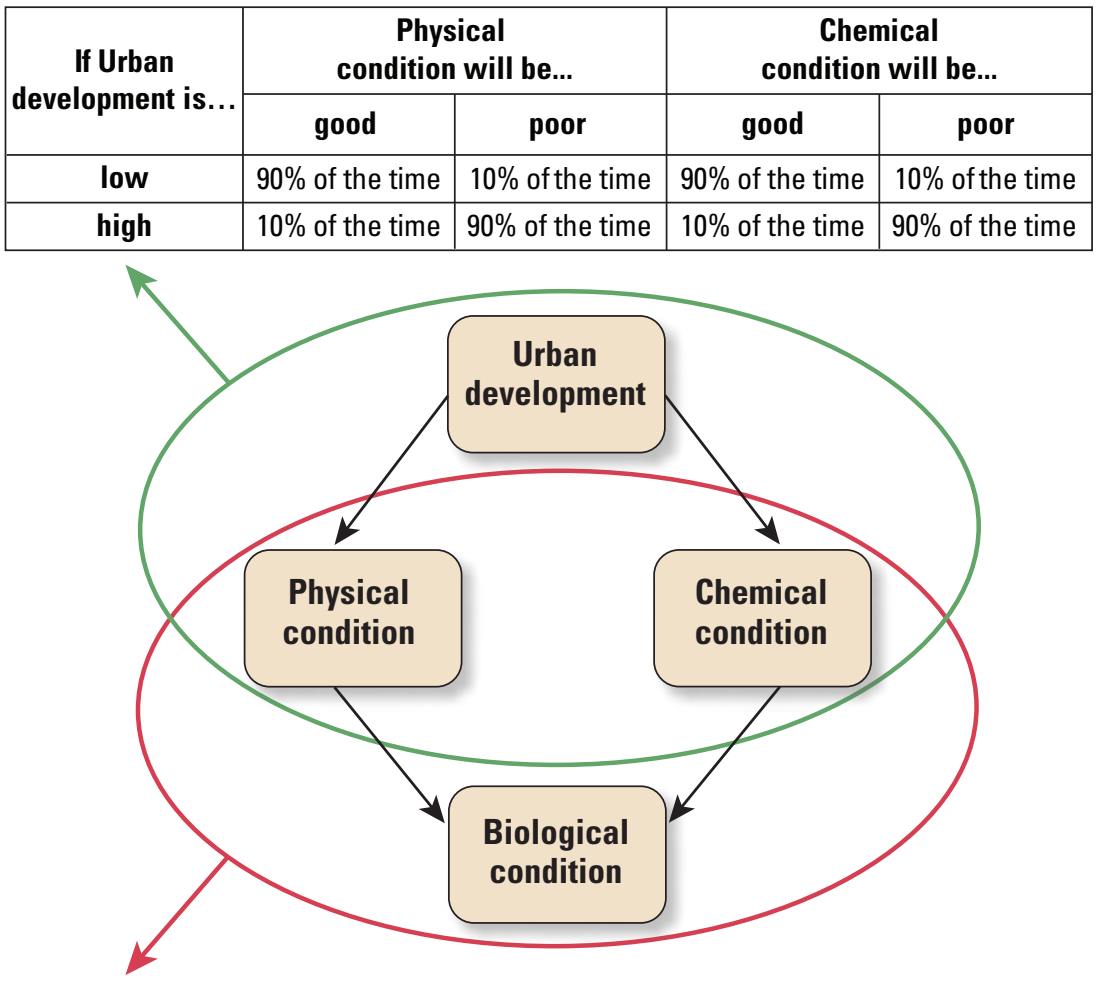

B. Physical and Chemical conditions as PARENT nodes to Biological condition:

\begin{tabular}{|c|c|c|c|}
\hline \multirow{2}{*}{$\begin{array}{c}\text { If Physical } \\
\text { condition is... }\end{array}$} & \multirow{2}{*}{$\begin{array}{c}\text { and Chemical } \\
\text { condition is... }\end{array}$} & \multicolumn{2}{|c|}{$\begin{array}{c}\text { Biological } \\
\text { condition will be... }\end{array}$} \\
\cline { 3 - 4 } & & good & poor \\
\hline good & pood & $95 \%$ of the time & $5 \%$ of the time \\
\hline good & good & $25 \%$ of the time & $75 \%$ of the time \\
\hline poor & poor & $30 \%$ of the time & $70 \%$ of the time \\
\hline poor & & $1 \%$ of the time & $99 \%$ of the time \\
\hline
\end{tabular}

Figure 6-8. The relation between each child node and its parent nodes is specified with a conditional probability table. The upper conditional probability table describes $(A)$ the relations when Urban development is the parent node of two child nodes: Physical condition and Chemical condition. The lower conditional probability table describes $(B)$ the relations when Physical condition and Chemical condition are the parents of Biological condition. 


\section{Using a Bayesian Network Approach to Link Urban Development, Stressors, and Biota to Stream Health}

The Bayesian network developed for the Northeastern United States demonstrates the utility of using a probabilitybased model that links urban development, stressors, and aquatic biota to specific endpoints that are characterized by the BCG tiers. The Northeast Bayesian network uses Urban development as the primary parent node, from which arrows point to Hydrology, Habitat, and Chemistry as the reach-scale stressor nodes representing three major abiotic processes affected by urban development (fig. 6-9). Arrows from the Hydrology node also point directly to the Habitat and Chemistry nodes, which indicate the influence of Hydrology on Habitat and Chemistry. These three stressor nodes are linked to the nodes representing the biological condition metrics for invertebrate communities. The values for these three metrics determine the outcome of the final child node represented by the BCG.
A preliminary step in developing a Bayesian network model is to create an initial or "prior model" of conditional probabilities between nodes, based either on empirical data or on the knowledge of experts. The prior model developed for the Northeast Bayesian network was based on expert knowledge from professional ecologists and land-use planners. This prior model was updated with USGS data to create the more comprehensive "posterior model." A description of the Bayesian network nodes and the factors used to characterize them are shown in table 6-2. An important feature of using a Bayesian network model is that it can be continually updated as new expert knowledge or data from new studies becomes available; the old model becomes the prior model, and the new data are used to create an updated posterior model. This dynamic updating of the model continually improves confidence in the model predictions.

Generally, results from the model applications demonstrate that urban development results in increased streamflow flashiness, a decrease in size of channel substrate, and an increase in specific conductance of stream water.

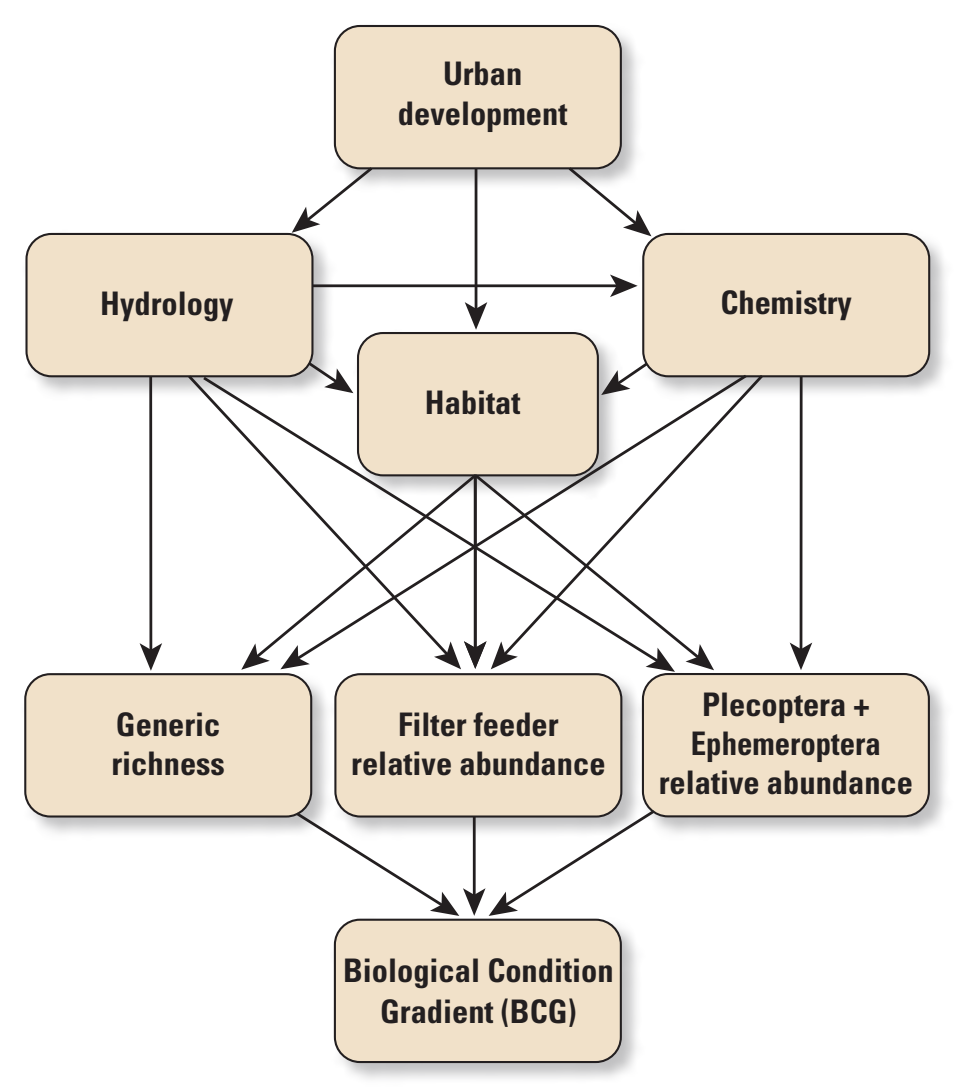

Figure 6-9. Structure of the Bayesian network model developed for the Northeast. Definitions of the nodes and the factors that characterize them are provided in table $6-2$. 
These changes result in decreased richness of the invertebrates (identified at the genus taxonomic level), increased relative abundance of filter feeders, and decreased relative abundance of Plecoptera plus Ephemeroptera. Collectively, changes in these biological condition metrics help to predict the extent of the decline in stream health in response to urban development. The model can be used by managers to help identify methods (such as BMPs) for reducing the detrimental effects of urban development on stream-reach processes, which in turn affect stream health. For example, to ensure that stream health is protected in an urbanizing watershed, a desired BCG endpoint for a stream is established (such as tier 3 or better), and then the Bayesian network model can probabilistically diagnose the environmental conditions that are necessary to maintain that BCG tier. Similarly, a manager can assess the importance of different stream-reach processes on a desired BCG tier to determine management actions that will have the greatest likelihood of meeting the ecosystem requirements of that $\mathrm{BCG}$ tier.

The benefit of using conditional probability tables to specify relations in a Bayesian network model is that the degree of uncertainty can be estimated for various outcomes, which can then be used to indicate the degree of confidence in different management options. Because the factor representing each node is quantified as a probability distribution across possible values of that factor, and the links between parent and child nodes are described using conditional probability tables, the Bayesian network model does not just predict a single value for a child node. Instead, the model predicts the probability that any given value will occur at a node across the range of possible values for a factor based on a set of its parent-node conditions. Consequently, sensitivity analysis can help determine which node is likely to have the largest effect on the BCG endpoint. This analysis is performed by varying each node incrementally in the model, from a stressed state associated with disturbed conditions, to increasingly improved states associated with more nearly natural conditions. The likelihood of improving stream health, indicated by probabilities of attaining a better BCG tier, is then evaluated for changes predicted in each node.

For example, if the goal for stream rehabilitation is BCG tier 3 or better, but the level of Urban Development in the watershed is in the high category (greater than 31 percent in this example), the likelihood of attaining the BCG goal is only 25 percent (fig. 6-10A). However, if water quality were managed so that a low contaminant level was maintained through appropriate management actions (such as BMPs) implemented at the Chemistry node, the likelihood of attaining the BCG goal increases to 57 percent. Furthermore, if additional management actions were implemented at the Hydrology node so that flashiness was maintained at the medium level, the likelihood of attaining the BCG goal improves to 70 percent (fig. 6-10B). This change in likely BCG outcome can occur because the connections from the Urban Development node to the Hydrology and Chemistry nodes are in essence interrupted by the management actions. Generally, the predictions of the Bayesian network model indicated that the effects of urban development on aquatic biota are conveyed through multiple pathways that are best evaluated collectively and incrementally to improve the likelihood of achieving a healthy stream ecosystem.

Table 6-2. Nodes and factors selected to characterize major ecosystem components in Bayesian network model for the Northeastern United States.

[>, greater than; ${ }^{\circ} \mathrm{C}$, degrees Celsius $]$

\begin{tabular}{|c|c|c|}
\hline Ecosystem scale & Node & Factors \\
\hline Watershed & Urban development & Percent urban land cover in watershed \\
\hline \multirow{7}{*}{ Stream reach } & Hydrology & Flashiness: rises greater than 7 times the annual median rise \\
\hline & Habitat & Substrate: dominant ( $>50$ percent of transects) substrate type \\
\hline & Chemistry & Specific conductance: at low base flow, in microsiemens per centimeter at $25^{\circ} \mathrm{C}$ \\
\hline & Generic richness & Total number of invertebrate taxa at genus level \\
\hline & Filter feeder relative abundance & Percent of total invertebrate abundance that are filter feeders \\
\hline & $\begin{array}{l}\text { Plecoptera plus Ephemeroptera } \\
\text { relative abundance }\end{array}$ & Percent of total invertebrate abundance that are stonefly plus mayfly species \\
\hline & $\begin{array}{l}\text { Biological Condition Gradient } \\
\text { (BCG) }\end{array}$ & Scale of stream health with discrete tiers that indicate degree of impairment \\
\hline
\end{tabular}


When Urban Development is High and management interventions are minimal, the predicted changes to the stream ecosystem are greatest, as indicated in the boxes below.
The generic richness of the invertebrate community is medium to low, the relative abundance of filter-feeder organisms is high, and the relative abundance of Plecoptera + Ephemeroptera organisms (sum of stoneflies and mayflies) is low to medium.

\section{A. Before management actions} substrate is relatively coarse, and the water has high specific conductance.

The likelihood of attaining a Biological Condition Gradient goal of tier 3 or better (indicating a healthy stream) is only $25 \%$.

Figure 6-10. The Bayesian network model can assess the probable outcome of implementing management actions. (A) Before management actions, the likelihood of attaining a Biological Condition Gradient goal of tier 3 or better is only 25 percent. $(B)$ If management actions are used to reduce stream chemistry to the "low" constituent level and stream flashiness to a "medium" level, the likelihood of attaining the Biological Condition Gradient goal improves to 70 percent.

\section{\begin{tabular}{ccc}
\hline \multicolumn{3}{c}{ Urban development } \\
\hline $\begin{array}{c}\text { Urban } \\
\text { category }\end{array}$ & $\begin{array}{c}\text { Development in } \\
\text { watershed (\%) }\end{array}$ & $\begin{array}{c}\text { Percentage of } \\
\text { watersheds }\end{array}$ \\
\hline
\end{tabular}}

Low $\quad 0$ to 7

Medium $\quad 7$ to $31 \quad 0$

High >31

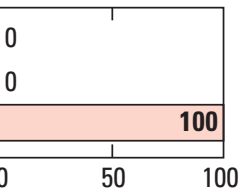

Chemistry

specific conductance)

Factor Probability of

level occurring

Low 5

Medium 24

High

Fine 17

Coarse

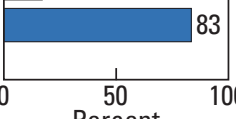$$
\text { 政 }
$$
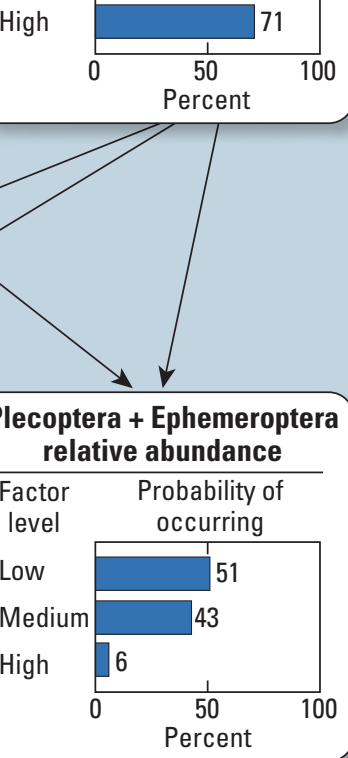


\section{B. After management actions}

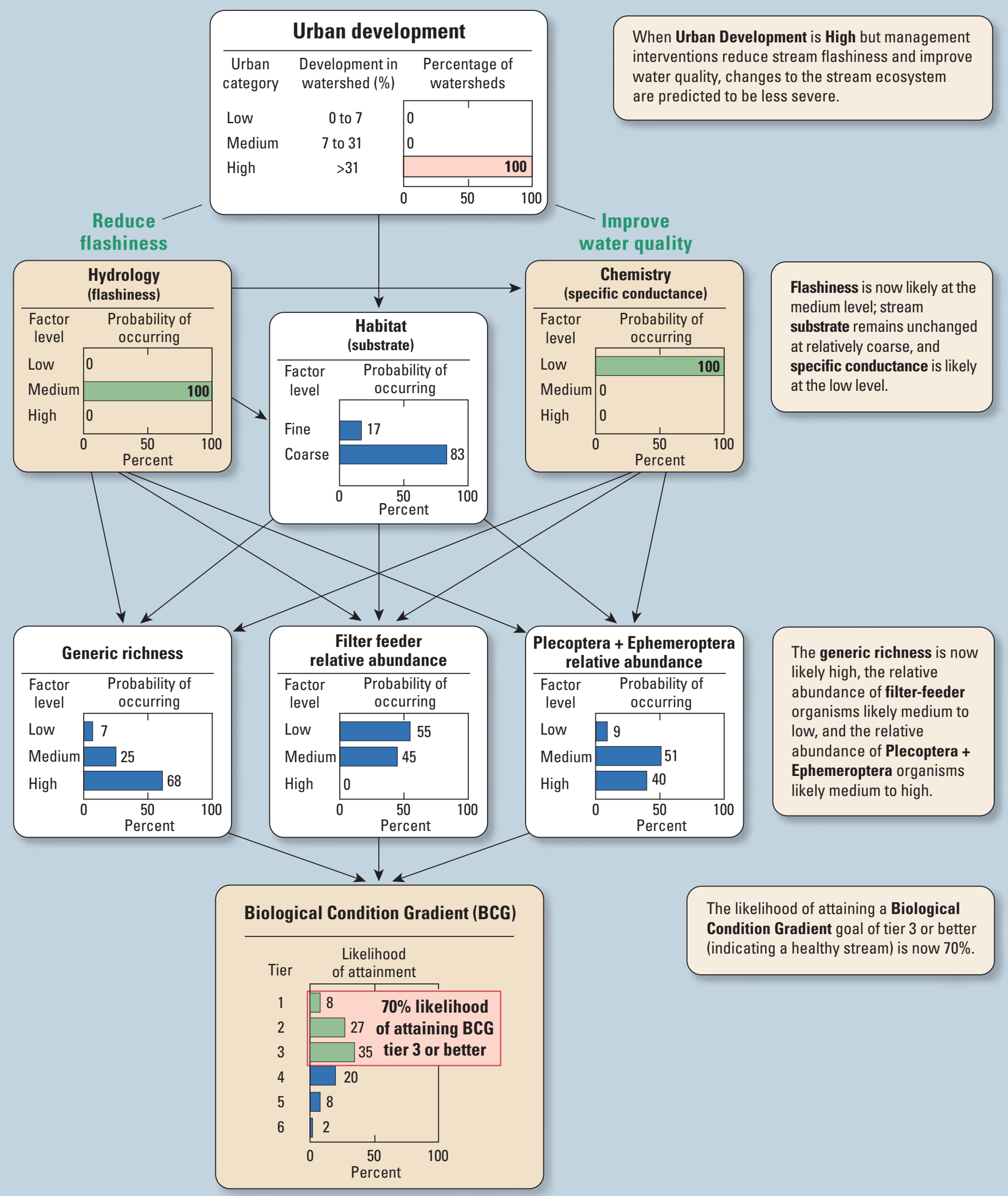





\section{Chiopter \\ $\geqslant$ \\ Key Challenges in Managing \\ Urban Stream Ecosystems}

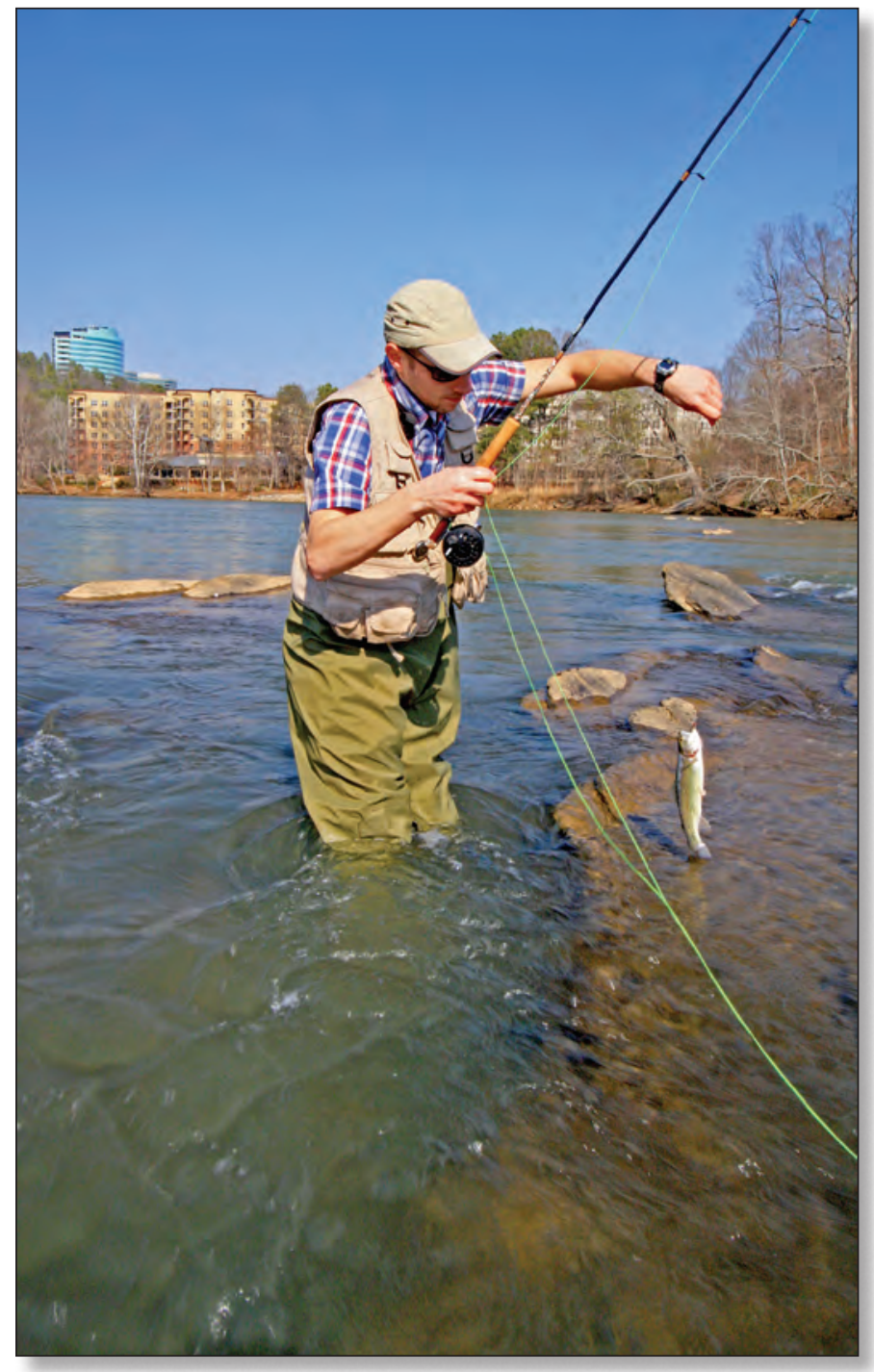

The previous chapter underscores the importance of linking the degree of urban development to the condition of a stream and describing this condition in terms that society recognizes as important. How are resource managers to make use of this information? For example, if a stream's chemical or biological conditions are meeting or attaining water-quality standards, how can these conditions be maintained? If a stream is impaired, how can the health of the stream be improved?

In this chapter, specific management challenges and strategies are discussed in the context of three major findings:

1. Urban streams are affected by multiple stressors;

2. The response of streams to urban development varies across the country; and

3. Indicators of the effects of urban development must be both scientifically based and relevant to important social values. 
Because the condition of urban stream ecosystems is defined by complex, interacting systems that function at multiple spatial and temporal scales, the findings of this study suggest that management strategies for a healthy stream are likely to be multifaceted. The management strategies described in this chapter are drawn from the experiences of municipalities that are seeking to protect the condition of streams in urbanizing watersheds. These strategies are presented not as recommended courses of action but as examples of how municipalities have responded to the challenges summarized in chapters 4-6. In most of these municipalities, either comprehensive monitoring programs have not been established to assess the attainment of desired changes in physical, chemical, and biological characteristics, or the programs have not been in place long enough to yield measurable results. In much of the United States, the lack of a framework, methods, and funding to evaluate such programs are common problems that have motivated a recent call for more comprehensive monitoring and watershed-oriented planning (National Research Council, 2008). A more complete set of potential actions to support management strategies is presented and discussed in a companion document (Cappiella and others, 2012).

\section{Urban Streams Are Affected by Multiple Stressors}

There are multiple physical and chemical factors that affect aquatic biota in an urbanizing watershed. Analyses of the responses of the three biological communities to changes in stream hydrology, habitat, and chemistry indicated that no single factor was universally important in explaining responses to urban development across all study areas or biological communities. Because algae, invertebrates, and fish differ in their life cycles and requirements for food, shelter, and reproduction, these respective communities generally respond differently to stressors arising from changes in the physical and chemical processes that operate within the ecosystem. These differing responses can provide important clues about the types of stressors that are present in the ecosystem and may indicate potential avenues for management actions.

\section{Management Implications Associated With Findings Related to Multiple Stressors}

- Because the degradation of aquatic biological communities begins at the onset of urban development, heightened attention to innovative

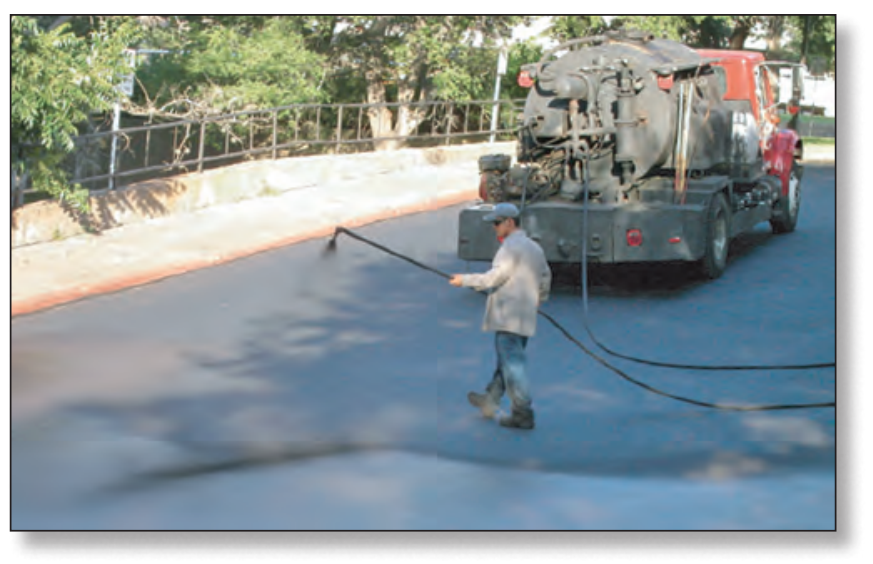

Applications of coal-tar-based sealcoat, applied to asphalt pavement, such as parking lots and driveways, can be a major source of PAH contamination in stormwater runoff. (Photograph from Van Metre and others, 2006.)

strategies for carefully managing development in undisturbed watersheds, such as land-use planning and zoning tools that address multiple stressors, is important to minimize degradation of aquatic biological communities.

- Different responses among the three communities, however, can provide important clues about the types of stressors that occur with urban development, which can be linked then to management actions that may be appropriate for improving stream conditions.

- In watersheds with impaired streams, opportunities to redevelop urban lands, including reducing, disconnecting, and (or) treating impervious cover, may provide a means to reverse the adverse impacts to streams because previous development of these lands often did not include measures to treat runoff from impervious surfaces.

- Responses of stream biota to urban development described in chapters 5-6 indicate that streamrehabilitation efforts could have a positive effect on the biological condition and health of streams.

- Continuous declines in biological diversity and foodweb complexity with increasing urban development may make streams more vulnerable to other changes, such as the introduction of non-native species.

- Management strategies that prevent rapid runoff from individual parcels of developed land to nearby streams also can help limit the transport of contaminants to the streams. 


\section{Using Impervious Cover as a Surrogate for Multiple Stressors}

In 2006, the Connecticut Department of Environmental Protection issued a Total Maximum Daily Load (TMDL) for impervious cover in the Eagleville Brook watershed, located on the University of Connecticut campus and adjacent to the town of Mansfield, Conn. A TMDL is the maximum amount of a pollutant that a water body can receive and still meet water-quality standards, and it usually is based on modeling, monitoring data, or a combination of both (U.S. Environmental Protection Agency, 2010a). The Eagleville Brook TMDL, approved by the USEPA in February 2007, represents the first of its kind in the Nation. While TMDLs typically apply to a specific contaminant, this one addresses the impacts of urban development directly by using impervious cover as the TMDL metric. This approach was chosen, in part, because the biological impairment of Eagleville Brook could not be attributed to any one contaminant. The Connecticut Department of Environmental Protection recognized that while impervious cover may not be the direct cause of the impairment, the strong link between impervious cover and the multiple stressors that affect stream biota make impervious cover a strong surrogate for these multiple stressors.

Beginning in 2005, the Connecticut Department of Environmental Protection has been evaluating the relation between impervious cover and stream health, which was based on values of an invertebrate multimetric index that indicated the biological condition (fig. 7-1). The Connecticut Department of Environmental Protection analyzed the relation between invertebrate communities and impervious cover for 125 streams, by using impervious-cover estimates from a model created by the University of Connecticut's Center for Land Use Education and Research (CLEAR). Based on this analysis, the Connecticut Department of Environmental Protection concluded that 12-percent impervious cover is an appropriate limit for protecting aquatic life in the State's streams and a defensible basis for a TMDL in areas with complex and unspecified water-quality problems.

The impervious cover TMDL for Eagleville Brook was set at 11 percent to include a margin of safety. Mapping and field surveys were conducted by the CLEAR's Nonpoint Education for Municipal Officials Program, the Center for Watershed Protection, and the Horsley Witten Group to measure the current watershed impervious cover and to identify opportunities to remove or disconnect and treat impervious cover. The goal of the TMDL is to have the watershed ecosystem look and act as if land cover in the watershed were 11-percent impervious or less. Approximately 50 retrofit opportunities were identified, including rain gardens, bioretention, downspout disconnection, green roofs, swale enhancements, soil amendments, dry swales, porous pavement, cisterns, sand filters, constructed wetlands, floodplain reconnection, impervious cover removal, tree plantings, pervious area restoration, and stormwater planters. Retrofit designs were produced for 10 sites, and the University of Connecticut has committed to implementing them as improvement projects are made on the campus.

Although the reduction in the area of impervious cover is the "yardstick" used to measure progress in this TMDL, the ultimate success will be the recovery of the biological communities in Eagleville Brook by improving the stream's habitat and water quality. Initial monitoring results indicate that additional sources of contaminants, not attributed to impervious cover alone, may be present and need to be identified; these results indicate the importance of ongoing monitoring to quantify the effects of a project or program (Christopher Bellucci, Connecticut Department of Environmental Protection, State of Connecticut, written commun., 2011).

To learn more, go to http://www.epa.gov/owow_keep/ tmdl/tmdlsatwork/eagleville_brook.html.
Figure 7-1. The Eagleville Brook impervious cover TMDL is based on a Connecticut Department of Environmental Protection study that indicated streams in watersheds with impervious cover exceeding approximately 12 percent (the darker area) failed to met the Connecticut aquatic-life criterion for healthy streams. (Graph by Christopher Bellucci, Connecticut Department of Environmental Protection.)

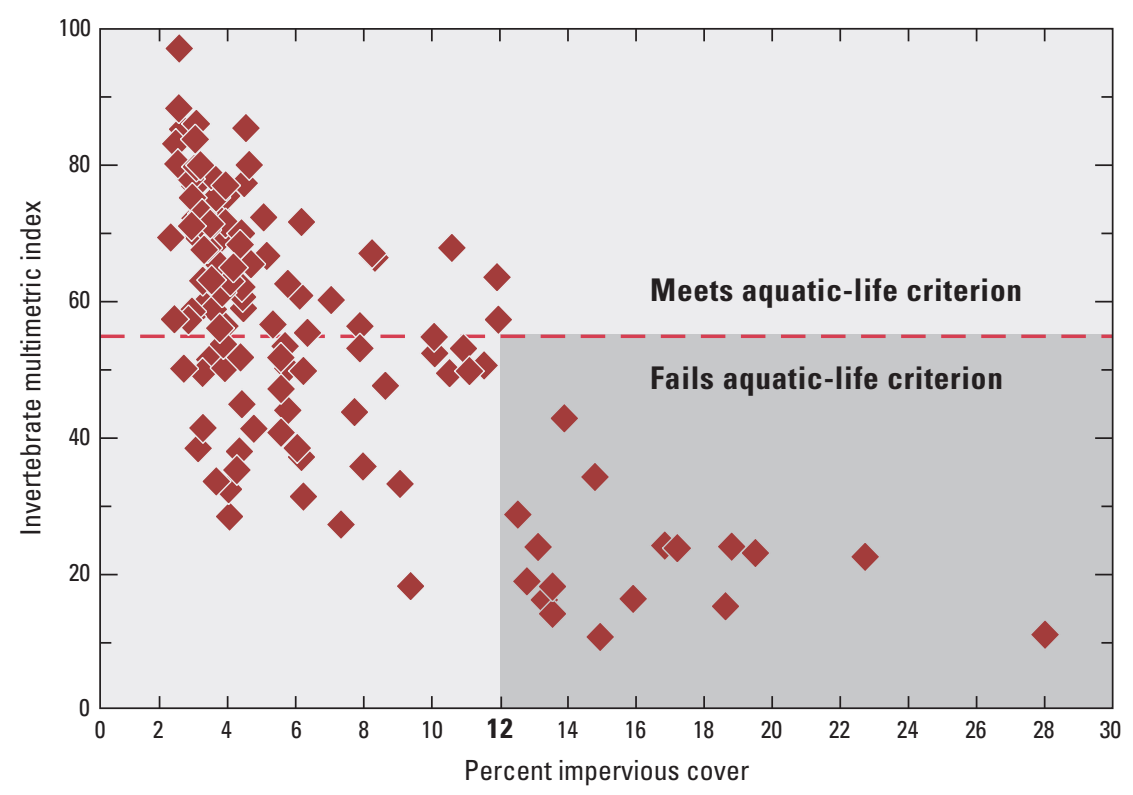




\section{Benefits of Protecting Stream Buffers in Kansas City, Missouri}

Since 2004, Kansas City environmental managers have systematically evaluated stream quality throughout the city and quantified the relation between riparian buffers and stream quality. A comprehensive inventory of stream assets demonstrated that the health and stability of the city's streams are influenced by the quantity and quality of riparian buffers. The results support national research on the importance of stream buffers in watershed management. Consequently, Kansas City adopted a stream-setback ordinance in August 2008 that prohibits flood-plain development and focuses on preserving adjacent riparian buffers through development controls, low-impact development provisions, and incentives.

The stream-setback ordinance is designed to help avoid future liabilities by protecting new development and infrastructure from flood damage while preserving natural resources that provide multiple benefits. Limiting development near streambanks also could improve Kansas City's water quality, reduce erosion and sedimentation, and protect ripariancorridor habitat and greenways. This ordinance addresses stormwater management, natural-resource protection, and future development by protecting sufficient riparian buffers to maintain the city's streams and environmental quality while providing incentives and flexibility for developers who build near streams. A provision for conservation development protects ecologically important riparian resources while, at the same time, allowing development within the outer zone of the buffer. Little development under the guidance of this setback ordinance has occurred since its enactment because of economic conditions. A formal monitoring program to assess the effect of the program on stream conditions does not exist at this time (Patty Noll, Kansas City Planning and Development Department, Kansas City, Missouri, oral commun., 2011).

To learn more, go to http://ww4.kcmo.org/planning/ devmgmt/zoningord/Stream\%20setback\%20fact\%20sheet.pdf.

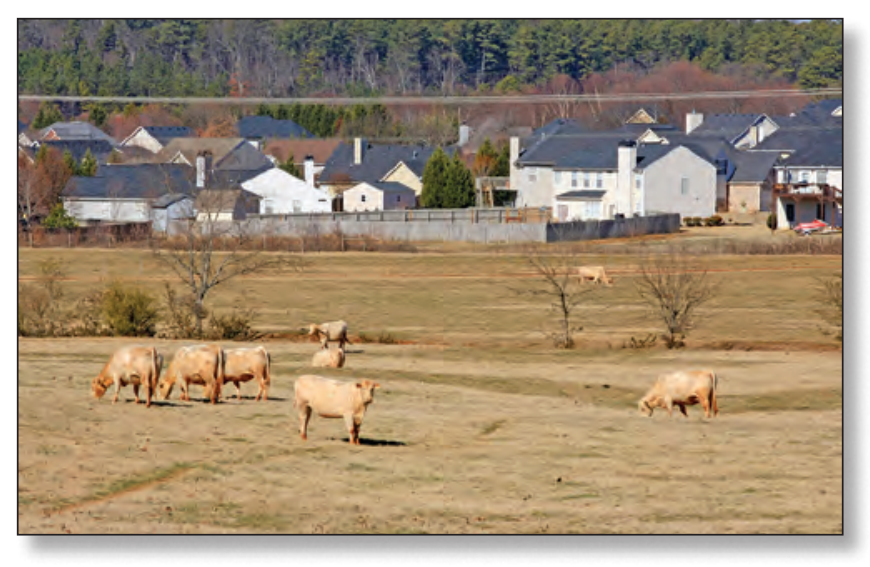

Urban development is occurring on all types of landscape, from mostly forested areas to mainly agricultural land cover such as grazing lands.

\section{Restoring Important Stream Habitats in Milwaukee, Wisconsin}

The Milwaukee, Menomonee, and Kinnickinnic Rivers drain densely populated areas of Milwaukee, and the mouths of these rivers form an important harbor system for industry and recreation on Lake Michigan. As in other highly developed urban coastal cities, many miles of streams in the Milwaukee area were dredged, straightened, dammed, buried, or lined with concrete and stone to control flooding as urban areas expanded. Stream habitat that provided food and shelter for aquatic biota was lost. Flood plains and wetlands in and along riparian corridors were filled in and developed. Dams, culverts, and cement-lined channels barred the migration of native fish from Lake Michigan into important historical spawning headwater areas. Remaining habitats were disconnected and fragmented. Massive flooding continued to cause problems during large runoff-producing storms in the 1990s and 2000s.

Several large projects by multiple agencies and volunteer organizations have worked toward improving flood control, reconnecting important habitats, and improving water quality. During 1999-2002, Milwaukee Metropolitan Sewerage District (MMSD) completed the Lincoln Creek Environmental Restoration and Flood Control Project, a $\$ 111$ million effort to protect 1,600 homes and businesses located within the flood plain from 100-year storms. Since 2007, the Southeastern Wisconsin Watersheds Trust has been focusing efforts on watershed restoration plans, watershed action teams, rehabilitation projects, and land protection. In 2009, a $\$ 4.7$ million grant from the National Oceanic and Atmospheric Administration (NOAA) was awarded to Ozaukee County to remove fish barriers and reconnect 158 miles of streams and 119,000 acres of biologically important riparian, near-shore, and river mouth areas of the Milwaukee River.

In 2010, MMSD was awarded about $\$ 4$ million in USEPA Great Lakes Restoration Initiative grants to improve habitat and fish passage in the Kinnickinnic River and redesign the last stretch of the Menomonee River, which acts as a fish-passage barrier between Lake Michigan and the rest of the watershed (fig. 7-2). Residential properties are being purchased to widen flood plains for re-creating flood storage and to rehabilitate the system to a more natural flow regime. Other areas require cleanup of contaminated sediment. The construction of a deep tunnel by MMSD helped alleviate flooding and pollution problems associated with an aging combined stormwater and sanitary-sewer system, preventing more than 70 billion gallons of wastewater from entering Lake Michigan since the Deep Tunnel came online in 1994.

To learn more, go to http://v3.mmsd.com/DeepTunnel.aspx. 


\section{The Response of Streams to Urban Development Varies Across Regions of the Country}

Because of differences in climate, geology, topography, and historical land-use patterns, all of which define stream ecosystems, streams in different regions of the country respond differently to urban development. These environmental differences lead to variations in how hydrology, habitat, stream chemistry, and aquatic biota respond to urban development. These regional differences also were evident in the biological community characteristics of streams with undeveloped watersheds as well as in the rate at which the biological communities changed as urban development occurred.

\section{Management Implications}

- Protection and rehabilitation strategies for urban stream ecosystems need to account for the influence of regional characteristics, such as climate, geology, topography, and historical land-use patterns, in addition to the effects of multiple stressors.

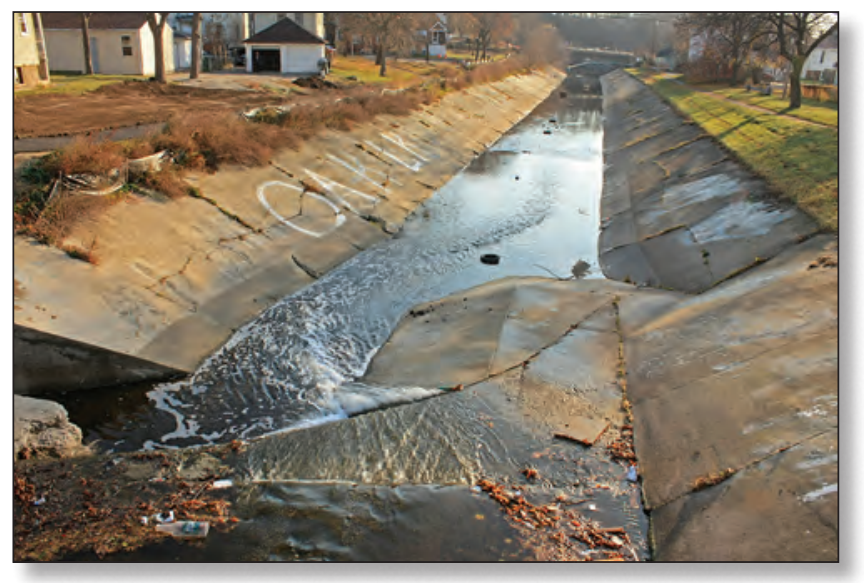

Figure 7-2. Habitat is being restored along the Kinnickinnic River in Milwaukee, Wis., to improve fish passage and reconnect the stream to the flood plain.

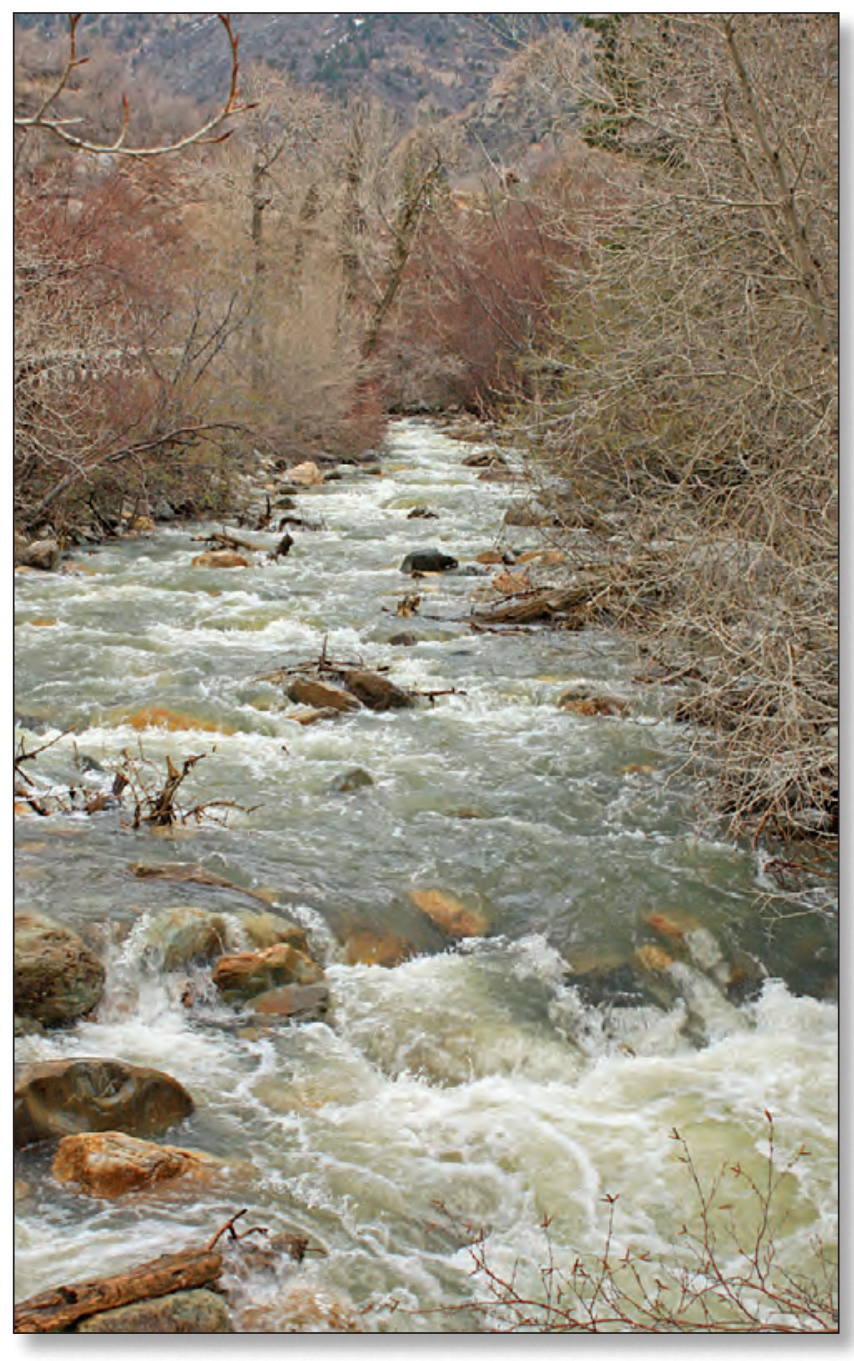

Streams draining forested watersheds are likely to support the most sensitive biological communities; therefore, forest conservation is particularly important to limit impacts as forested watersheds are urbanized. 


\section{Comparing Aquatic Biological Conditions Across Regions}

Assessing the relative health of a stream in a particular region often requires comparing its biological community to biological communities typically observed in streams with the least-disturbed watersheds in the region. Characterizing the set of conditions that are expected for a least-developed stream in a region is a major challenge, however, especially when comparing stream health in different parts of the country (Herlihy and others, 2008). Invertebrate samples from a USEPA study of the Temperate Plains region, which includes extensive agricultural lands in the eastern Dakotas and through Iowa, Minnesota, Missouri, Kansas, and Nebraska to Indiana and Ohio, indicate that 62 percent of the stream lengths in this region were in good or fair condition (fig. 7-3). In contrast, invertebrate sample data from the Northern Appalachians region, which includes all of the New England states, most of New York, the northern half of Pennsylvania, and northeastern Ohio, indicate that only 28 percent of the stream lengths were in good or fair condition. A conclusion that could be drawn from these data, collected as part of the USEPA Wadeable Streams Assessment, is that the biological conditions in the least-disturbed streams in the Midwestern agricultural region are better than conditions in the least-disturbed, largely forested Northern Appalachian region (U.S. Environmental Protection Agency, 2006).

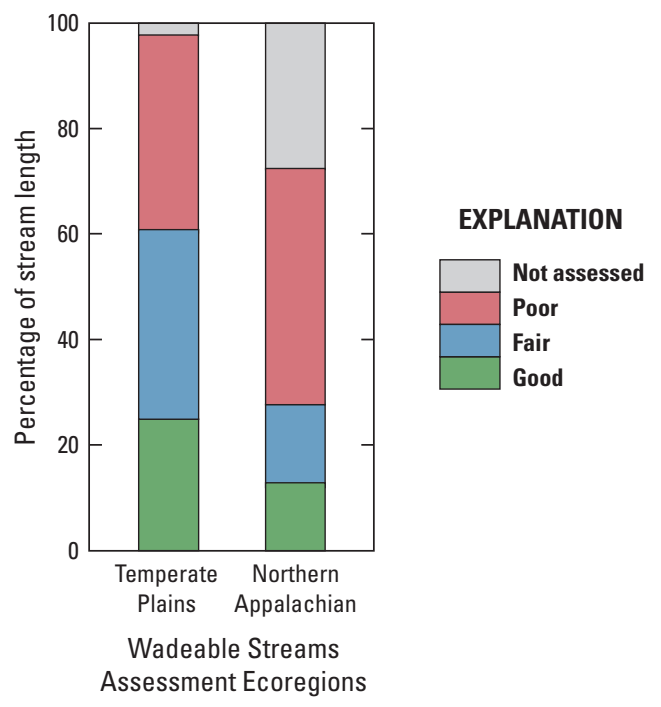

Figure 7-3. Comparison of stream conditions between regions may not be valid when the least-disturbed conditions vary between the regions. Variations in these least-disturbed conditions may lead to inaccurate conclusions about relative health of streams in a region. Tools such as the Biological Condition Gradient may enable more accurate comparisons of the health of streams across regions. (Modified from U.S. Environmental Protection Agency, 2006.)

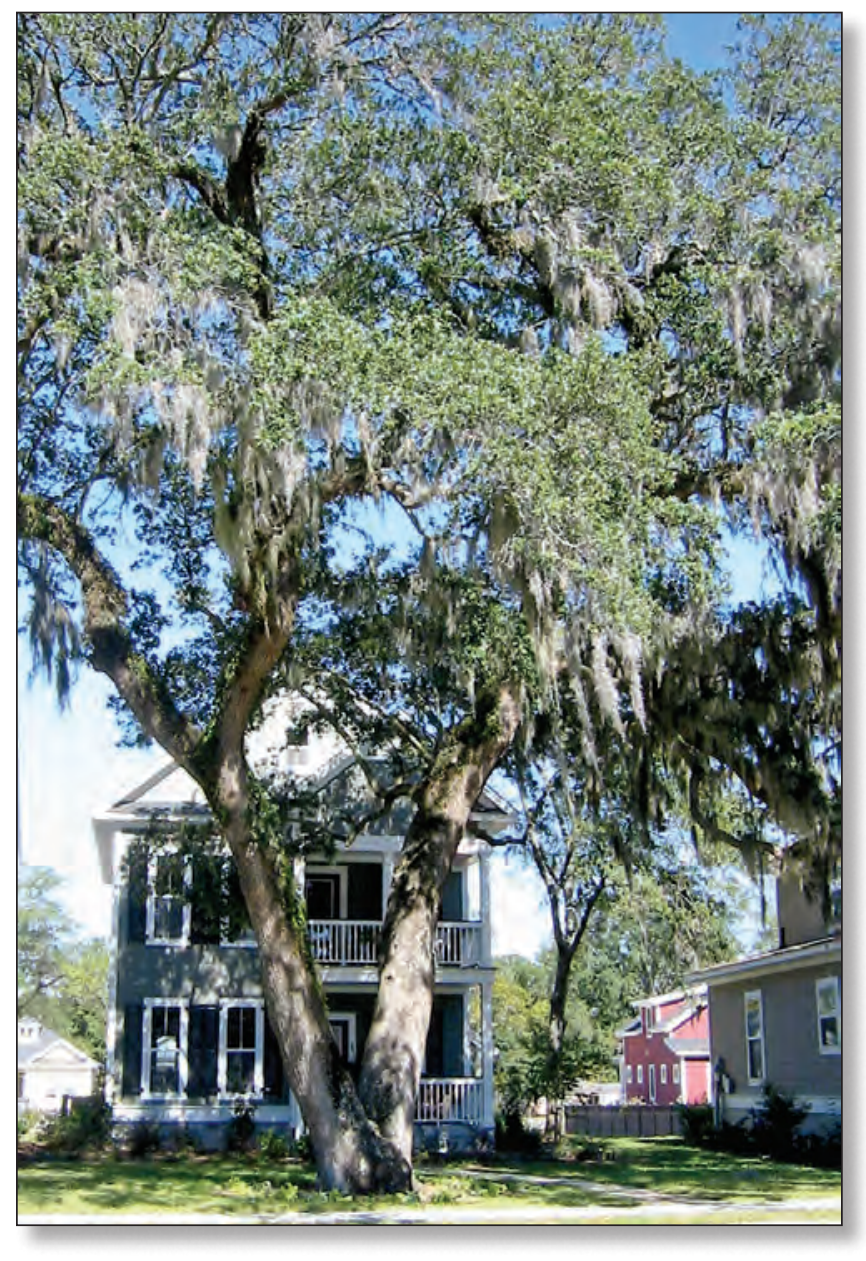

Preservation of existing trees and tree planting in urban areas are cost-effective strategies to reduce runoff and pollutants. Trees capture rainfall in their canopies and further reduce runoff and pollutants through processes such as evapotranspiration, infiltration, and nutrient transformation. Yet, these natural processes vary widely by tree species and other characteristics, making it difficult to measure these benefits and translate them into a simple and quantifiable credit system. (Photograph by Center for Watershed Protection, Ellicott City, Md.) 
A likely reason for the larger percentage of stream miles in good and fair condition in the Temperate Plains region compared to the Northern Appalachian region is the relative difference in the biological condition of their least-disturbed streams. Invertebrate communities in least-disturbed streams typically have more sensitive species than streams in watersheds that have been subjected to some degree of human disturbances. However, much of the Temperate Plains region has been altered by human disturbance, such as agricultural activities, and streams meeting the criterion for least-disturbed conditions had relatively fewer sensitive species than did the least-disturbed streams in the Northern Appalachian region.

Comparison of stream conditions between regions may not be valid when the least-disturbed conditions vary between the regions. In essence, this led to different starting points for comparing streams in the Temperate Plains region with those in the Northern Appalachians region. In the Temperate Plains region, relatively little difference in the biological conditions of streams reflected the presence of agricultural land uses in the least-disturbed watersheds. In the Northern Appalachian region, where the least-disturbed watersheds were primarily forested, the streams were more likely to have sensitive species. Therefore, for a given level of disturbance in a watershed, a stream in the Northern Appalachian region would be more likely to show greater departure from least-disturbed conditions than would a stream in the Temperate Plains region. Additionally, the limited range of change in the Temperate

\section{A}

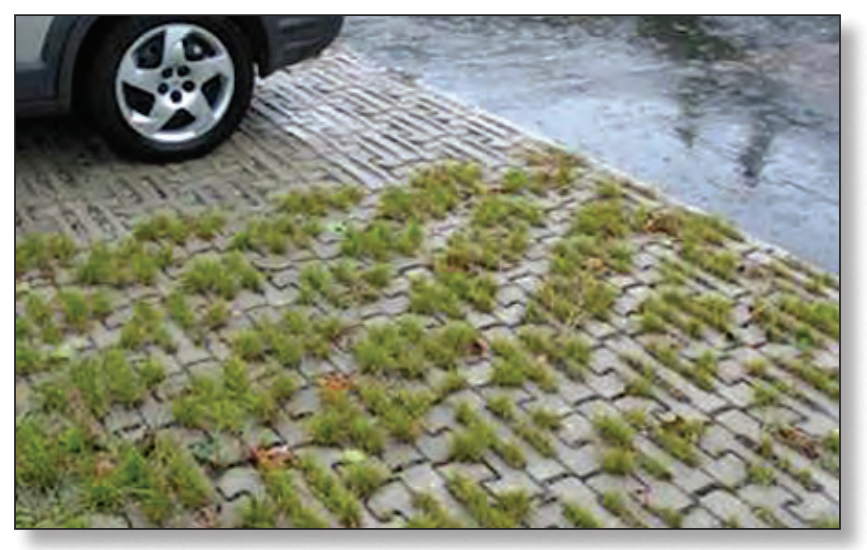

C

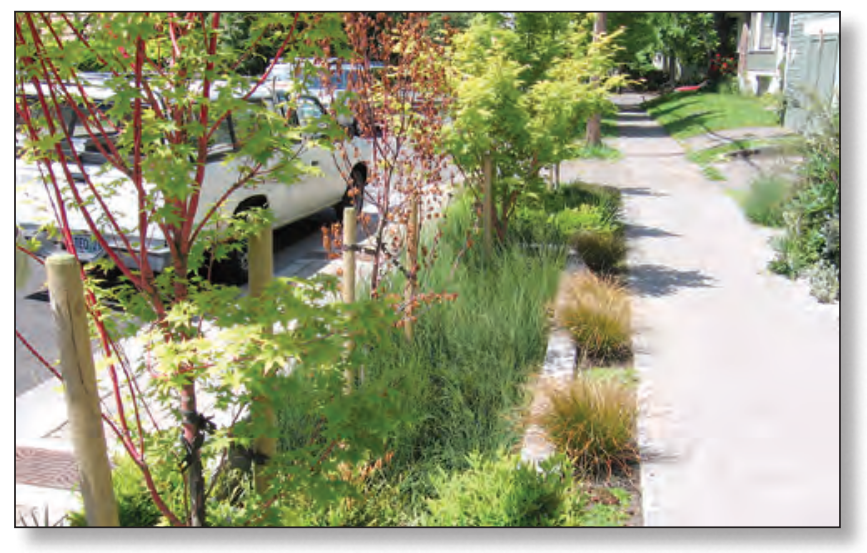

Plains region is consistent with the USGS investigation finding that agricultural land cover in watersheds with low levels of urban development, as in the Milwaukee, Dallas, and Denver study areas, likely led to a reduction in the number of sensitive species in streams prior to urban development.

An issue of potential concern for resource managers in using least-disturbed streams to define reference conditions is that the qualities of what is considered a healthy stream can vary greatly from region to region. When assessments of stream health are based on regionally distinct reference biological communities, they are generally difficult to compare across regions. This is evident, for example, when tolerant species dominate the biological community in least-disturbed streams of a region where prior land-use disturbances have caused a decrease in the number of sensitive species. One solution that addresses this inconsistency is the use of a biological condition gradient (BCG), which is summarized in chapter 6 and discussed at length in Davies and Jackson (2006). The BCG provides a frame of reference for assessing aquatic biological conditions across the United States. Leastdisturbed conditions in some parts of the country may support high-quality biological communities associated with BCG tier 1 or 2 (see chapter 6 ). In other parts of the country, leastdisturbed conditions may support only biological communities associated with BCG tier 3 or 4. Informative comparisons across regions can be made only when they are based on a common frame of reference.

$\boldsymbol{B}$

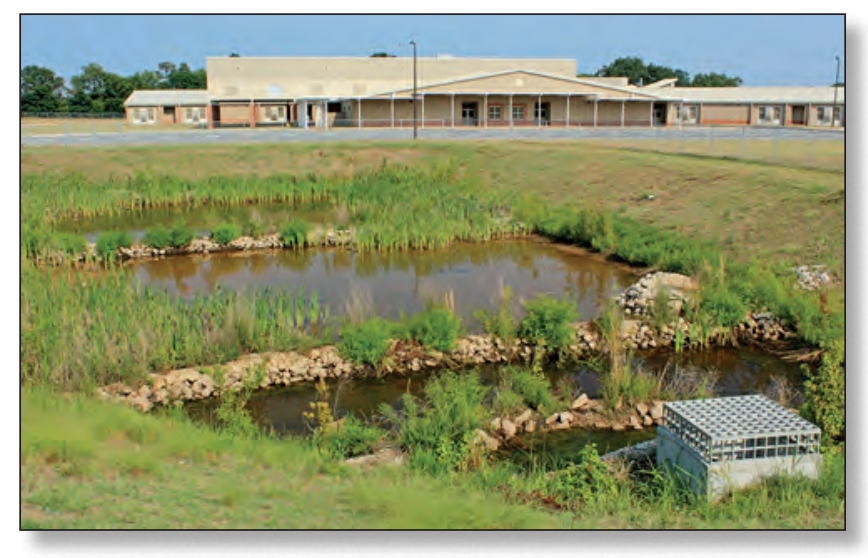

Strategies to reduce, disconnect, or treat impervious cover and increase stormwater infiltration include $(A)$ installing permeable pavements instead of impervious asphalt or concrete in low-traffic parking areas (photograph by Center for Watershed Protection, Ellicott City, Md.); (B) disconnecting rooftop downspouts and parking lots from the storm sewer system and redirecting into a rain garden (photograph by Alan M. Cressler, USGS); and (C) incorporating street bioretention to capture and treat runoff from the adjacent street (photograph by Center for Watershed Protection, Ellicott City, Md.). 


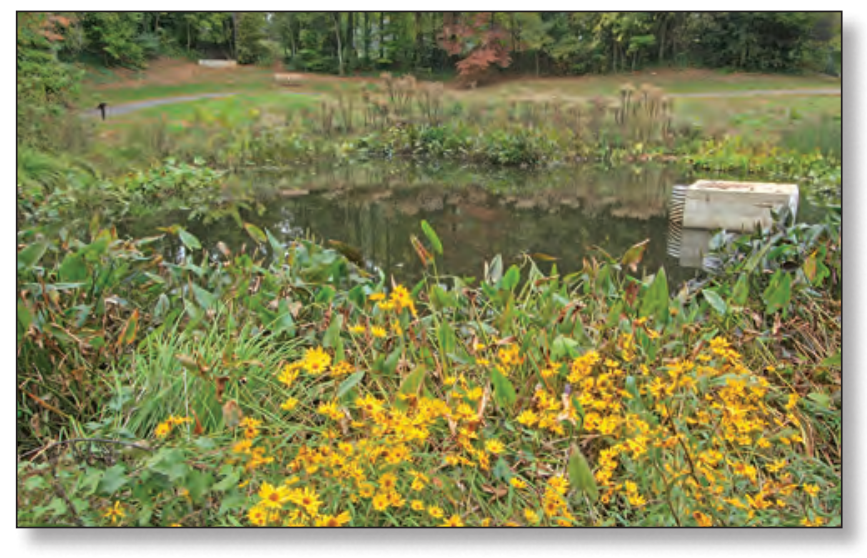

Management strategies to reduce pollutants from urban land include installation of stormwater BMPs to capture runoff and remove pollutants, and programs to encourage residents to adopt pollution-preventing behaviors, such as this pet-waste pickup station at a local park. (Photographs by Alan M. Cressler, USGS, and Center for Watershed Protection, Ellicott City, Md., respectively.)

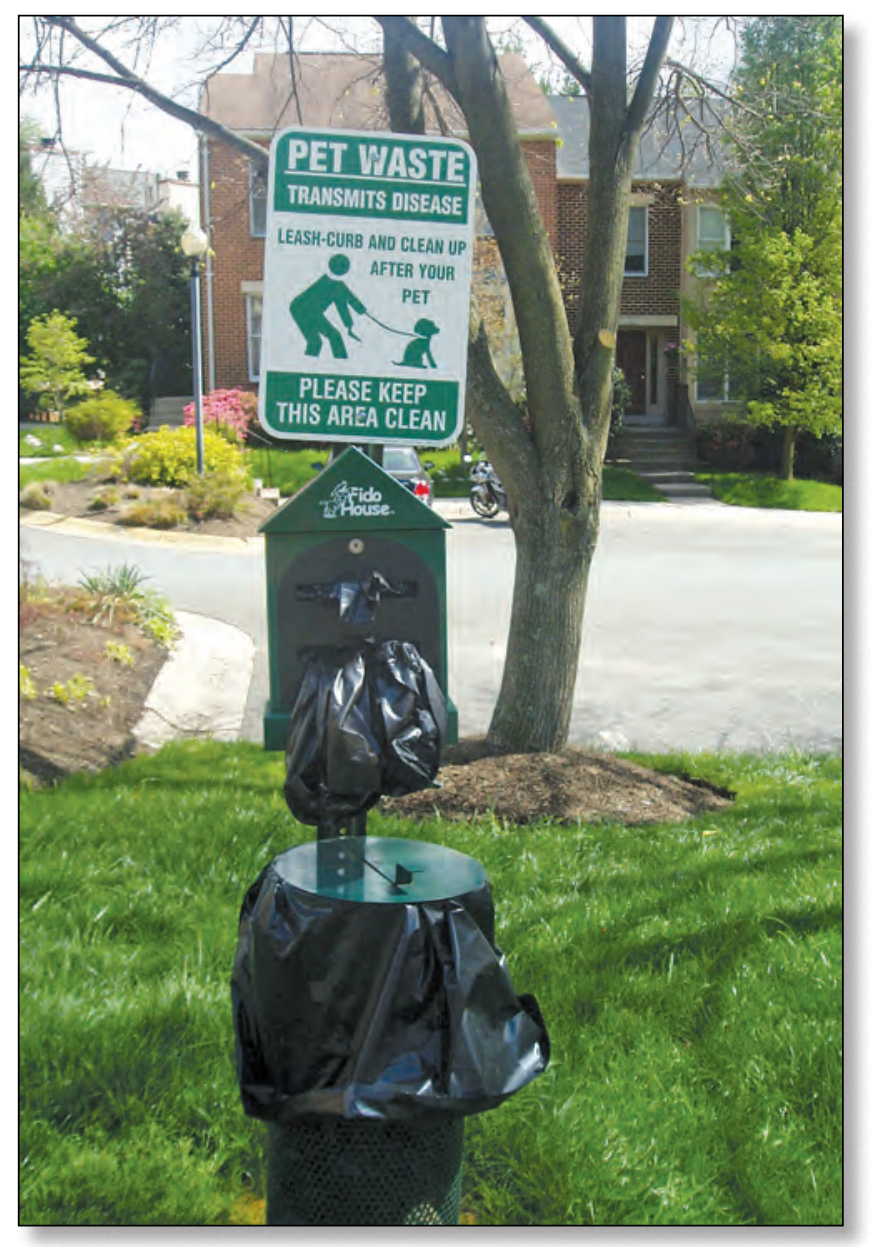

\section{Indicators of the Effects of Urban Development Must Be Both Scientifically Based and Relevant to Important Social Values}

Natural and physical scientists have developed scientific measures, such as those reported in chapters $4-6$, to communicate information about the outcomes of physical, chemical, and biological processes associated with urban streams to a scientific audience. Social scientists are interested in characterizing the value and benefits of these same outcomes to society, whether the benefits are tangible, such as revenue from tourism, or intangible, such as the enjoyment of walking along a healthy stream. If stream condition is defined solely by scientific metrics that the public might not readily relate to or value, such as chloride ion concentrations or the number of EPT invertebrate species, then generating public support for the protection of urban streams may be hindered. As noted by Boyd and Banzhaf (2007), when natural and physical science are disconnected from social science, science-based information that is expressed only in terms that are meaningful to scientists cannot effectively influence public policy. Consequently, policymakers may not be able to make a direct connection between the condition of a stream described solely in scientific terms, however valid, and its impacts on human well-being. For instance, even a very complete and scientifically sound description of species diversity in a stream may not provide a meaningful connection to tangible benefits to people.

Environmental endpoints can be used for making a connection between scientifically oriented descriptions of stream conditions and the value that society places on these conditions. In order to provide a connection between the scientific and social domain, endpoints must make sense from both a scientific and social value perspective (Boyd and Banzhaf, 2007). From a scientific perspective, a useful environmental endpoint has several characteristics:

- Endpoints are biophysical results, such as EPT species richness or chloride ion concentration;

- Endpoints are tangible and can be measured in a consistent manner; and

- Endpoints make ecological sense by describing results of one or more ecological processes. 
To be useful in determining the social value of an environmental outcome, ideally, an environmental endpoint should have these additional characteristics:

- Endpoints can be translated into terms that are commonly understood;

- Endpoints can be connected to some measure of human well-being that society cares about; and

- Endpoints are physically required for a societal benefit to be realized.

The BCG used in the New England study described in chapter 6 illustrates an approach to synthesize information about stream condition and societal benefits related to water quality in a way that meets the scientific and social criteria listed above. The BCG has six tiers for assessing the health of a stream by using biological samples. These tiers synthesize information about biological endpoints and the meaning of endpoints in terms of meeting or not meeting Clean Water Act standards. The assignment of a stream to any tier is based on a regionally appropriate assessment of a stream's aquatic biota, which is completed in a consistent, replicable, and scientifically accepted manner.

Because the BCG framework can be used to map changes in biological endpoints to levels of stream health, assignment of a BCG tier to a stream can be used to determine if the stream is attaining water-quality standards of the Clean Water Act. The BCG tier assigned to a stream indicates to managers whether or not the stream meets a mandated standard for classification as a healthy stream. If not, enforcement actions, such as a TMDL, can be taken, which could have important financial repercussions for an individual, corporation, or government jurisdiction.

\section{Disconnect Between Jurisdictional and Watershed Boundaries}

One of the challenges in developing and implementing urban watershed-management efforts is that the watershed scale, which is the scale at which urban stream impacts are managed most effectively, may not align with the jurisdictional boundaries in which most regulations and policies are applied. This can make it difficult for a downstream municipality to protect its water resources when part of the watershed is outside its jurisdiction, such as when an upstream municipality has a disincentive to control development because of loss of potential tax revenue.

\section{Fiscal Disparity Law Enhances Cross- Jurisdictional Land-Use Planning}

While interjurisdictional collaboration could enhance effective management of urban development or other activities affecting water quality at the watershed scale, this collaboration has not been widely practiced or accepted. Obtaining interjurisdictional consensus for implementing a watershed protection-oriented land-use plan that benefits one jurisdiction more than another is difficult at best, especially if one jurisdiction gains water-quality protection without having to limit development.

The Minnesota Fiscal Disparities Program is one approach for dealing with potential inequalities by granting all jurisdictions within a metropolitan area a partial share of the commercial-industrial property-tax base. Created by the Minnesota Fiscal Disparities Act of 1971, the Twin Cities tax-base sharing program was in response to interjurisdictional concerns about tax-base and tax-rate disparities and competition for development.

As described by Orfield and Wallace (2007), the Twin Cities program requires each taxing jurisdiction in a seven-county area to contribute 40 percent of the growth in value of its commercial-industrial tax capacity to a regional pool of funds. Municipalities are assigned a portion of the pool based on population and the ratio of total market value of property per capita in the jurisdiction to average market value of property per capita in the region. The formula assigns a greater share of the funds in the pool to municipalities with lower-than-average market value per capita than would be justified based on population alone, while high market-value localities receive a lower portion than their population share.

The Twin Cities metropolitan area has benefited from tax-base sharing by reducing incentives for individual jurisdictions to engage in fiscal zoning and tax-base competition practices that could jeopardize land conservation, which benefits the region as a whole. By reducing the need for local governments to compete with each other for revenue-generating land uses, such policies enhance the possibility for engaging in regional landuse planning.

For more information, go to http://www.metrocouncil. org/newsletter/planning2010/FiscalDisparitiesOct4.htm. 


\section{Managing Stormwater: Adapting Management Approaches to Lessons Learned}

The implementation of what are now thought of as traditional stormwater BMPs in the 1970s and 1980s addressed a goal of preserving the pre-development hydrologic regime by controlling the peak rate of flow leaving a site, such as the use of stormwater-detention ponds. In some cases, however, this led to increased downstream flooding as a result of cumulative increased flow from individual development sites within a watershed, particularly if each site was designed, approved, and constructed on a site-by-site basis (Clark and Hamilton, 2008). Some studies also concluded that stormwater-detention systems could actually worsen downstream channel erosion (Lee and Ham, 1988; MacRae, 1996). Based on this information, stormwater management is shifting to management strategies that improve infiltration to groundwater and increase base flow by reducing runoff volume and the frequency and duration of peak flows so as to reduce stream flashiness, prevent channel erosion, and protect stream habitat (fig. 7-4; National Research Council, 2008).

\section{A. Before}

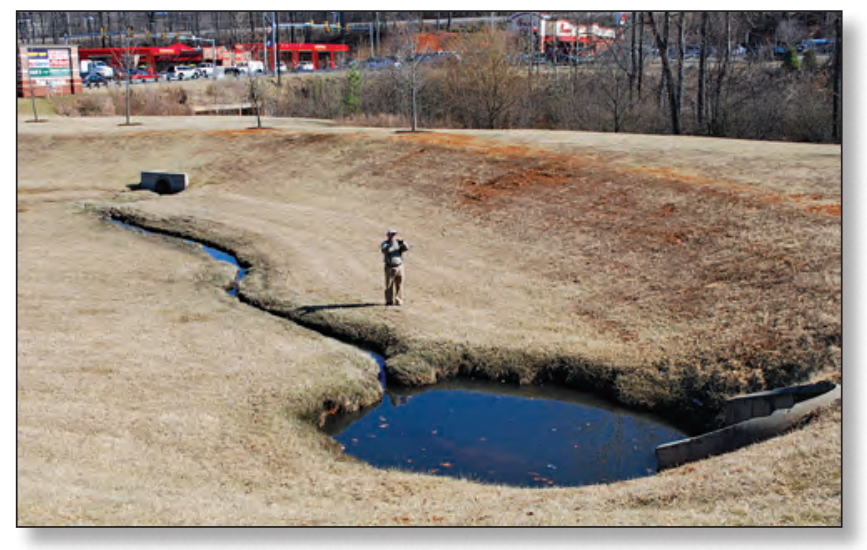

B. After

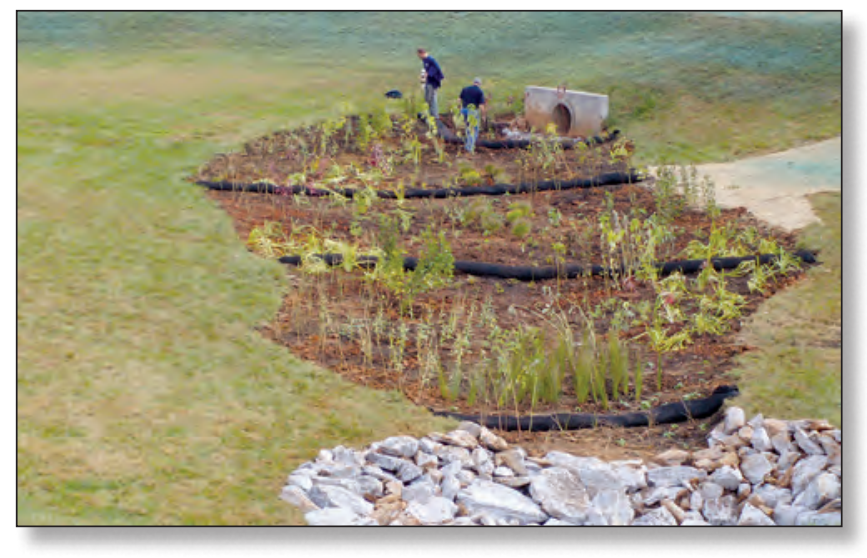

\section{Virginia's Runoff-Reduction Method}

In 2004, the Commonwealth of Virginia amended its stormwater law to promote the use of low-impact development. Although few municipalities developed a strategy for implementing low-impact development practices, such as bioretention and planting of grass swales to reduce runoff volume and peak flows, no statewide regulatory framework was in place to provide incentives to use low-impact development and other site design strategies aimed at reducing the impacts of development. During the process of updating the Virginia Stormwater Management Permit program regulations in 2007, however, the Virginia Department of Conservation and Recreation proceeded to update the BMP performance standards and develop a framework for measuring compliance with water-quality and channelprotection requirements. One of the results is the Runoff Reduction Method (fig. 7-5; Hirschman and others, 2008).

The Runoff Reduction Method is a spreadsheet-based, stormwater design system that incorporates built-in incentives for the use of site-design strategies that minimize impacts to the natural or existing site hydrology. By addressing runoff volume, duration, velocity, frequency, groundwater recharge, and protection of stream channels, this method is intended to facilitate approaches that move beyond managing solely for peak flow rate and water-quality treatment. When used in conjunction with site-based pollutant load limits, this method also can help municipalities meet pollutant-reduction goals (for example, nutrient strategies, TMDLs) of the larger watershed.

The Virginia Runoff Reduction Method is focused on site compliance to meet site-based phosphorus load limits. Under this method, site designers can use combinations of practices that receive variable runoff-reduction and pollutantremoval credits based on average annual values derived from research studies (Hirschman and others, 2008). Site designers are encouraged to use practices that reduce the overall volume of runoff for the post-development condition to achieve the required load limit. The Virginia stormwater BMP clearinghouse web site includes a list of BMPs that can be used and provides design standards and specifications for each BMP.

For more information, go to http://vwrrc.vt.edu/swc/.

Figure 7-4. A grassed channel leading from a partially visible strip mall $(A)$ before and $(B)$ after construction of a stormwater management channel leading to an outfall pipe in Lynchburg, Va. The previously grassed channel was converted to a wetland to reduce runoff and filter pollutants. (Photographs by Center for Watershed Protection, Ellicott City, Md.) 


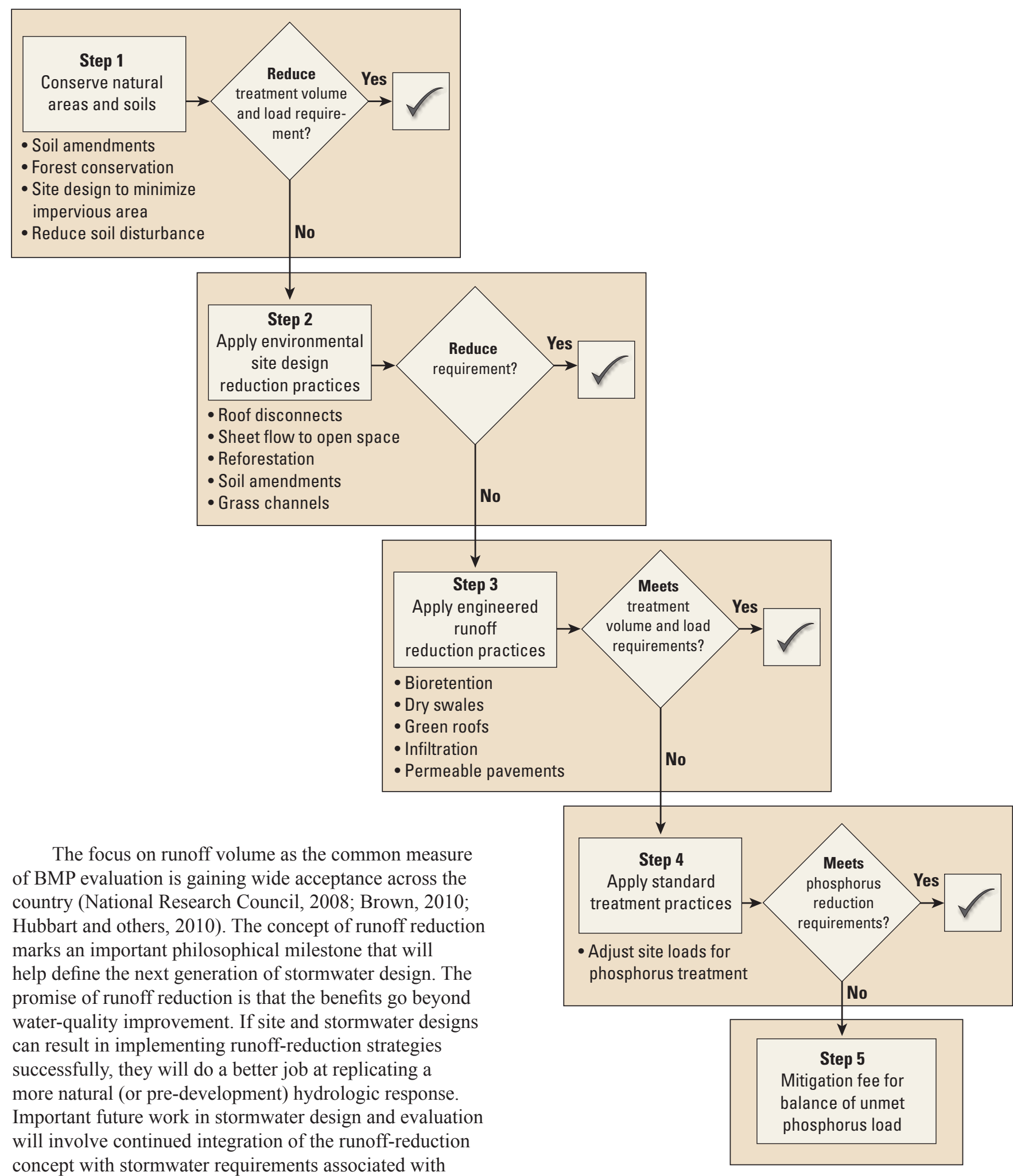

concept with stormwater requirements associated with channel protection and flood control, so that managing the effects of post-development stormwater can occur in a unified approach.

To learn more, go to http://www.dcr.virginia.gov/lr2f.shtml.

Figure 7-5. The Virginia Runoff Reduction Method is a planning approach for reducing the hydrologic response associated with urban development. 


\section{Educating the Public on Recognizing Good Stream-Management Practices}

Educating the general public about how their actions at home affect stream health is critical for environmental protection. Protecting streams may require making different choices, such as reducing fertilizer applications to residential lawns and gardens (fig. 7-6), which require re-evaluating familiar practices based on new awareness. A variety of studies, however, have determined that increasing awareness alone may not result in changing behavior (Costanzo and others, 1986; McKenzie-Mohr, 2000). Concerns over convenience and perceptions of the cost in time and resources can result in reluctance to adopt new practices, even if they are seen as beneficial.

Signage and other public educational tools that explain the purpose of BMPs are important to help the public understand the connection between things they see every day and the quality of the environment. For example, the King Farm urban-development plan in Rockville, Maryland, has an openspace framework intended to reflect the environmentally sensitive areas analysis completed by Montgomery County (U.S. Environmental Protection Agency, 2010b).

Initially, the public did not understand the purpose of "no-disturbance" areas along the valleys of the Watts Branch tributaries that flow through the site. This was particularly true for the valleys that are lined with homes built only on the side of the street opposite the valley. The public felt that

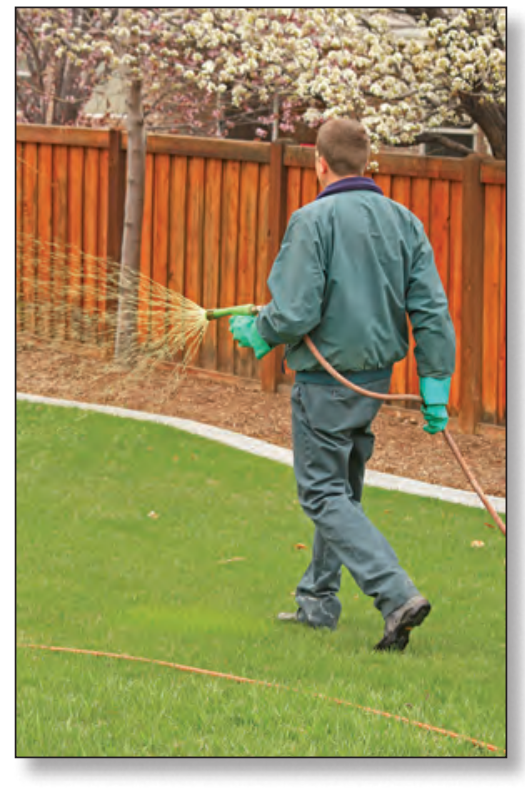

Figure 7-6. Resident behaviors, such as applying lawn fertilizer, can have a cumulatively large impact on water quality. It is not well understood, however, what types of outreach programs are most effective in encouraging widespread behavioral change. the undeveloped side of the street should be mowed and landscaped. Because these actions would limit the ability of the stream valleys to help remove contaminants from stormwater runoff, however, the City of Rockville instituted an educational signage program called "Growing... Not Mowing" and placed signs along all the stream valleys in King Farm (fig. 7-7). The signs explained that the natural, undeveloped space along the stream valleys was for the purpose of water-quality protection and stormwater-runoff mitigation. This effort eventually led to the public's understanding and support of the diverse reasons for open space and the value of communicating the intended purpose of management decisions (MacDonald and others, 2003).

\section{Conclusion}

Urban development that degrades the condition of stream biota can lead to the non-attainment of water-quality standards and result in the need for costly remediation efforts. Nevertheless, humans are choosing in ever greater numbers to live, work, and recreate in urban areas, and the continuing growth of urban areas in the Nation and world appears to be an inescapable fact. Finding a balance between urban development and its effects on the health and resilience of urban stream ecosystems from multiple stressors presents watershed managers and policymakers with management challenges that require innovative, adaptive management solutions.

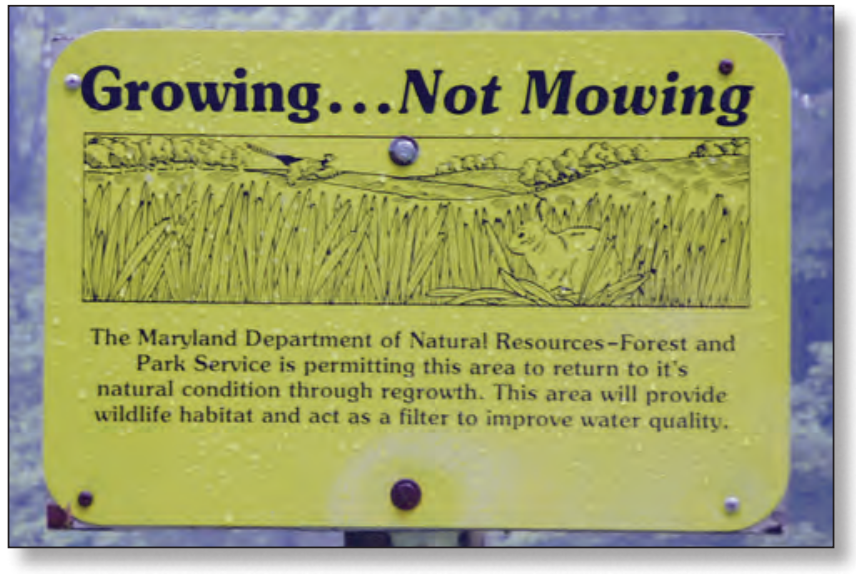

Figure 7-7. "Growing... Not Mowing" signs along the streams in King Farm, Md., emphasize the importance of natural areas in providing wildlife habitat and water-quality protection. (Photograph by Center for Watershed Protection, Ellicott City, Md.) 


\section{References Cited}

Alberti, M., and Marzluff, J.M., 2004, Ecological resilience in urban ecosystems: Linking urban patterns to human and ecological functions: Urban Ecosystems, v. 7, no. 3, p. 241-265.

Alberti, M., Marzluff, J.M., Shulenberger, E., Bradley, G., Ryan, C., and Zumbrunnen, C., 2003, Integrating humans into ecology: Opportunities and challenges for studying urban ecosystems: BioScience, v. 53, no. 12, p. 1169-1179.

Allan, J.D., and Castillo, M.M., 2007, Stream ecology: Structure and function of running waters ( $2 \mathrm{~d}$ ed.): Dordrecht, The Netherlands, Springer.

Allan, J.D., Erickson, D.L., and Fay, J., 1997, The influence of catchment land use on stream integrity across multiple spatial scales: Freshwater Biology, v. 37, no. 1, p. 149-161.

American Farmland Trust, 2009, Farming on the edge report: What's happening to our farmland?: American Farmland Trust, accessed June 30, 2010, at http://www.farmland.org/ resources/fote/default.asp.

Amweg, E.L., Weston, D.P., You, J., and Lydy, M.J., 2006, Pyrethroid insecticides and sediment toxicity in urban creeks from California and Tennessee: Environmental Science and Technology, v. 40, no. 5, p. 1700-1706.

Ash, C., Jasny, B.R., Roberts, L., Stone, R., and Sugden, A.M., 2008, Reimagining cities: Science, v. 319, no. 5864, p. 739.

Baily, R.G., 1996, Ecosystem geography: New York, SpringerVerlag, 204 p.

Baron, J.S., Poff, N.L., Angermeier, P.L., Dahm, C.N., Gleik, P.H., Hairston, N.G., Jackson, R.B., Johnston, C.A., Richter, B.D., and Steinman, A.D., 2002, Meeting ecological and societal needs for freshwater: Ecological Applications, v. 12 , no. 5 , p. $1247-1260$.

Beal, R.H., Mauldin, J.K., and Jones, S.C., 1994, Subterranean termites - Their prevention and control in buildings: U.S. Department of Agriculture, Forest Service Home and Garden Bulletin No. 64, 36 p.

Beaulieu, K.M., Bell, A.H., and Coles, J.F., 2012, Variability in stream chemistry in relation to urban development and biological condition in seven metropolitan areas of the United States, 1999-2004: U.S. Geological Survey Scientific Investigations Report 2012-5170, 27 p., available at http://pubs.usgs.gov/sir/2012/5170/.
Blazer, V.S., Iwanowicz, L.R., Iwanowicz, D.D., Smith, D.R., Young, J.A., Hedrick, J.D., Foster, S.W., and Reeser, S.J., 2007, Intersex (testicular oocytes) in smallmouth bass from the Potomac River and selected nearby drainages: Journal of Aquatic Animal Health, v. 19, no. 4, p. 242-253, doi:10:1577/H07-031.1.

Bluestone, B., Stevenson, M.H., and Williams, R., 2008, The urban experience: Economics, society, and public policy: Oxford University Press, 624 p.

Boyd, J., and Banzhaf, S., 2007, What are ecosystem services? The need for standardized environmental accounting units: Ecological Economics, v. 63, no. 2-3, p. 616-626.

Brown, L.R., Gregory, M.B., and May, J.T., 2009, Relation of urbanization to stream fish assemblages and species traits in nine metropolitan areas of the United States: Urban Ecosystems, v. 12, no. 4, p. 391-416.

Brown, T., 2010, Can volume-based stormwater criteria make a difference to receiving stream health?: Water Resources Impact, v. 12, no. 2, p. 5-8.

Bryant, W.L., and Carlisle, D.M., 2012, The relative importance of physicochemical factors to stream biological condition in urbanizing basins: Evidence from multimodel inference: Journal of Freshwater Science, v. 31, no. 1, p. 154-166.

Bryant, W.L., and Goodbred, S.L., 2008, The response of hydrophobic organics and potential toxicity in streams to urbanization of watersheds in six metropolitan areas of the United States: Environmental Monitoring and Assessment, v. 157 , nos. 1-4, p. 419-447.

Bryant, W.L., Goodbred, S.L., Leiker, T.L., Inouye, L., and Johnson, B.T., 2007, Use of chemical analysis and assays of semipermeable membrane devices extracts to assess the response of bioavailable organic pollutants in streams to urbanization in six metropolitan areas of the United States: U.S. Geological Survey Scientific Investigations Report 2007-5113, 47 p.

Budrock, Helen, 1997, Summary guide to the terms of the watershed agreement, A guidebook for government officials, planning and zoning board members, and citizens of the Catskill/Delaware Watershed: Arkville, N.Y., The Catskill Center for Conservation and Development, Inc., 31 p., 3 apps., accessed March 20, 2012, at http://www.cwconline. org/pubs/Summary\%20Guide.pdf.

Bunn, S.E., and Arthington, A.H., 2002, Basic principles and ecological consequences of altered flow regimes for aquatic biodiversity: Environmental Management, v. 30, no. 4, p. 492-507. 
Burnham, K.P., and Anderson, D.R., 2002, Model selection and multimodel inference: A practical information-theoretic approach ( $2 \mathrm{~d}$ ed.): New York, Springer, 488 p.

Callender, E., and Rice K.C., 2000, The urban environmental gradient: Anthropogenic influences on the spatial and temporal distributions of lead and zinc in sediments: Environmental Science and Technology, v. 34, no. 2, p. 232-238.

Cappiella, Karen, Stack, W.P., Fraley-McNeal, Lisa, Lane, Cecilia, and McMahon, Gerard, 2012, Strategies for managing the effects of urban development on streams: U.S. Geological Survey Circular 1378, 69 p.

Cardinale, B.J., 2011, Biodiversity improves water quality through niche partitioning: Nature, v. 472, p. 86-89.

Cardinale, B.J., Matulich, K.L., Hooper, D.U., Byrnes, J.E., Duffy, E., Gamfeldt, L., Balvanera, P., O'Connor, M.I., and Gonzalez, A., 2011, The functional role of producer diversity in ecosystems: American Journal of Botany, v. 98, no. 3 , p. $572-592$.

Chalmers, A.T., Van Metre, P.C., and Callender, E., 2007, The chemical response of particle-associated contaminants in aquatic sediments to urbanization in New England, U.S.A.: Journal of Contaminant Hydrology, v. 91, p. 4-25.

Chambers, D.B., and Leiker, T.J., 2006, A reconnaissance for emerging contaminants in the South Branch Potomac River, Cacapon River and Williams River basins, West Virginia, April-October 2004: U.S. Geological Survey Open-File Report 2006-1393, 28 p.

Chin, A., 2006, Urban transformation of river landscapes in a global context: Geomorphology, v. 79, no. 3-4, p. 460-487.

Clark, J.J., and Hamilton, J., 2008, Effects of land use, stormwater management, and channel materials on the channel morphology of Apple Creek, WI: Journal of Agricultural, Food and Environmental Sciences, v. 2, no. 1, 17 p.

Coles, J.F., Bell, A.H., Scudder, B.C., and Carpenter, K.D., 2009, The effects of urbanization and other environmental gradients on algal assemblages in nine metropolitan areas across the United States: U.S. Geological Survey Scientific Investigations Report 2009-5022, 19 p.

Coles, J.F., Cuffney, T.F., McMahon, G., and Beaulieu, K.M., 2004, The effects of urbanization on the biological, physical, and chemical characteristics of coastal New England streams: U.S. Geological Survey Professional Paper 1695, 56 p. Available at http://pubs.usgs.gov/pp/pp1695/.

Corsi, S.R., Graczyk, D.J., Geis, S.W., Booth, N.L., and Richards, K.D., 2010, A fresh look at road salt-Aquatic toxicity and water-quality impacts on local, regional, and national scales: Environmental Science and Technology, v. 44, no. 19 , p. $7376-7382$.
Costanzo, M., Archer, D., Aronson, E., and Pettigrew, T., 1986, Energy conservation behavior: The difficult path from information to action: American Psychologist, v. 41, no. 5, p. 521-528.

Cuffney, T.F., Brightbill, R.A., May, J.T., and Waite, I.R., 2010, Responses of benthic macroinvertebrates to environmental changes associated with urbanization in nine metropolitan areas: Ecological Applications, v. 20, no. 5, p. 1384-1401.

Cuffney, T.F., Kashuba, R.O., Qian, S.S., Alameddine, I., Cha, Y.K., Lee, B., Coles, J.F., and McMahon, G., 2011, Multilevel regression models describing regional patterns of invertebrate and algal responses to urbanization across the United States: Journal of the North American Benthological Society, v. 30, no. 3, p. 779-786.

Davies, S.P., and Jackson, S.K., 2006, The biological condition gradient: A descriptive model for interpreting change in aquatic ecosystems: Ecological Applications, v. 16, no. 4, p. 1251-1266.

Ding, Y., Harwood, A.D., Foslund, H.M., and Lydy, M.J., 2010, Distribution and toxicity of sediment-associated pesticides in urban and agricultural waterways from Illinois, U.S.A.: Environmental Toxicology and Chemistry, v. 29, no. 1, p. 149-157.

Einstein, H.A., 1950, The bed-load function for sediment transportation in open channel flows: Washington D.C., U.S. Department of Agriculture Technical Bulletin 1026.

Falcone, J.A., Stewart, J.S., Sobieszczyk, S., Dupree, J.A., McMahon, G., and Buell, G.R., 2007, A comparison of natural and urban characteristics and the development of urban intensity indices across six geographic settings: U.S. Geological Survey Scientific Investigations Report 20075123, 45 p. Available at http://pubs.usgs.gov/sir/2007/5123/.

Fitzpatrick, F.A., and Peppler, M.C., 2010, Relation of urbanization to stream habitat and geomorphic characteristics in nine metropolitan areas of the United States: U.S. Geological Survey Scientific Investigations Report 2010-5056, 29 p. Available at http://pubs.usgs.gov/ sir/2010/5056/.

Fitzpatrick, F.A., Waite, I.R., D'Arconte, P.J., Meador, M.R., Maupin, M.A., and Gurtz, M.E., 1998, Revised methods for characterizing stream habitat in the National Water-Quality Assessment program: U.S. Geological Survey WaterResources Investigations Report 98-4052, 67 p. Available at http://pubs.usgs.gov/wri/wri984052/.

Freeman, O.L., and Bennett, I.L., Jr., 1969, Control of agriculture-related pollution, A report to the President: Washington, D.C., U.S. Department of Agriculture, Office of Science and Technology, $102 \mathrm{p}$. 
Fulton, W., Pendall, R., Nguyen, M., and Harrison, A., 2001, Who sprawls most? How growth patterns differ across the U.S.: Washington, D.C., The Brookings Institution, Center on Urban and Metropolitan Policy, accessed September 7, 2010, at http://www.brookings.edu/es/urban/publications/ fulton.pdf.

Gellis, A.C., and others, 2009, Sources, transport, and storage of sediment in the Chesapeake Bay Watershed: U.S. Geological Survey Scientific Investigations Report 2008-5186, 95 p.

Georgia Forestry Commission, 2001, Georgia model urban forest book: Georgia Forestry Commission, 78 p.

Giddings, E.M.P., Bell, A.H., Beaulieu, K.M., Cuffney, T.F., Coles, J.F., Brown, L.R., Fitzpatrick, F.A., Falcone, J.A., Sprague, L.A., Bryant, W.L., Peppler, M.C., Stephens, C., and McMahon, G., 2009, Selected physical, chemical, and biological data used to study urbanizing streams in nine metropolitan areas of the United States, 1999-2004: U.S. Geological Survey Data Series 423, 11 p. Available at http://pubs.usgs.gov/ds/423/.

Giddings, E.M.P., Brown, L.R., Short, T.M., and Meador, M.R., 2006, Relation of fish communities to environmental conditions in urban streams of the Wasatch Front, Utah: Western North American Naturalist, v. 66, no. 2, p. $155-186$.

Giddings, E.M.P., Moorman, M.C., Cuffney, T.F., McMahon, Gerard, and Harned, D.A., 2007, Selected physical, chemical, and biological data for 30 urbanizing streams in the North Carolina Piedmont ecoregion, 2002-2003: U.S. Geological Survey Data Series 279, 14 p. Available at http://nc.water.usgs.gov/reports/ds279/.

Gilliom, R.J., Barbash, J.E., Crawford, C.G., Hamilton, P.A., Martin, J.,D., Nakagaki, N., Nowell, L.H., Scott, J.C., Stackelberg, P.E., Thelin, G.P., and Wolock, D.M., 2006, The quality of our nation's water-Pesticides in the nation's streams and ground water, 1992-2001: U.S. Geological Survey Circular 1291, 172 p. Available at http://pubs.usgs. gov/circ/2005/1291/.

Gourlay, C., Miège, C., Noir, A., Ravelet, C., Garric, J., and Mouchel, J.-M., 2005, How accurately do semi-permeable membrane devices measure the bioavailability of polycyclic aromatic hydrocarbons to Daphnia magna?: Chemosphere, v. 61 , no. 11, p. $1734-1739$.

Graffy, E.A., Helsel, D.R., and Mueller, D.K., 1996, Nutrients in the nation's waters: Identifying problems and progress, A national water-quality assessment of nutrients: U.S. Geological Survey Fact Sheet FS-218-96, 6 p. Available at http://pubs.usgs.gov/fs/fs218-96/.
Gregory, M.B., and Bryant, W.L., 2003, Effects of urbanization on stream ecosystems in the Piedmont Ecoregion of Georgia and Alabama-A study design, in Hatcher, K.J., ed., Proceedings of the 2003 Georgia Water Resources Conference, April 23-24, 2003, Athens, Ga., p. 5.

Gregory, M.B., and Calhoun, D.L., 2007, Physical, chemical, and biological responses of streams to increasing watershed urbanization in the Piedmont Ecoregion of Georgia and Alabama, 2003: U.S. Geological Survey Scientific Investigations Report 2006-5101-B, 118 p. Available at http://pubs.usgs.gov/sir/2006/5101B/.

Grimm, N.B., Faeth, S.H., Golubiewski, N.E., Redman, C.L., Wu, J., Bai, X., and Briggs, J.M., 2008, Global change and the ecology of cities: Science, v. 319, no. 5864, p. 756-760.

Groffman, P.M., Bain, D.J., Band, L.E., Belt, K.T., Brush, G.S., Grove, J.M., Pouyat, R.V., Yesilonis, I.C., and Zipperer, W.C., 2003, Down by the riverside: Urban riparian ecology: Frontiers in Ecology and the Environment, v. 1 , no. 6, p. 315-321.

Gurnell, A.M., Lee, M., and Souch, C., 2007, Urban riversHydrology, geomorphology, ecology, and opportunities for change: Geography Compass, v. 1, no. 5, p. 1118-1137.

Hector, A., 2011, Ecology: Diversity favours productivity: Nature, v. 472, p. 45-46.

Herlihy, A.T., Paulsen, S.G., Van Sickle, J., Stoddard, J.L., Hawkins, C.P., and Yuan, L.L., 2008, Striving for consistency in a national assessment: The challenges of applying a reference-condition approach at a continental scale: Journal of the North American Benthological Society, v. 27, no. 4, p. $860-877$.

Hinck, J.E., Schmitt, C.J., Chojnacki, K.A., and Tillitt, D.E., 2009, Environmental contaminants in freshwater fish and their risk to piscivorous wildlife based on a national monitoring program: Environmental Monitoring and Assessment, v. 152 , no. $1-4$, p. $469-494$.

Hintzen, E.P., Lydy, M.J., and Belden, J.B., 2009, Occurrence and potential toxicity of pyrethroids and other insecticides in bed sediments of urban streams in central Texas: Environmental Pollution, v. 157, no. 1, p. 110-116.

Hirschman, D., Collins, K., and Schueler, T.R., 2008, Technical memorandum: The runoff reduction method: Ellicott City, Md., Center for Watershed Protection, $25 \mathrm{p}$. Available at http://www.dcr.virginia.gov/documents/ stmrunredmethmemo.pdf.

Holmes, R.W., Anderson, B.S., Phillips, B.M., Hunt, J.W., Crane, D.B., Mekebri, A., and Connor, V., 2008, Statewide investigation of the role of pyrethroid pesticides in sediment toxicity in California's urban waterways: Environmental Science and Technology, v. 42, no. 18, p. 7003-7009. 
Homer, C., Dewitz, J., Fry, J., Coan, M., Hossain, N., Larson, C., Herold, N., McKerrow, A., Van Driel, J.N., and Wickham, J., 2007, Completion of the 2001 national land cover database for the conterminous United States: Photogrammetric Engineering and Remote Sensing, v. 73, no. 4, p. 337-341.

Homer, C., Huang, C., Yang, L., Wylie, B., and Coan, M., 2004, Development of a 2001 national land-cover database for the United States: Photogrammetric Engineering and Remote Sensing, v. 70, no. 7, p. 829-840.

Hubbart, J.A., Holmes, J., and Bowman, G., 2010, TMDLs: Improving stakeholder acceptance with science-based allocations: Watershed Science Bulletin, Fall 2010, p. 19-24.

Huckins, J.N., Petty, J.D., and Booij, K., 2006, Monitors of organic chemicals in the environment: Semipermeable membrane devices: New York, Springer, 223 p.

Huckins, J.N., Petty, J.D., Orazio, C.E., Prest, H.F., Tillitt, D.E., Ellis, G.S., Johnson, B.T., and Manuweera, G.K., 1996, Semipermeable membrane devices (SPMDs) for the concentration and assessment of bioavailable organic contaminants in aquatic environments, in Ostrander, G.K., ed., Techniques in aquatic toxicology: Boca Raton, Fla., CRC Lewis Publishers, p. 625-655.

Ingersoll, C.G., Kemble, N.E., Kunz, J.L., Brumbaugh, W.G., MacDonald, D.D., and Smorong, D.E., 2009, Toxicity of sediment cores collected from the Ashtabula River in Northeastern Ohio, USA, to the amphipod Hyalella azteca: Archives of Environmental Contamination and Toxicology, v. 57, no. 2, p. 315-329.

Ingersoll, C.G., MacDonald, D.D., Wang, N., Crane, J.L., Field, L.J., Haverland, P.S., Kemble, N.E., Lindskoog, R.A., Severn, C., and Smorong, D.E., 2001, Predictions of sediment toxicity using consensus-based freshwater sediment quality guidelines: Archives of Environmental Contamination and Toxicology, v. 41, no. 1, p. 8-21

Ingersoll, C.G., Wang, N., Hayward, J.M.R., Jones, J.R., Jones, S.B., and Ireland, D.S., 2005, A field assessment of long-term laboratory sediment toxicity tests with the amphipod Hyalella azteca: Environmental Toxicology and Chemistry, v. 24, no. 11, p. 2853-2870.

Karr, J.R., and Chu, E.W., 1999, Restoring life in running waters-Better biological monitoring: Washington, D.C., Island Press, 206 p.

Karr, J.R., and Dudley, D.R., 1981, Ecological perspective on water quality goals: Environmental Management, v. 5, no. 1, p. 55-68.
Kashuba, R.O., Cha, YoonKyung, Alameddine, Ibrahim, Lee, Boknam, and Cuffney, T.F., 2010, Multilevel hierarchical modeling of benthic macroinvertebrate responses to urbanization in nine metropolitan regions across the conterminous United States: U.S. Geological Survey Scientific Investigations Report 2009-5243, 88 p. Available at http://pubs.usgs. gov/sir/2009/5243/.

Kashuba, R.O., McMahon, Gerard, Cuffney, T.F., Qian, S., Reckhow, K., Gerritsen, J., and Davies, S., 2012, Linking urbanization to the Biological Condition Gradient (BCG) for stream ecosystems in the Northeastern United States using a Bayesian network approach: U.S. Geological Survey Scientific Investigations Report 2012-5030, 48 p.

Kaushal, S.S., Groffman, P.M., Likens, G.E., Belt, K.T., Stack, W.P., Kelly, V.R., Band, L.E., and Fisher, G.T., 2005, Increased salinization of fresh water in the northeastern United States: Proceedings of the National Academy of Sciences of the United States of America, v. 102, no. 38, p. 13517-13520.

Kaushal, S.S., Likens, G.E., Jaworski, N.A., Pace, M.L., Sides, A.M., Seekell, D., Belt, K.T., Secor, D.H., and Wingate, R.L., 2010, Rising stream and river temperatures in the United States: Frontiers in Ecology and the Environment, v. 8 , no. 9 , p. 461-466.

Kemble, N.E., Hardesty, D.K., Ingersoll, C.G., Kunz, J.L., Sibley, P.K., Calhoun, D.L., Gilliom, R.J., Kuivila, K.M., Nowell, L.H., and Moran, P.W., in press, Contaminants in stream sediments from seven U.S. metropolitan areas: II. Sediment toxicity to the amphipod Hyalella azteca and the midge Chironomus dilutus: Archives of Environmental Contamination and Toxicology.

Kennen, J.G., Riva-Murray, K., and Beaulieu, K.M., 2010, Determining hydrologic factors that influence stream macroinvertebrate assemblages in the northeastern U.S.: Ecohydrology, v. 3, no. 1, p. 88-106.

Klein, R.D., 1979, Urbanization and stream quality impairment: Journal of the American Water Resources Association, v. 15 , no. 4, p. 948-963.

Konrad, C.P., and Booth, D.B., 2005, Hydrologic changes in urban streams and their ecological significance, in Brown, L.R., Gray, R.H., Hughes, R.M., and Meador, M.R., eds., Effects of urbanization on stream ecosystems: Bethesda, Md., American Fisheries Society, Symposium 47, p. $157-177$.

Kuivila, K.M., Hladik, M.L., Ingersoll, C.G., Kemble, N.E., Moran, P.W., Calhoun, D.L., Nowell, L.H., and Gilliom, R.J., 2012, Occurrence and potential sources of pyrethroid insecticides in stream sediments from seven U.S. metropolitan areas: Environmental Science and Technology, v. 46, p. 4297-4303. 
Lee, C.J., and Ziegler, A.C., 2010, Effects of urbanization, construction activity, management practices, and impoundments on suspended-sediment transport in Johnson County, Northeast Kansas, February 2006 through November 2008: U.S. Geological Survey Scientific Investigations Report 2010-5128, 54 p.

Lee, K.B., and Ham, P.J., 1988, Effects of Surrey's storm water management policy on channel erosion, in Proceedings, International Symposium on Urban Hydrology and Municipal Engineering, Town of Markham, Ontario, Canada, p. C5-1-C5-15.

Leiker, T.J., Abney, S.R., Goodbred, S.L., and Rosen, M.R., 2009 , Identification of methyl triclosan and halogenated analogues in male common carp (Cyprinus carpio) from Las Vegas Bay and semipermeable membrane devices from Las Vegas Wash, Nevada: Science of the Total Environment, v. 407, no. 6, p. 2102-2114.

Lemly, A.D., 1982, Modification of benthic insect communities in polluted streams: Combined effects of sedimentation and nutrient enrichment: Hydrobiologia, v. 87, no. 3, p. 229-245.

Leopold, L.B., 1968, Hydrology for urban land planningA guidebook on the hydrologic effects of urban land use: U.S. Geological Survey Circular 554, 18 p., accessed August 17, 2012, at http://enviro.lclark.edu/resources/ Tryon/Water/Hydrology.pdf.

Leopold, L.B., Huppman, R., and Miller, A., 2005, Geomorphic effects of urbanization in forty-one years of observation: Proceedings of the American Philosophical Society, v. 149 , no. 3 , p. $349-371$.

Leopold, L.B., Wolman, M.G., and Miller, J.P., 1964, Fluvial processes in geomorphology: San Francisco, W.H. Freeman, $522 \mathrm{p}$.

Livingston, E.H., and McCarron, E., 1992, Stormwater management —A guide for Floridians: Tallahassee, Fla., Florida Department of Environmental Regulation, 72 p., accessed July 13, 2011, at http://www.dep.state.fl.us/water/nonpoint/ docs/nonpoint/Stormwater_Guide.pdf.

Lowe, R.L., and LaLiberte, G.D., 1996, Benthic stream algae: Distribution and structure, in Hauer, F.R., and Lamberti, G.A., eds., Methods in stream ecology: San Diego, Calif., Academic Press, p. 295-313.

Lytle, D.A., and Poff, N.L., 2004, Adaptation to natural flow regimes: Trends in Ecology and Evolution, v. 19, no. 2, p. $94-100$.
Mabe, J.A., 2007, Nutrient and biological conditions of selected small streams in the Edwards Plateau, Central Texas, 2005-06, and implications for development of nutrient criteria: U.S. Geological Survey Scientific Investigations Report 2007-5195, 46 p.

MacDonald, D.D., Ingersoll, C.G., and Bergher, T.A., 2000, Development and evaluation of consensus-based sediment quality guidelines for freshwater ecosystems: Archives of Environmental Contamination and Toxicology, v. 29, no. 1, p. 20-31.

MacDonald, Joseph, Oury, Kat, Ryznar, Rhonda, Holmes, Michael, and Berke, Philip, 2003, Case study of King Farm, MD: Comprehensive report of the impact of urban design on water resources: North Carolina State University and Tufts University, 23 p., accessed October 5, 2012, at http:// newurbanismwatershed.unc.edu/PDF/king_farm.pdf.pdf.

Machlis, G.E., Force, J.E., and Burch, W.R., Jr., 1997, The human ecosystem, Part I: The human ecosystem as an organizing concept in ecosystem management: Society and Natural Resources, v. 10, no. 4, p. 347-367.

MacRae, C.R., 1996, Experience from morphological research on Canadian streams: Is control of the two-year frequency runoff event the best basis for stream channel protection?, in Roesner, L.A., ed., Effects of watershed development and management on aquatic ecosystems, Proceedings of an Engineering Foundation Conference, August 4-9, 1996, Snowbird, Utah: New York, American Society of Civil Engineers, p. 144-162.

Mahler, B.J., Van Metre, P.C., Bashara, T.J., Wilson, J.T., and Johns, D.A., 2005, Parking lot sealcoat: An unrecognized source of urban polycyclic aromatic hydrocarbons: Environmental Science and Technology, v. 39, no. 15, p. 5560-5566.

Maine Department of Environmental Protection, 2005, Biological monitoring glossary, accessed July 13, 2011, at http://www.maine.gov/dep/blwq/docmonitoring/ biomonitoring/glossary.htm.

Markham, V.D., and Steinzor, N., 2006, U.S. national report on population and the environment: New Canaan, Conn., Center for Environment and Population, p. 69, accessed June 30, 2010, at http://www.cepnet.org/documents/ USNatlReptFinal_000.pdf.

Maul, J.D., Brennan, A.A., Harwood, A.D., and Lydy, M.J., 2008, Effect of sediment-associated pyrethroids, fipronil, and metabolites on Chironomus tentans growth rate, body mass, condition index, immobilization, and survival: Environmental Toxicology and Chemistry, v. 27, no. 12 , p. 2582-2590. 
McKenzie-Mohr, D., 2000, Promoting sustainable behavior: An introduction to community-based social marketing: Journal of Social Issues, v. 56, no. 3, p. 543-554.

McMahon, G., Bales, J.D., Coles, J.F., Giddings, E.M.P., and Zappia, H., 2003, Use of stage data to characterize hydrologic conditions in an urbanizing environment: Journal of the American Water Resources Association, v. 39, no. 6, p. 1529-1546.

Meador, M.R., Coles, J.F., and Zappia, H., 2005, Fish assemblage responses to urban intensity gradients in contrasting metropolitan areas: Birmingham, Alabama, and Boston, Massachusetts, in Brown, L.R., Gray, R.H., Hughes, R.M., and Meador, M.R., eds., Effects of urbanization on stream ecosystems: Bethesda, Md., American Fisheries Society, Symposium 47, p. 409-423.

Meyer, J.L., Strayer, D.L., Wallace, J.B., Eggert, S.L., Helfman, G.S., and Leonard, N.E., 2007, The contribution of headwater streams to biodiversity in river networks: Journal of the American Water Resources Association, v. 43 , no. 1 , p. 86-103.

Millenium Ecosystem Assessment, 2005, Ecosystems and human well-being: Synthesis: Washington, D.C., Island Press, $155 \mathrm{p}$.

Moran, P.W., Calhoun, D.L., Nowell, L.H., Kemble, N.E., Ingersoll, C.G., Hladik, M.L., Kuivila, K.M., Falcone, J.A., and Gilliom, R.J., 2012, Contaminants in stream sediments from seven U.S. metropolitan areas: Data summary of a national pilot study: U.S. Geological Survey Scientific Investigations Report 2011-5092, 66 p.

Moring, J.B., 2009, Effects of urbanization on the chemical, physical, and biological characteristics of small Blackland Prairie streams in and near the Dallas-Fort Worth metropolitan area, Texas: U.S. Geological Survey Scientific Investigations Report 2006-5101-C, 31 p. Available at http://pubs. usgs.gov/sir/2006/5101C/.

Mullaney, J.R., Lorenz, D.L., and Arntson, A.D., 2009, Chloride in groundwater and surface water in areas underlain by the glacial aquifer system, Northern United States: U.S. Geological Survey Scientific Investigations Report 2009-5086, 41 p. Available at http://pubs.usgs.gov/ sir/2009/5086/.

Munn, M.D., and Gilliom, R.J., 2001, Pesticide toxicity index for freshwater aquatic organisms: U.S. Geological Survey Water-Resources Investigations Report 01-4077, 61 p. Available at http://pubs.usgs.gov/wri/wri014077/.

Munn, M.D., Gilliom, R.J., Moran, P.W., and Nowell, L.H., 2006, Pesticide toxicity index for freshwater aquatic organisms (2d ed.): U.S. Geological Survey Scientific Investigations Report 2006-5148, 87 p. Available at http://pubs.usgs.gov/sir/2006/5148/.
National Oceanic and Atmospheric Administration, 1999, U.S. snow climatology (data set documentation TD-9641M): Asheville, N.C., National Climatic Data Center.

National Research Council, 2008, Urban stormwater management in the United States: Washington, D.C., The National Academies Press, 610 p.

New York City Environmental Protection, 2011, accessed July 11, 2011, at http://www.nycwatershed.org.

Nowell, L.H., Capel, P.D., and Dileanis, P.D., 1999, Pesticides in stream sediment and aquatic biota-Distribution, trends, and governing factors: New York, Lewis Publishers, $1,001 \mathrm{p}$.

Nowell, L.H., Moran, P.W., Gilliom, R.J., Calhoun, D.L., Ingersoll, C.G., Kemble, N.E., Kuivila, K.M., and Phillips, P.J., in press, Contaminants in stream sediments from seven U.S. metropolitan areas: I. Distribution in relation to urbanization: Archives of Environmental Contamination and Toxicology.

Omernik, J.M., 1987, Ecoregions of the conterminous United States: Annals of the Association of American Geographers, v. 77 , no. 1, p. 118-125.

Omernik, J.M. , 2004, Perspectives on the nature and definition of ecological regions: Environmental Management, v. 34, supplement 1, p. 27-38.

Orfield, M., and Wallace, N., 2007, The Minnesota Fiscal Disparities Act of 1971: The Twin Cities struggle and blueprint for regional cooperation: William Mitchell Law Review, v. 33, no. 2, p. 591-612.

Owens, D.W., Jopke, P., Hall, D.W., Balousek, J., and Roa, A., 2000, Soil erosion from two small construction sites, Dane County, Wisconsin: U.S. Geological Survey Fact Sheet FS-109-00, 4 p. Available at http://wi.water.usgs.gov/pubs/ fs-109-00/.

Paul, M.J., and Meyer, J.L., 2001, Streams in the urban landscape: Annual Review of Ecology and Systematics, v. 32, p. 333-365.

Pickett, S.T.A., Cadenasso, M.L., Grove, J.M., Groffman, P.M., Band, L.E., Boone, C.G., Burch, W.R., Jr., Grimmond, C.S.B., Hom, J., Jenkins, J.C., Law, N.L., Nilon, C.H., Pouyat, R.V., Szlavecz, K., Warren, P.S., and Wilson, M.A., 2008, Beyond urban legends: An emerging framework of urban ecology, as illustrated by the Baltimore Ecosystem Study: BioScience, v. 58, no. 2, p. 139-150.

Pickett, S.T.A., and Grove, J.M., 2009, Urban ecosystems: What would Tansley do?: Urban Ecosystems, v. 12, no. 1, p. 1-8. 
Pinay, G., Clémet, J.C., and Naiman, R.J., 2002, Basic principles and ecological consequences of changing water regimes on nitrogen cycling in fluvial systems: Environmental Management, v. 30, no. 4, p. 481-491.

Poff, N.L., Allan, J.D., Bain, M.B., Karr, J.R., Prestegaard, K.L., Richter, B.D., Sparks, R.E., and Stromberg, J.C., 1997, The natural flow regime: BioScience, v. 47, no. 11, p. 769-784.

Poff, N.L., Olden, J.D., Pepin, D.M., and Bledsloe, B.D., 2006, Placing global stream flow variability in geographic and geomorphic contexts: River Research and Applications, v. 22 , no. 2 , p. 149-166.

Poff, N.L., Richter, B.D., Arthington, A.H., Bunn, S.E., Naiman, R.J., Kendy, E., Acreman, M., Apse, C., Bledsloe, B.D., Freeman, M.C., Henriksen, J.A., Jacobson, R.B., Kennen, J.G., Merritt, D.M., O'Keeffe, J.H., Olden, J.D., Rogers, K., Tharme, R.E., and Warner, A., 2010, The ecological limits of hydrologic alteration (ELOHA): A new framework for developing regional environmental flow standards: Freshwater Biology, v. 55, no. 1, p. 147-170.

Rees, W.E., and Wackernagel, M., 1994, Ecological footprints and appropriated carrying capacity: Measuring the natural capital requirements of the human economy, in Jansson, A., Hammer, M., Folke, C., and Costanza, R., eds., Investing in natural capital: Washington, D.C., Island Press, p. 362-390.

Richards, K.D., Scudder, B.C., Fitzpatrick, F.A., Steuer, J.J., Bell, A.H., Peppler, M.C., Stewart, J.S., and Harris, M.A., 2010, Effects of urbanization on stream ecosystems along an agriculture-to-urban land-use gradient, Milwaukee to Green Bay, Wisconsin, 2003-2004: U.S. Geological Survey Scientific Investigations Report 2006-5101-E, 210 p. Available at http://pubs.usgs.gov/sir/2006/5101E/.

Roy, A.H., Freeman, B.J., and Freeman, M.C., 2007, Riparian influences on stream fish assemblage structure in urbanizing streams: Landscape Ecology, v. 22, no. 3, p. 385-402.

Roy, A.H., Freeman, M.C., Freeman, B.J., Wenger, S.J., Ensign, W.E., and Meyer, J.L., 2006, Importance of riparian forests in urban catchments contingent on sediment and hydrologic regimes: Environmental Management, v. 37, no. 4 , p. 523-539.

Roy, A.H., Rosemond, A.D., Paul, M.J., Leigh, D.S., and Wallace, J.B., 2003, Stream macroinvertebrate response to catchment urbanisation (Georgia, U.S.A.): Freshwater Biology, v. 48, p. 329-346.

Schlosser, I.J., 1987, A conceptual framework for fish communities in small warm-water streams, in Matthews, W.J., and Heins, D.C., eds., Community and evolutionary ecology of North American stream fishes: Norman, Okla., University of Oklahoma Press, p. 17-24.
Schueler, T.R., 1994, The importance of imperviousness: Watershed Protection Techniques, v. 1, no. 3, p. 100-111.

Schueler, T.R., Fraley-McNeal, L., and Cappiella, K., 2009, Is impervious cover still important? A review of recent research: Journal of Hydrologic Engineering, v. 14, no. 4, p. 309-315.

Schumm, S.A., and Khan, H.R., 1972, Experimental study of channel patterns: Bulletin of the Geological Society of America, v. 83, p. 1755-1770.

Schumm, S.A., and Lichty, R.W., 1965, Time, space, and causality in geomorphology: American Journal of Science, v. 263, p. $110-119$.

Scoggins, M., McClintock, N.L., Gosselink, L., and Bryer, P., 2007, Occurrence of polycyclic aromatic hydrocarbons below coal-tar-sealed parking lots and effects on stream benthic macroinvertebrate communities: Journal of the North American Benthological Society, v. 26, no. 4, p. 694-707.

Sear, D.A., and Newson, M.D., 2003, Environmental change in river channels: A neglected element towards geomorphological typologies, standards and monitoring: Science of the Total Environment, v. 310, no. 1-3, p. 17-23.

Sedell, J.R., Reeves, G.H., Hauer, F.R., Stanford, J.A., and Hawkins, C.P., 1990, Role of refugia in recovery from disturbances-Modern fragmented and disconnected river systems: Environmental Management, v. 14, no. 5, p. 711-724.

Short, T.M., Giddings, E.M.P., Zappia, H., and Coles, J.F., 2005, Urbanization effects on habitat characteristics of streams in Boston, Massachusetts, Birmingham, Alabama, and Salt Lake City, Utah, in Brown, L.R., Gray, R.H., Hughes, R.M., and Meador, M.R., eds., Effects of urbanization on stream ecosystems: Bethesda, Md., American Fisheries Society, Symposium 47, p. 317-332.

Sierra Club, 2003, Population growth and suburban sprawl:

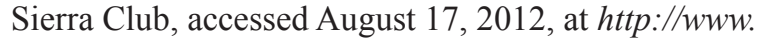
sierraclub.org/sprawl/SprawlPop_2003.pdf.

Somerville, D.E., and Pruitt, B.A., 2004, Physical stream assessment: A review of selected protocols for use in the Clean Water Act Section 404 Program: Washington, D.C., Prepared for the U.S. Environmental Protection Agency, Office of Wetlands, Oceans, and Watersheds, Wetlands Division Order No. 3W-0503-NATX, 213 p. 
Sprague, L.A., Harned, D.A., Hall, D.W., Nowell, L.H., Bauch, N.J., and Richards, K.D., 2007, Response of stream chemistry during base flow to gradients of urbanization in selected locations across the conterminous United States: U.S. Geological Survey Scientific Investigations Report 2007-5083, 132 p. Available at http://pubs.usgs.gov/ sir/2007/5083/.

Sprague, L.A., Zuellig, R.E., and Dupree, J.A., 2006a, Chapter A. Effects of urbanization on stream ecosystems in the South Platte River basin, Colorado and Wyoming: U.S. Geological Survey Scientific Investigations Report 2006-5101-A, 139 p. Available at http://pubs.usgs.gov/ sir/2006/5101A/.

Sprague, L.A., Zuellig, R.E., and Dupree, J.A., 2006b, Effects of urban development on stream ecosystems along the front range of the Rocky Mountains, Colorado and Wyoming: U.S. Geological Survey Fact Sheet 2006-3083, 4 p. Available at $h t t p: / / p u b s . u s g s . g o v / f s / 2006 / 3083 /$.

Spurlock, F., and Lee, M., 2008, Synthetic pyrethroid use patterns, properties, and environmental effects, in Gan, J., Spurlock, F., Hendley, P., and Weston, D.P., eds., Synthetic pyrethroids: Occurrence and behavior in aquatic environments: Washington, D.C., American Chemical Society, p. 3-25.

Steuer, J.J., Stensvold, K.A., and Gregory, M.B., 2010, Determination of biologically significant hydrologic condition metrics in urbanizing watersheds: An empirical analysis over a range of environmental settings: Hydrobiologia, v. 654 , no. 1, p. $27-55$.

Takada, H., Onda, T., Harada, M., and Ogura, N., 1991, Distribution and sources of polycyclic aromatic hydrocarbons (PAHs) in street dust from the Tokyo Metropolitan area: The Science of the Total Environment v. 107, p. 45-69.

Terziotti, Silvia, McMahon, Gerard, and Bell, A.H., 2012, Representation of regional urban development conditions using a watershed-based gradient study design: U.S. Geological Survey Scientific Investigations Report 2012-5070, $109 \mathrm{p}$.

U.S. Environmental Protection Agency, 1993, Provisional guidance for quantitative risk assessment of polycyclic aromatic hydrocarbons: U.S. Environmental Protection Agency, EPA/600/R-93/089.

U.S. Environmental Protection Agency, 1995, Ecological restoration: U.S. Environmental Protection Agency, Office of Water Report No. EPA 841-F-95-007, accessed July 11, 2011, at http://water.epa.gov/type/watersheds/archives/ ecology_index.cfm.
U.S. Environmental Protection Agency, 1997, National water quality inventory: 1996 Report to Congress: U.S. Environmental Protection Agency, EPA 841-R-97008, 527 p., accessed July 11, 2011, at http://www.epa. gov/305b/96report/index.html.

U.S. Environmental Protection Agency, 2003, Procedures for the derivation of equilibrium partioning sediment benchmarks (ESBs) for the protection of benthic organisms: PAH mixtures: U.S. Environmental Protection Agency, Office of Research and Development, EPA-600-R-02-13 [variously paged].

U.S. Environmental Protection Agency, 2006, Wadeable streams assessment: A collaborative survey of the nation's streams: U.S. Environmental Protection Agency, Office of Research and Development, Office of Water Report No. EPA 841-B-06-002, 113 p., accessed August 17, 2012, at http://www.epa.gov/owow/monitoring/wsa/ factsheet_10_25_06.pdf.

U.S. Environmental Protection Agency, 2010a, Overview of impaired waters and total maximum daily loads program, accessed June 7, 2011, at http://water.epa.gov/lawsregs/ lawsguidance/cwa/tmdl/intro.cfm.

U.S. Environmental Protection Agency, 2010b, Smart growth illustrated, accessed June 1, 2011, at http://www.epa.gov/ smartgrowth/case/kingfarm.htm.

Vajda, A.M., Barber, L.B., Gray, J.L., Lopez, E.M., Woodling, J.D., and Norris, D.O., 2008, Reproductive disruption in fish downstream from an estrogenic wastewater effluent: Environmental Science and Technology, v. 42, no. 9, p. 3407-3414.

Van Metre, P.C., and Mahler, B.J., 2005, Trends in hydrophobic organic contaminants in urban and reference lake sediments across the United States, 1970-2001: Environmental Science and Technology, v. 39, no. 15, p. 5567-5574.

Van Metre, P.C., and Mahler, B.J., 2010, Contribution of PAHs from coal-tar pavement sealcoat and other sources to 40 U.S. lakes: Science of the Total Environment, v. 409, p. 334-344.

Van Metre, P.C., Mahler, B.J., and Furlong, E.T., 2000, Urban sprawl leaves its PAH signature: Environmental Science and Technology, v. 34, no. 19, p. 4064-4070.

Van Metre, P.C., Mahler, B.J., Scoggins, Mateo, and Hamilton, P.A., 2006, Parking lot sealcoat: A major source of polycyclic aromatic hydrocarbons (PAHs) in urban and suburban environments: U.S. Geological Survey Fact Sheet 2005-3147, 4 p. 
Van Metre, P.C., Mahler, B.J., and Wilson, J., 2009, PAHs underfoot: Contaminated dust from sealcoated pavements: Environmental Science and Technology, v. 43, no. 1, p. $20-25$.

Vannote, R.L., Minshall, G.W., Cummins, K.W., Sedell, J.R., and Cushing, C.E., 1980, The river continuum concept: Canadian Journal of Fisheries and Aquatic Sciences, v. 37, no. 1, p. $130-137$.

Waite, I.R., Sobieszczyk, S., Carpenter, K.D., Arnsberg, A.J., Johnson, H.M., Hughes, C.A., Sarantou, M.J., and Rinella, F.A., 2008, Effects of urbanization on stream ecosystems in the Willamette River basin and surrounding area, Oregon and Washington: U.S. Geological Survey Scientific Investigations Report 2006-5101-D, 62 p.

Walker, C.E., and Pan, Y., 2006, Using diatom assemblages to assess urban stream conditions: Hydrobiologia, v. 561, no. 1, p. 179-189.

Walsh, C.J., Fletcher, T.D., and Ladson, A., 2005a, Stream restoration in urban catchments through redesigning stormwater systems: Looking to the catchment to save the stream: Journal of the North American Benthological Society, v. 24, no. 3, p. 690-705.
Walsh, C.J., Roy, A.H., Feminella, J.W., Cottingham, P.D., Groffman, P.M., and Morgan, R.P., II, 2005b, The urban stream syndrome: Current knowledge and the search for a cure: Journal of the North American Benthological Society, v. 24 , no. 3 , p. $706-723$.

Waters, T.E., 1995, Sediment in streams-Sources, biological effects and control: Bethesda, Md., American Fisheries Society Monograph, v. 7, 251 p.

Watershed Agricultural Council, 2011, accessed July 11, 2011,

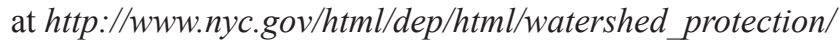
index.shtml.

Weston, D.P., Holmes, R.W., You, J., and Lydy, M.J., 2005, Aquatic toxicity due to residential use of Pyrethroid insecticides: Environmental Science and Technology, v. 39, no. 24 , p. $9778-9784$.

Wolman, M.G., 1967, A cycle of sedimentation and erosion in urban river channels: Geografiska Annaler, Series A, Physical Geography, v. 49, no. 2/4, p. 385-395.

Wolman, M.G., and Miller, J.P., 1960, Magnitude and frequency of forces in geomorphic processes: Journal of Geology, v. 68, p. 54-74. 



\section{Glossary}

\section{A}

abundance The number of organisms within a taxonomic group. For example, if 100 individual fish are identified in the community survey of which 80 were minnows, the total abundance is 100 and minnow abundance is 80 .

aquatic Related to water.

\section{B}

bankfull The level in the stream channel where rising streamflow begins to enter the flood plain.

base flow Sustained flow of a stream in the absence of direct runoff. It includes natural and human-induced streamflows. Natural base flow is sustained largely by ground-water discharges.

Best Management Practice (BMP) A generally accepted practice for some aspect of natural resources management, such as water conservation measures, drainage management measures, or erosion control measures. Typically incorporates conservation criteria.

bioassay A laboratory test which measures the effects of a substance on living organisms. Effeccts commonly assessed include survival, growth, or reproductive output.

biodiversity A characteristic of a biological community based on the number of species and evenness in the number of individual organisms among the different species. A high biodiversity is considered a positive attribute of a biological community.

biological condition metric A calculated metric that focuses on a particular species that is likely to be affected by and respond to urban development. These metrics are regarded as "indicators," because they are based on certain species in a community that respond to specific environmental stressors.

biota The ensemble of all aquatic organisms found at a stream location.

\section{C}

channelization Portions of a stream channel that have been modified by humans, usually for flood control. Channelization usually involves straightenening of the channel and removal of riparian vegetation.

chemistry The condition of steam water including physical attributes such as temperature and chemical attributes including $\mathrm{pH}$, dissolved oxygen, and concentrations of nutrients, ions, and pesticides, among other constituents.

chloride A chemical ion most familiar as a component of common salt, sodium chloride. Chloride can enter streams from leaking sewage lines and septic tanks, road salt application, fertilizer use, and the use of water softeners, bleach, and swimming pool chemicals; chloride may be transported to streams through groundwater and wastewater-treatment plant discharges.

Clean Water Act (CWA) The goal of the Clean Water Act (CWA) is "to restore and maintain the chemical, physical, and biological integrity of the Nation's waters."

community A general group of organisms, either algae, invertebrates, or fish, that interact within the physical area defined by the stream reach.

community composition score A calculated metric that represents overall changes in the types of species and the number of organisms in the community. These scores were calculated by using a technique called multivariate ordination, which in essence looks at the differences and similarities in the species composition of a community across all sites in a study area. 
Community Tolerance Index A metric calculated as the average tolerance to stressors based on all species in the invertebrate community; species values range from 0 (most sensitive) to 10 (most tolerant). The average tolerance typically increases when sensitive invertebrate species are being lost in the community.

connectivity The degree to which a stream is connected with upstream and downstream areas and other streams. Connectivity can be affected by natural factors such as droughts and waterfalls and human factors such as road culverts, impoundments and water diversions.

contaminant Chemicals such as chloride, pesticides and polycyclic aromatic hydrocarbons among others that can be toxic to aquatic biota.

D

duration The length of time that a high-flow event lasts.

E

ecosystem services Measurable outcomes, produced by ecosystem processes such as nutrient assimilation or healthy, functioning biological communities, which are directly enjoyed, consumed or used by individuals, households, or communities.

endpoint A terminal component of a system that is used to assess the system, such as an environmental factor or biological metric that is evaluated for assessing the health of a stream ecosystem. Endpoints are typically an explicit expression of an environmental value (such as the concentration of a certain chemical or presence of certain species) that is relevant to the resource being protected.

Ephemeroptera, Plecoptera, and Trichoptera (EPT) Invertebrates belonging to the insect classes Ephemeroptera (mayflies), Plecoptera (stoneflies), and Trichoptera (caddisflies). Species in these groups are generally considered sensitive.

evapotranspiration The process by which water that is absorbed by plants, usually through the roots, is evaporated into the atmosphere from the plant surface, such as leaf pores; plus the process of liquid water becoming water vapor, including vaporization from water surfaces, land surfaces, and snow fields.

$\mathbf{F}$

factor A specific feature or attribute of the physical, chemical, or biological environment that contributes to the response of streams to urban development.

flashy (flashiness) A descriptive term for streams exhibiting rapid increases in streamflow during or following storms and then similarly rapid decreases when storm runoff ceases.

flood plain The area adjacent to a stream that is inundated during a flood.

foodweb The interconnected energy transfer beginning with the conversion of sunlight to organic matter by terrestrial and aquatic primary producers, and then moving to primary consumers, secondary consumers, and decomposers.

frequency The number of peak storm flows in a given amount of time.

G

genus The usual major subdivision of a family or subfamily in the classification of organisms, usually consisting of more than one species.

grade controls Engineered features used to affect the gradient of a stream reach to control the direction and velocity of flow. Such features include culverts, weirs, and engineered step pools. 
groundwater (1) Water that flows or seeps downward and saturates soil or rock, supplying springs and wells. The upper surface of the saturate zone is called the water table. (2) Water stored underground in rock crevices and in the pores of geologic materials that make up the Earth's crust.

\section{H}

habitat The actual structure of the stream that is home for organisms (biota), such as invertebrates and fish, including the bottom and its substrate, sides, and structures such as woody debris and undercut banks.

high flow A descriptor for sampling conducted during the season when generally elevated flows are expected to occur because of snowmelt or increased precipitation.

hydrology In the context of stream habitat, the flow regime experienced by the organisms within a reach, including magnitude, frequency, duration, and flashiness of flow events.

hydrophobic contaminants Compounds that do not dissolve easily in water.

\section{I}

impervious cover (surface) Hard surfaces that block the infiltration of rain and snowmelt into the ground, including rooftops and paved surfaces, such as roads, parking lots, and driveways.

insecticide A pesticide designed to kill specific insects.

\section{L}

land cover Physical materials, such as vegetation and human-constructed roads and buildings that cover the Earth's surface.

land use How people utilize the land to accommodate their needs. In urban areas common land uses are roads, houses, and businesses, as well as other kinds of built infrastructure, such as wastewater treatment plants or dams and reservoirs.

low flow A descriptor for sampling conducted during the season when generally low flows are expected to occur because of reduced precipitation.

\section{M}

metropolitan area The term metropolitan area refers to a region consisting of a densely populated urban core and its less-populated surrounding territories, sharing industry, infrastructure, and housing.

moderately tolerant species Species most abundant at intermediate levels of development.

\section{$\mathbf{N}$}

nutrients Chemicals, such as nitrogen, phosphorus, and carbon, that are used by primary producers to produce organic matter from sunlight. These chemicals occur naturally in streams but also can be introduced through various human activities.

\section{0}

organochlorine An organic compound that contains one or mor chlorine atoms. These compounds can be highly toxic and include pesticides like DDT and chlorodane, vinyls such as polyvinyl chloride (PVC), polychlorinated biphenyl (PCB) insulators, and chlorinated hydrocarbons like chloroform. 
$\mathbf{P}$

pesticide Products designed to kill insect pests and weeds in gardens, agricultural fields, rights of way, and structures.

pesticide toxicity index (PTI) Represents a single value for the relative toxicity of a water sample that is based on the concentrations of all pesticides measured in the sample, each weighted by its individual toxicity threshold, as estimated from laboratory toxicity studies.

polycyclic aromatic hydrocarbons (PAH) Hydrophobic contaminants which originate from natural sources, such as oil seeps, and as a consequence of human activities, such as power generation and stormwater runoff.

Probable Effect Concentration (PEC) A contaminant concentration above which adverse effects on aquatic organisms are expected to occur more often than not.

Probable Effect Concentration Quotient (PECQ) A relative toxicity value for a contaminant (or contaminant class) in sediment, calculated by dividing the concentration of that contaminant (or class) by its Probable Effect Concentration (PEC).

pyrethroids A synthetic chemical compound used as a pesticide that is chemically similar to the natural chemicals (pyrethrins) produced by Chrysanthemums.

\section{$\mathbf{R}$}

rate of decline A measure of how fast or slow streamflow returns to normal conditions following the peak storm flow.

reach A section of a stream that typically extends between 10 and 20 bankfull widths in length and incorporates a suite of physical, chemical, and biological features that generally characterize the stream. For the USGS urban development studies, a reach was delineated within each stream as the sampling area for measuring the hydrology, habitat, water chemistry, and aquatic biota.

response An apparent relation between two factors, based on a Spearman rank correlation (see rho, below). Although a response implies a direct cause and effect relation of one factor on another, the EUSE study was not designed to make cause and effect determinations.

rho The strength of the correlation between two factors and ranges from 0 (no correlation) to 1.0 (perfect correlation). This report utilized the Spearman rank correlation.

richness The number of different species in a stream reach.

riparian The narrow corridor of land immediately adjacent to both sides of a stream where terrestrial and aquatic ecosystems meet.

\section{S}

Semipermeable Membrane Device (SPMD) Passive sampling devices designed to mimic the bioaccumulation of organic compounds across the gill membranes of fish.

sensitive species Species most abundant in undisturbed areas, which can decline rapidly with the onset of development.

species Biological organisms within a community that are closely related taxonomically. In this report, species is used even when biological data were reported at taxonomic levels other than species. For example, some invertebrates could be identified only to genus because certain diagnostic features for species-level identification were indistinct. 
streamflow The water discharge that occurs in a natural channel. A more general term than runoff, streamflow may be applied to discharge whether or not it is affected by diversion or regulation.

stressor (environmental) Factors having a negative effect on stream ecosystems that can occur by changes to the chemical and physical environment from urban development, degraded water quality, loss of habitat, and modified streamflow patterns.

\section{T}

taxa Categories of like organisms that are judged to be distinct unit sbased on certain genetic factors of similarity. Species and genera are examples. "Taxon" is the singular form.

terrestrial Related to land.

tolerance The ability of an organism to persist in the environment given increasing levels of contamination or other stressors.

tolerant species Species most abundant at high levels of development.

Total Maximum Daily Load (TMDL) A calculation of the maximum amount of a pollutant that a water body can receive and still safely meet water-quality standards.

toxic equivalents A measure of the amount of a known toxic substance that would cause the same response as the substances in a sample from the SPMD.

\section{U}

urban stream syndrome The collective outcome of human activities associated with urban development, including the conversion of land from rural to urban uses, creation of impervious cover, chemical contamination, armored stream banks, and use of storm drains and dams, affect the biological, physical, and chemical components of streams.

W

water quality A term used to describe the chemical, physical, and biological characteristics of water, usually in respect to its suitability for a particular purpose.

watershed The land area that drains water to a particular stream, river, or lake. It is a land feature that can be identified by tracing a line along the highest elevations between two areas on a map, often a ridge. Large watersheds, like the Mississippi River basin contain thousands of smaller watersheds. 



\section{Appendixes}

Appendix 1A - Study Watersheds in Nine Metropolitan Areas Used in the Effects of Urban Development on Stream Ecosystems Study
Portland
Salt Lake City
Birmingham
Atlanta
Raleigh
Boston
Denver
Dallas
Milwaukee

Appendix 1B - Characteristics of Nine Metropolitan Study Areas 


\section{Appendix 1A: Study Watersheds in Nine Metropolitan Areas Used in the Effects of Urban Development on Stream Ecosystems Study (from Terziotti and others, 2012)}

\section{Portland}

The Portland metropolitan study area is located in northwestern Oregon and southwestern Washington. The major drainage for the studied watersheds is the Willamette River, nestled between the Coast and Cascade Mountain Ranges. Most of the studied watersheds are located within the Willamette Valley ecoregion, characterized as a broad, lowland valley with a patchwork of land-use types that include evergreen forests, agriculture, urban areas, and wetlands. Landforms consist of terraces and flood plains that are interlaced and surrounded by rolling hills. Soil textures range from fine to medium-coarse. Slope and elevation in the area vary greatly from the lowland valleys to the foothills mountain range. The climate is mild with cool, wet winters and warm, dry summers. The major metropolitan centers in the area are Portland, Vancouver, Beaverton, Salem, Corvallis, and Eugene with a combined 2000 population of 2.7 million, a 24 percent increase from 1990. Portland is the dominant commercial center of the study area with extensive port facilities on the Columbia and Willamette Rivers. The economy includes forestry and timber processing; fruit, wheat, and specialized farming; dairying; food processing; and tourism.

Table 1A-1. Study watersheds located in the Portland, Oregon, metropolitan area.

\begin{tabular}{|c|c|c|c|}
\hline $\begin{array}{l}\text { Figure } \\
\text { number }\end{array}$ & $\begin{array}{l}\text { USGS station } \\
\text { identification }\end{array}$ & USGS station name & $\begin{array}{l}\text { Watershed drainage area } \\
\text { (square kilometers) }\end{array}$ \\
\hline 1 & 14199710 & Nate Creek near Colton, Oreg. & 28.75 \\
\hline 2 & 14205400 & East Fork Dairy Creek near Meacham Corner, Oreg. & 87.54 \\
\hline 4 & 14206435 & Beaverton Creek at SW 216th Ave, near Orenco, Oreg. & 95.62 \\
\hline 5 & 14206750 & Chicken Creek near Sherwood, Oreg. & 40.04 \\
\hline 8 & 434745123040200 & Silk Creek near Cottage Grove, Oreg. & 42.17 \\
\hline 9 & 435212122483300 & Lost Creek near Dexter, Oreg. & 83.42 \\
\hline 10 & 440257123103200 & Amazon Creek near Danebo Road at Eugene, Oreg. & 50.25 \\
\hline 11 & 443326123165200 & Oak Creek at Corvallis, Oreg. & 32.50 \\
\hline 12 & 445029122592600 & Battle Creek near Turner, Oreg. & 29.91 \\
\hline 16 & 451734122585400 & Chehalem Creek at Newberg, Oreg. & 97.85 \\
\hline 17 & 452149123194900 & North Yamhill Creek near Yamhill, Oreg. & 65.86 \\
\hline 18 & 452231122200000 & Deep Creek near Sandy, Oreg. & 31.36 \\
\hline 19 & 452337122243500 & North Fork Deep Creek at Barton, Oreg. & 37.01 \\
\hline 20 & 452414122213200 & Tickle Creek near Boring, Oreg. & 34.08 \\
\hline 21 & 452526122364400 & Kellogg Creek at Milwaukie, Oreg. & 34.11 \\
\hline 22 & 452912122291200 & Johnson Creek at Circle Ave, Oreg. & 55.63 \\
\hline 23 & 453506123125700 & Iler Creek near Forest Grove, Oreg. & 12.59 \\
\hline 24 & 454321122352300 & Curtin Creek near Vancouver, Wash. & 30.30 \\
\hline 25 & 454510122424900 & Whipple Creek near Salmon Creek, Wash. & 22.17 \\
\hline
\end{tabular}


124

$123^{\circ}$

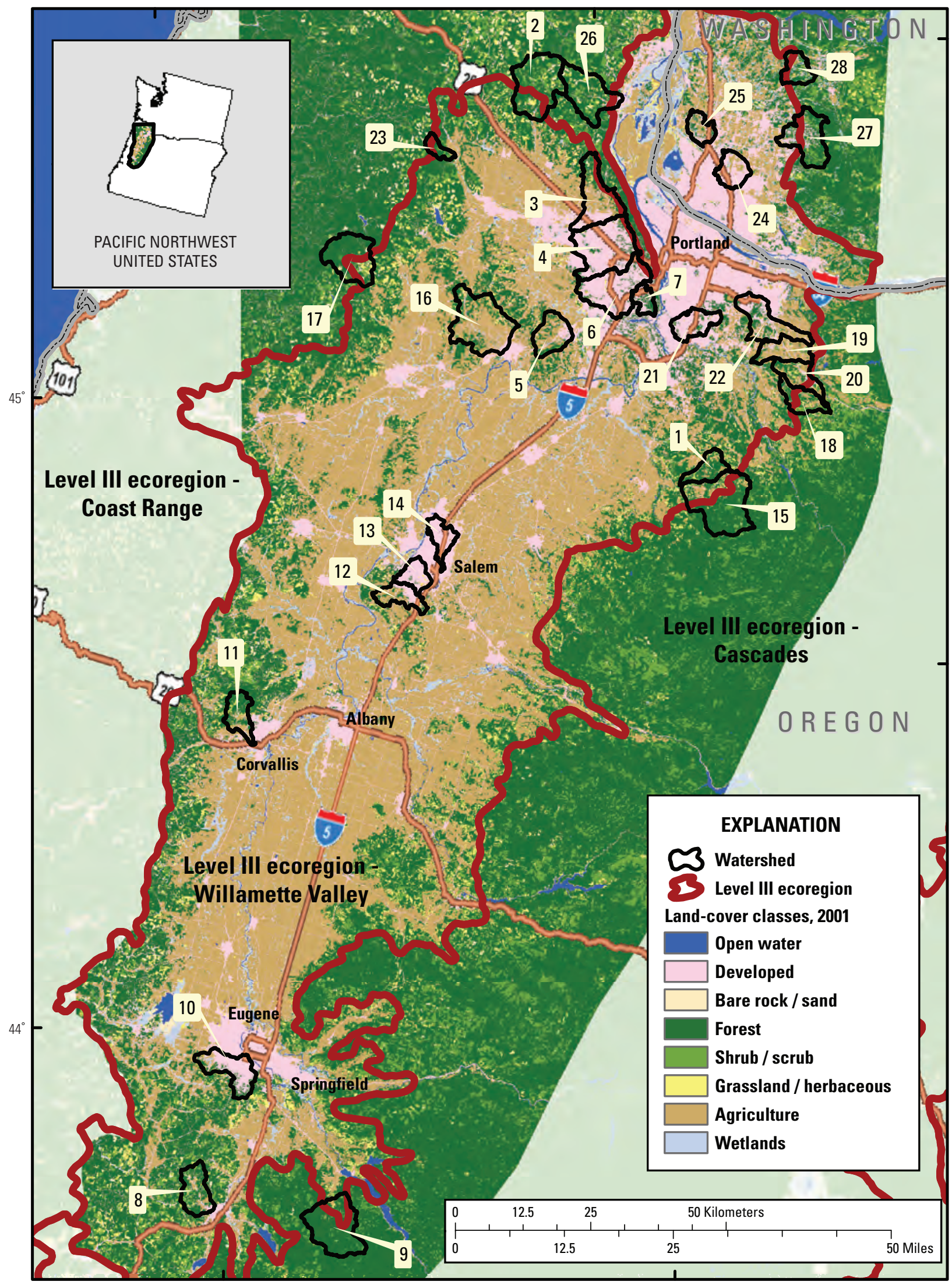

Figure 1A-1. Locations of study watersheds in the Portland, Oregon, metropolitan area. 


\section{Salt Lake City}

The Salt Lake City study watersheds are located in three major river systems: the Bear, the Weber, and the Utah Lake/ Jordan River systems. These river basins, in turn, are located in the Great Basin between the Wasatch Range in the Rocky Mountains and the Sierra Nevada Mountains, a closed area that allows no outflow to other bodies of water such as rivers or oceans. The study area is characterized by cold desert basins, scattered low and high mountains, and salt flats. The climate of the study area is semiarid with most of the precipitation occurring as winter snows or occasional summer thunderstorms. The lowland valleys have moderate temperature shifts between winter and summer; whereas, the high mountains have long, cold winters and short, cool summers.
Streams in the study area arise in the Wasatch Range and flow westerly through the urban areas.

The Salt Lake City study area includes four main metropolitan areas, Salt Lake City, Logan, Ogden, and Provo. The combined 2000 population was 1.9 million, a 29 percent increase from 1990. Typical of semiarid urban areas in the western United States, an array of reservoirs, diversions, and canals alters the hydrologic regime of most Salt Lake City streams, and water rights is a continuous area of contention. Land use in the study area was historically grasslands, evergreen forests, and desert shrubs, some of which has been converted to irrigated agriculture and urban. The economy is the area is largely supported by mining, church, government, finance, education, research, high-technology industries, transportation, recreation, and tourism.

Table 1A-2. Study watersheds located in the Salt Lake City, Utah, metropolitan area.

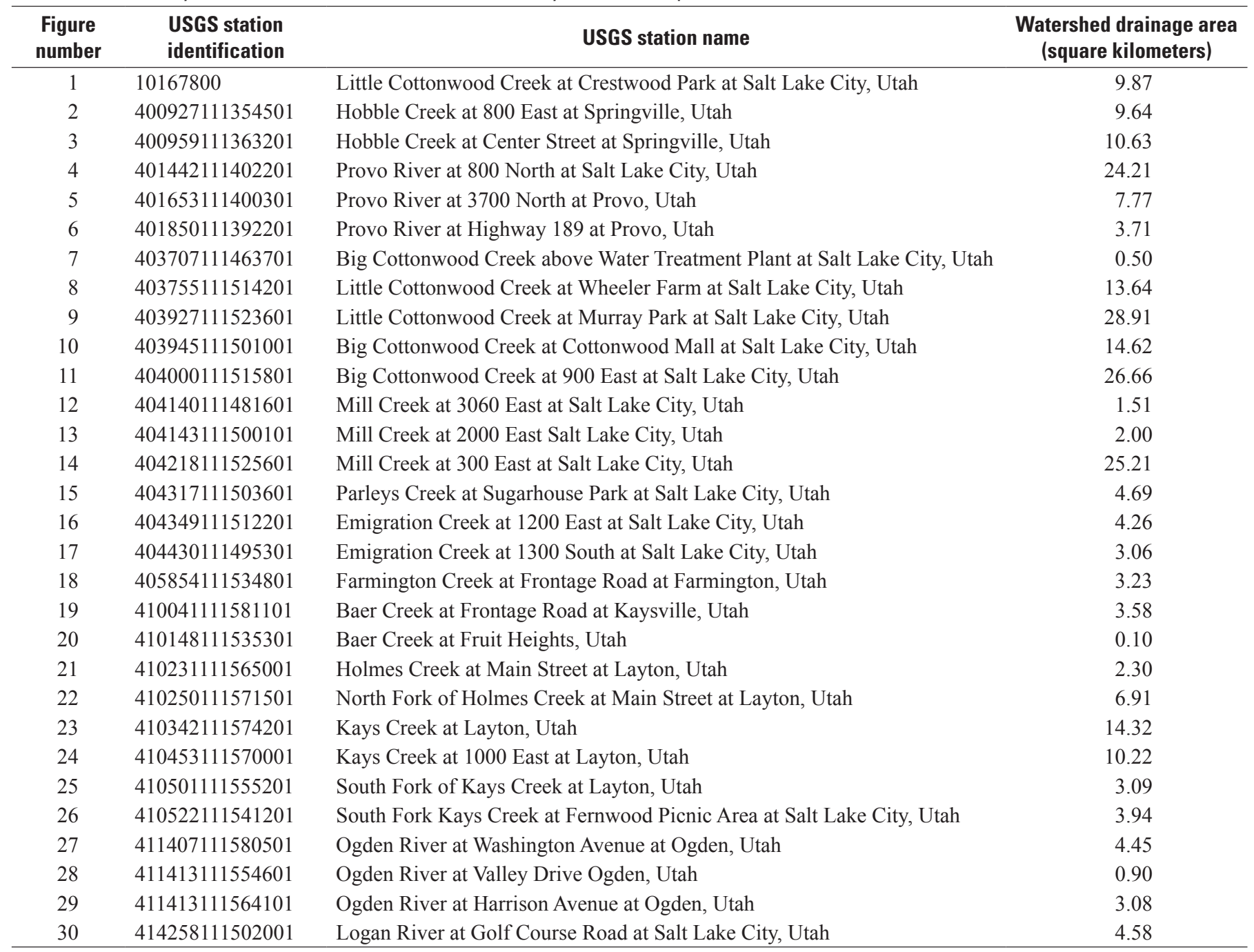




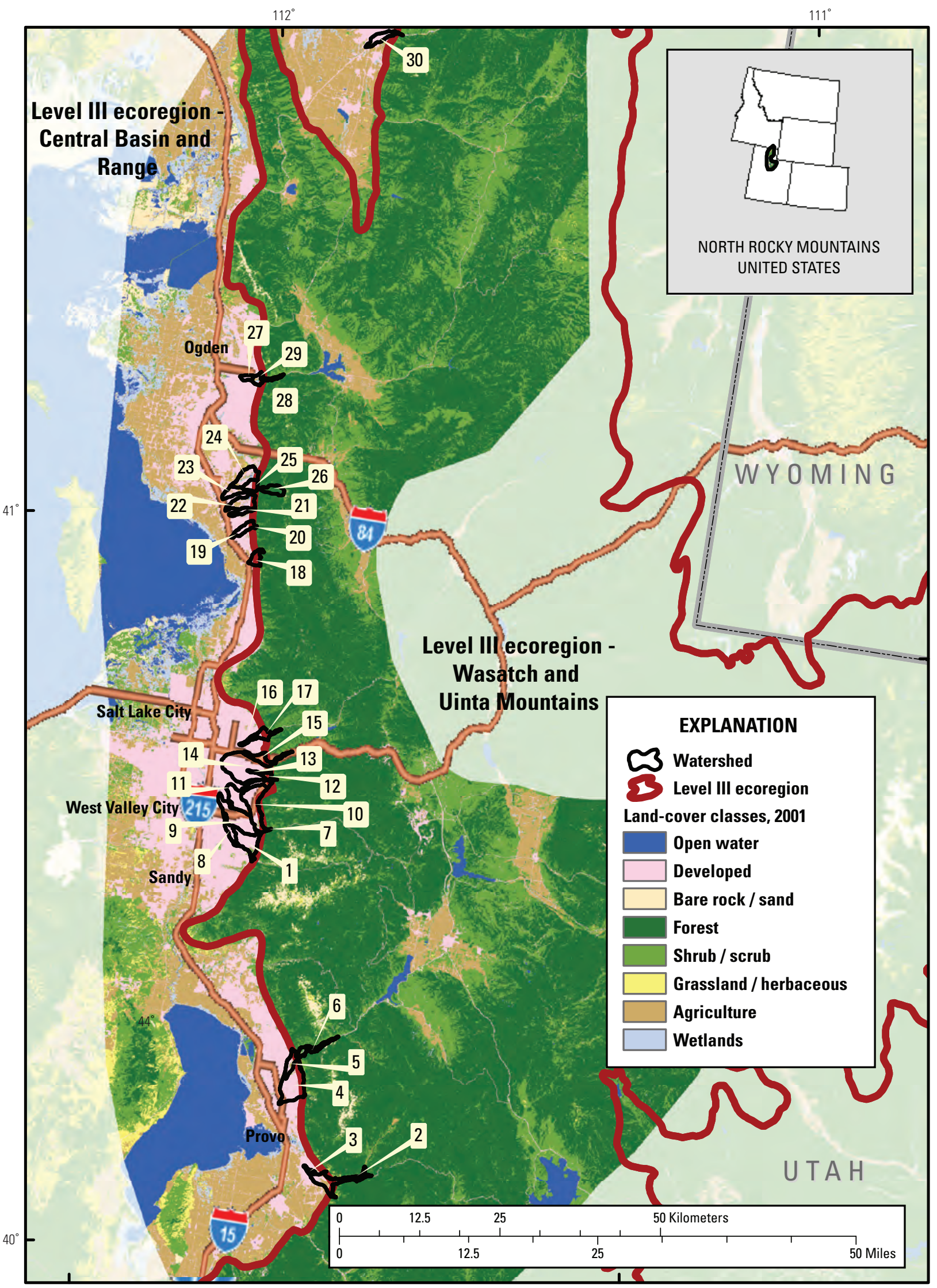

Figure 1A-2. Locations of study watersheds in the Salt Lake City, Utah, metropolitan area. 


\section{Birmingham}

The Birmingham study watersheds are located in the Mobile River Basin in Georgia and Alabama in the southeastern United States, where mountain ridges typically are sandstone and valley floors are primarily limestone or shale. The climate is warm and humid with rainfall evenly distributed throughout the year, except for a dry period in August to October.
Major metropolitan centers in the study area include Birmingham, Anniston, and Gadsden, Alabama. The combined 2000 population for these three cities was 1.3 million, an 8 percent increase from 1990. The dominant natural vegetative cover is Appalachian oak forest, and land use is predominantly cropland, pasture, and urban lands. Steel manufacturing is an important part of Birmingham's economy along with the medical, trade, finance, research, and government fields.

Table 1A-3. Study watersheds located in the Birmingham, Alabama, metropolitan area.

\begin{tabular}{|c|c|c|c|}
\hline $\begin{array}{l}\text { Figure } \\
\text { number }\end{array}$ & $\begin{array}{l}\text { USGS station } \\
\text { identification }\end{array}$ & USGS station name & $\begin{array}{l}\text { Watershed drainage area } \\
\text { (square kilometers) }\end{array}$ \\
\hline 1 & 02388518 & Little Dry Creek at US 27 at Rome, Ga. & 20.02 \\
\hline 2 & 02397939 & Chappel Creek at Long Branch Road near Trion, Ga. & 14.32 \\
\hline 3 & 02398001 & Town Branch near Summerville, Ga. & 4.70 \\
\hline 4 & 02400675 & Unnamed Tributary to Big Wills Creek at State Route 35 near Fort Payne, Ala. & 12.11 \\
\hline 5 & 02400725 & Mush Creek near Portersville, Ala. & 24.47 \\
\hline 6 & 02400800 & Little Wills Creek at Collins Chapel Road at Collinsville, Ala. & 27.88 \\
\hline 7 & 02401350 & Big Canoe Creek at Canoe Creek Road near Springville, Ala. & 54.37 \\
\hline 8 & 02401355 & Unnamed Tributary to Big Canoe Creek near Springville, Ala. & 10.50 \\
\hline 9 & 02401749 & Williams Branch near Jacksonville, Ala. & 23.92 \\
\hline 10 & 02401760 & Little Tallaseehatchee Creek near Weaver, Ala. & 38.12 \\
\hline 11 & 02403380 & Snow Creek below Anniston, Ala. & 44.72 \\
\hline 12 & 02406930 & Shirtee Creek near Odena, Ala. & 43.32 \\
\hline 13 & 02423120 & Cahaba River above Trussville, Ala. & 50.15 \\
\hline 14 & 0242339580 & Little Cahaba River near, Markeeta, Ala. & 15.70 \\
\hline 15 & 02423397 & Little Cahaba River below Leeds, Ala. & 43.95 \\
\hline 16 & 02423515 & Patton Creek near Bluff Park below Patton Chapel, Ala. & 28.77 \\
\hline 17 & 02423536 & Buck Creek at Buck Creek Road at Alabaster, Ala. & 38.70 \\
\hline 18 & 0242354650 & Cahaba Valley Creek at Indian Trail Road near Indian Springs, Ala. & 36.97 \\
\hline 19 & 0242354750 & Cahaba Valley Creek at Cross Creek Road at Pelham, Ala. & 66.07 \\
\hline 20 & 02423576 & Shades Creek at Lakeshore Drive near Mountain Brook, Ala. & 42.08 \\
\hline 21 & 02423581 & Shades Creek at Samford University at Homewood, Ala. & 56.30 \\
\hline 22 & 02423590 & Unnamed Tributary to Shades Creek near Oxmoor, Ala. & 5.99 \\
\hline 23 & 02423620 & Little Shades Creek at State Highway 150 near Bessemer, Ala. & 21.68 \\
\hline 24 & 02423729 & Dry Creek at Spring Creek Road near Montevallo, Ala. & 34.69 \\
\hline 25 & 0242372950 & Spring Creek at County Road 16 near Moores Crossroads, Ala. & 33.07 \\
\hline 26 & 02456900 & Fivemile Creek at Fivemile Road near Huffman, Ala. & 25.04 \\
\hline 27 & 02456980 & Fivemile Creek at Lawson Road near Tarrant City, Ala. & 48.66 \\
\hline 28 & 02458150 & Village Creek at East Lake in Birmingham, Ala. & 14.22 \\
\hline 29 & 02461200 & Valley Creek at Cleburn Avenue at Powderly, Ala. & 52.10 \\
\hline 30 & 02461670 & Five Mile Creek at Nevel Road near McCalla, Ala. & 33.90 \\
\hline
\end{tabular}




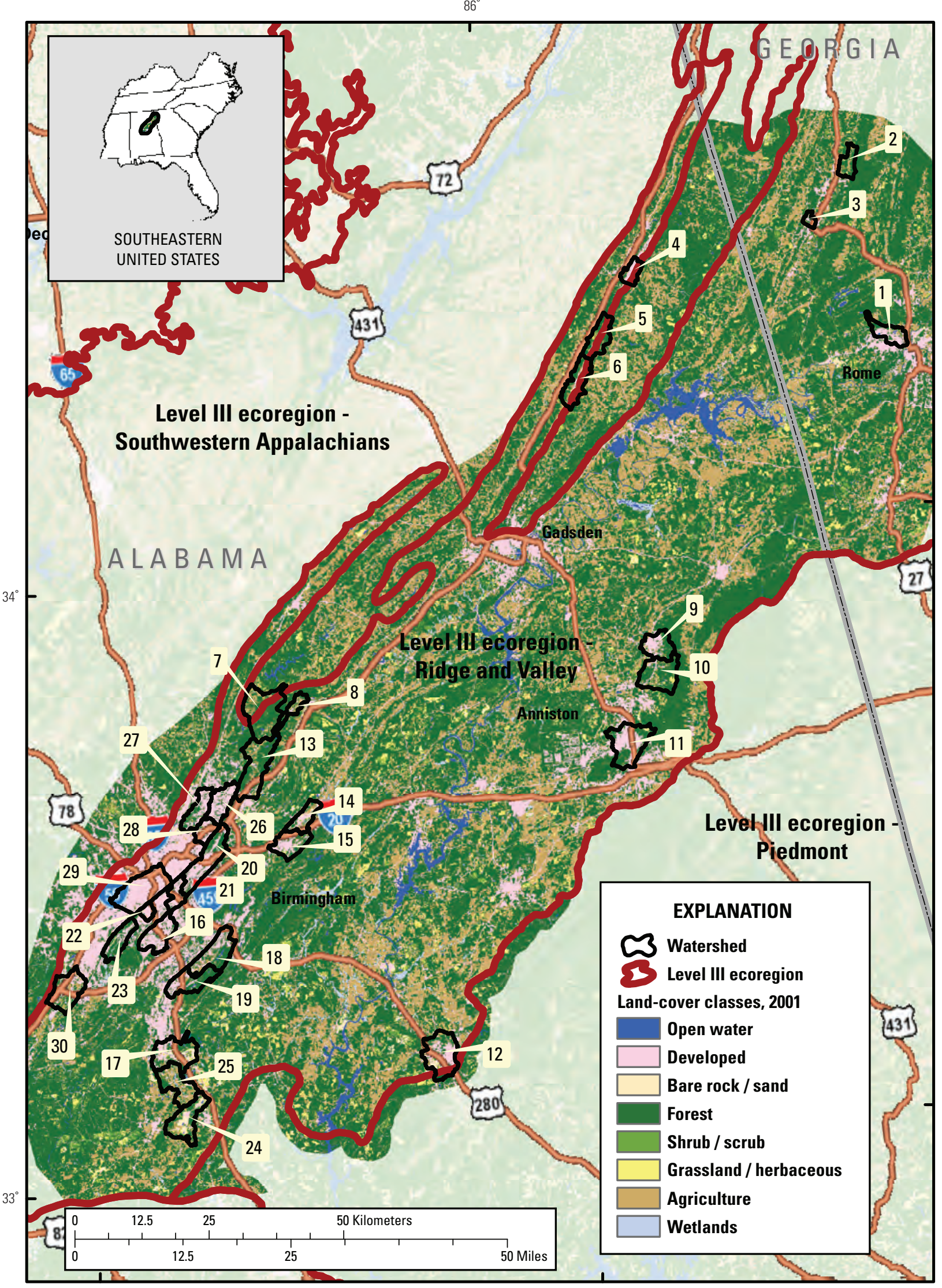

Figure 1A-3. Locations of study watersheds in the Birmingham, Alabama, metropolitan area. 


\section{Atlanta}

The Atlanta study watersheds, located in northern Georgia, are characterized by gently rolling topography and dissected irregular plains. The soils are almost exclusively fine-grained sediments. The climate is warm and humid with precipitation relatively consistent throughout the year, typical of the southeastern United States. Streams in the area typically have low to moderate gradients with cobble, gravel, and sandy substrates.
Three major population centers of the area are Atlanta, Sandy Springs, and Marietta with a 2000 population of $4,247,981$, a 38.4 percent increase from 1990. Natural land cover in the Atlanta study area is oak-hickory-pine forest; however, current land use and land cover includes forested areas in silviculture and agricultural production of hay, cattle and poultry, and sprawling urban development. The economy is diversified and includes medical, industrial, commercial, and service sectors.

Table 1A-4. Study watersheds located in the Atlanta, Georgia, metropolitan area.

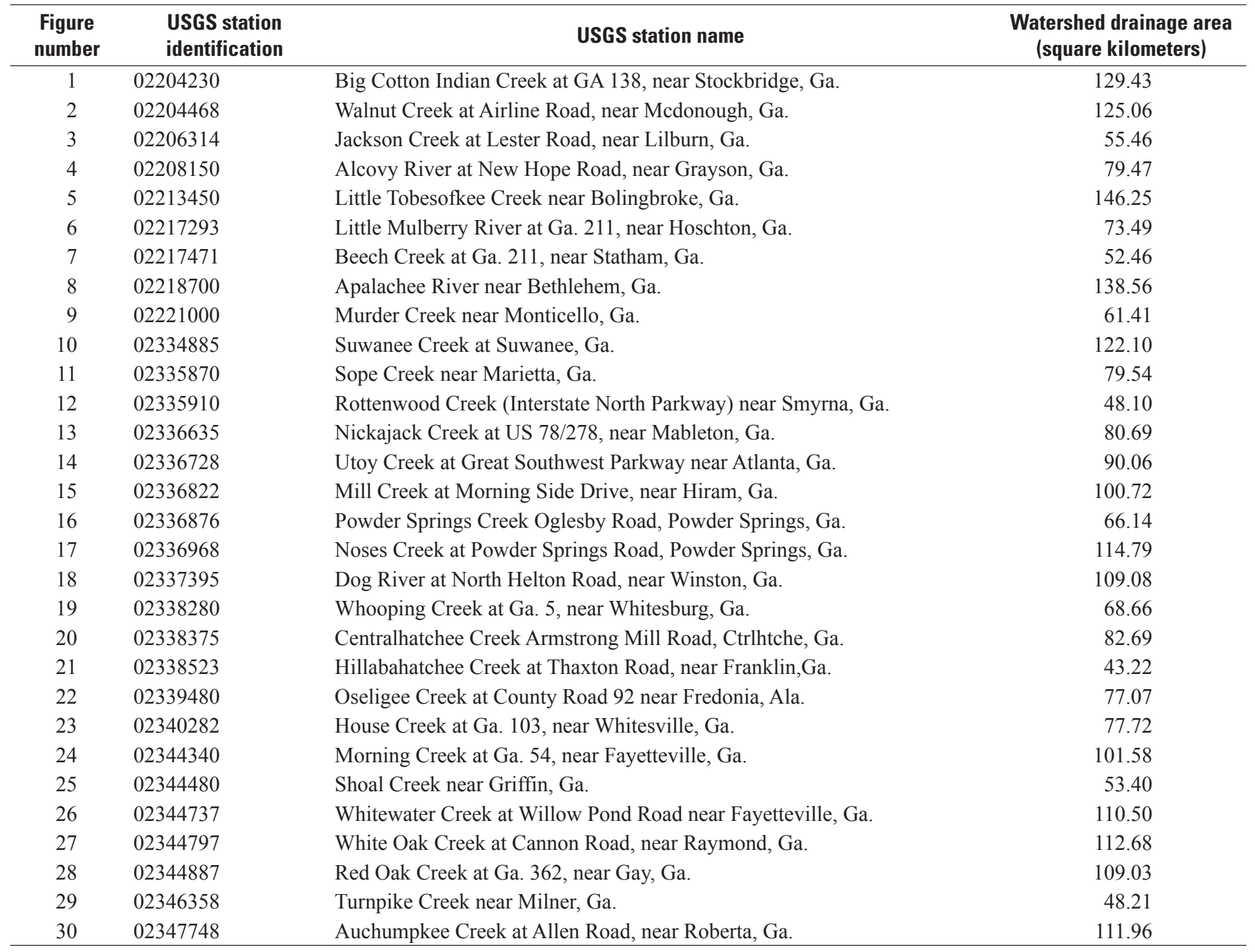




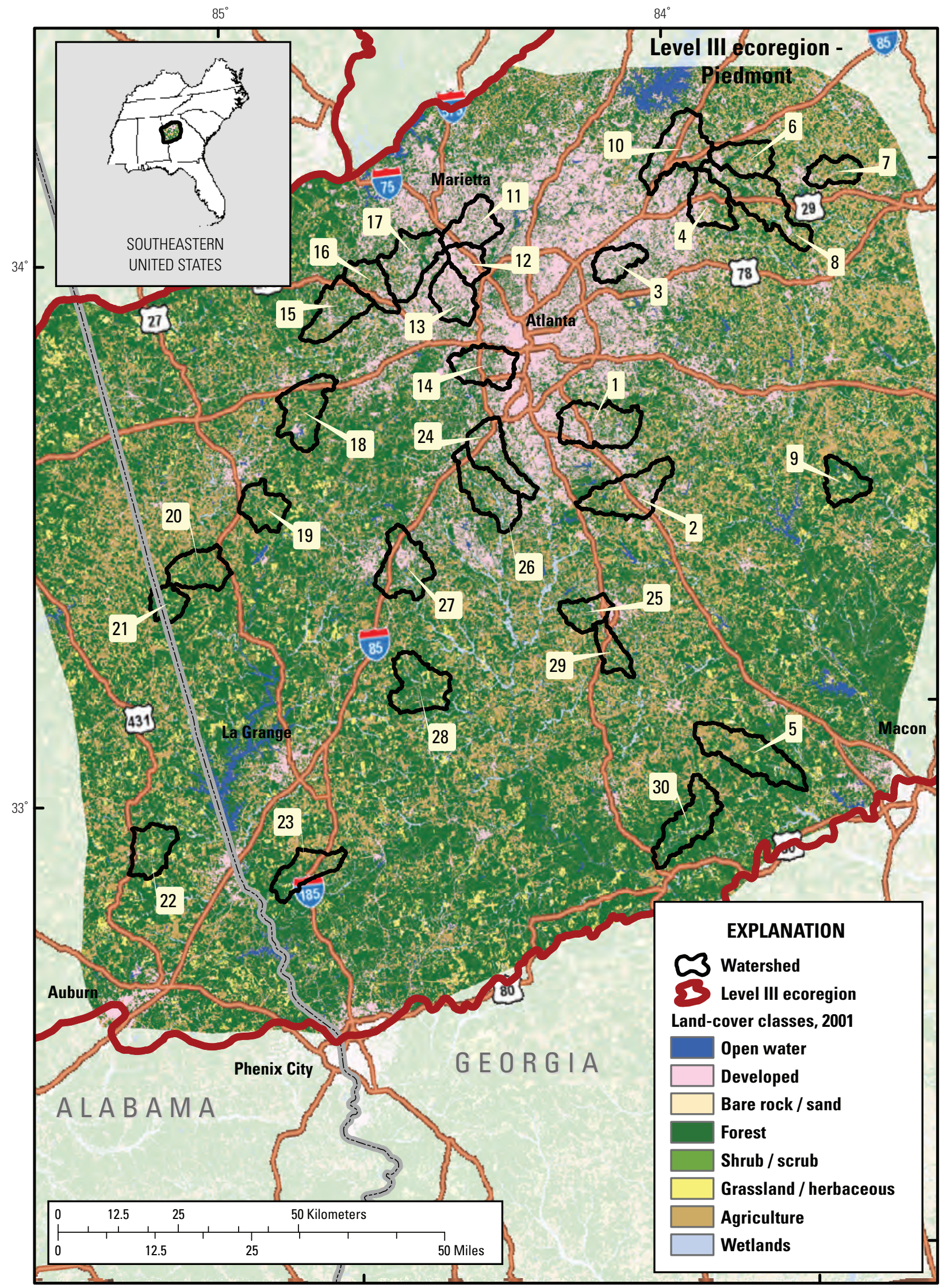

Figure 1A-4. Locations of study watersheds in the Atlanta, Georgia, metropolitan area. 


\section{Raleigh}

The Raleigh study watersheds are located in central North Carolina with irregular plains and some hills. Soils in the area vary from fine to moderately fine textures in the Coastal Plain and Piedmont areas. The climate is warm and humid, with rainfall evenly distributed throughout the year. Streams in all three subecoregions have low to moderate gradients and typically have gravel to cobble substrate.

The Raleigh study area includes five population centersRaleigh-Cary, Greensboro-High Point, Durham, WinstonSalem, and Burlington-with a combined 2000 population of 2.4 million, an increase of about 28 percent from 1990.
The economy of the study area is diversified and has grown substantially in recent decades, in part as a result of the "Research Triangle" of Raleigh-Durham-Chapel Hill, a successful corporate research area associated with three nearby universities. Heavier industry, primarily textiles, tobacco, chemicals, and furniture, dominate in the western part of the study area near Winston-Salem and Greensboro. Land use in the area has undergone major transformations, from forests to agricultural lands, to forest again, and as of late, to urban and suburban lands. At one time, the region was heavily farmed in cotton, tobacco, corn, and wheat, and many areas underwent moderate to severe erosion of the silt/ clay soils.

Table 1A-5. Study watersheds located in the Raleigh, North Carolina, metropolitan area.

\begin{tabular}{|c|c|c|c|}
\hline $\begin{array}{l}\text { Figure } \\
\text { number }\end{array}$ & $\begin{array}{l}\text { USGS station } \\
\text { identification }\end{array}$ & USGS station name & $\begin{array}{l}\text { Watershed drainage area } \\
\text { (square kilometers) }\end{array}$ \\
\hline 1 & 02081190 & Tar River near Berea, N.C. & 66.25 \\
\hline 2 & 02081510 & Foundry Branch at mouth near Oxford, N.C. & 12.56 \\
\hline 3 & 0208500600 & Cates Creek near Hillsborough, N.C. & 10.88 \\
\hline 4 & 0208501535 & Strouds Creek at St Marys Road near Hillsborough, N.C. & 23.15 \\
\hline 5 & 02085430 & Deep Creek near Moriah, N.C. & 82.49 \\
\hline 8 & 0208726995 & Hare Snipe Creek at SR 1822 near Leesville, N.C. & 16.01 \\
\hline 9 & 0208730725 & Beaverdam Creek at Glenwood Aveue at Raleigh, N.C. & 7.98 \\
\hline 10 & 0208732610 & Pigeon House Branch at Crabtree Boulevard at Raleigh, N.C. & 11.37 \\
\hline 11 & 02087580 & Swift Creek near Apex, N.C. & 54.26 \\
\hline 12 & 0208758440 & Dutchmans Branch at SR 1386 near Mccullers Crossrds, N.C. & 11.73 \\
\hline 16 & 0209647295 & Dry Creek above Service Creek at Burlington, N.C. & 6.50 \\
\hline 17 & 0209651815 & Branch Creek Below NC 54 near Graham, N.C. & 4.92 \\
\hline 18 & 0209665940 & Rock Creek Tributary at Stoney Creek Golf Course near Sedalia, N.C. & 11.66 \\
\hline 19 & 0209665990 & Rock Creek above Rock Creek Tributary near Whitsett, N.C. & 25.98 \\
\hline 20 & 0209679804 & Little Alamance Creek at SR 2309 near Graham, N.C. & 37.35 \\
\hline 21 & 0209695780 & Brooks Creek at Eddie Perry Road near Bynum, N.C. & 23.88 \\
\hline 22 & 0209697900 & Pokeberry Creek near Pittsboro, N.C. & 29.79 \\
\hline 23 & 02097355 & Bolin Creek above Franklin Streetnear Chapel Hill N.C. & 29.81 \\
\hline 24 & 02097464 & Morgan Creek near White Cross, N.C. & 21.45 \\
\hline 25 & 0209750881 & Wilson Creek at mouth near Chapel Hill, N.C. & 9.17 \\
\hline
\end{tabular}




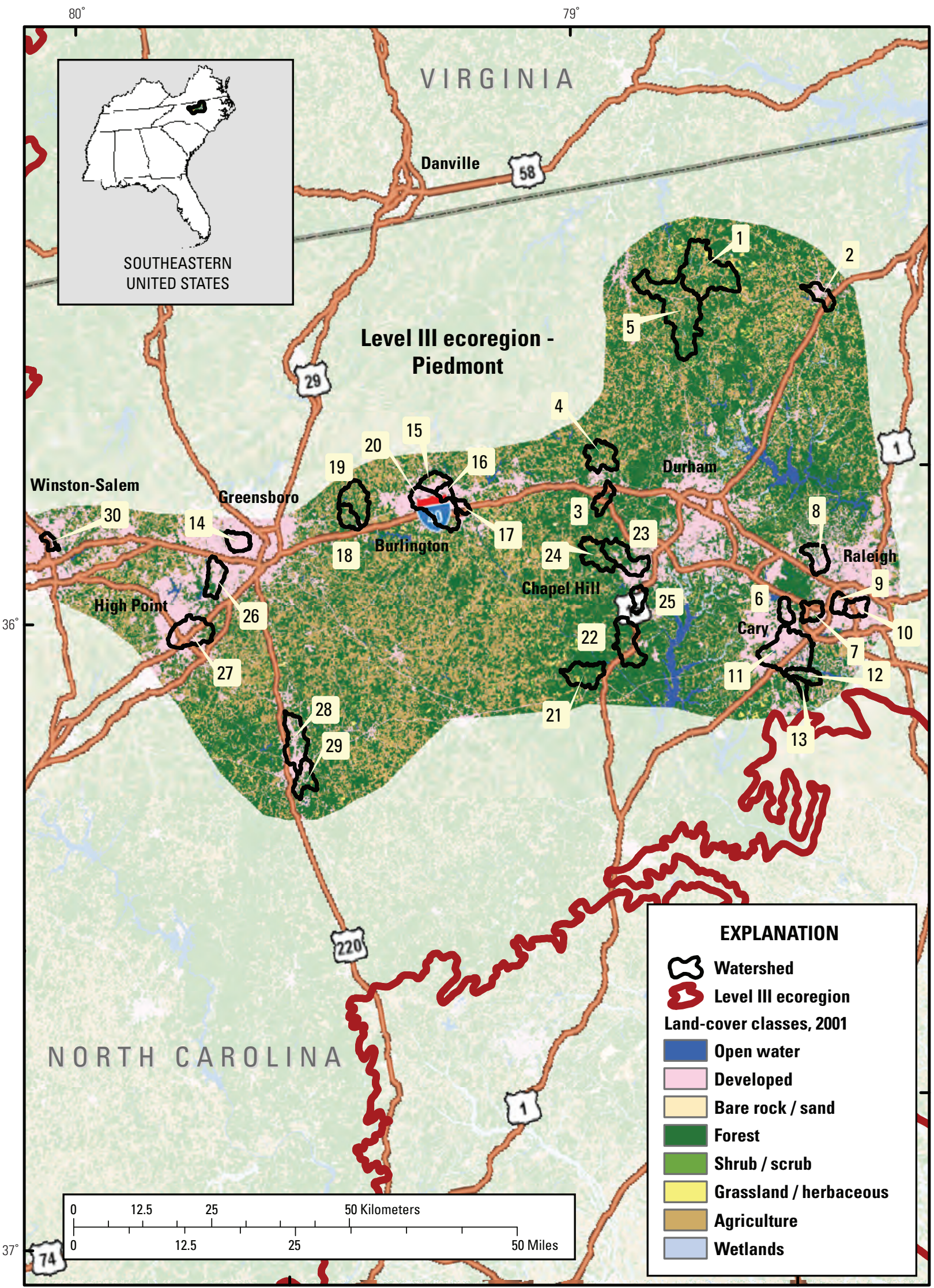

Figure 1A-5. Locations of study watersheds in the Raleigh, North Carolina, metropolitan area. 


\section{Boston}

The Boston study area includes portions of Massachusetts, New Hampshire, Maine, and Connecticut. The area is characteristic of New England with moderately coarse to coarse textured soils, low hills, forests, cropland and pasture, and urban lands. The climate is cool and humid, and the area experiences frost periods and snow in winter months, although precipitation is evenly distributed throughout the year, with slightly higher amounts in the spring and fall.

The Boston study area includes portions of four cities, including Boston, Massachusetts; Worcester, Massachusetts; Concord, New Hampshire; and Manchester-Nashua,
New Hampshire. The combined 2000 population for these cities, 5.7 million, increased by about 7 percent from 1990 . The land cover is composed of a mix of forest, urban, and agriculture. This area was first colonized and developed in the early to mid 1600s by immigrants from England for its location as an excellent port on the Atlantic Ocean. The natural land cover was mixed forest, but was cleared for lumber materials and the land was converted to agricultural uses. The area was allowed to revert back to forests as the industrial revolution encouraged families to abandon the farms for jobs in the cities. Many factories and mills were built along rivers, so that more than 1,600 dams in the area regulate flows in mid-sized to large rivers (basin areas greater than 250 square kilometers).

Table 1A-6. Study watersheds located in the Boston, Massachusetts, metropolitan area.

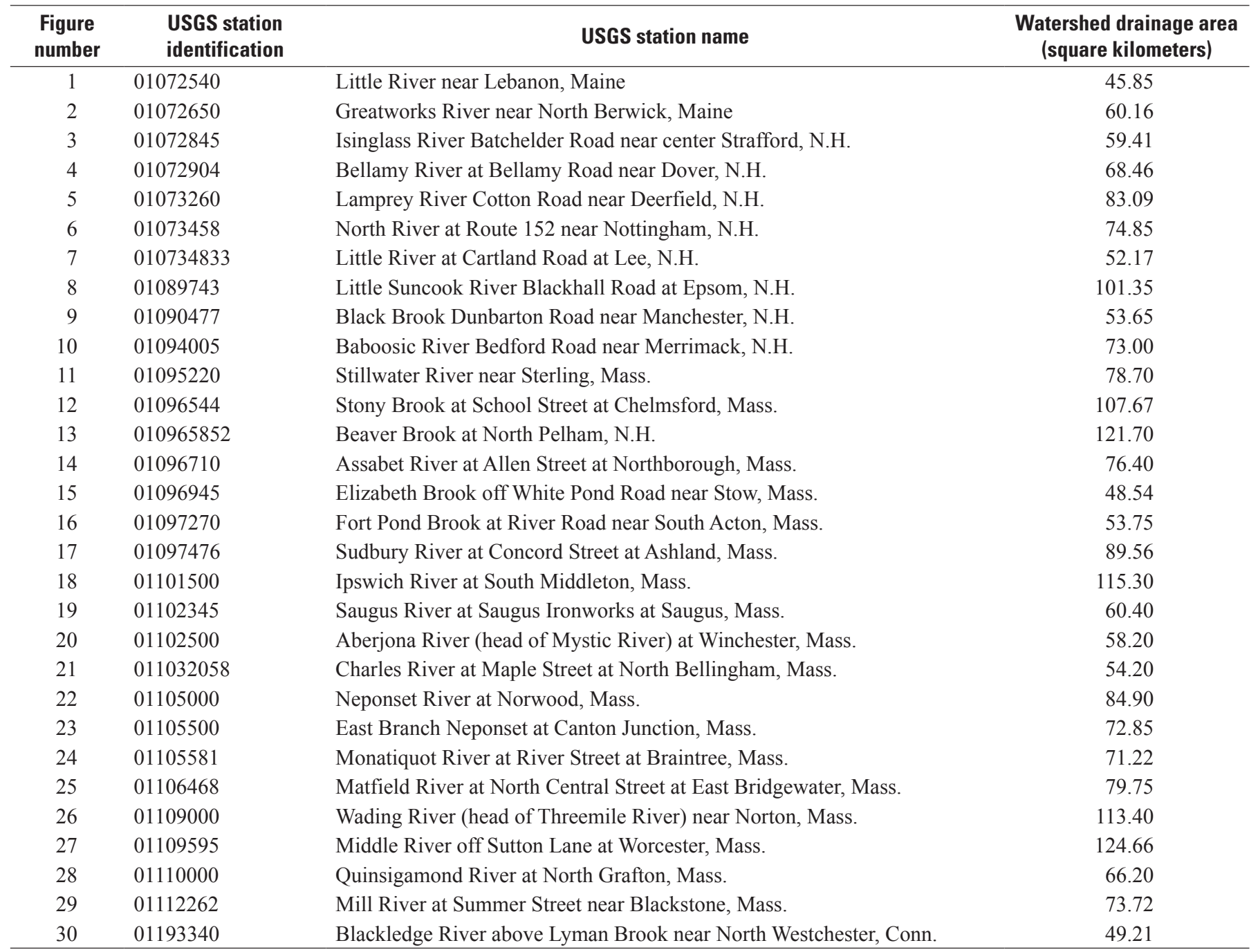




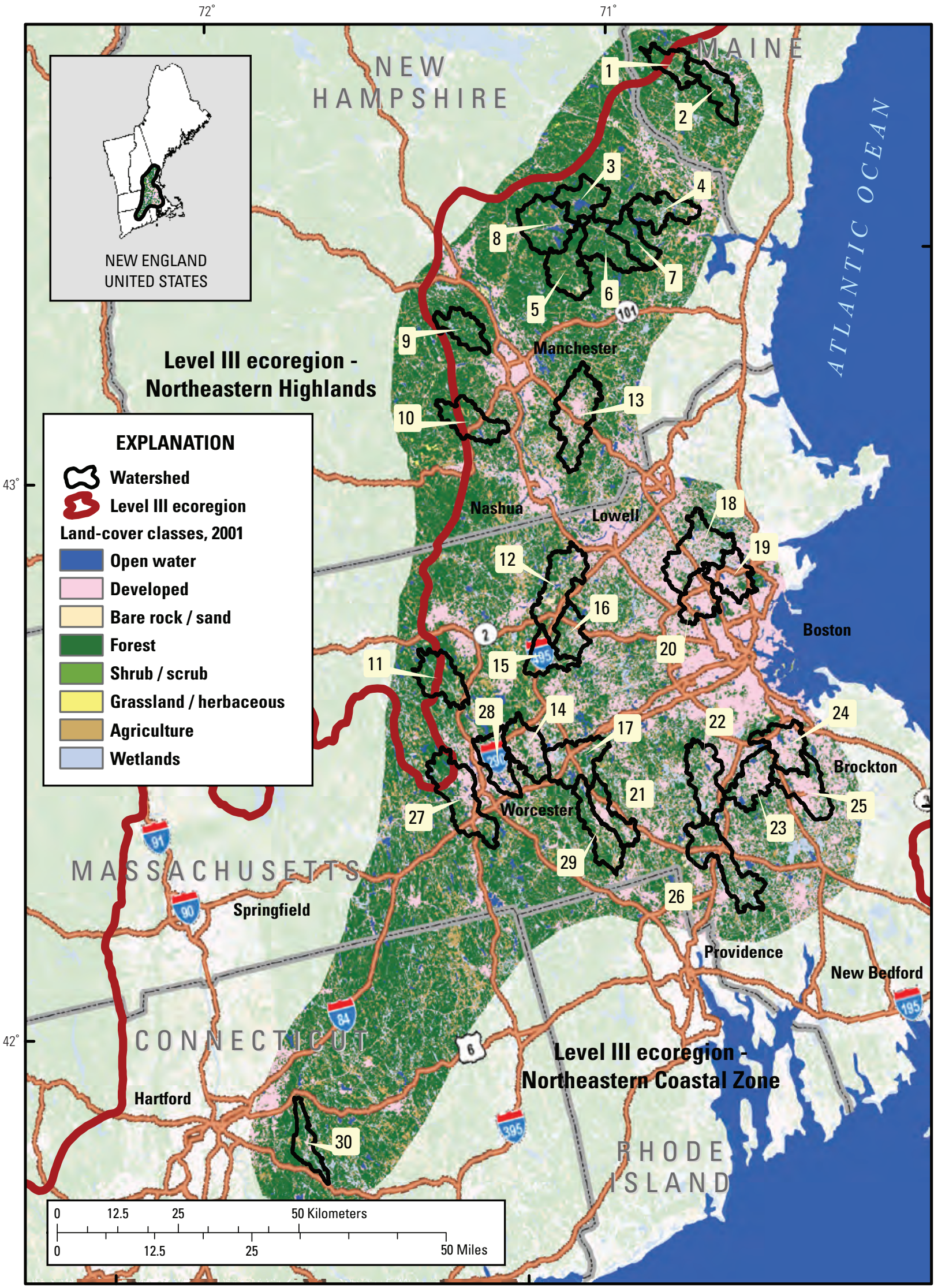

Figure 1A-6. Locations of study watersheds in the Boston, Massachusetts, metropolitan area. 


\section{Denver}

The major drainage basin in the Denver study area is the South Platte River and includes portions of north-central Colorado and southeastern Wyoming. Elevation in the study area ranges from about 1,500 to 2,500 meters above NAVD 88, although the study area is bordered on the west by the Southern Rockies ecoregion, where elevations are considerably higher. The climate is semiarid, and precipitation in the study area is affected considerably by topography. Most of the precipitation on the plains results from rainfall, primarily between April and September; however, perennial streamflow also is fed by snowmelt from the mountains. Smaller streams are often ephemeral, and a complex network of ditches and pipes moves water between different areas for domestic water supply, agricultural irrigation, and power generation. Land cover in the study area is dominated by grassland and agriculture in the plains and coniferous forest in the western mountains.

The Denver study area includes four main city centers-Denver-Aurora, Boulder, and Fort Collins-Loveland, Colorado, and Cheyenne, Wyoming. The combined 2000 population for these four cities, 2.8 million, was a 30 percent increase from 1990. The economy is diversified and includes telecommunications, software, agriculture, mining, and heavy industry. Denver is a major regional center for U.S. Government offices, a transportation hub, and a tourist gateway to the mountain recreational areas of the southern Rockies.

Table 1A-7. Study watersheds located in the Denver, Colorado, metropolitan area.

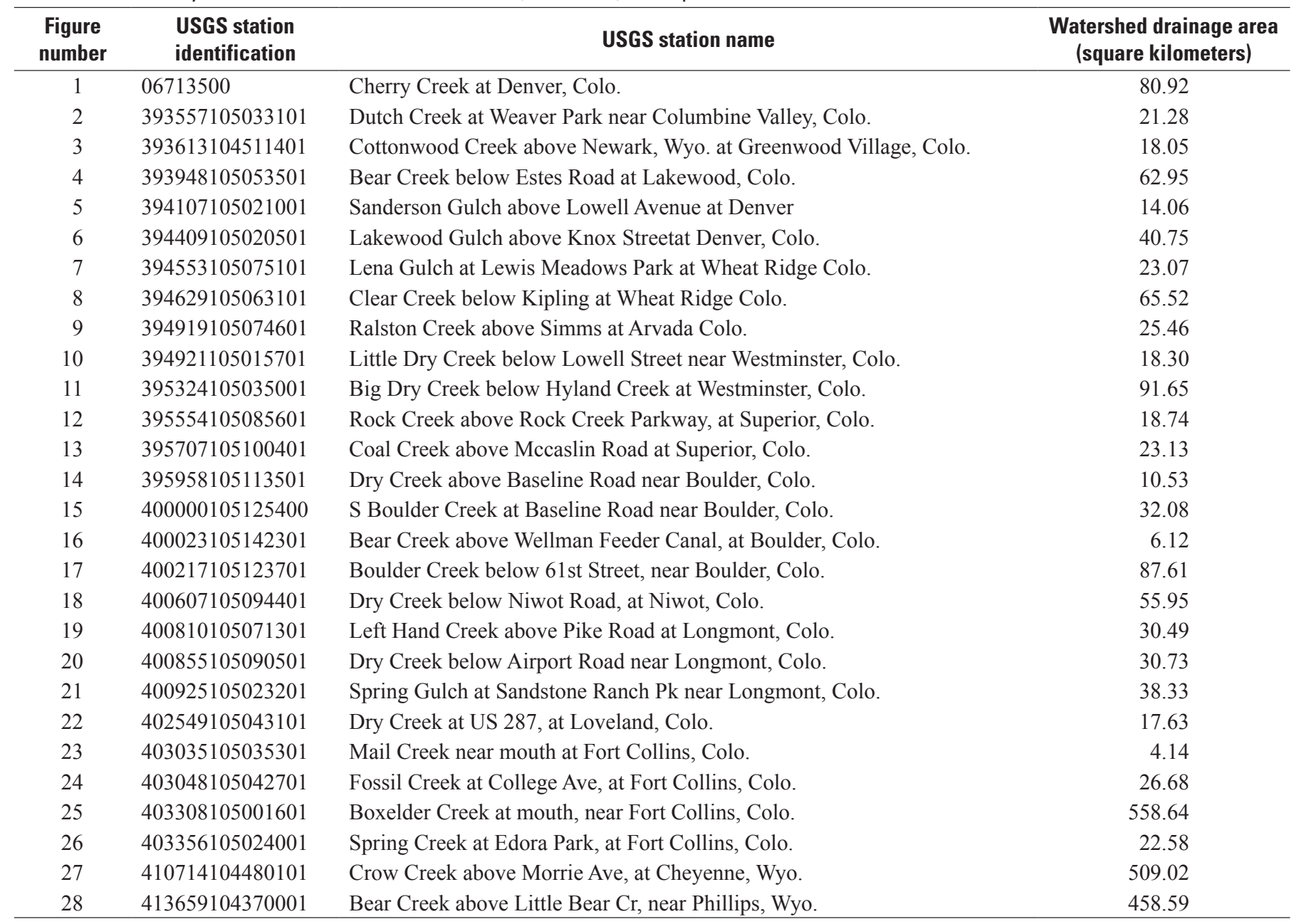




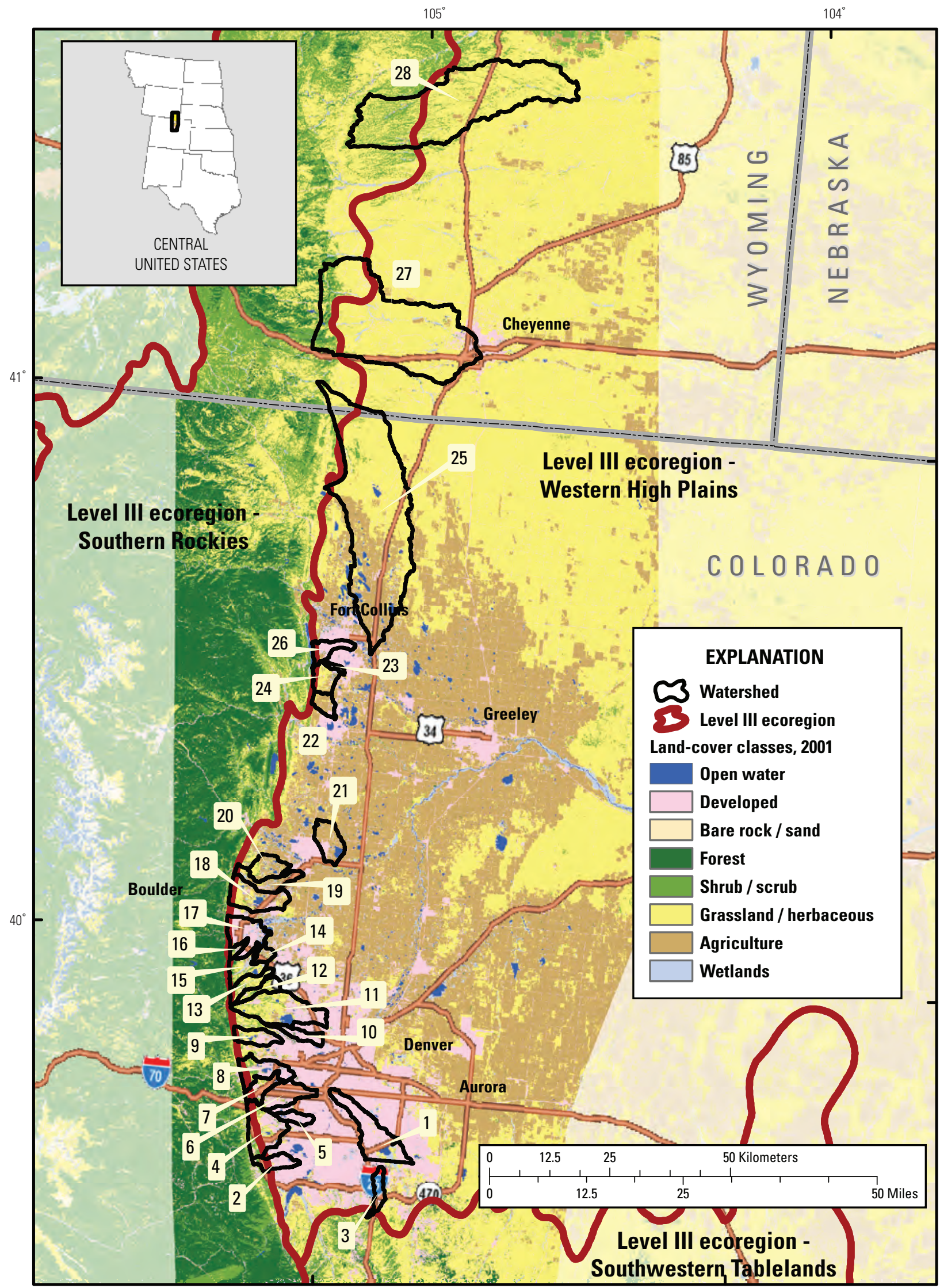

Figure 1A-7. Locations of study watersheds in the Denver, Colorado, metropolitan area. 


\section{Dallas}

The Dallas study area is located in the upper drainage of the Trinity River watershed in north-central Texas, which is an area of generally rolling to level plains. The soil texture is primary fine to moderately fine. The climate is warm and semiarid, with precipitation occurring primarily in the spring and late summer. Surface water in the study area consists primarily of reservoirs, intrawatershed transfers, diversions of water to municipalities, and wastewater effluent. Small streams in the area are generally intermittent. Land cover includes grasslands, pastures, row crops, and developed land.

The predominant metropolitan area of the Dallas metropolitan study area is Dallas-Fort Worth-Arlington, with a population in 2000 of 5 million, a 29.4 percent increase since 1990. Dallas is a major regional center, and the economy includes finance, oil, transportation, aerospace, and electronics. Fort Worth, a twin city to Dallas, has an economic focus based on cattle, railways, and agricultural processing.

Table 1A-8. Study watersheds located in the Dallas, Texas, metropolitan area.

\begin{tabular}{|c|c|c|c|}
\hline $\begin{array}{l}\text { Figure } \\
\text { number }\end{array}$ & $\begin{array}{l}\text { USGS station } \\
\text { identification }\end{array}$ & USGS station name & $\begin{array}{l}\text { Watershed drainage area } \\
\text { (square kilometers) }\end{array}$ \\
\hline 1 & 08049490 & Johnson Creek near Duncan Perry Road, Grand Prairie, Tex. & 43.23 \\
\hline 2 & 08049580 & Mountain Creek near Venus, Tex. & 51.96 \\
\hline 3 & 08049955 & Fish Creek at Belt Line Road, Grand Prairie, Tex. & 58.27 \\
\hline 4 & 08052740 & Doe Branch at Fishtrap Road near Prosper, Tex. & 94.53 \\
\hline 5 & 08057200 & White Rock Creek at Greenville Ave, Dallas, Tex. & 173.01 \\
\hline 8 & 08059530 & Tickey Creek near CR 400 near Princeton, Tex. & 26.81 \\
\hline 9 & 08059571 & Wilson Creek near Gray Branch Road near Mckinney, Tex. & 80.96 \\
\hline 10 & 08061536 & Spring Creek at Naaman School Road near Garland, Tex. & 91.09 \\
\hline 11 & 08061740 & Duck Creek at Town East Boulevard near Mesquite, Tex. & 102.33 \\
\hline 12 & 08061780 & Buffalo Creek near Trinity Road at Forney, Tex. & 88.16 \\
\hline 16 & 08062090 & Red Oak Creek near Hampton Road near Red Oak, Tex. & 53.82 \\
\hline 17 & 08062525 & Walker Creek near Oil Field Road near Rosser, Tex. & 59.26 \\
\hline 18 & 08062550 & Bois D'Arc Creek near CR 4072 near Rosser, Tex. & 57.89 \\
\hline 19 & 08062600 & Grays Creek at CR 1603 near Rice, Tex. & 64.83 \\
\hline 20 & 08062805 & Williams Creek near FM 1836 near Kemp, Tex. & 68.04 \\
\hline 21 & 08063047 & Bynum Creek near FM 308 near Malone, Tex. & 52.78 \\
\hline 22 & 08063300 & Pin Oak Creek near FM 73 near Coolidge, Tex. & 101.68 \\
\hline 23 & 08063510 & Little Pin Oak Creek near Ih 45 near Richland, Tex. & 40.87 \\
\hline 24 & 08063555 & S Fk Chambers Creek near CR 102 near Maypearl, Tex. & 291.37 \\
\hline 25 & 08063565 & Mill Creek at Lowell Road near Milford, Tex. & 80.37 \\
\hline
\end{tabular}




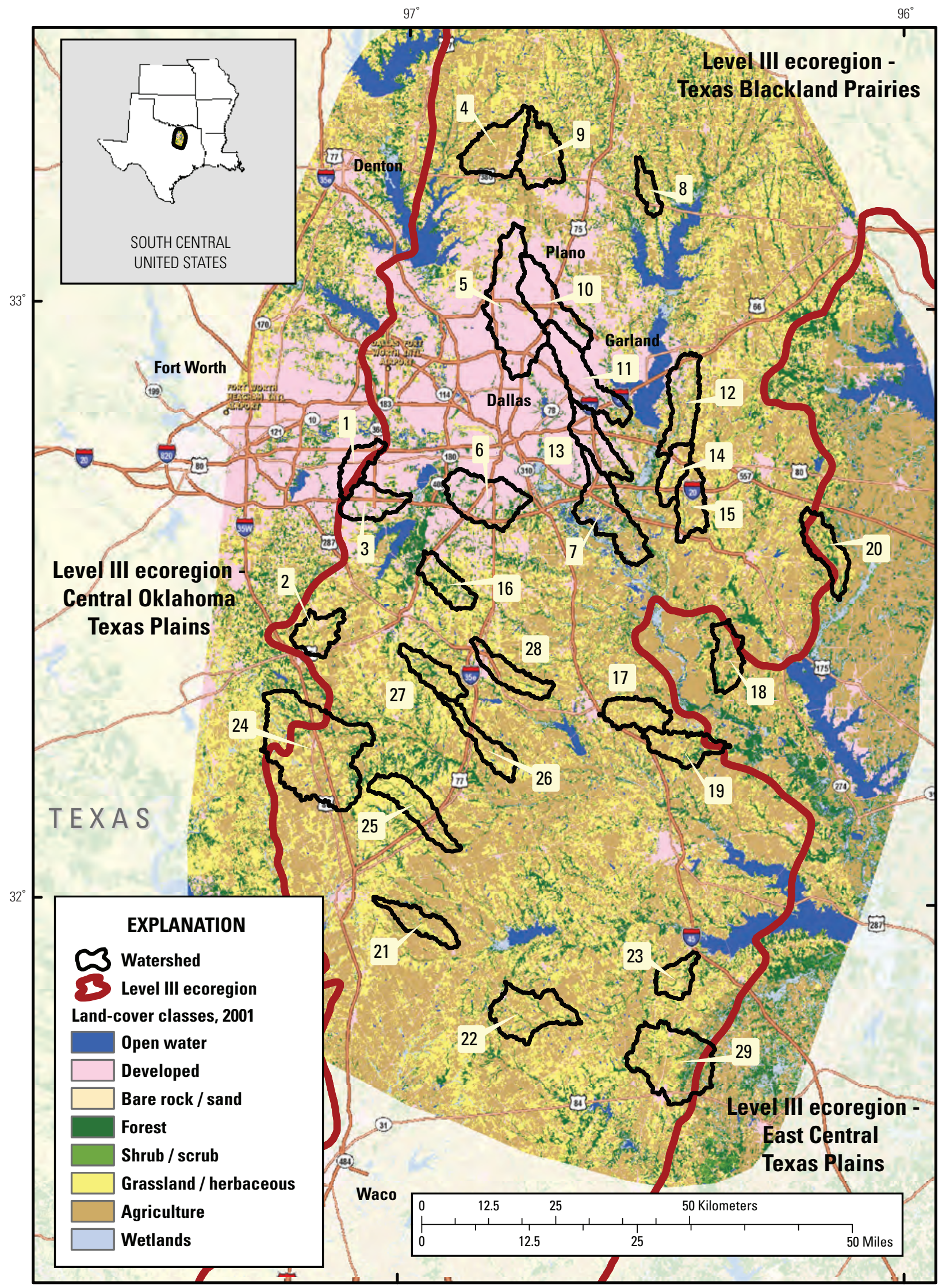

Figure 1A-8. Locations of study watersheds in the Dallas, Texas, metropolitan area. 


\section{Milwaukee}

The Milwaukee study area is located in the southeastern United States along the Lake Michigan shoreline. Land surface is characterized by glacial outwash plains, lacustrine watersheds, level to rolling till plains, and extensive wetland areas. The climate is characterized by cold winters and moderate, wet summers, with most of the precipitation occurring between May and September. Highest streamflows usually occur in March through May as a result of snowmelt or a combination of rain and snow; however, summer thunderstorms can produce flood peaks that exceed snowmelt peaks. The presettlement land cover was a mixture of hardwood forests (north), oak savannas (west), and tall-grass prairies (south).

The Milwaukee metropolitan study area includes five main population centers-Milwaukee-Waukesha-West Allis, Green Bay, Appleton, Racine, and Oshkosh-Neenah. The combined 2000 population for these five areas, 2.3 million, was an 8 percent increase from 1990. Milwaukee and Green Bay offer the largest industrial, manufacturing, and commercial centers of the study area for their shipping ports. Milwaukee has a reputation in the brewing industry; whereas, Green Bay is known for its meat packing industry. Dairy and livestock farming and associated corn and soybean production represent the dominant land use in the region.

Table 1A-9. Study watersheds in the Milwaukee, Wisconsin, metropolitan area.

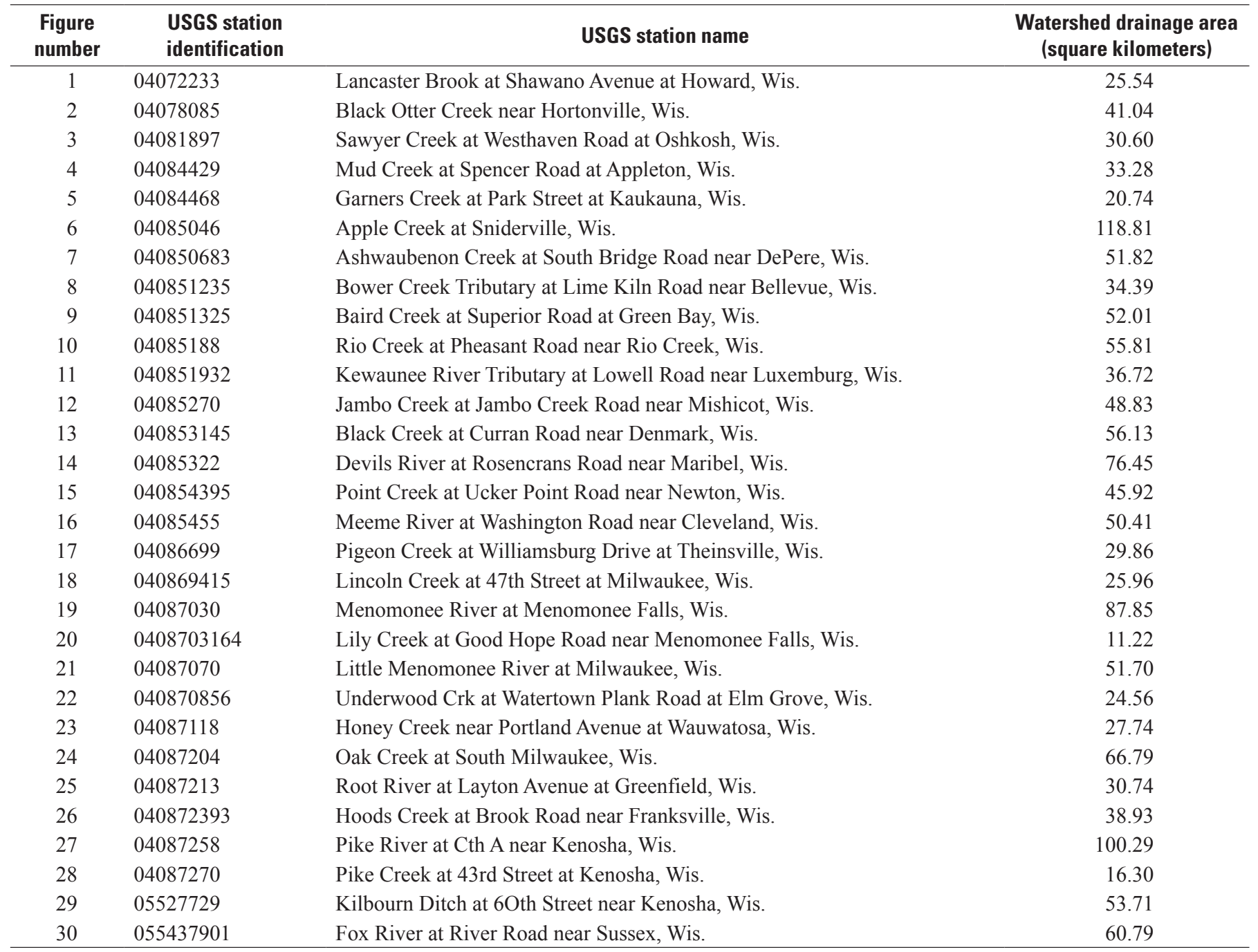




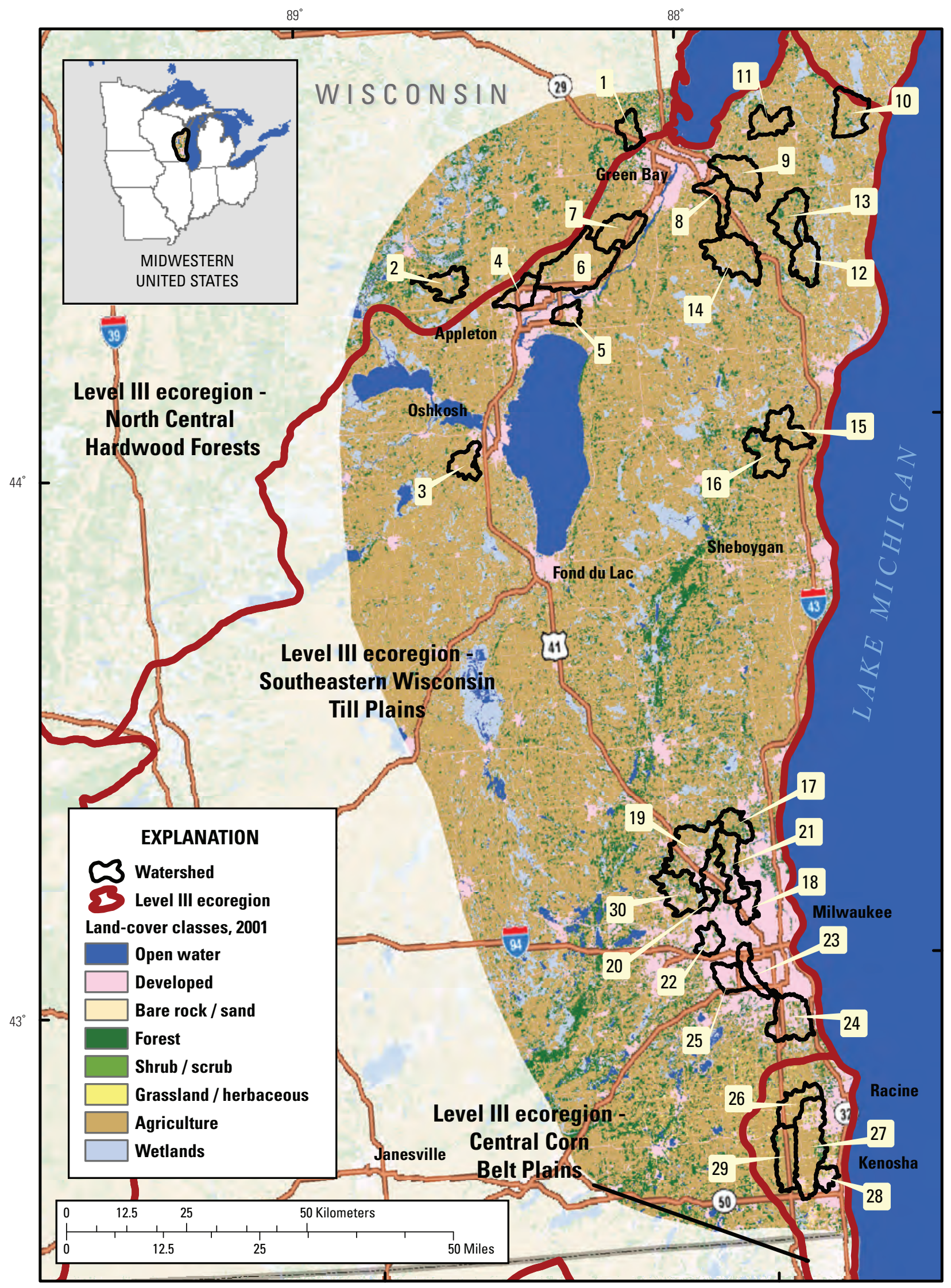

Figure 1A-9. Locations of study watersheds in the Milwaukee, Wisconsin, metropolitan area. 


\section{Appendix 1B: Characteristics of Nine Metropolitan Study Areas}

Table 1B-1. Geographic and climatic characteristics of the nine metropolitan study areas.

[Median values for study watersheds, range in parentheses]

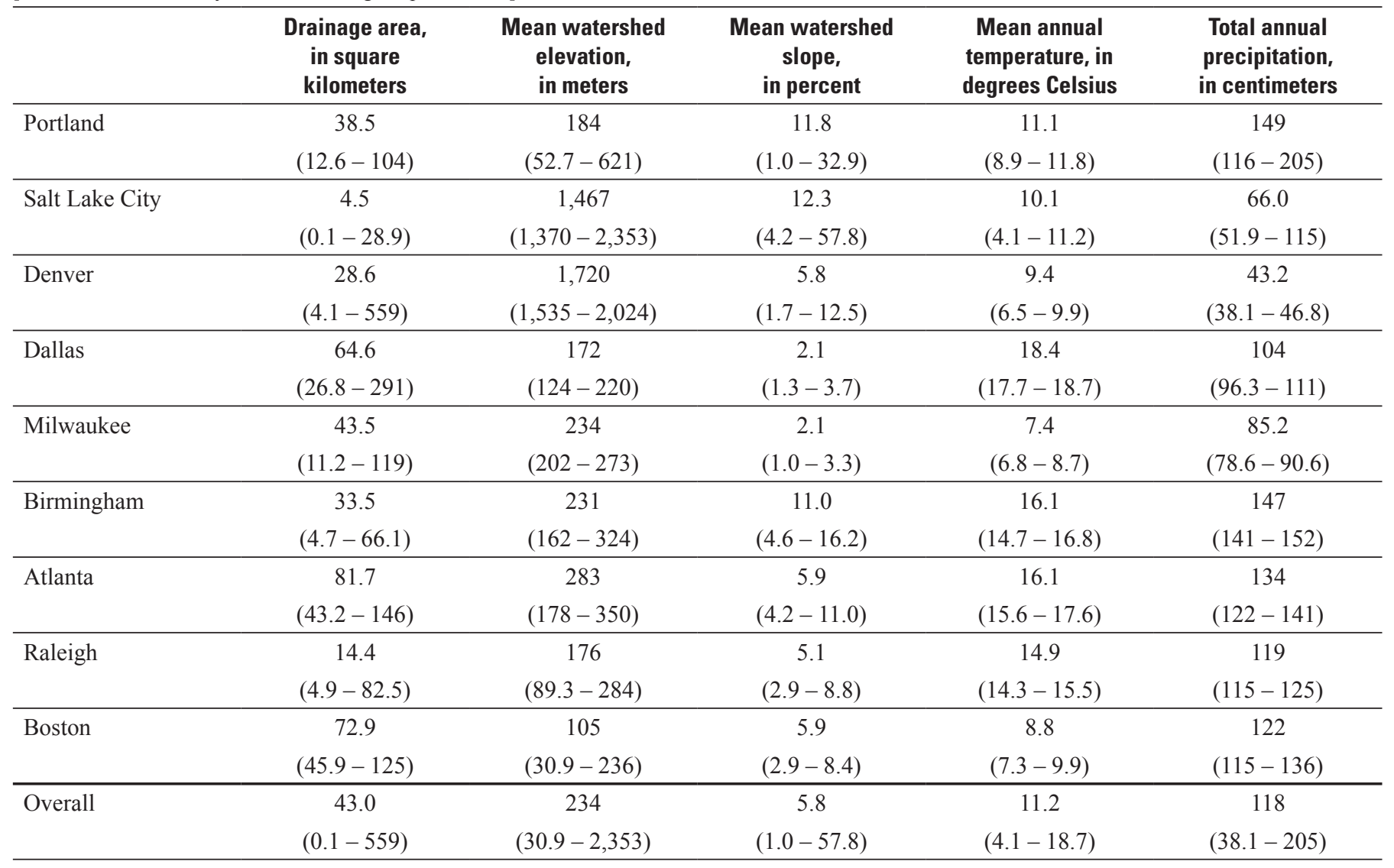


Table 1B-2. Soil characteristics of the nine metropolitan study areas.

[Median values for study watersheds, range in parentheses]

\begin{tabular}{|c|c|c|c|c|c|}
\hline & $\begin{array}{l}\text { Coarse soils in } \\
\text { watershed, } \\
\text { in percent }\end{array}$ & $\begin{array}{l}\text { Moderately coarse } \\
\text { soils in watershed, } \\
\text { in percent }\end{array}$ & $\begin{array}{l}\text { Medium coarse soils } \\
\text { in watershed, } \\
\text { in percent }\end{array}$ & $\begin{array}{l}\text { Moderately fine soils } \\
\text { in watershed, } \\
\text { in percent }\end{array}$ & $\begin{array}{c}\text { Fine soils in } \\
\text { watershed, } \\
\text { in percent }\end{array}$ \\
\hline \multirow[t]{2}{*}{ Portland } & 0.0 & 0.0 & 30.5 & 2.0 & 55.1 \\
\hline & $(0-0)$ & $(0-40.9)$ & $(0-100)$ & $(0-55.4)$ & $(0-100)$ \\
\hline \multirow[t]{2}{*}{ Salt Lake City } & 0.0 & 13.5 & 86.4 & 0.0 & 0.0 \\
\hline & $(0-13.2)$ & $(0-100)$ & $(0-100)$ & $(0-0.8)$ & $(0-0)$ \\
\hline Denver & $(0-0)$ & $(0-82.5)$ & $(0-97.1)$ & $(0-100)$ & $(0-35.0)$ \\
\hline \multirow[t]{2}{*}{ Dallas } & 0.0 & 0.0 & 0.0 & 0.0 & 100.00 \\
\hline & $(0-0)$ & $(0-0)$ & $(0-0)$ & $(0-78.5)$ & $(21.5-100)$ \\
\hline Milwaukee & 0.0 & 0.0 & 0.0 & 2.2 & 71.3 \\
\hline \multirow[t]{2}{*}{ Atlanta } & 0.0 & 0.0 & 0.0 & 0.0 & 100.00 \\
\hline & $(0-0)$ & $(0-21.5)$ & $(0-0)$ & $(0-8.8)$ & $(78.6-100)$ \\
\hline \multirow[t]{2}{*}{ Raleigh } & 0.0 & 0.0 & 0.0 & 89.8 & 10.3 \\
\hline & $(0-0)$ & $(0-0)$ & $(0-0)$ & $(0-100)$ & $(0-100)$ \\
\hline \multirow[t]{2}{*}{ Boston } & 19.1 & 76.8 & 0.0 & 0.0 & 0.0 \\
\hline & $(0-75.5)$ & $(24.5-100)$ & $(0-16.4)$ & $(0-0)$ & $(0-0)$ \\
\hline \multirow[t]{2}{*}{ Overall } & 0.0 & 0.0 & 0.0 & 0.0 & 23.3 \\
\hline & $(0-75.5)$ & $(0-100)$ & $(0-100)$ & $(0-100)$ & $(0-100)$ \\
\hline
\end{tabular}


Table 1B-3. Land-cover characteristics of the nine metropolitan study areas.

[Median values for study watersheds, range in parentheses]

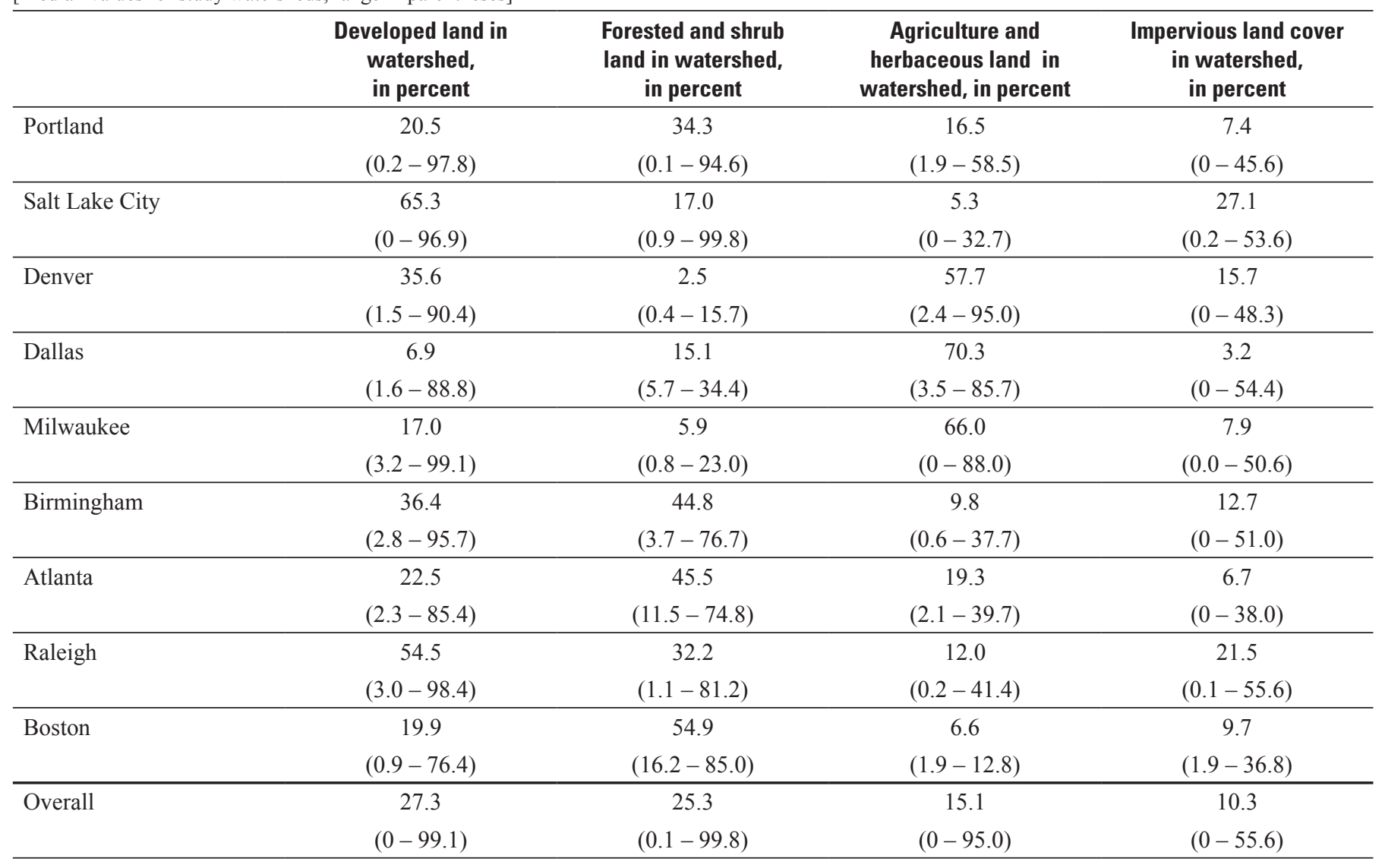


Table 1B-4. Demographics and infrastructure characteristics of the nine metropolitan study areas.

[Median values for study watersheds, range in parentheses]

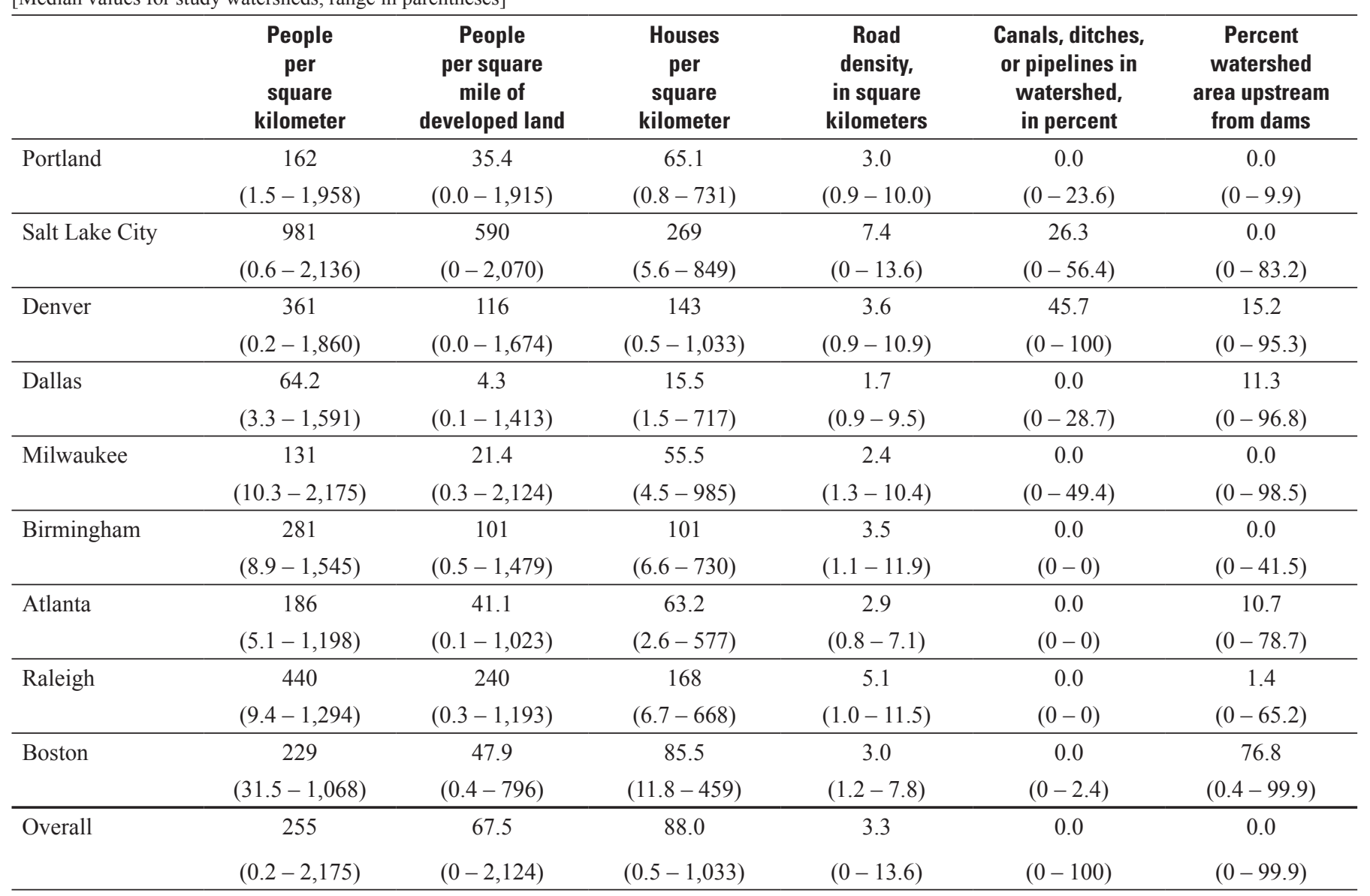



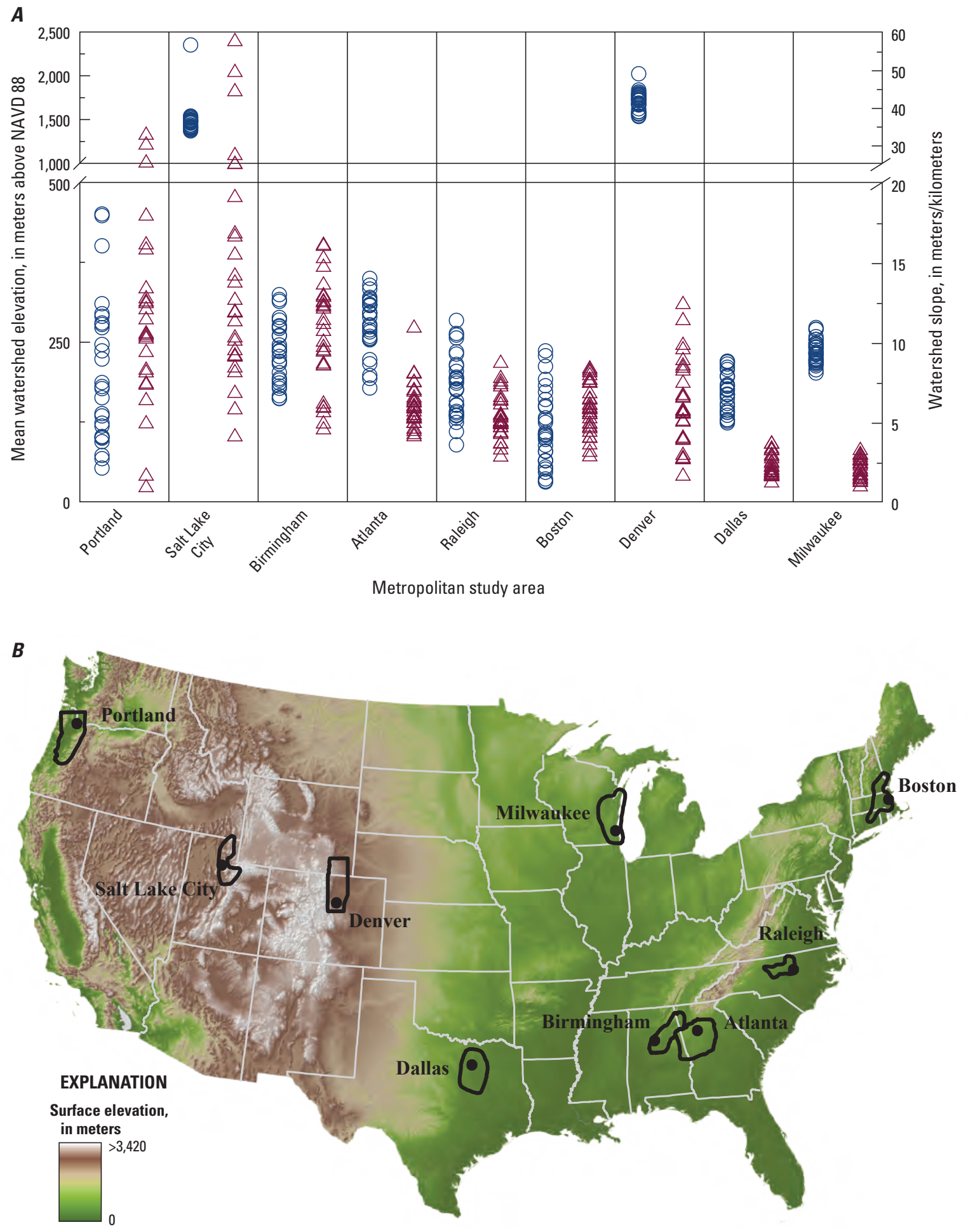

Source: National Atlas, Datum NAVD88, Elevation, 1 kilometer resolution, U.S. Geological Survey

Figure 1B-1. (A) Graph of the mean watershed elevation (in meters above sea level) and watershed slope (in meters per kilometer) for the nine metropolitan study areas and $(B)$ a national map showing surface elevation (in meters above sea level). 

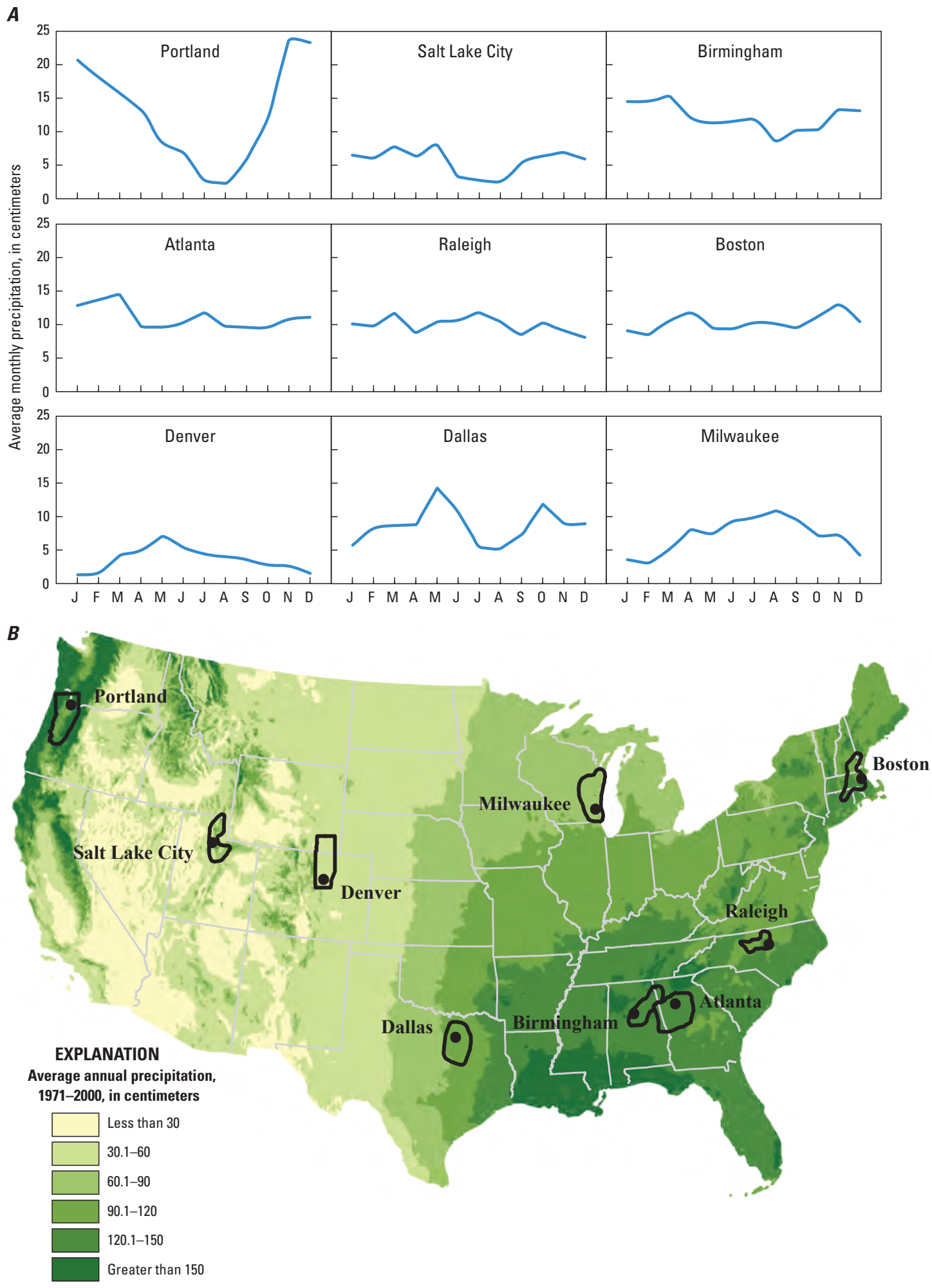

Source: The PRISM Group at Oregon State University, Corvallis, Oregon

Figure 1B-2. (A) Graphs of the average monthly precipitation for the nine metropolitan study areas and $(B)$ a national map showing average annual precipitation. 

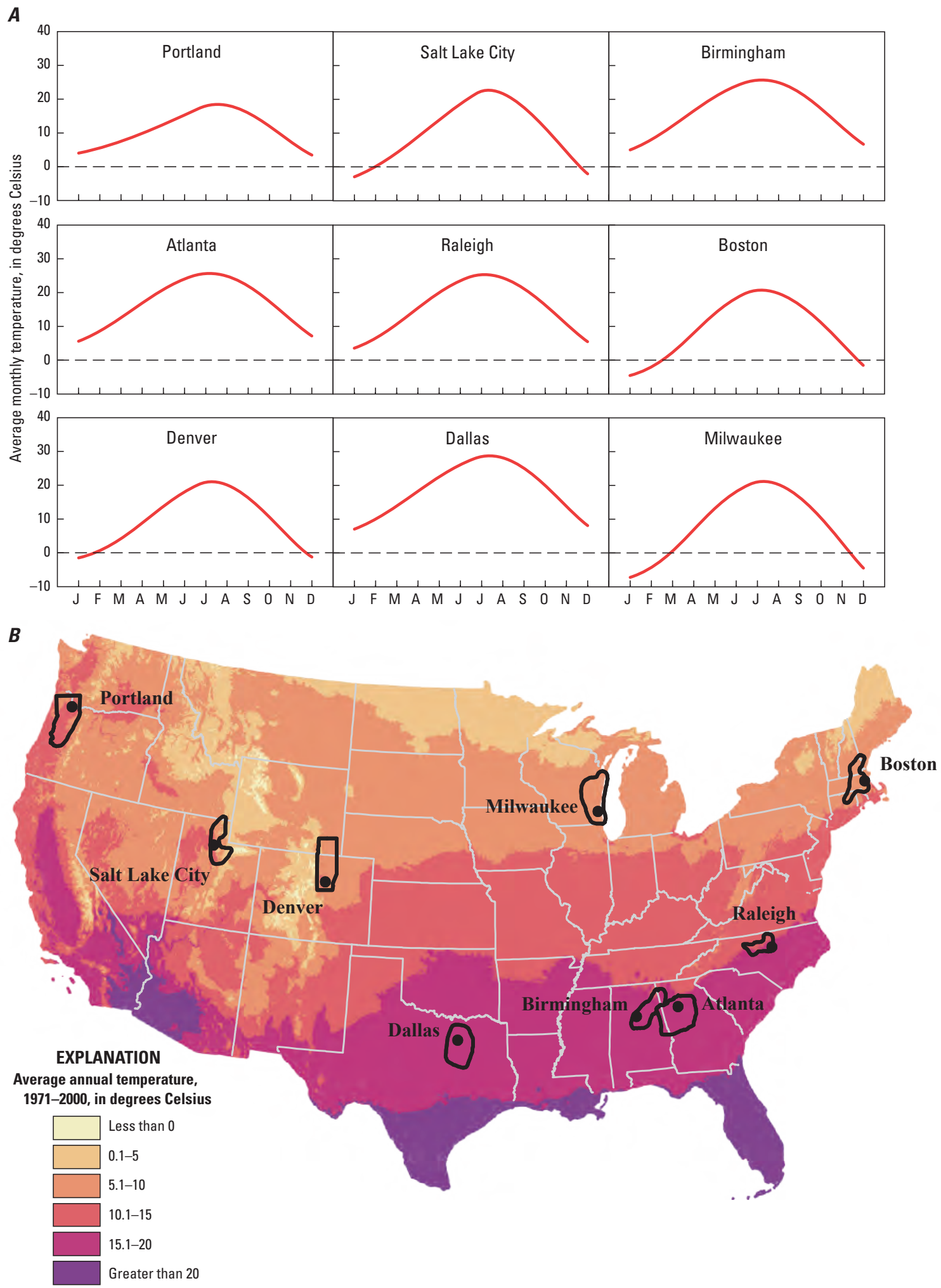

Source: The PRISM Group at Oregon State University, Corvallis, Oregon

Figure 1B-3. (A) Graphs of the average monthly air temperature for the nine metropolitan study areas and $(B)$ a national map showing average annual temperature. 
$\boldsymbol{A}$
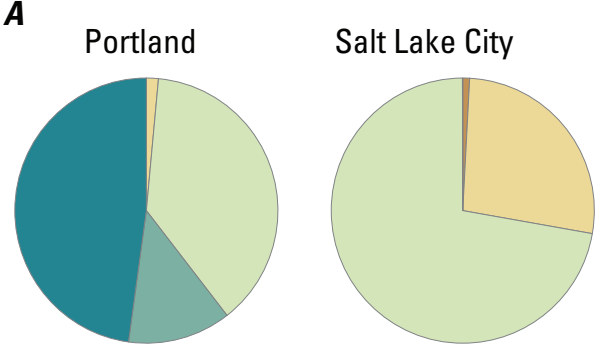

Birmingham

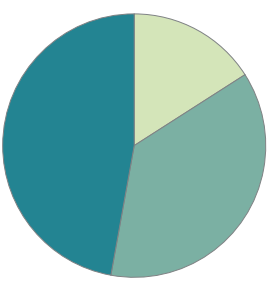

Dallas
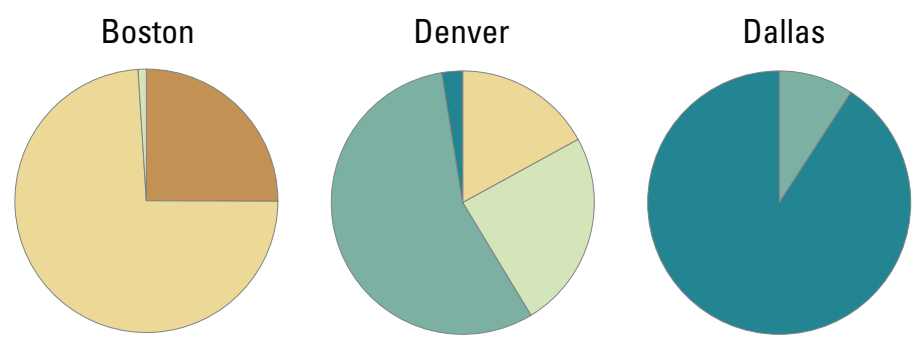
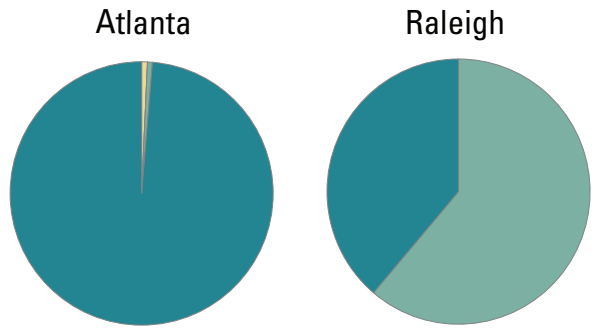

Milwaukee

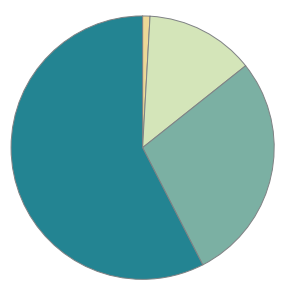

B

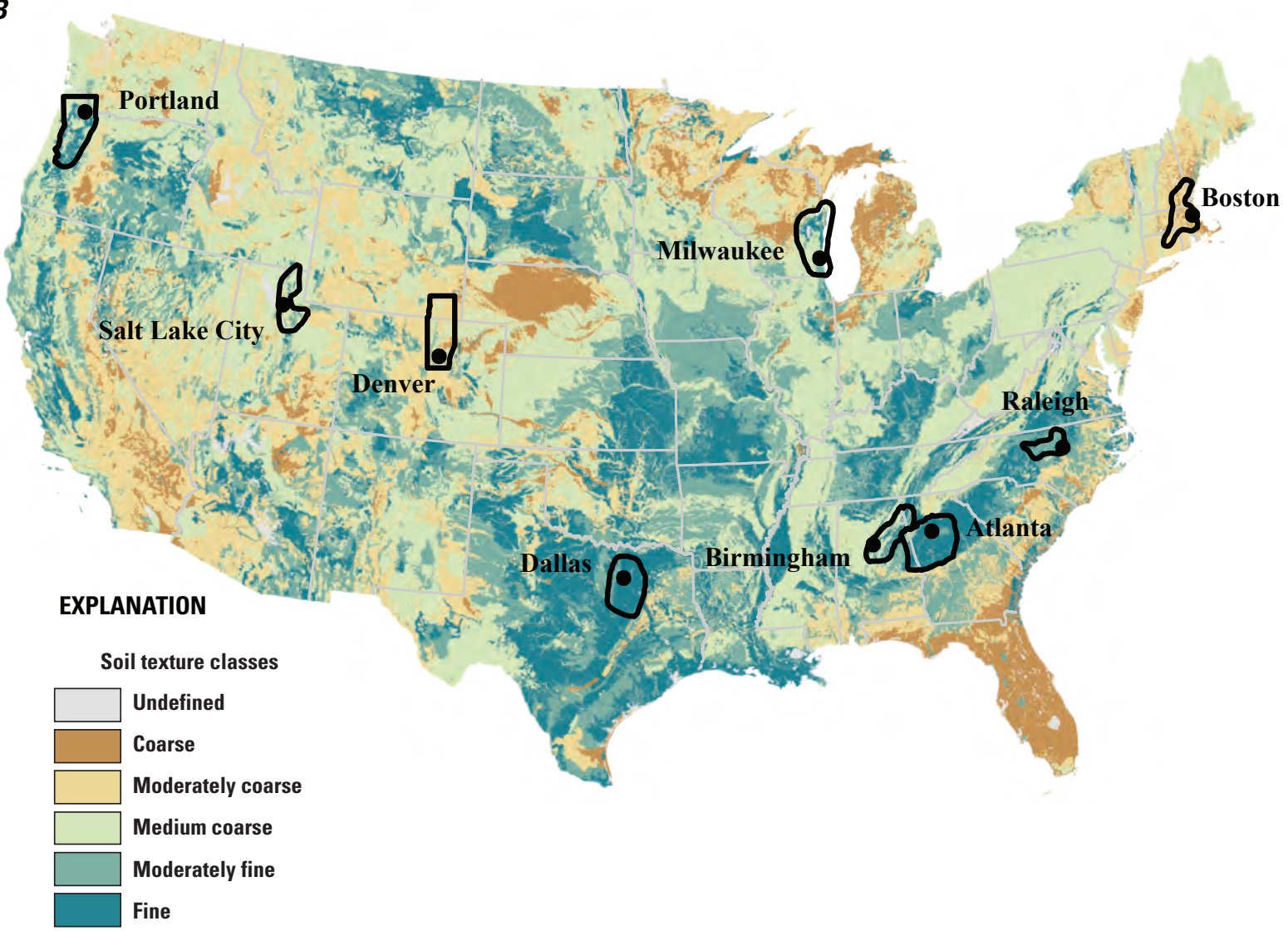

Source: State Soil Geographic database, USDA, and Soil Texture classes, USEPA, Shirazi, Mostafa A., Boersma, Larry, Johnson, Colleen B., 2001

Figure 1B-4. (A) Graphs and (B) a national map showing the average soil texture classes for the nine metropolitan study areas. 


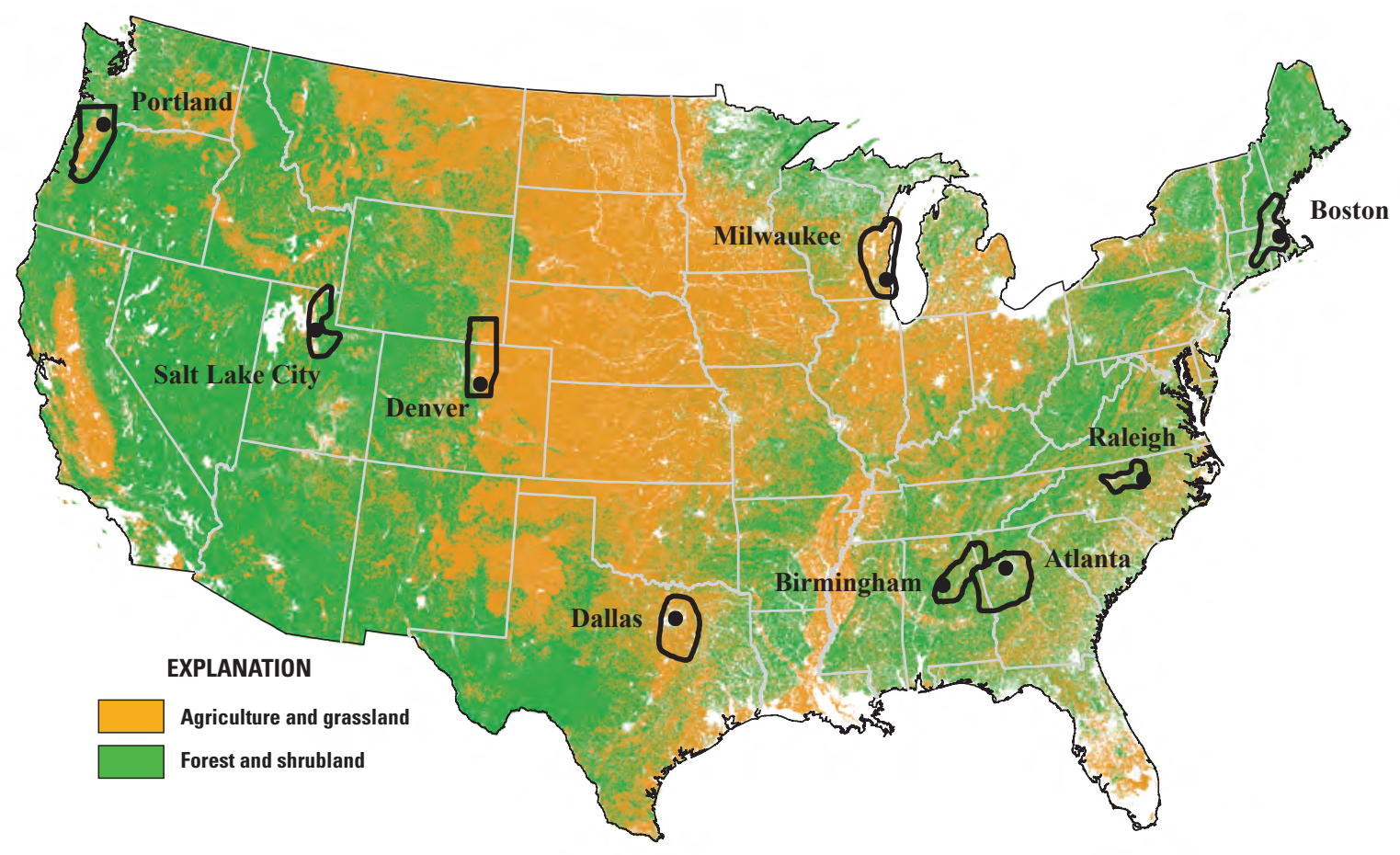

Figure 1B-5. National map showing agriculture/grassland and forest/shrubland land cover. 
Publishing support was provided by the USGS Science Publishing Network, Raleigh Publishing Service Center.

For additional information concerning the research in this report contact:

Chief, National Water-Quality Assessment Program

U.S. Geological Survey

413 National Center

12201 Sunrise Valley Drive

Reston, VA 20192

or visit our Web site at:

http://water.usgs.gov/nawqa/urban/ 
